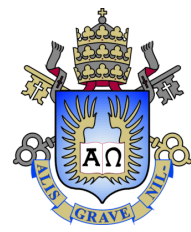

Tiago Santana Tristão

\title{
Essays on monetary policy
}

\section{Tese de Doutorado}

Thesis presented to the Programa de Pós-graduação em Economia of PUC-Rio in partial fulfillment of the requirements for the degree of Doutor em Economia.

Advisor: Prof. Carlos Viana de Carvalho 


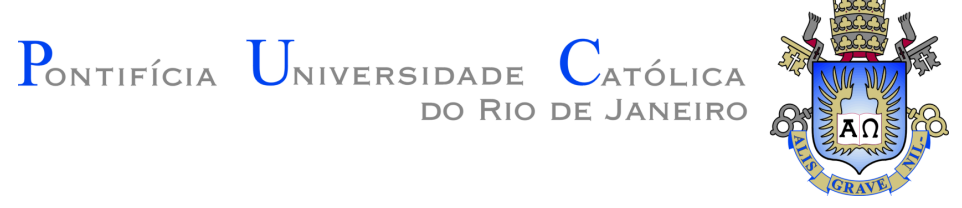

Tiago Santana Tristão

\section{Essays on monetary policy}

Thesis presented to the Programa de Pós-graduação em Economia of PUC-Rio in partial fulfillment of the requirements for the degree of Doutor em Economia. Approved by the undersigned Examination Committee.

Prof. Carlos Viana de Carvalho

Advisor

Departamento de Economia - PUC-Rio

Prof. Marcelo Cunha Medeiros

Departamento de Economia - PUC-Rio

Prof. Ruy Monteiro Ribeiro

Departamento de Economia - PUC-Rio

Prof. Marco Antonio Cesar Bonomo

Insper Instituto de Ensino e Pesquisa - INSPER - SP

Prof. Diogo Abry Guillén

Itaú Asset Management - ITAÚ-SP

Prof. Augusto Cesar Pinheiro da Silva

Vice Dean of the Centro de Ciências Sociais - PUC-Rio

Rio de Janeiro, November the 3rd, 2017 
All rights reserved.

\section{Tiago Santana Tristão}

Graduated with B.Sc. in Economics from the UFRGS and obtained his M.Sc. Degree in Economics from the UFRGS, and now a PhD in Economics from PUC-Rio.

Bibliographic data

Tristão, Tiago Santana

Essays on monetary policy / Tiago Santana Tristão; advisor: Carlos Viana de Carvalho. - Rio de janeiro: PUC-Rio, Departamento de Economia, 2017.

v., 143 f: il. color. ; $30 \mathrm{~cm}$

Tese (doutorado) - Pontifícia Universidade Católica do Rio de Janeiro, Departamento de Economia.

Inclui bibliografia

1. Economia - Teses. 2. Política monetária;. 3. Regra de Taylor;. 4. modelos DSGE;. I. Carvalho, Carlos Viana de. II. Pontifícia Universidade Católica do Rio de Janeiro. Departamento de Economia. III. Título. 


\section{Acknowledgments}

I would like to express my special appreciation to my advisor, professor Carlos Carvalho. You have offered not only essential research guidance but your trust and encouragement throughout this journey, all of this in the most thoughtful and kind manner, thank you. A special acknowledgement goes to professors and staff members at PUC-Rio who have strongly supported me academically during my Doctorate years. I would also like to thank my committee members, professor Marcelo Medeiros, professor Ruy Ribeiro, professor Marco Bonomo and Professor Diogo Guillén for carefully thought suggestions.

Thanks to all my family who shared my dream and supported me to pursue it. Words cannot express how grateful I am to my mother, Valdoníria, my father, Nilton, my sister, Fernanda, for all of the sacrifices that you've made on my behalf. Also I would like to thank my supportive, and patient, girlfriend Débora.

A special mention goes to my brother Diego Tristão, who have made hard times bearable and hard subjects surpassable, always guiding me on the right path. This work would not have been possible without you.

I am grateful for the funding sources, Conselho Nacional de Desenvolvimento Científico e Tecnológico $(\mathrm{CNPq})$ and Coordenação de Aperfeiçoamento de Pessoal de Nível Superior (CAPES). 


\section{Abstract}

Tristão, Tiago Santana; Carvalho, Carlos Viana de (Advisor). Essays on monetary policy. Rio de Janeiro, 2017. 143p. Tese de doutorado - Departamento de Economia, Pontifícia Universidade Católica do Rio de Janeiro.

This thesis consists of three essays on monetary policy. The first investigates the endogeneity problem related to monetary policy rules estimation. Ordinary Least Square estimator generates biased and inconsistent estimates due to endogeneity. Generalized Method of Moments (GMM) has been used on the pretext of eliminating the bias. We show analytically in the 3-equation New Keynesian model that the asymptotic bias is a function of the fraction of the variance of variables accounted for by monetary policy shocks. Since the monetary policy shocks explain only a small fraction of inflation and the output gap, hence, the endogeneity bias is small. We use Monte Carlo methods to show that this result survives in larger DSGE models. In the second article we estimate a medium-scale DSGE model to assess the effects of forward guidance in a framework with endogenous time-varying price of risk. We investigate how the forward guidance impact the term structure of interest rates, and document how different monetary policy news can impact macroeconomic variables. We find that forward guidance, through isolated news shocks, has limited impact on long term rates. Also, anticipated and surprise shocks have similar effects on bond yields as the economy is not restricted by the ZLB. Further, our results suggest that the "forward guidance puzzle" cannot be eliminated even within a framework in which forward guidance has limited impact on long term rates. The third essay exploits information from changes in yield curve to identify monetary news shocks in a macro-financial DSGE model. We allow a timevarying term premium and zero lower bound (ZLB) constraints. Although the DSGE econometric literature has argued in favor of the likelihood-based methods to identify and estimate the anticipated components of exogenous innovations, we show evidence that this approach, in combination with a standard New Keynesian DSGE model, does not provide a satisfactory estimation of the recent course of forward guidance shocks. This failure is associated with the absence of a richer mechanism to deal with the yield curve in the the recent recession.

\section{Keywords}

Monetary policy; Taylor Rule; DSGE models; 


\section{Resumo}

Tristão, Tiago Santana; Carvalho, Carlos Viana de. Ensaios sobre política monetária. Rio de Janeiro, 2017. 143p. Tese de Doutorado - Departamento de Economia, Pontifícia Universidade Católica do Rio de Janeiro.

Esta tese consiste de três ensaios sobre política monetária. O primeiro investiga o problema de endogeneidade relacionado a estimação de regras de política monetária. O estimador de Mínimos Quadrados Ordinários gera estimativas viesadas e inconsistentes devido ao problema de endogeneidade. O uso de Método Generalizados dos Momentos (MGM) tem sido defendido como uma maneira eficiente de eliminar o viés. Nós usamos um modelo Novo Keynesiano de três equações para mostrar analiticamente que o viés de endogeneidade é uma função da fração da variância das variáveis contabilizadas pelo choque monetário. Se os choques monetários explicam apenas uma pequena fração das variações da inflação e do hiato do produto, então o viés de endogeneidade é pequeno. Nós então usamos métodos de Monte Carlo para mostrar que este resultado sobrevive em modelos econômicos mais complexos. No segundo artigo nós estimamos um modelo dinâmico estocástico de equilíbrio geral para avaliar os efeitos de forward guidance em um ambiente em que o prêmio de risco varia no tempo. Nós avaliamos os efeitos de forward guidance sobre a curva de juros e documentamos como choques de news impactam as variáveis macroeconômicas. Os resultados mostram que forward guidance tem impacto limitado na macroeconomia. Além disso, nossos resultados sugerem que o "forward guidance puzzle" não pode ser eliminado mesmo em um ambiente no qual forward guidance tem papel limitado nas taxas de juros mais longas. O terceiro artigo explora informações das variações dos juros para identificar choques monetários de news em um modelo macro-financeiro dinâmico. Nós permitimos variação no prêmio de risco e correlação entre os choques de news em um modelo restrito à taxa nominal de juros igual a zero. Apresentamos evidências de que o uso de métodos de máxima verossimilhança, combinado com modelos dinâmicos, não é suficiente para identificar os choques de news. Esta falha está associada com a ausência de mecanismos mais sofisticados para lidar com os movimentos da curva de juros durante o período recente de recessão econômica.

\section{Palavras-chave}

Política monetária; Regra de Taylor; modelos DSGE; 


\section{Table of contents}

1 Taylor rule estimation by OLS 12

$\begin{array}{lll}1.1 & \text { Introduction } & 12\end{array}$

$\begin{array}{ll}1.2 \text { The Estimation of Monetary Policy Rules } & 15\end{array}$

1.2.1 Three Equation New Keynesian Model 18

1.3 Medium-scale DSGE model 23

1.4 Large-scale DSGE model 28

1.5 Conclusion 32

2 Forward guidance through the lens of a DSGE model with time-varying price of risk 33

2.1 Introduction 33

2.2 The Model $\quad 37$

$\begin{array}{lll}2.2 .1 & \text { Households } & 37\end{array}$

$\begin{array}{lll}2.2 .2 & \text { Firms } & 39\end{array}$

2.2.3 Market Clearing 41

2.2.4 Nominal Bonds 42

2.3 Solution Method and Estimation Procedure 43

$\begin{array}{lll}2.3 .1 & \text { Estimation } & 45\end{array}$

2.3.2 Calibrated Parameters 46

2.3.3 Parameter Estimates 46

$\begin{array}{lll}2.4 & \text { Empirics } & 47\end{array}$

2.4.1 Implied Macro Dynamics 48

$\begin{array}{lll}2.5 & \text { Policy Experiments } & 57\end{array}$

2.5.1 Announced shock in isolation 58

2.5.2 Anticipated shocks to condition interest rate path 62

$\begin{array}{lll}2.6 & \text { Conclusion } & 70\end{array}$

3 A structural model to back out the forward guidance shocks $\quad 72$

3.1 Introduction $\quad 72$

$\begin{array}{ll}\text { 3.2 A new keynesian model } & 75\end{array}$

$\begin{array}{lll}3.2 .1 & \text { Essentially affine approach } & 78\end{array}$

$\begin{array}{ll}\text { 3.2.2 Occasionally binding constraints } & 79\end{array}$

3.3 What Yield Data Tells Us About Financial Crisis 80

3.4 Smoothed Shocks Prior 2008 Financial Crisis 83

3.5 Smoothed Shocks During 2008 Financial Crisis 86

3.5.1 Smoothed Shocks from Unconstrained Model 87

3.5.2 News Shocks from Occbin Solution 90

$\begin{array}{lll}3.6 & \text { Conclusion } & 98\end{array}$

$\begin{array}{ll}\text { Bibliography } & 100\end{array}$

A Chapter 1 - Asymptotic Bias - 3-equation New Keynesian Model 107

$\begin{array}{ll}\text { A.1 Solving by undetermined coefficients } & 107\end{array}$

A.1.0.1 Testing solutions for the technology shock: 109 
A.1.0.2 Testing solution for the monetary shock: 111

A.1.1 With monetary shocks only: 111

A.1.1.1 Solving: $\quad 112$

$\begin{array}{ll}\text { A.1.2 With only productivity shocks: } & 114\end{array}$

A.1.3 With both shocks - variance decomposition: 115

B Chapter 2 - The Model 116

B.1 Solving the model $\quad 116$

B.1.1 Household 116

B.1.1.1 The Stochastic Discount Factor 117

$\begin{array}{ll}\text { B.1.2 Firms } & 119\end{array}$

B.1.3 Market Clearing 124

B.1.4 Real and Nominal Default-Free Bonds $\quad 125$

B.1.5 Model Equations $\quad 125$

$\begin{array}{ll}\text { B.2 Appendix: Model Solution } & 128\end{array}$

B.2.1 Steady State 128

$\begin{array}{ll}\text { B.2.2 Essentially affine approximation } & 128\end{array}$

B.2.3 Yields under Essentially affine approximation 136

B.3 Why is Forward Guidance So Powerful? 138

$\begin{array}{lll}\text { B.4 Data } & 139\end{array}$

C Chapter 3 - Constrained Model $\quad 141$

C.1 Yield Curve Equation under ZLB 141

C.1.1 The Minimization Algorithm 142 


\section{List of figures}

Figure 1.1 Concentration parameter for a range of values of $\rho_{\pi}$ and $\rho_{a}$

Figure 1.2 OLS and GMM estimate distributions - autocorrelation in monetary shocks.

Figure 1.3 OLS and GMM estimate distributions - with $\rho_{v}=0 . \quad 21$

Figure 1.4 IRF's from Smets-Wouters model 26

Figure 1.5 Parameters estimation as a function of the variance of montary shock

Figure 1.6 IRF's form (23).

Figure 1.7 Parameters estimation as a function of the variance of montary shock - large model.

Figure 2.1 Steady-State Nominal Bond Yields.

Figure 2.2 Bond Yield Errors.

Figure 2.3 Impulse-Responses to Structural Shocks 51

Figure 2.4 Term Premium Responses to Technology Shock 52

Figure 2.5 Term Premium Responses to Technology Shock 53

Figure 2.6 Impulse Responses of Term Structure Factors to Structural Shocks.

$\begin{array}{lll}\text { Figure 2.7 } & \text { Forecast Error Variance Decomposition. } & 57 \\ \text { Figure 2.8 } & \text { Impulse-Responses to Monetary News Shocks } & 59\end{array}$

Figure 2.9 Impulse-Responses to Monetary News Shocks 60

Figure 2.10 Impulse Response Functions to Monetary News Shocks at ZLB.

Figure 2.11 Macroeconomic Consequences of Forward Guidance 66

Figure 2.12 Forward Guidance and Yield Curve 67

Figure 2.13 Macroeconomic Consequences of Forward Guidance in a Calibrated Liftoff.

$\begin{array}{lll}\text { Figure 3.1 } & \text { Observed Yields } & 82\end{array}$

Figure 3.2 Bond Yield Errors 84

Figure 3.3 The correlation of Output Growth with Productivity 85

Figure 3.4 The Correlation of th Federal Funds Rate with Monetary Policy Shock

$\begin{array}{lll}\text { Figure 3.5 } & \text { Bond Yield Errors } & 87\end{array}$

Figure 3.6 $\quad$ Output Growth and Actual Monetary News 88

Figure 3.7 Output Growth and Bin of Announced Shocks 89

Figure 3.8 The Correlation of the Observable with Smoothed Variables 92

Figure 3.9 The Correlation of the Observable with Smoothed Yields 93

Figure 3.10 Output Growth and Actual Monetary News - Constrained Model

Figure 3.11 Output Growth and Bin of Announced Shocks - Constrained Model 
Figure 3.12 Decomposition of Bin of Announced Shocks - Constrained Model

Figure 3.13 Risk Aversion and Technological Shocks - Constrained Model 


\section{List of tables}

Table 1.1 OLS and GMM Mean of Estimates with T=80. 22

Table 1.2 OLS and GMM Estimates of Structural Parameters 25

Table 1.3 OLS and GMM Estimates of Structural Parameters 30

$\begin{array}{lll}\text { Table 2.1 Priors and Posterior Modes } & 47\end{array}$

Table 2.2 One-Quarter-Ahead Variance Decompositions 56

Table 3.1 Correlation Among News Shocks and FG Dates 90

Table C.1 Chapter 3 model estimation - Priors and Posterior Modes 143 


\section{Taylor rule estimation by OLS}

\section{1}

\section{Introduction}

The macroeconomics literature frequently uses some variant of an interest rate rule, such as the ones introduced in (1) and (2), to represent the monetary authority reaction function. Such policy rules provide some guidelines on how the monetary authority would typically vary its policy instrument (typically, a short term interest rate) in response to deviations of inflation and/or economic conditions (output or unemployment, for example) from their objectives. The change in policy instrument by the monetary authority is only one decision among several others that are taken by agents simultaneously in a economy (households decide how much to consume, firms decide how much produce, etc.). A bunch of economic variables endogenously respond to each other's movements at the same time the monetary authority changes its policy instrument, and its reaction function is not the only macroeconomic relationship working for the determination of output and inflation. The movements in these variables are all simultaneously determined in equilibrium.

Since the macroeconomic variables are simultaneously determined, this raises a challenge to empirical frameworks that focus on simple estimation methods. In particular, the empirical literature seems to agree that the use of Ordinary Least Square (OLS) estimates of a Taylor rule in single equation approach would lead to biased and inconsistent results (see (3), (4), and (5)). This bias would arise due to endogeneity among the macroeconomic variables; therefore, the estimation must be performed by resorting to alternative empirical approaches, such as instrumental variables. The literature has pointed to the General Method of Moments (GMM), attached by a set of suitable instruments, as a statistically better way of proceeding empirically (see (6), (7)).

In this paper we assess how the estimation of interest rate rules are affected by the aforementioned endogeneity problems in a broad class of New Keynesian models. We show analytically in the 3-equation New Keynesian model that the asymptotic bias is a function of the fraction of the variance 
of variables accounted for by monetary policy shocks. Hence the Endogeneity bias is small. This simple framework serves to illustrate the mapping between the variance decomposition and the asymptotic bias. Further, we quantify the bias through different classes of general equilibrium models, as laboratories for Monte Carlo experiments, and show that this result survives in larger DSGE models. In particular, we consider three different general equilibrium model specifications and compare the magnitudes of the biases obtained when the rules are estimated using a simple one-equation OLS methods versus results obtained using instrumental variables. More specifically, for each model specification, we generate data through Monte Carlo simulations and use the different classes of model-generated data to estimate the interest rate rules to measure the magnitudes of the biases. In this analysis, we are able to use the alternative models and the underlying model-generated data as laboratories to assess how typical limitations to empirical analysis, such as a suboptimal set of instruments or small samples, affect the estimation results.

Our results suggest that endogeneity does induce some bias for the estimation of interest rate rules using OLS methods. For a broad class of models, we find evidence that the biases under OLS estimates is not harmful in the most commonly used versions of New Keynesian models. In other words, the bias is not worrisome in the sense of impulse-response analysis and the assessment of the Taylor principle. The magnitude of the bias, however, depends on the model specification

The magnitudes of GMM estimation biases discussed here focus in cases where the instrumental variables have low correlation with monetary shocks. These cases gain particular importance due to the widespread use of lagged state variables as instruments, as well as current state variables. For example, in (8) the set of instruments is composed of four lags of inflation, output gap, federal funds rate, the short-long interest rate spread, and commodity price inflation. If we rationalize a large general equilibrium model that encompasses those variables, it is hard to assume they will not be correlated with monetary policy shocks. Furthermore, (9) provide evidence suggesting that the gradual adjustment of interest rates is related with inertia in monetary policy, which can be explained by serial correlation in monetary policy shocks. These findings add to the list of concerns about the set of instrumental variables commonly used in recent literature.

Of course, GMM estimation with a proper set of instruments generates unbiased estimates asymptotically. However, in a general equilibrium model all variables are endogenous, making it impossible to consider state variables as suitable instruments. In such models, endogenous variables can be written as 
functions of exogenous disturbances, which are i.i.d.. In that case, if one uses all exogenous disturbances, except the monetary policy shock, as the set of instruments, the GMM estimates will be unbiased and consistent. Justifying and implementing such approach empirically, however, raises numerous challenges as perfect instruments are not available and it is hard to justify asymptotic properties in finite (and sometimes relatively short) samples.

Estimated rules can be used to evaluate monetary policy decisions and the outcomes of those decisions made in the past. The Taylor rules' parameter estimates are paramount in monetary economics, as the magnitude of coefficients inform on how strongly the monetary authority responds to variations in inflation and output.

The literature about Taylor rule estimation is large and this paper does not have the ambition of exhausting all contributions on this topic. Instead, we shed light on the main challenges associated with the estimation of Taylor rules and balance the costs and benefits of undertaking one methodology versus another.

The macroeconomic literature has had considerable interest in determining whether monetary policy actions taken by the Fed under Alan Greenspan mandate can be summarized by a Taylor rule respecting the Taylor principle. (2) argues that the Federal Reserve (FED) did not adhere to the Taylor principle before 1979, and this failure may well have been responsible for the greater U.S. macroeconomic instability during the 1960s and 1970s. (10) estimate the Taylor rule adding partial-adjustment dynamics for two different sample periods, corresponding to the Fed chairmanships of Paul Volcker and Alan Greenspan, respectively. They find a higher coefficient to inflation deviations in Greenspan period indicating a more "aggressive" FED reaction to inflation variability. (6) analyzes a Taylor rule equation, before and after Volcker appointment as Fed Chairman in 1979, where operating target depends on deviations of expected inflation to the target instead of current deviations. They find that interest rate policy in the Volcker-Greenspan period appears to have been much more sensitive to changes in expected inflation than in the earlier period. Using a simple New Keynesian model they show that VolckerGreenspan rule is stabilizing while the rule used earlier was not. These findings are agreement with (2). (11) argues that the (2) and others authors findings are distorted by the use of inflation and output gap data which were not available to the Fed at the time that FED decisions were made. Using the (6) reaction function, they find a very similar estimates for the post-Volcker periods, thus confirming only the post 1979 interpretation of (6).

The papers cited above suggest that the Fed helped to stabilize the US 
economy in the early 1980s by adopting a more stronger reaction in response to inflation and other variables. (12), however, argues against this historical interpretation, asserting that the Taylor rule parameters are not identified in the baseline New Keynesian model. He claims that the satisfaction of the Taylor principle in the model is equivalent to a threat which is never actually carried out in equilibrium, therefore, data generated from the model can never reveal the values of the policy parameters in the rule which lend credibility to the threat. More related with this paper, some authors assesses the properties of Taylor rule estimation. (4) shows that (12)'s finding is not a generic implication of the New Keynesian models, but is rather the result of a particular assumption on the policy rule. Under standard specifications the policy parameters are identified and may be estimated consistently using conventional techniques. Besides that, he examines the properties of the IV estimator under the baseline New Keynesian model. (13) investigate the magnitude of the estimation bias when monetary shocks are serially correlated and lags of inflation and output gap are endogenous to monetary shocks, and thus, not valid instruments. They find that the endogeneity problem caused by serial correlation does not cause large bias in the conventional estimation of Taylor rules based on the three equations New Keynesian model.

\section{2}

\section{The Estimation of Monetary Policy Rules}

We are interested in the estimation of a interest-rate rule described as a Taylor rule. Changes in interest rates are associated with the current path of aggregate macroeconomic variables. In brief, estimation by single equation approach leads to biased and inconsistent estimatives since Taylor rule equation is part of a broad system of equations. The problem is due to the correlation between monetary policy shocks and explanation variables.

Consider the states of economy evolve according to a micro funded New Keynesian model. Large macroeconomic models provide complicated solutions, because analytical solutions are a cumbersome task in most models due to the number of equations and parameters that should be taken in account when dealing with the DSGE framework. Even a small model has a lot of parameters to deal with. Nevertheless, some simple models as described in (14), chapter 3, can be solved analytically yielding pedagogical insights. We begin our analysis by investigating the basic New Keynesian model described in (14). 


$$
\begin{aligned}
\pi_{t} & =\beta E_{t}\left(\pi_{t+1}\right)+\kappa y_{t} \\
y_{t} & =E_{t}\left(y_{t+1}\right)-\frac{1}{\sigma}\left(i_{t}-E_{t}\left(\pi_{t+1}\right)-r_{t}^{n}\right) \\
i_{t} & =\rho+\phi_{\pi} \pi_{t}+v_{t} \\
r_{t}^{n} & =\rho+\sigma \psi_{y a}^{n} E_{t}\left(\Delta a_{t+1}\right) \\
a_{t} & =\rho_{a} a_{t-1}+\epsilon_{t}^{a} \\
v_{t} & =\rho_{v} v_{t-1}+\epsilon_{t}^{v}
\end{aligned}
$$

This simple model consists of three equations describing how output, inflation, and interest rate evolve in time. Equation (1-1) is a Phillips curve, which is related to supply curve because it shows how inflation responds to deviations of output from its potential level. The Equation (1-2) represents a IS curve, and Equation (1-3) is a simple version of the Taylor rule. Equation (1-4) describes the evolution of natural interest rate, the interest would prevail when output is in its potential level, which is linked to technology shocks. Finally, Equations (1-5)-(1-6) are the technology shocks and monetary policy shocks, respectively.

So the solution will take the form ${ }^{1}$

$$
\begin{aligned}
& \pi_{t}=\psi_{\pi v} v_{t}+\psi_{\pi a} r_{t}^{n} \\
& y_{t}=\psi_{y v} v_{t}+\psi_{y a} r_{t}^{n}
\end{aligned}
$$

where

$$
\begin{aligned}
\Lambda_{v} & =\frac{1}{\left(1-\beta \rho_{v}\right) \sigma\left(1-\rho_{v}\right)+\kappa\left(\phi_{\pi}-\rho_{v}\right)} \\
\Lambda_{a} & =\frac{1}{\left(1-\beta \rho_{a}\right) \sigma\left(1-\rho_{a}\right)+\kappa\left(\phi_{\pi}-\rho_{a}\right)} \\
\psi_{\pi v} & =-\kappa \Lambda_{v} \\
\psi_{\pi a} & =\kappa \Lambda_{a} \\
\psi_{y v} & =-\left(1-\beta \rho_{v}\right) \Lambda_{v} \\
\psi_{y a} & =\left(1-\beta \rho_{a}\right) \Lambda_{a}
\end{aligned}
$$

Along with the policy rule

$$
i_{t}=\rho+\phi_{\pi} \pi_{t}+v_{t}
$$

Then we have

$$
\operatorname{plim} \hat{\phi}_{\pi}^{O L S}=\phi_{\pi}-\frac{1}{\kappa \Lambda_{v}} \lambda_{v}
$$

${ }^{1}$ See Appendix for the derivation. 
where

$$
\lambda_{v}=\frac{\left(\kappa \Lambda_{v}\right)^{2} \operatorname{var}\left(v_{t}\right)}{\left(\kappa \Lambda_{v}\right)^{2} \operatorname{var}\left(v_{t}\right)+\left(\sigma \psi_{y a}^{n}\left(1-\rho_{a}\right) \kappa \Lambda_{a}\right)^{2} \operatorname{var}\left(a_{t}\right)},
$$

is the fraction of the variance of $\pi_{t}$ that is accounted for by monetary policy shocks. What determines the size of the OLS bias? In this simple example, the bias depends on $\Lambda_{a}, \Lambda_{v}$, and $\lambda_{v}$. However, insofar as the standard calibration yields $\Lambda_{a}, \Lambda_{v}>0$, we expect a negative downward bias in $\hat{\phi}_{\pi}^{O L S}$.

To overcome endogeneity issues, the typical strategy to estimate the Taylor rule has been the use of GMM estimator where lagged state variables are used as instrumental variables. Note that the system equations (1-1)-(1-6) can be cast in matrix form. Define

$$
X_{t}=\left(\begin{array}{c}
y_{t} \\
\pi_{t}
\end{array}\right), \quad \varepsilon_{t}=\left(\begin{array}{c}
a_{t} \\
v_{t}
\end{array}\right), \quad \text { and } \quad U_{t}=\left(\begin{array}{c}
\epsilon_{t}^{v} \\
\epsilon_{t}^{a}
\end{array}\right),
$$

then we can rewrite the system as

$$
\begin{aligned}
\Gamma_{0} X_{t} & =\Gamma_{1} E_{t} X_{t+1}+\Gamma_{2} \varepsilon_{t} \\
\varepsilon_{t} & =\Pi \varepsilon_{t-1}+U_{t}
\end{aligned}
$$

The solution takes the form

$$
\begin{aligned}
X_{t} & =A \varepsilon_{t} \\
\varepsilon_{t} & =\Pi \varepsilon_{t-1}+U_{t}
\end{aligned}
$$

Putting equation (1-9) one period forward and substituting for $\varepsilon_{t}$ :

$$
\begin{gathered}
X_{t}=A \Pi A^{-1} X_{t-1}+A U_{t} \\
\text { where } A=\left(\begin{array}{ll}
\psi_{\pi v} & -\psi_{\pi a} \sigma \psi_{y a}^{n}\left(1-\rho_{a}\right) \\
\psi_{y v} & -\psi_{y a} \sigma \psi_{y a}^{n}\left(1-\rho_{a}\right)
\end{array}\right), \quad \text { and } \quad \Pi=\left(\begin{array}{cc}
\rho_{v} & 0 \\
0 & \rho_{a}
\end{array}\right) \text {. }
\end{gathered}
$$

Equation (1-9) motivates the use of $y_{t-1}$ and $\pi_{t-1}$ as instruments for $\pi_{t}$. However, GMM estimation is an appropriate option when the model is identified. It is then straightforward to show that the determinant of the coefficient matrix $\Pi$ is $\rho_{v} \rho_{a}$, so the rank condition for identification is satisfied if and only if $\rho_{v} \neq 0$ and $\rho_{a} \neq 0$. Thus, identification requires persistence in innovation processes. Furthermore, the rank condition is not sufficient for reliable estimation and inference since the problem of weak instruments may arise. (15) show that weak identification leads to poor parameter identification and, also, asymptotic results become a poor guide 
to the actual sampling distributions. The strength of identification has been studied using the concentration parameter (see (17) and (16)), which can be seen as a measure of signal to noise ratio of the instruments. More precisely, the concentration parameter is a measure of the variation of the endogenous regressors that is explained by the instrumental variables after controlling for any exogenous regressors, relative to the variance of the residuals of the firststage regression in a Two-Stage Least Square (TSLS) approach. For the firststage regression as described in equation (1-9), we can define the concentration parameter as $C P=T \Sigma^{-1 / 2}\left(A \Pi A^{-1}\right)^{\prime} E\left(Z_{t} Z_{t}^{\prime}\right)\left(A \Pi A^{-1}\right) \Sigma^{-1 / 2}$, where $T$ is the sample size and $\Sigma$ is the variance of residuals of the first-stage regression. The dimension of this matrix is determined by the number of endogenous regressors and the strength of the instruments is measured by the smallest eigenvalue of the concentration matrix. For the Monte Carlo experiments described below, the concentration parameter is computed by simulation due to the complexity of analytical derivation. All Monte Carlo experiments performed in this paper are calibrated to guarantee strong identification of GMM estimates. Therefore the bad performance of GMM cannot be assigned to weak identification.

In short, we face two difficulties when estimating Taylor rules. If one wishes use OLS to estimate Taylor rule parameters, equation (2-19) indicates the presence of bias due to endogeneity. On the other hand, if one wishes use of GMM to estimate the parameters, its necessary to check identification and how strong it is. Even if the model is identified, weak identification which depends on the structural model - may result not only in biased and inconsistent GMM estimates but also that asymptotic results become a poor guide to the actual sampling distributions. The model described above clarifies that without serial correlation in exogenous shocks, lagged state variables cannot be used as instruments. Also, if the shocks have weak persistence, in the case of $\rho_{a}$ and $\rho_{v}$ close to zero, we fall in the problem of weak identification; therefore, there is no guarantee that GMM will generate estimates close to true parameters values.

\subsection{1}

\section{Three Equation New Keynesian Model}

We simulate the three equation New Keynesian model, as exposed in equations (1-1)-(1-6) augmented by an unanticipated persistent inflation shock, $p_{t}=\rho_{\pi} p_{t-1}+\varepsilon_{t}^{p}$, which enters in the Phillips curve. Also, the Taylor rule is augmented by a forth term $\phi_{y} y_{t}$. The first modification is necessary in order to generate three independent state variables, and it can be explained as exogenous disturbances hitting the inflation path. The latter is imposed to 
Figure 1.1: Concentration parameter for a range of values of $\rho_{\pi}$ and $\rho_{a}$
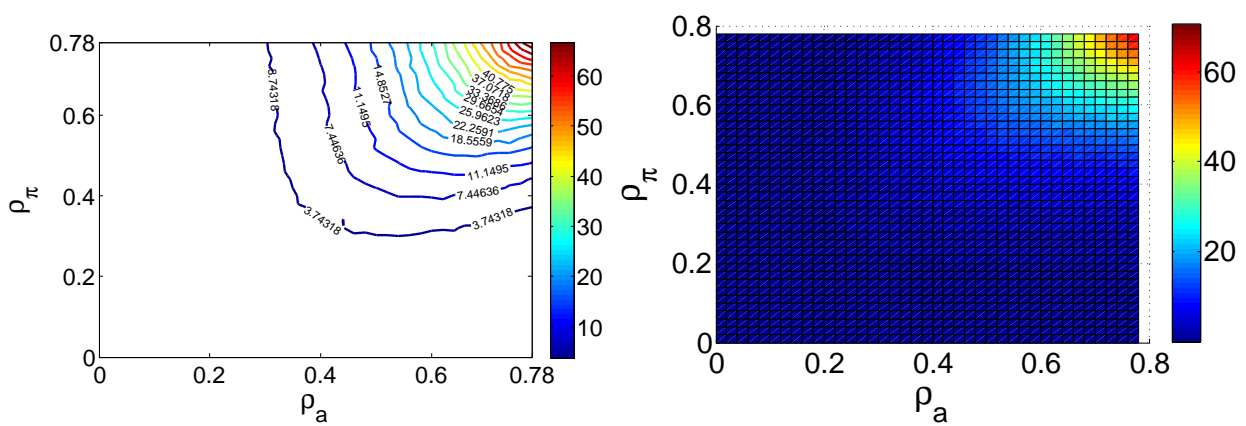

bring this monetary rule closer to other rules used in literature.

This model will be used as a laboratory to our experiments in Taylor rule estimation. However, as discussed before, some concern in its identification is noteworthy. Using a very standard calibration, $\sigma=1, \beta=0.99, \phi_{\pi}=1.5, \phi_{y}=$ $0.125, \rho_{v}=0, \lambda=0.0425, \kappa=0.1275, \psi_{y a}^{n}=1$, we calculate the concentration parameter for different values of $\rho_{\pi}$ and $\rho_{a}$. The Figure (1.1) shows how much persistence we need, to be able to identify Taylor rule parameters in a framework where inflation and output gap are endogenous and one lag of each are used as instrumental variables.

Following (18), for two endogenous variables and two instruments, $\mu^{2} \geq$ 18 would suffice, where $\mu^{2}=\operatorname{mineval}(C P)$. These simulations were performed using a sample size of $T=100$. Figure (1.1) suggests that $\rho_{\pi} \geq 0.6$ and $\rho_{a} \geq 0.6$ imply $\mu^{2} \geq 18$. Therefore, all Monte Carlo experiments performed in this framework are calibrated, through $\rho_{\pi}$ and $\rho_{a}$, to guarantee strong identification of GMM estimates.

to assess the proficiency of a single equation estimation approach, we simulate a data set of 80,150 , and 500 observations, using a very standard calibration: $\sigma=1, \beta=0.99, \phi_{\pi}=1.5, \phi_{y}=0.125, \rho_{v}=0.8, \rho_{a}=0.8, \rho_{\pi}=$ $0.8, \kappa=0.1275, \psi_{y a}^{n}=1 .^{2}$

As we can see from Equation (2-20), there is an important role to the variance of exogenous shocks in OLS bias determination. Seeking to bring this exercise close to empirical findings, we calibrate the variances backed up in (19) results. They find evidence that monetary policy shocks contribute only a small fraction of the forecast variance of output and inflation at all horizons. ${ }^{3}$ The same conclusion is reported in (20). Thus we set the standard deviation of exogenous shocks to be 0.08 for monetary policy shocks, 0.6 for techno-

${ }^{2}$ We choose $80-150$ observations because the majority of the empirical papers work with approximately this number of observations. See (6).

${ }^{3}$ The dominant source of shifts in inflation is driven by price and wage mark-up shocks. However, they show that monetary policy shocks play a significantly higher role in the rise of inflation in the 1970s until Volker period. 
Figure 1.2: OLS and GMM estimate distributions - autocorrelation in monetary shocks.
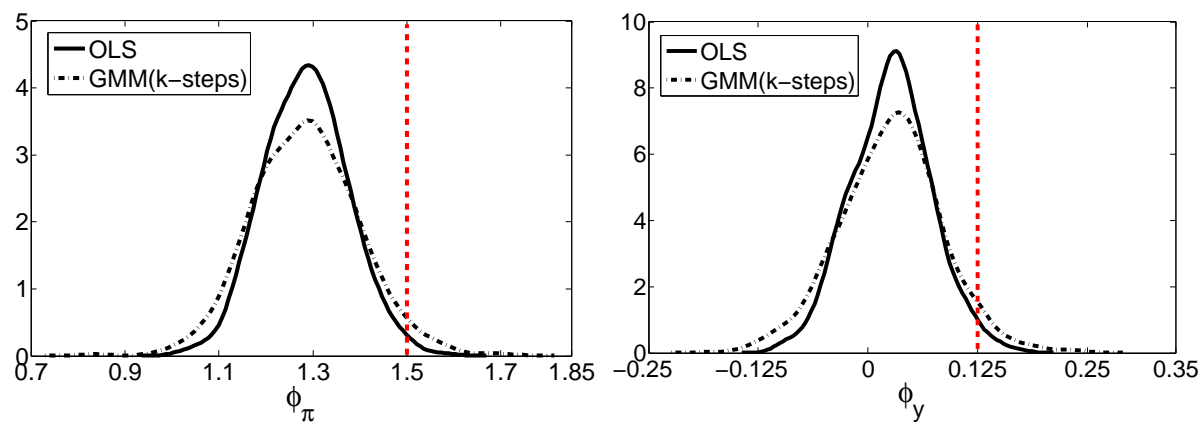

Note: OLS and GMM estimate distributions. True parameter is the red dotted line, $\mathrm{T}=80$. The distributions using $\mathrm{T}=150$ and $\mathrm{T}=500$ look similar.

logical shocks, and 0.07 for inflation shocks (drawn from a Standard Normal distribution). Those calibrations are set to match the unconditional variance decomposition presented in (19). In this fashion, the variance decomposition grants the monetary shock a small importance for changes in output and inflation, respectively $2.73 \%$ and $4.88 \%$.

Finally, we estimate a regression of nominal interest rate on current inflation and output gap. By GMM estimation we make use of k-steps estimator. We also tested the Continuous Updating Estimator (CUE) proposed by (21); however, the results were not satisfactory. ${ }^{4}$ As discussed in (21), the continuousupdating criterion can make numerical search for the minimizer difficult. The problem is that under weak identification the true parameter does not satisfy the second-order condition for a minimum, resulting in "extreme" estimates for true parameters. Because of that, we concentrate on k-steps estimator which is widely used in empirical literature. Two lags of inflation and output gap are used as instruments, and the estimation follows Newey-West heteroskedasticity and autocorrelation consistent (HAC) procedure. ${ }^{5}$. This process is repeated 1000 times, and the result is presented below.

Figure 1.2 shows that OLS and GMM have identical estimate distributions, where the mean of $\phi_{\pi}$ is 1.28 , and the mean of $\phi_{y}$ is 0.026 for both estimators. It is not a novelty because it is well known that GMM is biased due to the persistence in monetary policy shocks: as long as monetary shocks are serially correlated, lags of inflation and output are no longer suitable instrument variables, yielding to GMM estimates the same bias of OLS. But

${ }^{4}$ Many "extreme" estimates appeared.

${ }^{5} \mathrm{HAC}$ allows population moment conditions to be a serially correlated process. We use of Bartlett kernel function with six autocorrelation lags correction - the same as (6). It should be noted that estimators differ according to the choice of kernel and the bandwidth parameter. However, the results remains almost unchanged with other lags specifications. 
Figure 1.3: OLS and GMM estimate distributions - with $\rho_{v}=0$.
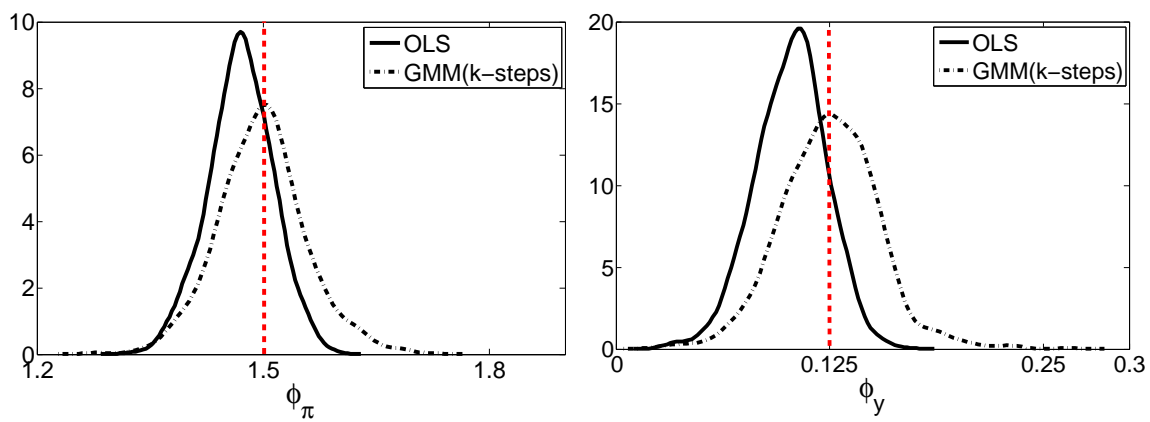

Note: OLS and GMM estimate distributions with $\rho_{v}=0$. True parameter is the red dotted line, $\mathrm{T}=80$.

as far as we impose no serial correlation in monetary policy shocks, GMM estimates considerably differ from OLS.

Figure 1.3 suggests that OLS does a slightly worse job compared with GMM when we have $\rho_{v}=0$ and $\mathrm{T}=80$. The GMM and OLS parameter estimates are very close to the true values: the mean of $\hat{\phi}_{\pi}^{G M M}$ is 1.498, against $\hat{\phi}_{\pi}^{O L S}=1.421$; and the mean of $\hat{\phi}_{y}^{G M M}$ is 0.1248 against $\hat{\phi}_{y}^{O L S}=0.928$. It is important to note that the set of instruments is the same used before: two lags of inflation and output gap. But here, they are good instruments, since $\rho_{v}=0$. Furthermore, they are highly correlated with explanatory variables - correlations vary between 0.59 and 0.75 in absolute terms -, and we consider only cases that the model is not rejected in Hansen's J-test. As discussed before, $\rho_{p}=\rho_{a}=0.8$ generates strong identification measured by concentration parameter. Comparing OLS and GMM results we can conclude that the endogeneity problem does not cause large bias in OLS estimates, since monetary policy shocks have a small contribution to output and inflation shifts.

The analysis of the three equation new Keynesian model shows that OLS estimation leads to the same results of GMM if monetary policy shocks are highly serially correlated and lags of explanatory variables are used as instruments, whatever the sample size. In this case, those lagged variables are not suitable as instrumental variables. This observation becomes relevant because, as pointed out by (13), the literature on estimating monetary policy rules largely ignores this specific endogeneity problem. As the persistence of monetary policy shocks decrease, the GMM estimates get better than OLS in a monotonically fashion. Therefore, it is necessary to deal with this persistence when using GMM approach. To shed light on the differences between OLS and GMM biases in small samples, Table 1.1 shows the relative bias of estimates for some different serial correlation values.

The relative bias is calculated by $\frac{\left|\hat{\beta}^{G M M}-\beta\right|}{\left|\hat{\beta}^{O L S}-\beta\right|}$, and the Relative Mean 
Table 1.1: OLS and GMM Mean of Estimates with $\mathrm{T}=80$.

\begin{tabular}{|c|c|c|c|c|c|c|c|}
\hline & \multicolumn{7}{|c|}{$\rho_{v}=0$ and $\mathrm{T}=80$} \\
\hline & True values & OLS & OLS bias & GMM & GMM bias & Relative Bias & Relative MSE \\
\hline$\phi_{\pi}$ & 1.5 & 1.4679 & -0.0321 & 1.5019 & -0.0019 & 0.0981 & 1.0919 \\
\hline$\phi_{y}$ & 0.125 & 0.1005 & -0.0245 & 0.1248 & -0.0002 & 0.0082 & 1.1149 \\
\hline & \multicolumn{7}{|c|}{$\rho_{v}=.5$ and $\mathrm{T}=80$} \\
\hline & True values & OLS & OLS bias & GMM & GMM bias & Relative Bias & Relative MSE \\
\hline$\phi_{\pi}$ & 1.5 & 1.4248 & -0.0752 & 1.4506 & -0.0494 & 0.6569 & 1.0754 \\
\hline$\phi_{y}$ & 0.125 & 0.0779 & -0.0471 & 0.0932 & -0.0318 & 1.0413 & 0.9322 \\
\hline & \multicolumn{7}{|c|}{$\rho_{v}=0.9$ and $\mathrm{T}=80$} \\
\hline & True values & OLS & OLS bias & GMM & GMM bias & Relative Bias & Relative MSE \\
\hline$\phi_{\pi}$ & 1.5 & 1.1768 & -0.3232 & 1.1640 & -0.3360 & 1.0396 & 1.1077 \\
\hline$\phi_{y}$ & 0.125 & 0.0055 & -0.1195 & 0.0002 & -0.1248 & 1.0444 & 1.1641 \\
\hline
\end{tabular}

Squared Error is calculated by $\frac{M S E\left(\hat{\beta}^{G M M}\right)}{M S E\left(\hat{\beta}^{O L S}\right)}$. Therefore, when the relative coefficients are smaller than one, this means that GMM does better than OLS.

We can see that GMM and OLS estimates are very close to each other for all values of $\rho_{v}$. In spite of the small relative bias in $\rho_{v}=0$ case, the absolute $\hat{\beta}^{O L S}$ have small biases, -0.0321 , and -0.0245 , respectively. These biases are small compared with the magnitude of the true parameters.

When $\rho_{v}=0$, OLS estimates are slightly worse than GMM. However, the GMM superiority is small. The findings shown above, through simulation exercise, indicate that using a sample size rather common in the literature, we find very similar results in the uses of OLS and GMM, even in the presence of endogeneity.

The results presented in Table 1.1 hold as sample size increases. No matter the sample size, GMM cannot do better than OLS in a framework of substantial serial correlation in monetary policy shocks. None of the estimators can recover the true values when $\rho_{v} \neq 0$. Nonetheless, the bias are small when unanticipated monetary policy shocks are not too important to variations in output and inflation. The persistence of monetary policy shocks implies inconsistency of both estimators and a downward bias. However, this bias is very small (in relation to the magnitude of true values), so that we do not make wrong assessment about Taylor principle validity, since both estimates are higher than one in all simulations. These results suggest no gain in using GMM over OLS in monetary policy rule estimation.

In the next section we generalize this exercise to more complicated models and thus more realistic frameworks. 


\section{3 \\ Medium-scale DSGE model}

The three equations new Keynesian model is very simple as a description of an economic environment with only three exogenous shocks to describe all endogenous variables. In a medium-scale model, macroeconomic variables might be described by a linear combination of a larger set of disturbances. Furthermore, if one wants to use the GMM single equation approach to estimate monetary policy rules, generally a broader set of instrumental variables than lags of inflation and output are available to the researcher.

The new Keynesian framework falls into in a large class of rational expectation models that can be written as a system of linear stochastic first order difference equations. The Taylor rule is a monetary policy equation which is part of the equilibrium equations. So the monetary shocks are correlated to state variables of the system.

We begin by introducing notation, we outline the solution, and discuss the issues associated with the single equation estimation of the Taylor rule. ${ }^{6}$ A new Keynesian model can be cast in the form

$$
\Gamma_{0} y_{t}=C+\Gamma_{1} y_{t-1}+\Psi z_{t}+\Pi \eta_{t},
$$

where $y_{t}$ is a vector of state variables, $C$ is a vector of constants, $z_{t}$ is an exogenous vector of variables involving normally distributed random disturbance, and $\eta_{t}$ is an expectational error, satisfying $E_{t} \eta_{t+1}=0$, for all $t$. The interest rate is included in the vector $y_{t}$, while the monetary shock appears in the vector $z_{t}$, with independent identically distributed (iid), or in $y_{t}$ in case of persistence of monetary shocks. The solution can be stated as a reduced form of the linear rational expectation model as follows

$$
y_{t}=A_{c}(\theta)+A_{x}(\theta) y_{t-1}+A_{z}(\theta) z_{t},
$$

where $\theta \in \Theta$ represents the parametric space of structural parameters. Simulated data from a New Keynesian model will follow the solution described by equation (3-2). This solution has a vector autoregressive representation (VAR) with the interest of rate as an element of the vector $y_{t}$. Looking to equation (3-2), we can see that in general all state variables, including interest rate, are correlated with monetary shocks. Therefore inflation and output are correlated with monetary shocks, so these variables play a role of endogenous variables, resulting in OLS bias in Taylor rule estimation. Furthermore, when monetary shocks are persistent (serially correlated), then the lagged state variables are correlated with monetary shocks as well. In this case, lags of

${ }^{6}$ We follow (45) notation. 
state variables - as for instance, lags of inflation and output, which are the most commonly used as instruments in empirical papers - are not proper instruments for estimating Taylor rule in the single equation approach. The set of permissible instruments depends on the specification of the policy rule.

To considering a richer data generating process, we simulate the (19) model generating data from seven disturbances, instead of three, and assess OLS and GMM estimates of the monetary policy rule in a single equation approach. This model was chosen due to its wide usage in macrocoecnonomics literature. Its identification issue is checked by (22) in a classical treatment of identification as a "yes-or-no" problem, where he argues for local identification of the model. He evaluates the Jacobian of moment conditions at arbitrary points in the parametric space in order to check the rank condition. He concludes that almost all of the points in the parametric space imply local identification, and the mode of the posterior is one of them. This local identification make its possible the consistent estimation of the structural parameters with any estimation method that uses the first two second order moments of the state variables. Also it guarantees the usual asymptotic properties of the estimator.

The parameters of the model are calibrated using the mode of the posterior distribution as presented in (19). We generate different sample sizes of $T=80, T=150$, and $T=500$ observations for the estimation. As described in (19), the monetary rule is

$$
\begin{aligned}
r_{t}= & \rho r_{t-1}+(1-\rho)\left[\phi_{\pi} \pi_{t}+r_{y}\left(y_{t}-y_{t}^{p}\right)\right]+ \\
& r_{\Delta}\left[\left(y_{t}-y_{t}^{p}\right)-\left(y_{t-1}-y_{t-1}^{p}\right)\right]+\varepsilon_{t}^{r} \\
\varepsilon_{t}^{r}= & \rho_{r} \varepsilon_{t-1}^{r}+\eta_{t}^{r} .
\end{aligned}
$$

Equation (2-21) can be written as

$$
r_{t}=\theta_{1} r_{t-1}+\theta_{2} \pi_{t}+\theta_{3} \tilde{y}_{t}+\theta_{4} \tilde{y}_{t-1}+\epsilon_{t}^{r},
$$

where $\theta_{1}=\rho, \theta_{2}=(1-\rho) \phi_{\pi}, \theta_{3}=(1-\rho) r_{y}+r_{\Delta y}$, and $\theta_{4}=-r_{\Delta y} . \tilde{y}_{t}=y_{t}-y_{t}^{p}$ denotes output gap. We estimate a regression of nominal interest rate on current inflation, output gap, lagged output gap, and lagged nominal rate. Although the parameters of the policy rule, in equation (3-5), are functions of the structural parameters, we can recover the structural parameters of the policy rule through the estimates $\left\{\hat{\theta}_{1}, \hat{\theta}_{2}, \hat{\theta}_{3}, \hat{\theta}_{4}\right\}$. For GMM estimation, current values and three lags of marginal cost and wages are used as instruments and the estimation follows the Newey-West procedure. Only the GMM estimates 
robust to Hansen's J-test are used.

Table 1.2 shows the estimate results from 1000 Monte Carlo simulations. As we can see, the estimates of the persistence of interest rate are very close to the true value, for both estimators. OLS can capture this structural parameter even with endogeneity problem and does it better than GMM, whatever sample size - in terms of relative MSE. The parameter that draws more attention is $\phi_{\pi}$, the slope of current inflation, because it indicates how monetary authority reacts to inflation deviations from steady-state values. Looking at small samples, OLS and GMM present a meaningful bias, $-23.94 \%$ and $-10.67 \%$, respectively; however, both biases decrease as the number of observations increases. The problem related to GMM estimation is that instrumental variables are taken from endogenous vector of variables, which results in correlation between the instrumental variables and exogenous shocks - causing bias in GMM estimate. GMM biases of $\rho$ and $\phi_{\pi}$ decrease as sample size increases. When $\mathrm{T}=500, \hat{\phi}_{\pi}^{G M M}$ overwhelms $\hat{\phi}_{\pi}^{O L S}$. The estimates for parameters related to the lag of output gap improve related to sample size: when $\mathrm{T}$ goes to 500 the GMM bias shrinks by half.

Table 1.2: OLS and GMM Estimates of Structural Parameters

\begin{tabular}{|c|c|c|c|c|c|c|c|}
\hline \multicolumn{8}{|c|}{$\mathrm{T}=80$} \\
\hline & True values & OLS & OLS bias & GMM & GMM bias & Relative Bias & Relative MSE \\
\hline$\rho$ & 0.81 & 0.7898 & -0.0202 & 0.7562 & -0.0538 & 2.6634 & 7.2152 \\
\hline$\phi_{\pi}$ & 2.03 & 1.5440 & -0.4860 & 1.8133 & -0.2167 & 0.4459 & 2.2029 \\
\hline$r_{y}$ & 0.08 & 0.0612 & -0.0188 & 0.0943 & 0.0143 & 0.7606 & 5.5941 \\
\hline$r_{\Delta}$ & 0.22 & 0.0916 & -0.1284 & 0.1240 & -0.0960 & 0.7477 & 1.0623 \\
\hline \multicolumn{8}{|c|}{$\mathrm{T}=150$} \\
\hline & True values & OLS & OLS bias & GMM & GMM bias & Relative Bias & Relative MSE \\
\hline$\rho$ & 0.81 & 0.8021 & -0.0079 & 0.7741 & -0.0359 & 4.5443 & 9.7637 \\
\hline$\phi_{\pi}$ & 2.03 & 1.5574 & -0.4726 & 1.9436 & -0.0864 & 0.1828 & 2.4089 \\
\hline$r_{y}$ & 0.08 & 0.0537 & -0.0263 & 0.0949 & 0.0149 & 0.5665 & 7.8304 \\
\hline$r_{\Delta}$ & 0.22 & 0.0949 & -0.1251 & 0.1436 & -0.0764 & 0.6107 & 0.6799 \\
\hline & \multicolumn{7}{|c|}{$\mathrm{T}=500$} \\
\hline & True values & OLS & OLS bias & GMM & GMM bias & Relative Bias & Relative MSE \\
\hline$\rho$ & 0.81 & 0.8157 & 0.0057 & 0.8014 & -0.0086 & 1.5088 & 17.5725 \\
\hline$\phi_{\pi}$ & 2.03 & 1.5852 & -0.4448 & 2.0604 & 0.0304 & 0.0683 & 2.7734 \\
\hline$r_{y}$ & 0.08 & 0.0529 & -0.0271 & 0.0996 & 0.0196 & 0.7232 & 11.6950 \\
\hline$r_{\Delta}$ & 0.22 & 0.0984 & -0.1216 & 0.1606 & -0.0594 & 0.4885 & 0.3623 \\
\hline
\end{tabular}

GMM and OLS lead to substantial underestimation of $\phi_{\pi}$ when the number of observation is small, but from $\mathrm{T}=150$ onwards GMM estimate gets better than OLS, converging to true value. The overall view can be summarized 
Figure 1.4: IRF's from Smets-Wouters model
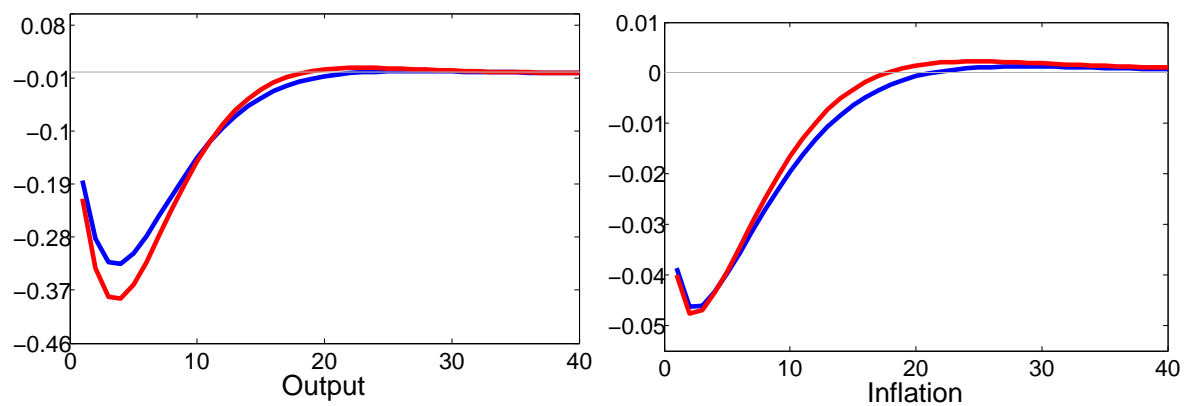

Note: The blue line represents the estimated responses of the model with parameters at the mode of posterior distributions; the red line represents the response implied by OLS estimates with $\mathrm{T}=80$.

as: (i) considering bias exclusively: GMM can be better than OLS depending on sample size. Small samples cause a worsening in GMM estimates; (ii) considering bias and variance (MSE): OLS is better than GMM for all but one estimate. When we weight to variance, GMM becomes less attractive, due to its higher variance compared to OLS.

What does explain? First, serial correlation in monetary shocks entails a poor performance in GMM, as exhaustively discussed above. Second, the mode of posterior of monetary shock's standard deviation is $\sigma_{r}=0.20$ (lowest value among all standard deviation estimates; technology shock has a standard deviation mode of $\sigma_{a}=0.58$, for instance). This makes the endogeneity problem less worrisome. The net effect of these two mechanisms is a good performance of OLS estimates, despite of endogeneity, as GMM estimates perform worse than expected.

What stands out in this analysis is that the OLS estimate of the slope of inflation, $\hat{\phi}_{\pi}^{O L S}$, is higher than one for all sample sizes. Even in small samples, the endogeneity bias is not capable to provoke a wrong interpretation about the reaction of monetary authority to changes in inflation. $\hat{\phi}_{\pi}^{O L S}>1$ in all samples means that OLS estimation leads to accepting that Taylor principle holds, which is true due to the GDP imposed.

Figure 1.4 shows impulse-response functions to output and inflation to a monetary policy shock. This figure shows what happen if one uses OLS estimates to generate impulse-response functions to evaluate the monetary policy role in economic activity.

As shown in Figure 1.4, both responses are very close to each other. Also the peak effect of a policy shock on inflation occurs before its peak effect on output. The endogeneity bias to which OLS estimates are subject to does not imply a large distortion in economic variables' response. This exercise suggests that OLS estimates do a good job despite of bias, when considering a medium- 
Figure 1.5: Parameters estimation as a function of the variance of montary shock
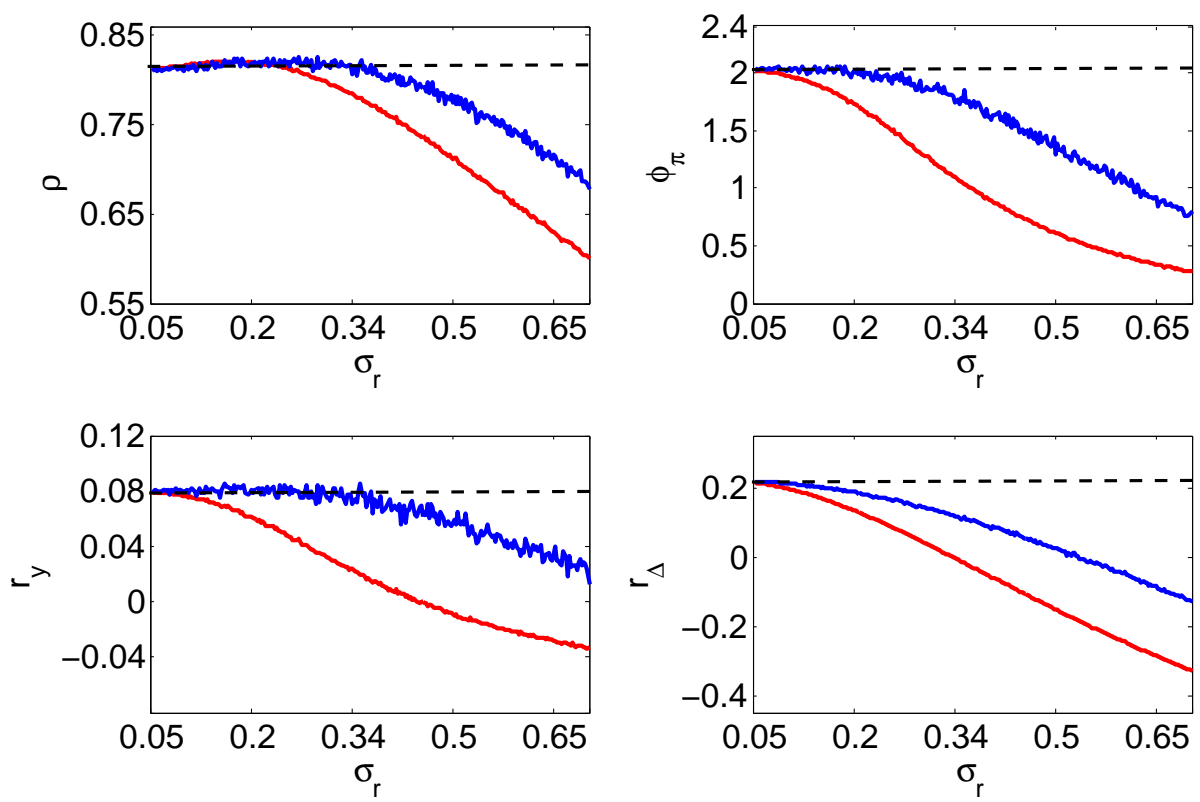

Note: The blue line represents the GMM estimates; the red line represents the OLS estimates. True parameter is the black dotted line. All simulations were made with $\mathrm{T}=500$.

scale GDP.

The endogeneity problem is harmful when the number of disturbances is small, as in the three-equation model. Considering a medium-scale model as (19), the OLS and GMM biases of the slope of current inflation and persistence of interest rate are attenuated. In small samples both estimators have similar results. However, as sample size increases, OLS proves better for $\rho$ estimates in terms of relative bias - while GMM proves better to $\phi_{\pi}, r_{y}$ and $r_{\Delta}$ estimates, although OLS does better in almost all scenarios when considering MSE. It is useful to verify how OLS and GMM estimates behave as monetary shocks become less important. The mode of the standard deviation of monetary policy shock is $\sigma_{r}=0.24$, and this value entails the monetary shock as responsible for $2.73 \%$ and $4.88 \%$ of the changes in output and inflation, respectively. As $\sigma_{r}$ gets lower, monetary shock lose its importance for variation decomposition. Conversely, as $\sigma_{r}$ gets bigger, monetary shocks enlarge its role in the economic. To verify how OLS and GMM estimates vary for different values of $\sigma_{r}$ is a worthwhile analysis, and its showed in the Figure 1.5.

Both estimates become biased as $\sigma_{r}$ increases. At $\sigma_{r}=0.05$, the Forecast Error Variance Decomposition (FEVD), ensures a small role to monetary policy shocks. In this calibration, the FEVD grants the monetary shock a small importance for changes in output and inflation, respectively $0.12 \%$ and $0.22 \%$. When monetary policy becomes relevant in terms of FEDV, the bias increases. 
The estimate $\hat{\phi}_{\pi}^{O L S}$ becomes lower than one when $\sigma_{r}=0.37$, which translates into a monetary shock responsible, in terms of FEVD, for $6.26 \%$ of the changes in output and $10.87 \%$ of changes in inflation, values much higher than VAR literature has been finding (see (78)). Therefore, using OLS estimates, we would reach a wrong conclusion about the Taylor principle only in a scenario where monetary shocks enjoy higher importance than the literature has documented. For all parameters the GMM estimates behave better, in terms of bias, than OLS, as $\sigma_{r}$ increases, despite the smaller variance of OLS estimates. The main conclusion of Figure 1.5 is that if the monetary policy shocks contribute to only a small fraction of the FEVD of output and inflation at all horizons, then endogeneity problem is irrelevant to estimation of monetary policy rules. One can apply OLS estimation rather than GMM approach, and, by doing so, benefit from simplicity of OLS, instead of spending effort searching for instrumental variables and dealing with identification issues.

\section{4}

\section{Large-scale DSGE model}

Now we consider a large-scale DSGE model proposed by (23). They develop and estimate an open economy DSGE model for the euro area. It contains an environment with rules for government consumption, investment and transfers with financial frictions in the form of liquidity-constrained households. The domestic and foreign firms produce a continuum of differentiated goods. The goods produced in the home country are imperfect substitutes for goods produced abroad. The model economy is populated by households and firms, and there is a monetary, and fiscal authority, both following rule-based stabilization policies. The model encompasses nineteen exogenous shocks: a wage mark up shock, a price mark-up shock, a monetary policy shock, a fiscal policy shock, world demand shock, a risk premium shock, a technology shock, an investment shock, a consumption shock, a trade shock, a labor demand shock, a foreign monetary policy shock, a dependency rate shock, a labor overhead shock, a participation rate shock, a population growth shock, a foreign TFP shock, a domestic TFP shock, and a foreign inflation shock. Monetary policy is modeled via a Taylor rule - with similar specification to (19) -, which allows for some smoothness of the interest rate response to the inflation and output gap

$$
i_{t}=\rho i_{t-1}+(1-\rho)\left[r^{E Q}+\pi^{T}+\phi_{\pi}\left(\pi_{t}-\pi^{T}\right)+\phi_{y, 1} y_{t-1}\right]+\phi_{y, 2}\left(y_{t}-y_{t-1}\right)+u_{t} .
$$

The central bank has a constant inflation target $\pi^{T}$, and $u_{t}$ is white noise. There is no serial correlation in monetary policy shock. Equation (3-6) can be 
written as

$$
i_{t}=\theta_{1} i_{t-1}+\theta_{2} \pi_{t}+\theta_{3} y_{t}+\theta_{4} y_{t-1}+u_{t},
$$

where $\theta_{1}=\rho, \theta_{2}=(1-\rho) \phi_{\pi}, \theta_{3}=\phi_{y, 2}$, and $\theta_{4}=\left[(1-\rho) \phi_{y, 1}-\phi_{y, 2}\right]$. We generate data from this model, using sample sizes of $\mathrm{T}=80, \mathrm{~T}=150$, and $\mathrm{T}=500$, to estimate the monetary policy rule. We run regressions of nominal interest rate on current inflation, output gap, and lagged output gap, to recover the parameters of equation (3-7). With these estimates in hand we can recover the structural parameters. For GMM estimation, four lags of inflation and two lags of output gap are used as instruments. The set of instruments is not the same as used before in medium-scale model simulation. The reason is that in (23), the monetary policy shock is white noise, so lags of endogenous variables are suitable instruments, which did not occurred before. However, other sets of instruments were used and the results did not change significantly. Table 1.3 examines the estimates from 1000 Monte Carlo simulations. To simulate data, the parameters of the model are calibrated using the mean of posterior distribution.

From results in Table 1.3 we can see that all OLS and GMM estimates are very close to true values for all sample sizes considered. Despite of Relative Bias being high in some particular cases, varying from 0.93 up to 7.8 , the absolute bias for both estimation methods are very small. GMM estimates should be unbiased because lagged variables are good instruments when $u_{t}$ is white noise. However, the estimates present small biases when $\mathrm{T}=80$ (the GMM small sample bias highlighted before). The bias tends to vanish when the number of observations increases, when $\mathrm{T}=500$, GMM gets smaller bias for all estimates. Considering Relative Bias or Relative MSE, OLS does better than GMM for all estimates from $\mathrm{T}=80$ onwards, excepting for $\phi_{\pi}$ with $T=500$. Table 1.3 reveals the superiority of OLS over GMM for almost all sample sizes. Despite these conclusions, it must be clear in mind that either OLS or GMM estimates do a very good job in recovering the parameters of Taylor rule.

Figure 1.6 shows output and inflation impulse-response functions to a monetary policy shock. There are two paths for both variables, but the paths overlap as a result of the small bias in OLS estimates. OLS can recover the true parameters of monetary policy rule and reproduce the true impulse-response functions (IRFs implied by true parameters of Taylor rule).

The large-scale model has a lot more disturbances than the mediumscale, which causes a reduction in the relative importance of monetary policy shocks over other disturbances. As an outcome, we have a huge reduction on the endogeneity problem. When DSGE model is simulated at the mean of 
Table 1.3: OLS and GMM Estimates of Structural Parameters

\begin{tabular}{|c|c|c|c|c|c|c|c|}
\hline & \multicolumn{7}{|c|}{$\mathrm{T}=80$} \\
\hline & True values & OLS & OLS bias & GMM & GMM bias & Relative Bias & Relative MSE \\
\hline$\rho$ & 0.9009 & 0.8995 & -0.0005 & 0.9031 & 0.0022 & 7.8 & 19.7097 \\
\hline$\phi_{\pi}$ & 1.959 & 1.9511 & -0.0079 & 1.9643 & 0.0053 & 1.0886 & 1.2420 \\
\hline$\phi_{y, 1}$ & 0.4274 & 0.4305 & 0.0031 & 0.4329 & 0.0055 & 1.9677 & 3.2049 \\
\hline$\phi_{y, 2}$ & 0.0783 & 0.0834 & 0.0051 & 0.0868 & 0.0085 & 1.8627 & 2.8349 \\
\hline & \multicolumn{7}{|c|}{$\mathrm{T}=150$} \\
\hline & True values & OLS & OLS bias & GMM & GMM bias & Relative Bias & Relative MSE \\
\hline$\rho$ & 0.9009 & 0.9017 & 0.0017 & 0.9037 & 0.0037 & 2.1765 & 4.5847 \\
\hline$\phi_{\pi}$ & 1.959 & 1.9605 & 0.0015 & 1.9627 & 0.0037 & 2.4667 & 6.0076 \\
\hline$\phi_{y, 1}$ & 0.4274 & 0.4321 & 0.0047 & 0.4333 & 0.0059 & 1.2553 & 1.5543 \\
\hline$\phi_{y, 2}$ & 0.0783 & 0.0843 & 0.0060 & 0.0868 & 0.0085 & 1.4167 & 2.0382 \\
\hline & \multicolumn{7}{|c|}{$\mathrm{T}=500$} \\
\hline & True values & OLS & OLS bias & GMM & GMM bias & Relative Bias & Relative MSE \\
\hline$\rho$ & 0.9009 & 0.9029 & 0.002 & 0.9030 & 0.0021 & 1.05 & 1.6066 \\
\hline$\phi_{\pi}$ & 1.959 & 1.9622 & 0.0032 & 1.9623 & 0.003 & 0.9375 & 1.0594 \\
\hline$\phi_{y, 1}$ & 0.4274 & 0.4327 & 0.0053 & 0.4328 & 0.0054 & 1.0566 & 1.0624 \\
\hline$\phi_{y, 2}$ & 0.0783 & 0.0848 & 0.0065 & 0.0866 & 0.0083 & 1.2769 & 1.7432 \\
\hline
\end{tabular}

posterior distributions of the structural parameters, the endogeneity does not harm the OLS estimates of monetary policy rule. FEVD ensures a small role to monetary policy shocks. In this calibration the FEVD grants the monetary shock a small importance for changes in output and inflation, respectively $4.7 \%$ and $2.88 \%$. However, as monetary policy becomes relevant, in terms of FEDV, the OLS bias increases while the GMM estimates are not affected. Figure 1.7 shows how OLS and GMM estimates vary for different values of the standard deviation of monetary policy shock, $\sigma_{u}$. We can see all OLS estimates diverging from the true values when standard deviation of monetary policy increases. As Figure 1.7 makes clear, $\hat{\phi}_{y, 1}^{O L S}$ and $\hat{\phi}_{y, 2}^{O L S}$ diverge too much from the true values. At $\sigma_{u}=0.36$ we have $E\left(\hat{\phi}_{y, 1}^{O L S}\right)-\phi_{y, 1}=0.1726$, which means a bias of $40.23 \%$. Also, we have $E\left(\hat{\phi}_{y, 2}^{O L S}\right)-\phi_{y, 2}=-0.5783$, which means a bias of $738.57 \%$, and the OLS estimate shows the wrong signal for this parameter, which indicates a very poor performance. However, the bias relative to $\hat{\rho}^{O L S}$ and $\hat{\phi}_{\pi}^{O L S}$ is not worrisome. At $\sigma_{u}=0.36$ we have $E\left(\hat{\rho}^{O L S}-\rho\right)=0.0591$, a bias of $6.56 \%$, and $E\left(\hat{\phi}_{\pi}^{O L S}\right)-\phi_{\pi}=-0.04$, a bias of $2.04 \%$. The endogeneity bias affect more harshly the parameters related to output gap and induce almost none bias to the parameters related to interest rate lag and inflation. Therefore, if one is interested in verifying whether the Taylor principle holds, OLS estimates of Taylor rule would indicate the right way.

These simulations with large-scale DSGE model supports the conclusion 
Figure 1.6: IRF's form (23).
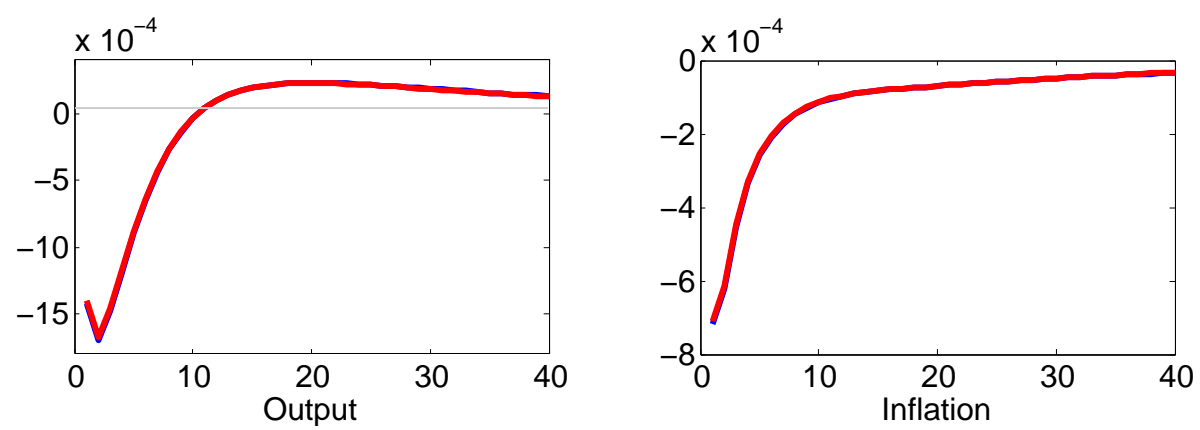

Note: The blue line represents the estimated responses of the model with parameters at the mean of posterior distributions; the red line represents the response implied by OLS estimates with $\mathrm{T}=80$.

about medium-scale model: As the model embraces more structure, the number of structural shocks increases, causing monetary policy shocks to play a limited role in inflation and output variations. That attenuates the endogeneity problem leading to similar estimates of OLS and GMM. Also, when standard deviation of monetary policy shocks decreases, holding all other parameters fixed, we have the a similar result: a lower standard deviation of monetary shocks attenuates endogeneity problem. The GMM approach brings no gain in terms of Relative Bias and Relative MSE.

Figure 1.7: Parameters estimation as a function of the variance of montary shock - large model.
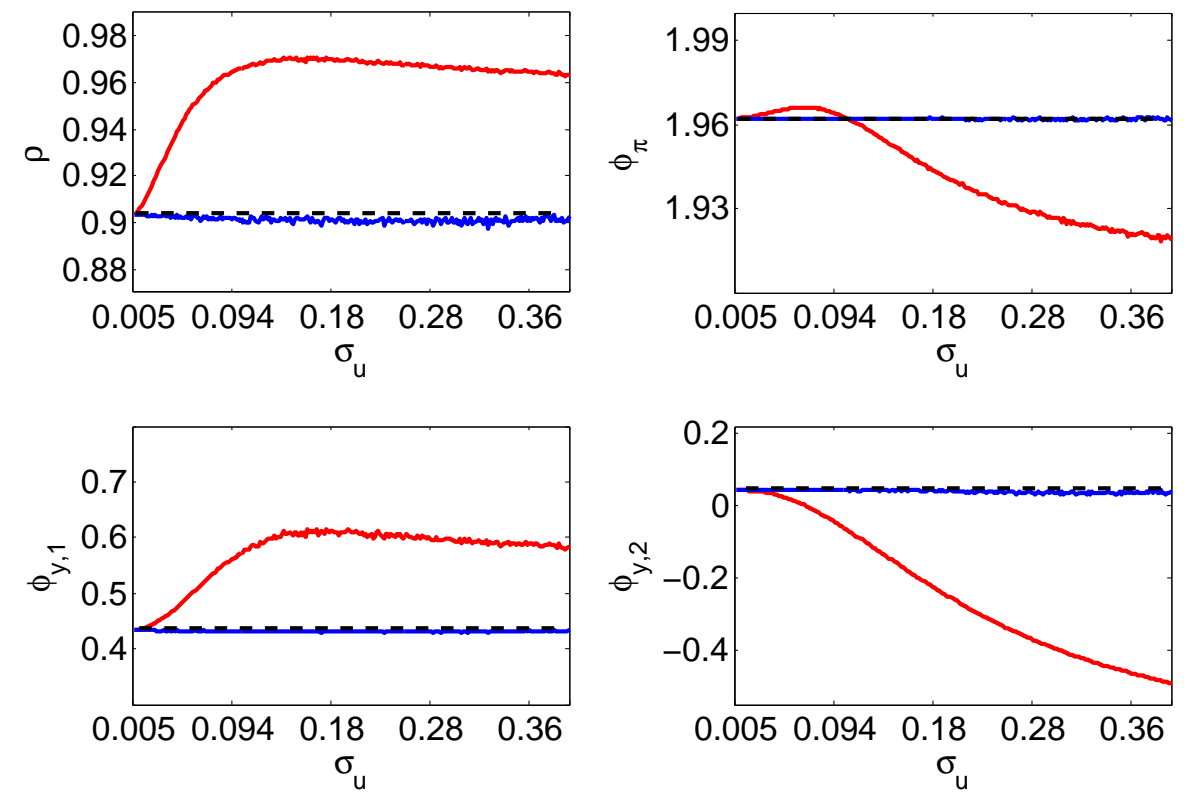

Note: The blue line represents the GMM estimates; the red line represents the OLS estimates. True parameter is the black dotted line. All simulations were made with $\mathrm{T}=500$. 


\section{5 \\ Conclusion}

This paper investigate how the estimation of Taylor rule is affected by the endogeneity problem in a broad class of New Keynesian models. We show analytically, in the 3-equation new Keynesian model, that the asymptotic bias is a function of the fraction of the variance of variables accounted for monetary policy shocks. That suggests a limited role to endogeneity bias when the monetary policy shocks explain only a small fraction of inflation and the output gap. To asses the endogeneity bias on lager models we resort to Monte Carlo simulations of medium-, and large-scale DSGE models (a framework that we know the true DGP).

Using the DSGE models as laboratories for our Monte Carlo experiments, our simulations indicate very similar Taylor rule point estimates in the use of OLS and GMM. The endogeneity problem attenuates as the number of disturbances increases, implying better estimates of OLS. The bias due to endogeneity proved to be a concern when the the DGP has few disturbances; however it causes not to much trouble when considering a DGP with many of random disturbances. When the model gets bigger, the variance of monetary policy shocks plays a smaller role inflation and output gap variation, which in turn reduces endogeneity problem in Taylor rule estimations. Even when when there are few disturbances, if standard deviation of monetary policy rule is small relative to other shocks, endogeneity is not harmful, and one can use OLS estimation in a single equation approach without worrying about endogeneity bias.

The endogeneity bias attenuates drastically as monetary policy shock decreases its importance in unconditional variance decomposition, in other words, when monetary policy play a small role in the variation of state variables.

The results presented here contribute to the related literature by expanding the understanding about of endogeneity problems in Taylor rule single equation estimation. The results show that endogeneity problem does not cause large bias in the OLS estimation of Taylor rules considering a rather plausible and realistic DGP ((19)). When considering a limited role to monetary policy shocks, as indicated by VAR literature, the endogeneity bias drops sharply, implying no significant difference between OLS and GMM estimates. One can apply OLS estimation rather than the GMM approach, and by doing so benefit from the simplicity of OLS, instead of spending effort searching for instrumental variables and dealing with identification issues. 


\section{2}

\section{Forward guidance through the lens of a DSGE model with time-varying price of risk}

\section{1 \\ Introduction}

The onset of financial crises of 2007 brought the nominal interest rate close to zero and gave rise to unconventional monetary policy experiments conducted by Federal Reserve (FED). With the federal funds rate at its effective lower bound, the forward guidance has turned one of the central monetary policy tools and was hurled in the spotlight of macroeconomic literature. Several efforts have been spent on understanding the macroeconomic responses to forward guidance policy through the lens of New Keynesian models. However, standard medium-scale dynamic stochastic general equilibrium models (DSGE) tend to overestimate the impact of forward guidance on the macroeconomy, a phenomenon labeled "forward guidance puzzle" (see (24)).

We examine the effects of different forward guidance policies experiments on the term structure of interest rates, and on the macroeconomy, in the light of a New Keynesian DSGE model. The model is extended by a term structure of interest rates that does not depend on the expectational hypothesis and provides a satisfactory fit of the yield curve. Since forward guidance announcements affect asset prices, yield data can provide useful information about FOMC announcements improving parameter estimation. So we use data on yield curve to identify news shocks. Our results indicate that forward guidance, through isolated news shocks, has small effects on long rates - we find smaller responses than those reported by event-studies.

We also document how DSGE model predictions behave under a fixed interest rate path. We find that the model must be able to fit the entire yield curve very well, otherwise it will probably overestimate the effect of forward guidance announcements on macroeconomic variables as output and inflation. The persistence of the monetary policy rule is equally important. Higher degrees of persistence result in slow convergence of the interest rate to its steady-state value, enlarging the output to unreasonable responses. This mechanism is crucial during the liftoff period whereby agents form expectations 
about the pace of fed funds lifting. Both channels expand current economic activity through Euler equation relation. Thus, overestimated effects on yields increases contemporaneous consumption at present value. We also document how the term premium vary due a several structural shocks. Our results point out the importance of the short-term yields and the monetary policy rule persistence, after the liftoff, as determinants to macroeconomic responses.

New Keynesian DSGE models has shown a good performance in fitting, and forecasting, macroeconomic data. Models like (20) and (19) track and forecast time series as well as a VAR. For that reason DSGE framework is useful to model monetary policy news shocks. However, in standard macroeconomic DSGE models, the term premium is small and rather stable relative to the data. Asset prices are overlooked in (19). This feature makes those structural models a poor framework to study the dynamics of the yield curve. Following another route, a branch of literature have analyzed bond yields in a affine framework to study the linkage between asset prices and macroeconomics, as in (26) and (27). Some authors work with latent factors driving prices without describing real economy fluctuations, others make use of reduced-form consumption movements (see (28)). In summary, traditional New Keynesian DSGE models can not handle changes in the term premium whereas traditional financial models leave the real economy out.

Our analysis overcomes the difficulties in dealing with the real economy along with the term structure by applying an "Essentially Affine Method", proposed by (29). He augments a structural macroeconomic models inserting time-varying risk aversion and generating an essentially affine stochastic discount factor; the result is a traditional DSGE model encompassed by a term structure of interest rate that does not depend on expectation hypothesis. (29) uses his model to fit data on yield curve getting fitting errors for bonds comparable with those obtained from a non-structural three-factor model. We use his essentially affine approximation to evaluate the effects of forward guidance. Furthermore, (24) has pointed that standard DSGE models implies large drops in the long-term interest rates. This should be the source of forward guidance puzzle - in the model, agents expect too low interest rates in the future, so they increase consumption. Therefore, our analysis verify the forward guidance effects under a framework in which the entire yield curve shows a good fit.

The reason to use a DSGE model approach is twofold: enables discussing term structure of interest rates in a framework in which the pricing kernel is derived, and comes from an explicit utility maximization problem; also, it is important due to its feature of a laboratory economy, in which we can isolate the policy to be analyzed. Furthermore, this kind of model has become 
a benchmark for policy analysis, so there is a great interest in evaluating yield curve responses to forward guidance policies in this framework. The approach set forth in this paper has a methodology contribution: the essentially affine approximation enables a richer term structure framework that can be estimated using yield data in a Bayesian framework, which enable a richer mechanism than reduced forms, latent factors approach, or expectational hypotheses of the term structure of interest rates.

Forward guidance is an unconventional monetary policy that means providing information about future monetary policy settings, in essence, the communication about the path of future short term interest rates. This paper is related to some recent works as (30) and (25). They emphasize the effects of this unconventional monetary policy on long term bond yields; an expansionary forward guidance shock reduces long term interest rates and drives economic activity upward. (31) use high-frequency data to evaluate the forward guidance effects on long-term bonds. They find that despite the federal funds rate being at zero lower bound the Federal Open Market Committee (FOMC) appears to have directly affected long term yields by managing expectations of future monetary policy. (33) highlights the two main ways in which forward guidance can impact financial markets: First, it should affect the future expected short term rates as well as long term bond yields; second, the volatility of market expectations of future policy rates should fall, possibly also compressing risk premium. The asset prices bear useful information about resources allocation and expectations. Investors and central banks assess the shape of yield curve to infer expectations about inflation and economic activity, thus we use yield data to improve the model's parameters estimation.

While there remains some controversy about the magnitude and sign of the response of long term rates to monetary news shocks, the prompt response of yield curve and expectations about the future economic outlook seems to be a consensus among economists. (34) use an event-study methodology to report econometric regressions based on daily changes in forward rates. They estimate the responses of those forward rates to economic news. They present evidence that long term rates react significantly to a monetary policy news shocks: 100 basis points innovation to the 1-period ahead forward guidance induces responses of 41 and 28 basis points to 1- and 10-year Treasury yields.

Using a similar approach, (25) examines FOMC's statement data to measure their impact on private expectations. The estimated effects of FOMC forward guidance on asset prices and private forecasts suggest the FOMC has had some success in communicating its future intentions to the public. According their findings, 100 basis points increase to the 1-period ahead 
forward guidance is associated with 200 basis points in 2- and 5-year Treasury yields, and 150 basis points in 10-year Treasury yield.

Our model says that a 100 basis points increase to the one period ahead forward guidance is associated with 20, 6.5 and 0.32 basis points in 1-, 5- and 10 -year bond yields. Therefore, forward guidance has small effects on long term bonds compared with event-studies literature (see (35)). One possible source of divergence lies on the nature of event-studies methodology. Empirical studies should be interpreted with a bit of caution. It is very difficult to obtain a pure measure of forward guidance shock because these announcements are often combined with other policy actions which may have independent effects on long term interest rates, such as Large-scale asset purchases (LSAPs). These asset purchase operations typically involve some forward guidance as well. Central bank purchases of long-term securities are announced in advance of the actual purchases, which are spread out over several quarters ahead. (36) and (37) present evidence that LSAPs can alter long-term interest rates and resembles forward guidance policy.In our model, by construction, forward guidance acts purely, and its policy actions are reflected solely by spoken statements. As a result, the event-studies might be overestimating the true effect.

Recent papers propose different solutions to the forward guidance puzzle. (55) show that the puzzle is substantially reduced in a sticky information model. With sticky information, as opposed to a sticky price, the Phillips curve is less forward looking, which decrease the mechanism described in Euler equation. ${ }^{1}$ (24) incorporate a perpetual youth structure into the standard model for providing a resolution to the puzzle. They assume that agents face each period a constant probability of dying and being replaced by a new agent. So the cohort structure translates into an aggregate economy that discounts the future more heavily, decreasing the importance of prediction about future. This implies that announcements of policy changes in the future generate smaller effects on current aggregate variables, attenuating the forward guidance puzzle. (56) consider a general equilibrium model in which agents face uninsurable, idiosyncratic income risk and borrowing constraints. They find that forward guidance is much less effective in incomplete markets than it is in standard macroeconomic models. In this paper, we show evidence that the forward guidance puzzle can not be solved in the standard macroeconomic models. Even in a framework that handles the yield curve very well, and adds information about yield curve movements. The model built here is an attempt to solve the puzzle in a standard DSGE approach.

\footnotetext{
${ }^{1}$ See Appendix for a more detailed discussion about the transmission mechanism of the forward guidance.
} 


\section{2}

\section{The Model}

The model is a dynamic macroeconomic model with generalized recursive preferences, consumption habit formation, nominal rigidities, and time-varying risk aversion. Generalized recursive preferences, as in (38) and (39) are required to allow the elasticity of intertemporal substitution to be unrelated to risk aversion which enable us to match the size of risk premia in the data. The consumption habit formation helps to solve the equity premium puzzle by decreasing consumption growth volatility. Nominal rigidities are required for model to match the basic behavior of inflation, nominal interest, and the risk premia on Treasuries. Finally, time-varying risk aversion helps the essentially affine solution method in generating an approximation with accuracy between second-and third-order perturbation.

The model follows New Keynesian structure of (32) with the extensions described above plus a term structure of interest rates block.

\subsection{1}

\section{Households}

There is an unit continuum of representative households, living forever in discrete time. The household solves the problem

$$
\begin{array}{ll}
\max _{\left\{c_{t}, a_{t+1}\right\}} & V_{t}=U\left(c_{t}, \bar{c}_{t-1}, l_{t}\right)-\beta E_{t}\left(-V_{t+1}^{1-\alpha_{t}}\right)^{\frac{1}{1-\alpha_{t}}} \\
\text { s.t. } & a_{t+1}=\exp \left(i_{t}\right) a_{t}+w_{t} l_{t}+d_{t}-P_{t} c_{t} .
\end{array}
$$

In each period the household receives the utility flow

$$
\begin{gathered}
U\left(c_{t}, \bar{c}_{t-1}, l_{t}\right)=\frac{c_{t}^{\delta(1-\gamma)} \bar{c}_{t-1}^{(1-\delta)(1-\gamma)}}{1-\gamma}+\chi_{0} \frac{\left(1-l_{t}\right)^{1-\chi}}{1-\chi} \\
\alpha_{t}=\left(1-\rho_{\alpha}\right) \bar{\alpha}+\rho_{\alpha} \alpha_{t-1}+\varepsilon_{t}^{\alpha},
\end{gathered}
$$

where $c_{t}$ and $l_{t}$ denote household consumption and labor in period $t .^{2} a_{t}$ denotes beginning-of-period nominal assets and $w_{t}$ and $d_{t}$ denote the nominal wage and exogenous transfer to the household. $\bar{c}_{t-1}$ is the aggregate consumption of the last period which the household takes as given. $\chi_{0}>0, \chi>1$ and $\gamma>1$ are parameters that make utility a negative flow, for that reason there are minus signals in the value function, Equation $(3-1) .^{3}$

$\alpha_{t}$ is the coefficient of relative risk aversion, which is allowed to vary over time following and AR(1) process. Although risk aversion shocks may have

\footnotetext{
${ }^{2}$ We normalized $l_{t}^{H}=1$. These nonmarket goods can be seen as "home production".

${ }^{3}$ Theorem 3.1 in (38) demonstrates the existence of a solution $\mathrm{V}$ for eq.(3-1) with $V \leq 0$ everywhere. For more details about different kinds of formulations see (50)
} 
small effects on $c_{t}$ and $l_{t}$, its volatility will be priced as risk which will be taken into account in precautionary saving effects. The utility function has a multiplicative habit formation term to ensure that changes in risk aversion are exclusive due to $\varepsilon_{t}^{\alpha}$. In this framework, where utility is a negative flow, higher values of $\alpha_{t}$ mean lower risk aversion.

The additive separability between consumption and leisure is not needed in the analysis that follows, but simplifies the elasticity of intertemporal substitution and Frisch elasticity expressions. This specification implies the following Frisch elasticity: $\varepsilon^{F}=\frac{\left(1-l_{s s}\right)}{\chi l_{s s}}$, where $l_{s s}$ is the steady-state labor; and the following term represents the elasticity of intertemporal substitution: $\varepsilon^{I S}=1 /(1-\delta(1-\gamma))$.

Households can borrow and lend in a default-free one-period nominal bond market at the continuously-compounded interest rate $i_{t}$. Continuous compounding simplifies the bound-pricing equations. The household faces a standard no-Ponzi scheme constraint,

$$
\lim _{T \rightarrow \infty} E_{t} \prod_{t=\tau}^{T} \exp \left(-i_{\tau+1}\right) a_{T+1} \geq 0 .
$$

In each period, the household solves Equation (3-1) subject to the constraint Equation (2-4). $a_{t}$ and $\Theta_{t}$ are the states variables of the optimization problem, where the latter is a vector denoting the state of the aggregate economy at the time $t$. The household value function satisfies the Bellman equation

$$
\tilde{V}\left(a_{t} ; \Theta_{t}\right)=\max _{\left\{c_{t}, l_{t}\right\}} U\left(c_{t}, \bar{c}_{t-1}, l_{t}\right)-\beta E_{t}\left(-\tilde{V}\left(a_{t+1} ; \Theta_{t}\right)^{1-\alpha_{t}}\right)^{\frac{1}{1-\alpha_{t}}}
$$

The household's stochastic discount factor is

$$
S_{t, t+1}=\beta E_{t} \frac{U_{c, t+1}}{U_{c, t}} \frac{\left(E_{t}-V_{t+1}^{1-\alpha_{t}}\right)^{\frac{\alpha_{t}}{1-\alpha_{t}}}}{-V_{t+1}^{-\alpha_{t}}}
$$

Some algebraic manipulation can show that the Equation (2-6) can be written as a function of the return of an asset, which corresponds to wealth return. ${ }^{4}$ Therefore the discount factor is given by

$$
S_{t, t+1}=E_{t} \beta^{1-\alpha_{t}}\left(\frac{U_{c, t+1}}{U_{c, t}}\right)^{1-\alpha_{t}} R_{J, t+1}^{-\alpha_{t}} \exp \left(-\pi_{t+1}\right)
$$

The Equation (2-7) is useful to deal with essentially affine approximation method.

${ }^{4}$ See algebraic manipulations in Appendix. 


\subsection{2}

\section{Firms}

There is a continuum of infinitely-lived monopolistically firms indexed by $f \in[0,1]$. Each firm produces a single differentiated good. Firms hire labor, as it's only input resource, from households in a competitive market following identical Cobb-Douglas production functions,

$$
y_{t}(f)=A_{t} l(f)^{\theta}
$$

where $y_{t}(f)$ corresponds to firm f's output, $A_{t}$ denotes aggregate productivity affecting all firms. $l_{t}(f)$ denote labor inputs at time $t$ and $\theta \in(0,1)$ is a parameter. As in (32), (40) and (14), the firms' capital stocks are fixed, for simplicity. According to (32), movements in the capital stock are small at business-cycle frequencies and are dominated by fluctuations in labor.

The technology is given by an $\mathrm{AR}(1)$ process

$$
\log A_{t}=\rho_{A} \log A_{t-1}+\varepsilon_{t}^{A}
$$

where $\rho_{A} \in(0,1)$, and $\varepsilon_{t}^{A}$ is an i.i.d white noise process.

Firms set prices according to (41) price contracts, which expire with probability $1-\zeta$ each period, $\zeta \in[0,1)$. Each time a Calvo contract expires, the firm sets a new contract price $p_{t}^{*}(f)$ freely, which then remains in effect for the life of the contract, with indexation to the past and steady-state inflation rate composite $\bar{\pi}$ each period. In each period $\tau \geq t$ that the contract remains in force, the firm must supply whatever output is demanded at the contract price $p_{t}^{*}(f) \exp (\tau-t) \pi_{t}^{\varpi} \bar{\pi}^{1-\varpi}$, hiring labor $l_{\tau}(f)$ from households at the market wage $w_{\tau}$. The firms are owned by households and distribute all profits and losses back to households each period in a lump-sum manner, denoted by $d_{t}$.

The output of each firm $f$ is purchased by a perfect competitive final good sector, which aggregate the differentiated goods into a single final good using a CES production technology. The intermediate differentiated goods work as inputs to final good production. The production function of final good is

$$
Y_{t}=\left(\int_{0}^{1} y_{t}(f)^{1 / \lambda} d f\right)^{\lambda}
$$

The final producer takes input prices, $p_{t}(f)$, and sell price, $P_{t}$, as given and chooses how much inputs to buy to maximize profits:

$$
\begin{array}{ll}
\underset{\left\{y_{t}(f)\right\}}{\operatorname{maximize}} & P_{t} Y_{t}-\int_{0}^{1} p_{t}(f) y_{t}(f) d f \\
\text { subject to } & Y_{t}=\left(\int_{0}^{1} y_{t}(f)^{1 / \lambda} d f\right)^{\lambda} .
\end{array}
$$

This maximization implies a final producer demand curve in the following 
form

$$
y_{t}(f)=\left(\frac{p_{t}(f)}{P_{t}}\right)^{\frac{\lambda}{1-\lambda}} Y_{t} .
$$

Furthermore, it might be shown that aggregate index of prices is given by

$$
P_{t}=\left(\int_{0}^{1} p_{t}(f)^{\lambda / 1-\lambda} d f\right)^{1-\lambda} .
$$

Note that $p_{t}(f)$ is the price chosen by firm $f$, but only a fraction $1-\zeta$ of the firms is allowed to reoptimize, the rest of them indexes a composed index of past inflation and steady-state inflation. The percentage of the composed index is determined by the parameter $\varpi$. So, we can rewrite Equation (2-13) as

$$
P_{t}=\left((1-\zeta)\left(p_{t}^{*}\right)^{1 / 1-\lambda}+\zeta\left(P_{t-1}\left(\pi_{t}\right)^{\varpi}(\bar{\pi})^{1-\varpi}\right)^{1 / 1-\lambda}\right)^{1-\lambda}
$$

where $p_{t}^{*}$ is the price that maximizes the value of shareholders of the intermediate firm's cash flows over the lifetime of the Calvo contract. In other words, the selected intermediate firms solve

$$
\begin{array}{ll}
\max _{\left\{p_{t}^{*}\right\}} & E_{t} \sum_{j=0}^{\infty} \zeta^{j} S_{t, t+j}\left[p_{t+j}(f)-w_{t+j} l_{t+j}(f)\right] \\
\text { s.t. } & y_{t+j}=\left(\frac{p_{t+j}(f)}{P_{t+j}}\right)^{\frac{\lambda}{1-\lambda}} Y_{t+j} \\
& p_{t+j}(f)=p_{t}^{*} \prod_{l=1}^{j}\left(\pi_{t+l-1}\right)^{\varpi}(\bar{\pi})^{1-\varpi},
\end{array}
$$

where $S_{t, t+j}=\prod_{i=1}^{j} S_{t, t+i}=S_{t, t+1} \times S_{t+1, t+2} \times \ldots \times S_{t+j-1, t+j}$ denotes shareholders' stochastic discount factor from period $t+j$ back to $t$, and $y_{t+j}(f)$ and $l_{t+j}(f)$ denote the firm's output and labor output in period $t+j$, respectively, conditional on the price $p_{t}^{*}(f)$ still being in effect. Equation (3-4) shows that each intermediate firm faces a demand curve with negative slope with elasticity $\epsilon=\lambda / 1-\lambda$.

Note that each intermediate producer faces the following marginal cost function at time $t$,

$$
\mu_{t}=\frac{w_{t} l_{t}^{1-\theta}}{A_{t} \theta}=\frac{w_{t} Y_{t}^{1-\theta / \theta}}{\theta A_{t}^{1 / \theta}}
$$

Differentiating Equation (3-4) with respect to $p_{t}^{*}(f)$ and setting the derivative equal to zero yields the price optimality condition, $p_{t}^{*}(f)=\lambda \frac{E_{t} \sum_{j=0}^{\infty} \zeta^{j} S_{t, t+j} \mu_{t+j} Y_{t+j}\left(\prod_{l=1}^{j}\left(\pi_{t+l-1}\right)^{\varpi}(\bar{\pi})^{1-\varpi}\right)^{\frac{\lambda}{1-\lambda}}\left(\prod_{m=1}^{j} \pi_{t+m}\right)^{\frac{\lambda}{1-\lambda}}}{E_{t} \sum_{j=0}^{\infty} \zeta^{j} S_{t, t+j} Y_{t+j}\left(\prod_{l=1}^{j}\left(\pi_{t+l-1}\right)^{\varpi}(\bar{\pi})^{1-\varpi}\right)^{\frac{1}{1-\lambda}}\left(\prod_{m=1}^{j} \pi_{t+m}\right)^{\frac{1}{1-\lambda}}}$, where $\lambda$ is a monopolistic markup over a discounted weighted average of expected future marginal costs over the lifetime of the contract. 


\subsection{3}

\section{Market Clearing}

There is no government and investments, so the aggregate resource constraint is

$$
Y_{t}=C_{t}
$$

Let $L_{t}$ denote the aggregate quantity of labor demanded by firms,

$$
\begin{gathered}
L_{t}=\int_{0}^{1} l_{t}(f) d f \\
L_{t}=\left(\frac{y_{t}(f)}{A_{t}}\right)^{1 / \theta},
\end{gathered}
$$

as presented above, $y_{t}(f)=\left(\frac{p_{t}^{*}}{P_{t}}\right)^{\lambda / 1-\lambda} Y_{t}$, thus

$$
L_{t}=\int_{0}^{1}\left(\frac{p_{t}^{*}}{P_{t}}\right)^{\lambda /(1-\lambda) \theta}\left(\frac{Y_{t}}{A_{t}}{ }^{1 / \theta}\right) d f=\left(\frac{Y_{t}}{A_{t}}\right)^{1 / \theta} \underbrace{\int_{0}^{1}\left(\frac{p_{t}^{*}}{P_{t}}\right)^{\lambda /(1-\lambda) \theta}}_{\Delta_{t}=\text { price dispersion }} .
$$

As demonstrated in (?) $\Delta_{t} \approx 1$ in first order approximations. Thus we have

$$
L_{t}=\left(\frac{Y_{t}}{A_{t}}\right)^{1 / \theta}
$$

Finally, there is an monetary authority that sets the one-period nominal interest rate $i_{t}$ according to a Taylor policy rule,

$$
i_{t}=i_{t-1}^{\rho_{i}}\left[i_{s s}\left(\frac{\pi_{t}}{\pi_{t}^{*}}\right)^{\phi_{\pi}}\left(\frac{y_{t}}{\bar{y}_{t}}\right)^{\phi_{y}}\right]^{1-\rho_{i}} \exp \left(\varepsilon_{t}^{i}\right) \underbrace{\exp \left(\varepsilon_{1, t-1}^{\text {news }}+\varepsilon_{3, t-3}^{\text {news }}+\varepsilon_{5, t-5}^{\text {news }}+\varepsilon_{8, t-8}^{\text {news }}\right),}_{\text {forward guidance shocks }}
$$

where $\pi_{t}=\log \left(P_{t} / P_{t-1}\right)$ denotes the inflation rate, $y_{t}=\log \left(Y_{t}\right)$,

$$
\bar{y}_{t}=\rho_{\bar{y}} \bar{y}_{t-1}+\left(1-\rho_{\bar{y}}\right) y_{t}
$$

denotes a trailing moving average of log output, and $\phi_{\pi}, \phi_{y} \in \Re$ and $\rho_{\bar{y}} \in[0,1)$ are parameters. The monetary authority pursuits inflation rate as close to inflation target as possible. The inflation target vary in time following $\mathrm{AR}(1)$ process

$$
\pi_{t}^{*}=\left(1-\rho_{\pi^{*}}\right) \bar{\pi}+\rho_{\pi^{*}} \pi_{t-1}^{*}+\varepsilon_{t}^{\pi^{*}}+\sigma_{a, \pi} \varepsilon_{t}^{a} .
$$

The forward-guidance shocks are designed following (42), in other words, they are news shocks in monetary policy rule. The news shocks are i.i.d with zero mean, where $\varepsilon_{k, t-k}^{\text {news }}$ is a shock that is known to private agents at time $t-k$, but affects the policy equation rule $k$ periods later. We chose, arbitrarily, news in $t-1, t-3, t-5, t-8$, which means that monetary authority can 
reveal monetary shocks one, three, five and/or eight quarters ahead. This specification enables the monetary authority to set forward guidance polices up to 2 years ahead. Under this specification, the surprise shock, $\varepsilon_{t}^{i}$, has the usual interpretation of a deviation from the Taylor rule that is not expected to private agents. News shocks, $\varepsilon_{j, t-j}^{n e w s}$, instead, capture future deviations form the Taylor rule that are (credibly announced by the monetary authority) anticipated by private agents. Then they affect the expectations about future endogenous variables and, therefore, the consumption and price-setting decisions. News affect future expectations, while surprise shocks do not.

\subsection{4}

\section{Nominal Bonds}

A default-free zero-coupon nominal bond pays one nominal dollar at maturity. Let $p_{t}^{\$(n)}$ denote the nominal price of an n-period zero-coupon nominal bond, with $p_{t}^{\$(0)}=1$. Then for $n \geq 1$,

$$
p_{t}^{\$(n)}=E_{t} S_{t, t+1} \exp \left(-\pi_{t+1}\right) p_{t}^{\$(n-1)} .
$$

The nominal yield is given by

$$
\operatorname{yield}_{t}^{(n)}=-\frac{1}{n} \log \left(p_{t}^{\$(n)}\right) .
$$

The bond pricing and yield equations are recursively defined. They are appended to the macroeconomic model described above and solved numerically along with the macroeconomic variables. Considering a bond with $n$ periods to maturity requires $n-1$ bond pricing equations appended to the model, one for each maturity from 2 to $n .^{5}$

The term premium on a bond is written as the difference between the yield to maturity on the bond and the risk-neutral yield to maturity on the same bond. The risk-neutral nominal price of an n-period zero-coupon bond is given by

$$
\hat{p}_{t}^{(n)}=\exp \left(-i_{t}\right) E_{t} \hat{p}_{t+1}^{(n-1)}
$$

where $\hat{p}_{t}^{(0)}=1$. Therefore, the nominal n-period term premium is given by

$$
t p_{t}^{(n)}=\frac{1}{n}\left(\log \hat{p}_{t}^{(n)}-p_{t}^{\$(n)}\right)
$$

The term structure block is necessary to bind the model to the yield data. The solution method described below allows term premium varying in time so that the yield curve is not necessarily flat, the model does not depends

${ }^{5}$ The model settles periods in quarters. This model considers yield up to 10 years, which means 40 pricing equations. Adding term structure of interest rate in this fashion enlarge considerably the dimension of state variables. 
on expectation hypotheses as highlighted by (29). To check all equations of the macroeconomic model and solution derivation see Appendix.

\section{3}

\section{Solution Method and Estimation Procedure}

The standard method to solve a functional equation is perturbation. The drawback of perturbation methods is that if we want time variation in risk aversion to have any effect on the model dynamics, we need to take at least a second-order approximation. First-order implies no risk premium, second-order generates constant risk premium, and third-order generates a time-varying risk premium. Since the solution would be nonlinear, we would have to use the particle filter or some other nonlinear method to calculate the marginal likelihood of the model. Generally it is very difficult to find the peak of the likelihood function and complicates the estimation. This is a common problem in models of the term structure (see (43)).

Instead of higher order approximations this paper uses the essentially affine approximation method laid out by (44). The essentially affine method delivers an approximation to the equilibrium dynamics of the model that is linear in the state variables but still allows time-varying risk aversion to affect the behavior of the endogenous variables. ${ }^{6}$ Appendix B provides further details.

Denote the vector of the state variables in the model as $s_{t}$ and the vector of fundamental shocks as $\varepsilon_{t}$. The equations determining the equilibrium of the model take the form:

$$
0=G\left(s_{t-1}, s_{t}, s_{t+1}, \varepsilon_{t+1}\right)
$$

where the expectation operator may appear in the function $G$. There is one equation for each variable. I approximate around the point $\sigma_{\varepsilon}=0$, with the non-stochastic steady state defined as the point $\bar{S}$ such that

$$
0=G(\bar{S}, \bar{S}, \bar{S}, 0)
$$

The equations $G$ can be divided into two types: those that do not involve taking expectations over the SDF, $D$, and those that do, $F$. In summary, the approximations to the equilibrium conditions are

$$
\begin{aligned}
0 & =D\left(s_{t-1}, s_{t}, s_{t+1}, \varepsilon_{t+1}\right) \\
1 & =E_{t}\left[M\left(s_{t}, s_{t+1}, \varepsilon_{t+1}\right) F\left(s_{t-1}, s_{t}, s_{t+1}, \varepsilon_{t+1}\right)\right]
\end{aligned}
$$

${ }^{6}(44)$ shows that Euler equation errors in simulated models are competitive with thirdorder perturbations. 
where $D$ and $F$ are vector-valued functions and $M$ is the (scalar-valued) stochastic discount factor.

For the equations that do not involve the SDF, I use standard perturbation methods and simply take a log-linear approximation. The second set of equations is dynamic and involves expectations. The key source of nonlinearity in the model is the time variation in risk aversion, which induces heteroskedasticity in the SDF. It is therefore natural to deal with $M$ and $F$ separately to isolate the relevant nonlinearity. I take approximations to $M$ and $F$ separately.

$$
\begin{aligned}
0 & =D_{0}+D_{x} s_{t}+D_{s^{\prime}} s_{t+1}+D_{\varepsilon} \epsilon_{t+1} \\
m_{t+1} & =\exp \left(m_{0}+m_{s} s_{t}+m_{s^{\prime}} s_{t+1}+m_{\varepsilon} \varepsilon_{t+1}\right) \\
f_{t+1} & =\exp \left(f_{0}+f_{s} s_{t}+f_{s^{\prime}} s_{t+1}+f_{\varepsilon} \varepsilon_{t+1}\right) \\
0 & =\log E_{t} \exp \left(m_{t+1}+f_{t+1}\right)
\end{aligned}
$$

Both real variables and bond prices are linear functions of the underlying state variables contained in the vector $s_{t}$ and we can write model in state-space form. So guess the solution: $s_{t+1}=H_{s} s_{t}+H_{\varepsilon} \varepsilon_{t+1}$. The system (3-13)-(3-16) can be written as

$$
\begin{aligned}
0= & D_{s} s_{t}+D_{s^{\prime}}\left(H_{s} s_{t}+H_{\varepsilon} \varepsilon_{t+1}\right)+D_{\varepsilon} \varepsilon_{t+1} \\
0= & \left(m_{s}+f_{s}\right) s_{t}+\left(m_{s^{\prime}}+f s^{\prime}\right) s_{t+1}+ \\
& \frac{1}{2}\left(m_{\varepsilon}+f_{\varepsilon}+\left(m_{s^{\prime}}+f s^{\prime}\right) H_{\varepsilon}\right) \Sigma\left(m_{\varepsilon}+f_{\varepsilon}+\left(m_{s^{\prime}}+f s^{\prime}\right) H_{\varepsilon}\right)^{\prime}
\end{aligned}
$$

where Equation (3-18) uses the formula for expectation of a log-normally distributed variable. To find the unknown matrices $H_{x}, H_{\varepsilon}$ we can solve the model iteratively where the initial guess, $H_{x, 0}$ and $H_{\varepsilon, 0}$, are exactly the transition matrices obtained by log-linear approximation of system (3-11)-(3$12){ }^{7}$

This solution method differs from perturbation because it corrects for the time-varying risk premium. (29) shows that this procedure can generate a large and volatile term premium. This is driven by the combination of two factors: A negative response of interest rates to positive technology shocks; and variation in risk aversion, which is modeled by a structural shock. In essence, risk aversion and technology shocks determine average asset returns, and they have only weak effects on real variables at business-cycle frequencies.

After iterating essentially affine approximation method we can write the model in state-space form:

${ }^{7}$ Using (45) method. 


$$
s_{t}=H_{s}(\Theta) s_{t-1}+H_{\varepsilon}(\Theta) \varepsilon_{t}
$$

where the matrices $H_{s}(\Theta)$ and $H_{\varepsilon}(\Theta)$ are functions of the model parameters $\Theta$, and $\varepsilon_{t}$ is the vector of structural shocks. We have also a set of observable variables which relates the measurement equations to the states:

$$
y_{t}=\Psi_{s}(\Theta) s_{t}+\Psi_{v} v_{t}
$$

where $v_{t}$ is the vector of measurement errors. The state vector is augmented with the auxiliary variables $b_{1}, \ldots, b_{8}$ and $\varepsilon_{1, t}^{\text {news }}, \varepsilon_{3, t}^{\text {news }}, \varepsilon_{5, t}^{\text {news }}, \varepsilon_{8, t}^{\text {news }}$ following

$$
\begin{aligned}
& b_{1, t}=b_{2, t-1}+\varepsilon_{1, t}^{\text {news }} \\
& b_{2, t}=b_{3, t-1} \\
& b_{3, t}=b_{4, t-1}+\varepsilon_{3, t}^{\text {news }} \\
& b_{4, t}=b_{5, t-1} \\
& b_{5, t}=b_{6, t-1}+\varepsilon_{5, t}^{\text {news }} \\
& b_{6, t}=b_{7, t-1} \\
& b_{7, t}=b_{8, t-1} \\
& b_{8, t}=\varepsilon_{8, t}^{\text {news }},
\end{aligned}
$$

where the shocks $\varepsilon_{t-1}^{\text {news }}, \varepsilon_{t-3}^{\text {news }}, \varepsilon_{t-5}^{\text {news }}, \varepsilon_{t-8}^{\text {news }}$ are in vector $\varepsilon_{t}$ in equation (2-40). Note that $b_{1, t-1}=\varepsilon_{1, t-1}^{\text {news }}+\varepsilon_{3, t-3}^{\text {news }}+\varepsilon_{5, t-5}^{\text {news }}+\varepsilon_{8, t-8}^{\text {news }}$, that is, $b_{1, t-1}$ is an auxiliary variable that collects all anticipated shocks that affect the monetary policy rule in period $t$.

The choice of have four news shocks spread out between one and eight quarters is merely a parsimonious choice. Including news considerably increases the size of state space. For longer horizons the state-space representations would have a huge increase on computational task.

\subsection{1}

\section{Estimation}

We estimate the model using standard Bayesian method measuring the likelihood function using the Kalman filter and proceed running a Monte Carlo Markov Chain (MCMC) from an initial point of parametric space to sample from full posterior distribution. The posterior distribution is obtained by Metropolis-Hasting algorithm with 250,000 draws.

On the issue of estimation, the anticipated shocks are independent from one another. That is a strong simplification as we know the Federal Reserve does not provide orthogonal peaces of information. It would be important to relax the independence assumption in estimation exercise. At same time, we 
are cautious about those shocks being correlated because they are defined in the model as structural shocks; orthogonality of structural shocks is the key identification principle to find source of variation.

The sample is 1982:Q1 to 2007:Q4. The sample is cut off in 1983 due to the evidence for breaks in monetary policy at earlier dates and the lack of yield data earlier than 1982. All data are in quarterly frequency. The data description is detailed in the Appendix.

\subsection{2}

\section{Calibrated Parameters}

Some parameters are calibrated. One of them is the labor in steady-state, $l_{s s}=1 / 3$. It's calibrated in order to made the Frisch elasticity estimation depending only one parameter, $\chi$ in this case. This is done to facilitate the estimation. To set $l_{s s}=1 / 3$ We must fix $\chi_{0}=\frac{\theta \delta 3^{\gamma(\theta-1)+\chi}}{\lambda 2 \chi}$.

The parameters we calibrate are those difficult to be estimated. The steady-sate inflation is 0.8 percent implying 3.2 percent annualized, very close to mean inflation in the estimation period. (?) provide evidence on an intertemporal elasticity of substitution (IES) lower than one, so we set it in 0.5. To guarantee IES inside unitary circle we impose $\gamma>2$ and $\delta=1 /(\gamma-1)$. This ensures $I E S=0.5$ and $0<\delta<1$. Time preference, $\beta$, is set to 0.9962 , which means an annualized discount rate of $1.5 \%$. Also, $\varpi$ is set to 0.8 , which means that $80 \%$ of the firms do not allowed to re-optimize index past inflation to the prices, the rest of them, index steady-state inflation. The remainder of the parameters are estimated. The remainder of parameters are estimated.

\subsection{3}

\section{Parameter Estimates}

Table 1 lists the prior distributions and the posteriors and 5 and 95 percentiles of the posterior distribution of the parameters. The priors were settled in accordance with related DSGE models estimations and those arbitrary choices are rather standard. The majority of estimated standard deviations are smaller than those arbitrarily imposed to the priors, which supports the hypothesis that the data are quite informative on the behavioral parameters. This strengthens the argument of that the parameters are well identified. Price contracts expire with probability of 0.33 , suggesting an average length of price contracts of ten months. This is a bit high when compared to (46) whose prices last 5.5 months or less. 
Table 2.1: Priors and Posterior Modes

\begin{tabular}{|c|c|c|c|c|c|c|c|c|}
\hline & \multirow[b]{2}{*}{ Description } & \multicolumn{3}{|c|}{ Priors } & \multicolumn{4}{|c|}{ Posterior } \\
\hline & & Distribution & Mean & Std. Dev. & Mode & Std. Dev. & $5 \%$ & $95 \%$ \\
\hline$\chi$ & Frisch Elasticity & Gamma & 3 & 1 & 3.27 & 0.145 & 3.02 & 3.471 \\
\hline$\gamma$ & IES & Gamma & 2 & 1 & 2.259 & 0.061 & 2.119 & 2.344 \\
\hline$\theta$ & Concavity of production & Normal & 0.6 & 0.5 & 0.692 & 0.043 & 0.629 & 0.767 \\
\hline$\lambda$ & Steady-state markup & Normal & 1.1 & 0.5 & 1.143 & 0.056 & 1.057 & 1.259 \\
\hline$\xi$ & Calvo parameter & Beta & 0.8 & 0.2 & 0.777 & 0.009 & 0.762 & 0.793 \\
\hline$\rho_{i}$ & Interest rate persistence & Beta & 0.8 & 0.1 & 0.852 & 0.043 & 0.777 & 0.915 \\
\hline$\phi_{\pi}$ & Taylor rule inflation & Normal & 7.5 & 2.5 & 7.736 & 0.062 & 7.628 & 7.832 \\
\hline$\phi_{y}$ & Taylor rule output & Normal & 1 & 0.5 & 0.168 & 0.097 & 0.038 & 0.366 \\
\hline$\rho_{\bar{y}}$ & Output gap persistence & Beta & 0.5 & 0.2 & 0.846 & 0.072 & 0.960 & 0.960 \\
\hline$\rho_{a}$ & Technology persistence & Beta & 0.5 & 0.2 & 0.995 & 0.002 & 0.991 & 0.998 \\
\hline$\rho_{\alpha}$ & risk aversion persistence & Beta & 0.5 & 0.2 & 0.721 & 0.051 & 0.61 & 0.783 \\
\hline $\bar{\alpha}$ & Steady-state risk aresion & Gamma & 10 & 4 & 12.061 & 0.094 & 11.931 & 12.222 \\
\hline$\rho_{\pi}$ & inflation target persistence & Beta & 0.98 & 0.05 & 0.949 & 0.016 & 0.92 & 0.972 \\
\hline$\sigma_{a}$ & Technology vol. & Inv Gamma & 0.1 & 2 & 0.331 & 0.013 & 0.309 & 0.354 \\
\hline$\sigma_{i}$ & Interest vol. & Inv Gamma & 0.1 & 2 & 0.105 & 0.01 & 0.09 & 0.123 \\
\hline$\sigma_{\alpha}$ & Risk aversion vol. & Inv Gamma & 0.1 & 2 & 0.514 & 0.041 & 0.452 & 0.583 \\
\hline$\sigma_{\pi}$ & Inflation vol. & Inv Gamma & 0.1 & 2 & 0.094 & 0.008 & 0.08 & 0.109 \\
\hline$\sigma_{1}^{\text {news }}$ & 1-quarter News vol. & Inv Gamma & 0.1 & 2 & 0.143 & 0.012 & 0.132 & 0.158 \\
\hline$\sigma_{3}^{\text {news }}$ & 3-quarter News vol. & Inv Gamma & 0.1 & 2 & 0.09 & 0.008 & 0.07 & 0.11 \\
\hline$\sigma_{5}^{\text {news }}$ & 5-quarter News vol. & Inv Gamma & 0.1 & 2 & 0.124 & 0.018 & 0.08 & 0.163 \\
\hline$\sigma_{8}^{\text {news }}$ & 8-quarter News vol. & Inv Gamma & 0.1 & 2 & 0.088 & 0.006 & 0.07 & 0.101 \\
\hline$\sigma_{1 y}$ & 1-year measurement error & Inv Gamma & 0.1 & 2 & 0.092 & 0.008 & 0.079 & 0.107 \\
\hline$\sigma_{2 y}$ & 2-year measurement error & Inv Gamma & 0.1 & 2 & 0.093 & 0.009 & 0.079 & 0.109 \\
\hline$\sigma_{5 y}$ & 5-year measurement error & Inv Gamma & 0.1 & 2 & 0.094 & 0.009 & 0.08 & 0.111 \\
\hline$\sigma_{10 y}$ & 10-year measurement error & Inv Gamma & 0.1 & 2 & 0.008 & 0.034 & 0.08 & 0.109 \\
\hline
\end{tabular}

\section{4}

\section{Empirics}

In this Section we compare the model's predictions with some features of the yield data. Before presenting the results is necessary highlight some of the model's limitations and issues on observed yield data. When dealing with empirical yields movements, it must be clear that some of them can reflect the FOMC's announcements of LSAPs. However the model built in Section 2.2 does not have a financial intermediate sector and the LSAPs have no room in this paper. We focus only in forward guidance statements.

Actually the term "forward guidance" has a broader meaning than that stated until now. One must distinguish between Odyssean forward guidance, which publicly commits the FOMC to a future action, and Delphic forward guidance, which merely forecasts macroeconomic performance. Delphic statements are based on the policymaker's potentially superior information about future macroeconomic fundamentals and its own policy goals. A Delphic statement theoretically reduces private uncertainty and improves macroeconomic outcomes. Odyssean forward guidance can work influencing the public's expectations inflation. Done as a credible commitment to keep interest rate lower than otherwise would be for some time in the future, it should temporarily raise inflation expectations, which in turn means lower real interest rates, 
stimulating aggregate expenditures.

The general equilibrium model presented here does not distinguish between Delphic and Odyssean forward guidance. Implementing anticipated shocks as described in Section 2.2, we only can deal with Odyssean statements. There is no distinction between central bank and private forecasts inside the model, thus the anticipated shocks are announcements about the future path of short-term nominal interest rate. Hence we must interpret them only as Odyssean forward guidance.

Furthermore, our model has no time inconsistency between discretion and desire to commit to a policy path after a statement. This time inconsistency is not an issue because the model assumes that policymakers are fully committed to the pre-announced policy path and the public believes policymakers will follow through with their stated intentions. Although monetary news shocks acts through public's expectations inflation, our model presents no risk of unanchoring inflation expectations. There is no option to deviate from the announced path. In practice, forward guidance may risk unanchoring longterm inflation expectations in exceptionally long periods. Then the central bank must be run this policy tool without undermining its credibility to commitment to long-term price stability. Nevertheless, this is a practical issue that is absent in this model. We work only with unique solutions of the DSGE model, which means we assume central bank have perfect credibility. Working with ununchoring inflation expectation would lead us to deal with self-fulfilling expectations and multiple equilibrium, which is beyond the scope of this paper.

\subsection{1}

\section{Implied Macro Dynamics}

In this subsection we present the model adherence to historical data, and to some economic stylized facts. This subsection is motivated by a key question in monetary policy conduction, which is; how can we model the term premium within a DSGE model, and what are the implications of the model for different kinds of monetary policy design? The simultaneous relation between the real economy and bond prices, and how monetary policy affect this mechanism, is a key question for central bank's daily work.

Figure 2.1 plots the average term structure presented in the data and the steady-state of the model along with the unconditional standard deviation of observed data (shaded area). The sample period is the same used in the estimation. The dot-dashed line gives the steady-state term structure whereas the black solid line gives the average historical yield curve for 1982Q1-2007Q2. The model's steady state fits well the slope and level of the historical term 
Figure 2.1: Steady-State Nominal Bond Yields.

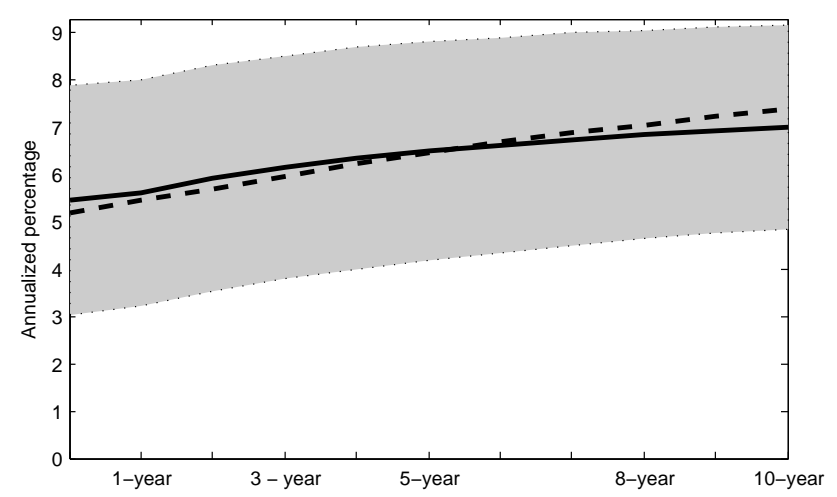

Note: Solid line gives the average historical yield curve; the spread between spot rate and ten years-maturity is 2.17 percentage points. The dot-dashed line gives the yield curve at the model's steady state. shaded area shows one unconditional standard deviation of the observed yield data.

structure for almost all maturities, however the level is slightly underestimated and the spread is slightly overestimated; the model's term spread is 217 basis points against 170 basis points observed in the data. Nevertheless, the model implied steady state captures the overall shape of the empirical curve - we can see in Figure 2.1 they are very close each other. It has an upward slope resulting in a positive term spread. Also, in this model, the risk aversion varies over time, so the term premium varies as well.

Figure (2.2) plots the deviations of the fitted yields from their actual values and are reported in annualized basis points. As measurement errors are attached to yield equations, those filtered errors captures movements that can not be explained by the model, therefore, they are a metric to evaluate the empirical ability of the model. The estimated standard deviations of the errors is 134 basis points (in annual terms) for the 1-year yield, 112 basis points for the 2-year yield, 91 basis points for the 5-year yield, and 79 basis points for the 10-year yield. The unconditional standard deviation of these yields over the sample period is 286, 290, 276 and 262 basis points, respectively. Hence, the DSGE model is able to explain $53 \%-69 \%$ of historical yield fluctuation. The yield errors are all centered around zero, meaning that the model can capture the shape of the term structure on average.

Our model generates a time-varying term premium that can contribute to understanding the links between the real and financial economy. To gain insights into which features of the model are of great significance for the term premium dynamics, we examine the model's impulse responses to shocks (the impulse response functions were calculated using the mode of posterior distributions presented in Table 1). In Figure 2.3 we present the impulse response functions of some variables of interest to a 100 basis points technology, 
Figure 2.2: Bond Yield Errors.
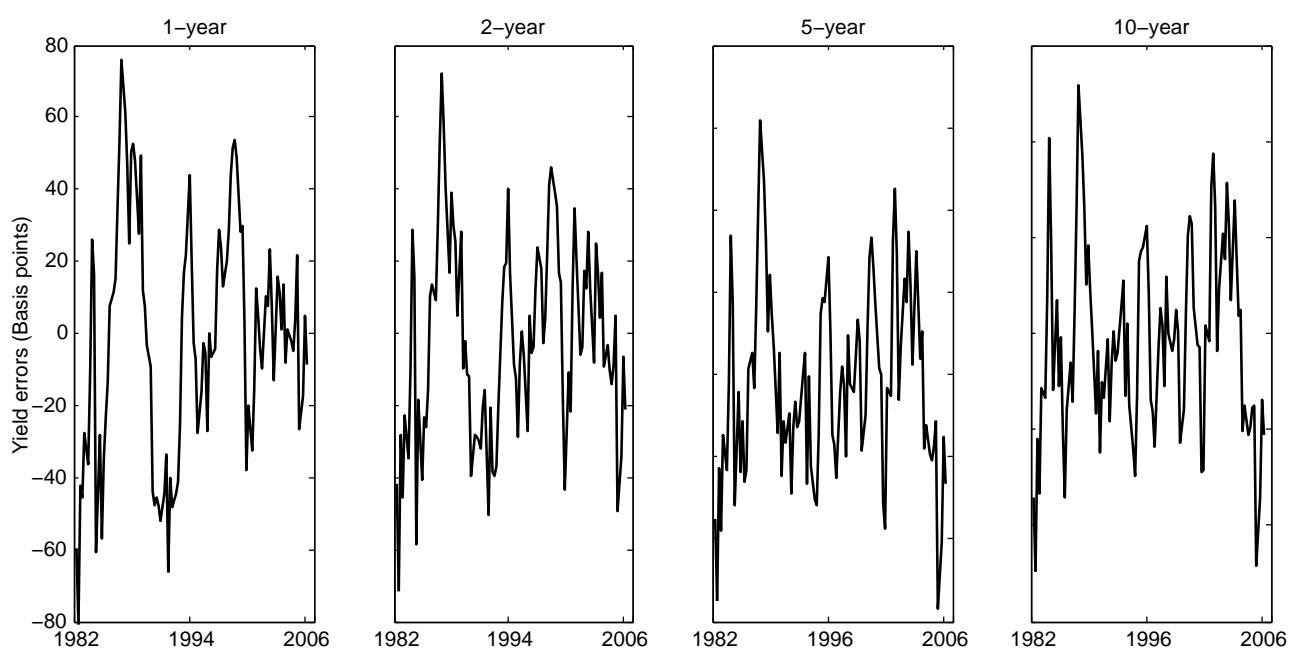

Note: Measurement errors in annual basis points. Errors are obtained from the Kalmanfiltered estimates at the posterior mode.

monetary policy and risk averse shock.

The first column shows the responses of the variables to a positive technology shock. Consumption is highly persistent while inflation converges faster to its steady-state value, this makes household fell wealthier and raises nominal bond prices. Bond prices rise because of the negative covariance between the stochastic discount factor and the long-term bond price (marginal utility of consumption is lower when consumption is growing). This negative covariance implies a negative term premium when consumption increases, and a positive term premium when consumption decreases. This result is in accordance with a view held in finance literature that term premiums are higher in recessions (see (47), and (48)).

The second column shows the responses to a positive monetary policy shock. The rise in short-term interest rates induces a fall in bond prices and output. Then we see a fall in consumption and a decrease in the marginal cost of inflation, next inflation fall as well. The term premium rises in this scenario, confirming that the term premium is a countercyclical variable that tends to rise during downturns and fall during upswings, however, the increase is small due the weak and fast effect of monetary policy on consumption. Consumption responds negatively immediately after a monetary contraction but it fades away vary fast. As a result, there is a small and short effect on yield bonds and term premium.

The third column exhibits the responses to a increase in risk aversion. The effects are very small compared to those for the technology and monetary policy. A 100 basis points increase in risk aversion lowers consumption by one-hundredth of $1 \%$. Is is necessary point out that the estimated standard- 
Figure 2.3: Impulse-Responses to Structural Shocks
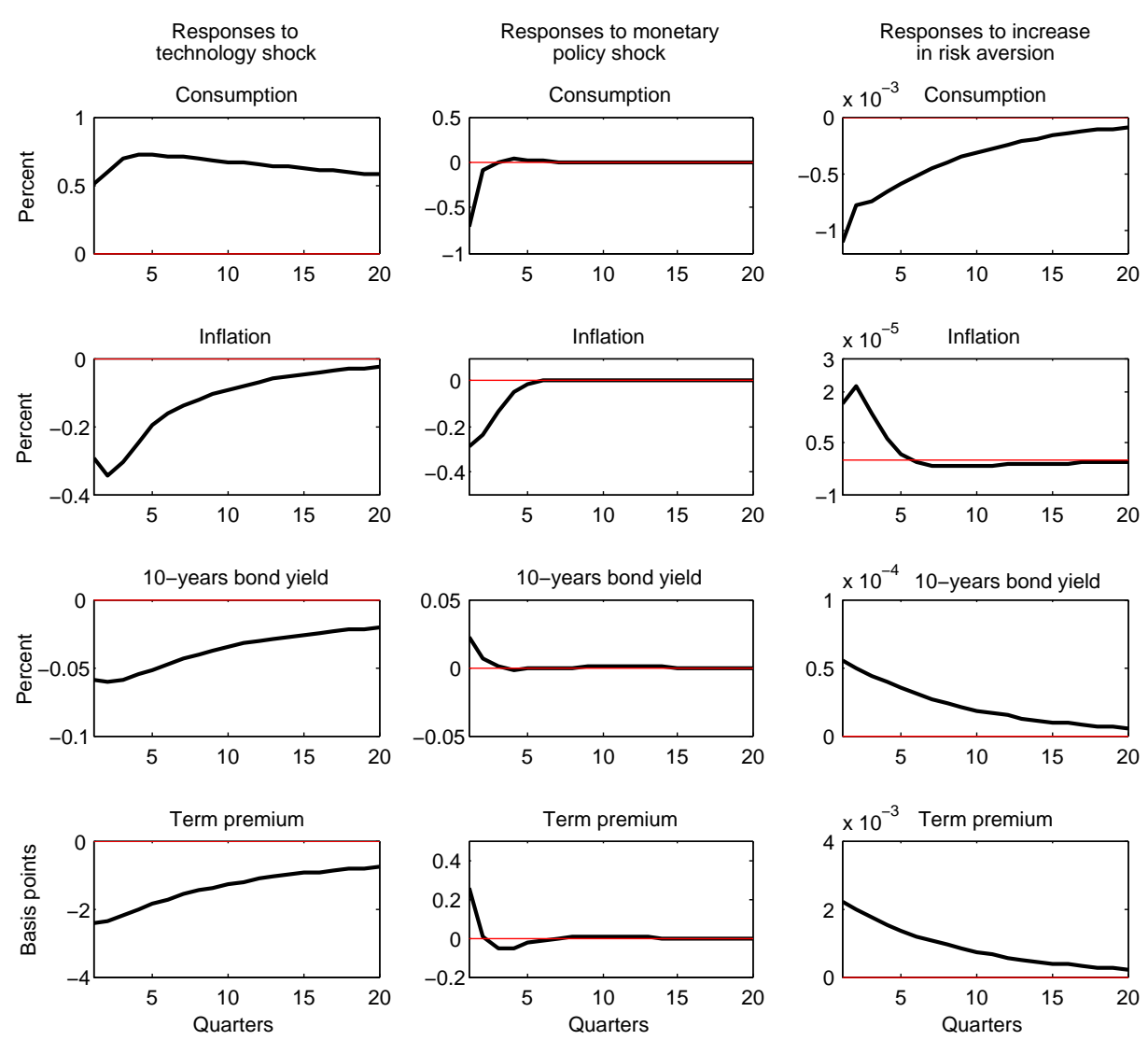

Note: Impulse responses to a positive 100 basis points shocks to technology and monetary policy.

deviation of risk aversion shock was 0.51 , therefore, 100 basis points is a small change if we consider its volatility. However, even a change of one-standard deviation in risk aversion implies a decline of $0.3 \%$ in consumption. The term premium raises by a small amount as well. Despite of the minor effect on real economy, the risk aversion is important to helping the model match asset prices. The introduction of risk aversion shock into the model help match the term premium because it generates negative covariance between inflation and consumption; an increase in risk aversion makes inflation falls and consumption rises, so long-term nominal bonds lose value. While technology shocks are the largest source of term premium fluctuations, the risk aversion shock also imply a negative covariance between the stochastic discount factor and the long-term bond price, and therefore help to match positive term premium. Both shocks hold the same intuition but the effects of risk aversion shocks on term premium are quantitatively smaller.

The model delivers a moderate response of term premium to structural shocks. When evaluating a technology shock, the changes in term premium is around 2.2 annualized basis points, which is four times smaller than those 
Figure 2.4: Term Premium Responses to Technology Shock

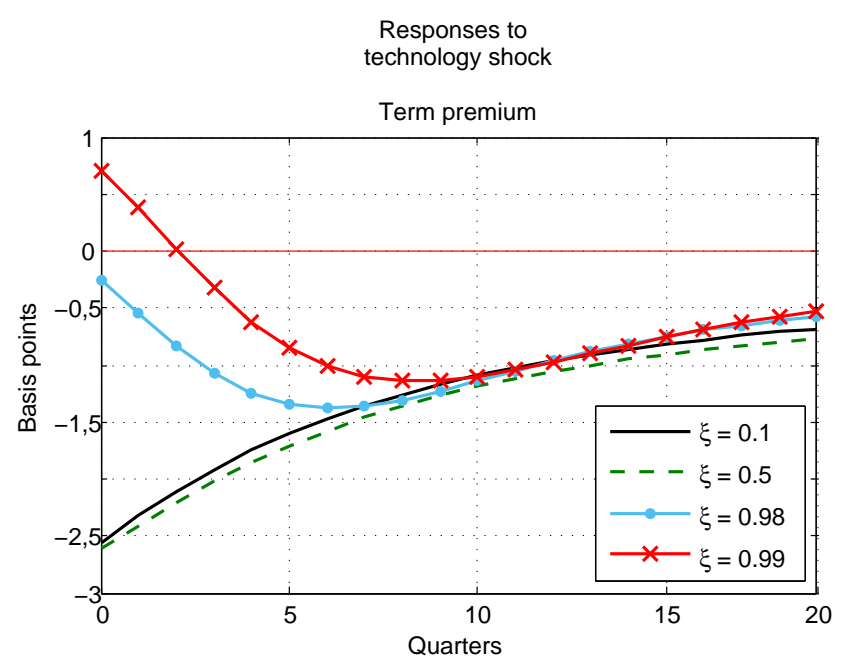

Note: Impulse responses to a positive 100 basis points shock to technology. Term premium responses to Calvo probability, $\xi=0.9, \xi=0.5$, and $\xi=0.05$.

reported by (32) and two times larger than (49). (50) find a term premium response of 12 basis points using a third-order approximation with a calibrated relative risk aversion coefficient of 75; a very large value for the curvature of agents' utility function. Our estimates are one-half of what was reported by those authors. In macroeconomic models that are approximated in second and third order (seeking to generate a constant or time-varying risk premium), as in (50) and (32), small changes in term premium are not surprising, because only in an extreme curvature, or almost implausible large stochastic variance, the third terms becomes relevant in the model. That is the drawback of traditional perturbation methods. Although our model has Euler equation errors similar to models in third-order perturbation, it shows a significant estimated variance, and therefore, delivers higher term premiums variations compared with some models in second- and third-order approximation's (when evaluated under plausible relative risk aversion coefficient).

Our simulations have shown that the magnitude of term premium changes is primarily driven by the consumption and inflation sensitivity to structural shocks - for a given covariance between the stochastic discount factor and the long-term bond price. If the model's parameters enable large consumption/inflation changes due to structural shocks - as technology shocks do -, than bond prices present greater variation leading to larger changes in term premium. Bond prices respond to inflation expectations because households dislike lose consumption and, for that reason, the inflation sensitivity to structural shocks is the the first key driver of the changes in term premium. To expose this result, in the Figure (2.4) we calibrate the Calvo parameter, $\xi$, to 
Figure 2.5: Term Premium Responses to Technology Shock

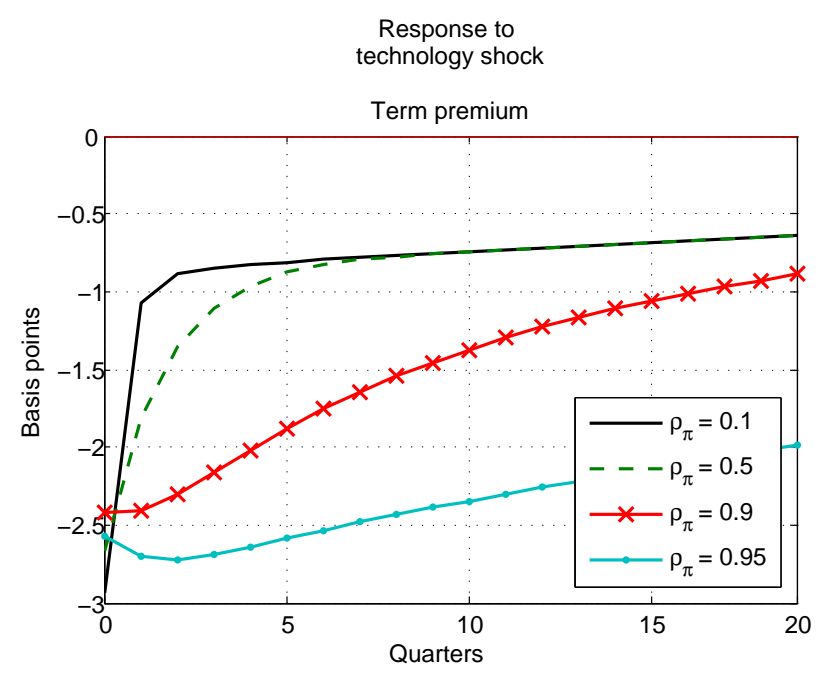

Note: Impulse responses to a positive 100 basis points shock to technology. Term premium responses to inflation target persistence, $\rho_{\bar{\pi}}=0.5, \rho_{\bar{\pi}}=0.8$, and $\rho_{\bar{\pi}}=0.95$.

different values and generate the responses of term premium to a 100 basis points increase in technology. The results can be see in Figure (2.4). If the firms can re-optimize their prices soon after the shock, low $\xi$, then inflation converges faster to steady-state and the inflationary risky is lower after the initial periods. The results are higher bond prices responses in initial periods and lower bond prices responses as time passes, therefore, term premium falls. As prices become more sticky, higher is the term premium demanded by agents to hold a nominal bond. In other words, more flexible price enable larger decline in term premium.

The persistence of inflation target, $\rho_{\bar{\pi}}$, influences term premium in a different way. This parameter is an important source of variation to fed funds rate - and hence to inflation - and therefore small changes in $\rho_{\bar{\pi}}$ implies large responses of inflation to structural shocks. In Figure (2.5) we present the term premium responses to 100 basis points in technology when different values to $\rho_{\bar{\pi}}$ are settled. As the inflation target becomes more persistent, inflation becomes more volatile because fundamental shocks that drive the inflation target away from its steady-state value last longer. In this scenario, the fundamental shocks cause higher variation in inflation; as a result, the magnitudes of term premium changes are higher. In Figure (2.5) we see that when inflation target is highly persistent, the target may persist several periods below its steady-state value (following a positive technology shock) what generates several periods of inflation below its steady-state value and enabling larger room to decline in term premium. An inflation target that evolves as a random walk increase the inflation responses to fundamental shocks and, therefore, can generates large 
term premiums variations.

In our model a 100 basis points increase in technology implies changes in output similar to those reported by (50), however, due the parameter estimation, in our model the inflation reacts approximately 3 times lower than in (50) model. As inflation is more sensitive to structural shocks, bonds price show higher fluctuation, because households fear lose consumption. In fact, in (50) the log-term bond price is almost 3 times more sensitive to technology shocks than in our model. This result remains true to other fundamental shocks. Therefore, to generate large changes in term premium, a structural model must be able to deliver an inflation quite responsive to structural shocks, otherwise household do not ask large term premium because bonds are not so risky.

It is standard to fit yield curve through factor models. Literature labels the two factors that are necessary to obtain a good fit of term structure dynamics as the level and the slope factors. (51) explores the links between macroeconomic variables and yield-curve factors. She documents that monetary policy innovations change the slope of the yield curve since they have higher effects on short over long rates. We follow (52) to construct these factors: The level is the equally weighted average of the yields; the slope is the 10-years to 1-quarter spread.

Figure 2.6 shows the impulse responses of the level and slope factors to the structural shocks. An unanticipated monetary shock increases the level and decreases the slope and both converge monotonically to steady-state value. The yield curve becomes more flat after a tightening monetary policy. This flattening occurs because shorter rates are more sensible to monetary surprises, the same pattern is found by (51).

A positive shock in risk aversion increases the level and the slope factor. However, in this case, the persistence in slope is very strong generating long lasting effects over the yield curve. Due to high persistence, the slope factor response looks like an upward shift. However, both effects are much smaller in magnitude than those measured of other structural shocks. As agents become more risk averse, they require a higher premium against inflationary shocks, and therefore, there is an upward shift in the yield curve.

The technology shock decreases the level factor in a highly persistent way. After forty quarters, the level stays lower than its steady-state value. The effect on the slope factor is; initially undershoots, but after eight quarters it turns positive implying higher spread while the level factor is falling. Similar to risk aversion shocks, technology innovations causes highly persistent effects in the level and slope factors. The yield curve suffers a downward shift and 
Figure 2.6: Impulse Responses of Term Structure Factors to Structural Shocks.
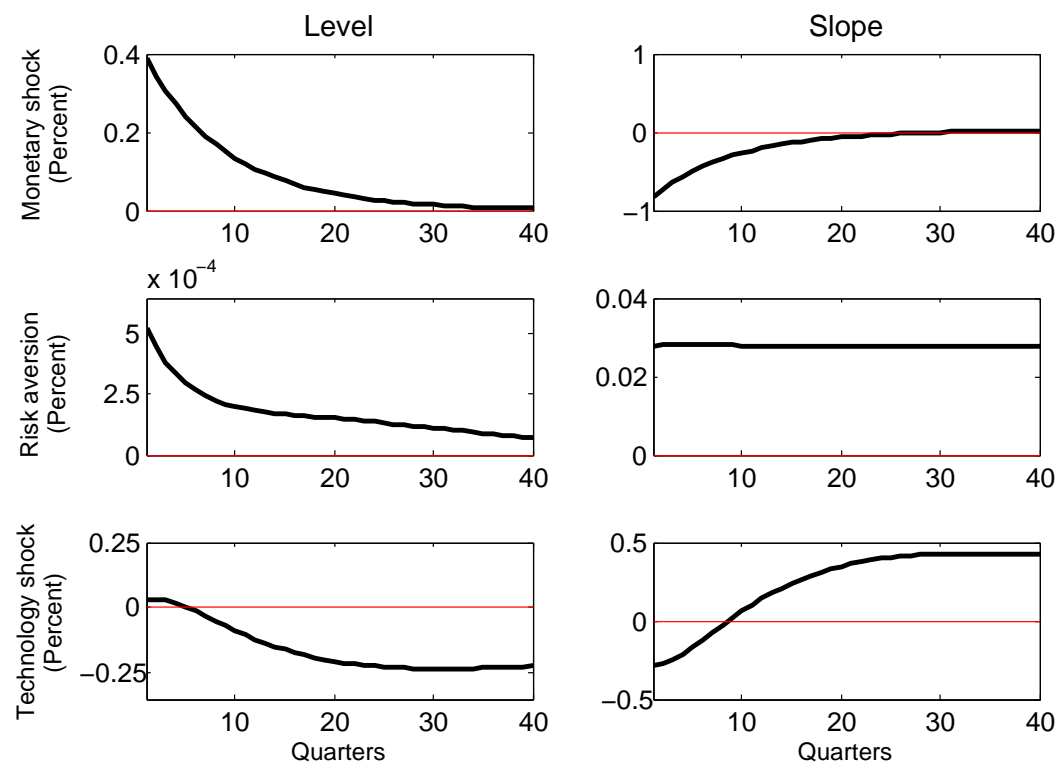

Note: This figure shows the impulse response functions (in percentage deviations from steady state) of the two term structure factors to the structural shocks.

becomes steeper after eight quarters. Theses findings are very similar to those exposed by (52), both qualitatively and quantitatively.

Our findings are in accordance with (53): i) slope changes in response to fluctuations on short-term yields; our model indicates that shorter rates are more sensible to monetary surprises. ii) slope fluctuations can predict economic activity; our model delivers a countercyclical term premium and the slope is positively correlated to economic growth. ii) monetary policy has a key role on the linkage between term structure and macroeconomics; the forecast error variance decompositions (FEVD), discussed further, shows that the movement in yields are primarily driven by inflation target and monetary news shocks.

In summary, the model generates an upward term structure of interest rates in average as we see in the data. It also implies that term premium is countercyclical, consistent with standard asset pricing theory, according to which term premium are higher in "bad states" of the world and lower in "good states". Finally, the model is capable of generating high term premium variation, similar to those generated by DSGE models in second and third order approximations.

Table 2 reports the one-quarter-ahead conditional variance decomposition of some variables. It shows the contribution of each macroeconomic shock to the overall forecast variance of each of the variables one step ahead. As discussed before, the technology shock and the inflation target shock dominates the variance of the macroeconomic variables. The difference between magni- 
tudes in the first and second columns of Figure 2.3 is explained by Table 2: the stochastic discount factor is determined mainly by the marginal utility of consumption, utility return and inflation, and these variables varies mostly due to technology and inflation target shocks. We can see that bond prices are almost totally driven by inflation target and monetary news shocks and is less responsive to other three shocks.

Figure 2.7 brings the FEVD for longer horizons for some variables. News shocks on monetary policy accounts for 20-25\% of medium-run fluctuations in consumption and $40 \%$ long-term yield. Our results confirm (54) findings: news shocks play an important role to business cycle fluctuations. Further, anticipated shocks have effects lasting longer for FFR and long-term yields, although, individually their effect are similar to unanticipated monetary shocks.

An expansionary inflation target shock is an exogenous shift in the preferences of the Fed regarding its monetary policy goal. It arises as an important source of variation because it might be interpreted as inflationary surprises: negative shocks in inflation targeting works as if the monetary authority was lowering its target. As a result, current inflation must be corrected through increases in short-term interest rate. For this reason, inflation target shocks appear so important in variance decomposition. Furthermore, (34) present evidence suggesting that changes in the central bank's inflation target is an important source of macroeconomic variables fluctuations and can account for most forward rates movements.

Table 2.2: One-Quarter-Ahead Variance Decompositions

\begin{tabular}{|c|c|c|c|c|}
\hline & Technology shock & Monetary shock & RA shock & IT shock \\
\hline \multicolumn{5}{|l|}{ Marginal utility } \\
\hline of consumption & 27.75 & 10.16 & 11.81 & 23.13 \\
\hline Fed funds rate & 3.3 & 0.4 & 0.47 & 76.52 \\
\hline Utility return & 23.27 & 7.2 & 8.3 & 30.5 \\
\hline Inflation & 4.12 & 36.06 & 43.65 & 11.12 \\
\hline Output & 27.75 & 10.16 & 11.81 & 23.13 \\
\hline \multicolumn{5}{|l|}{ 1-quarter } \\
\hline bond price & 3.3 & 0.5 & 0.5 & 76.52 \\
\hline \multicolumn{5}{|l|}{ 10-year } \\
\hline bond price & 6.41 & 4.2 & 4.98 & 46.23 \\
\hline
\end{tabular}


Figure 2.7: Forecast Error Variance Decomposition.
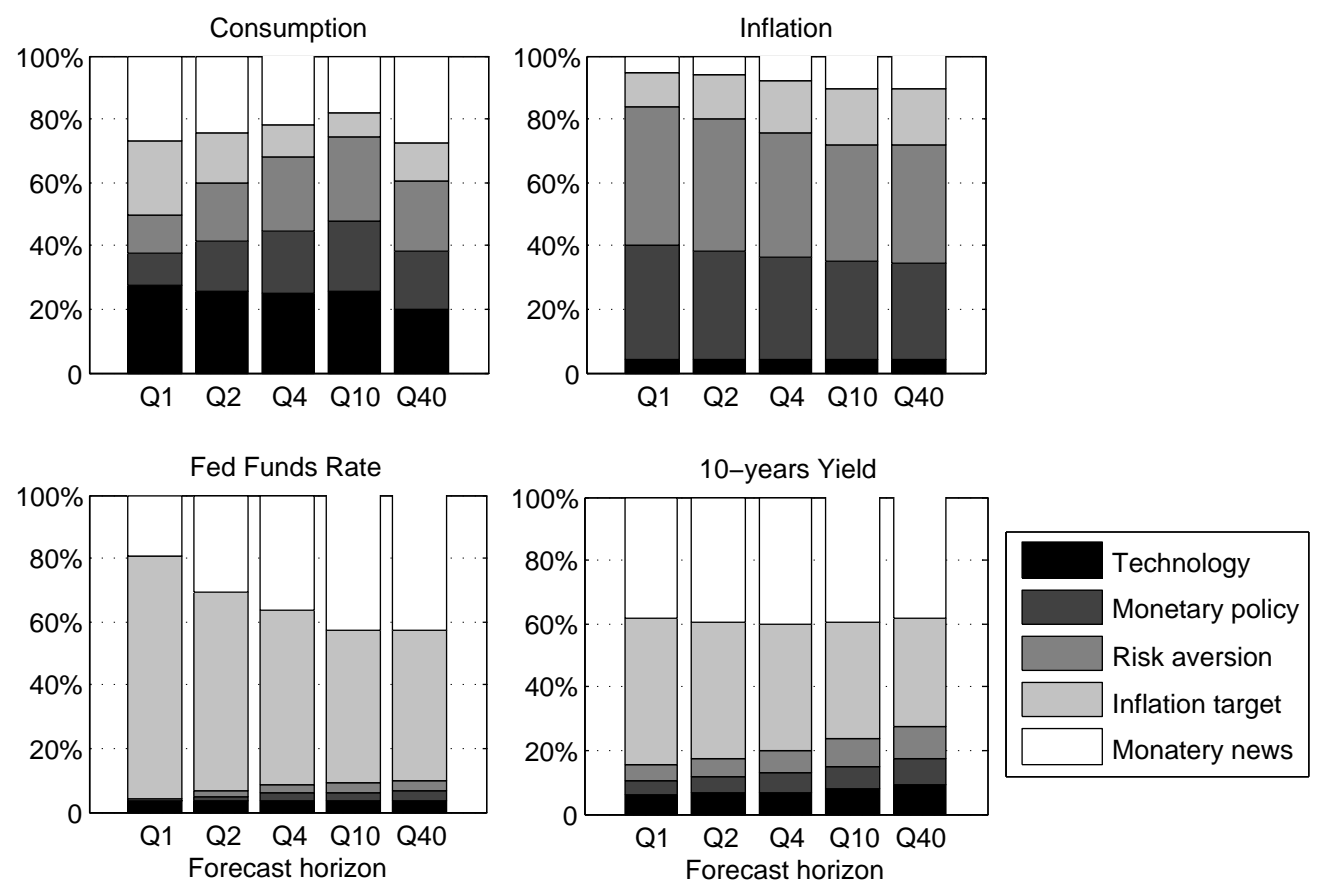

Note: At the mode of the posterior distribution. The Monetary news shock comprises the four monetary news.

\section{5}

\section{Policy Experiments}

Since the model fits very well the term structure of interest rates and is able to replicate several features of yields and macroeconomic variables, it can shed light on the movements of the yield curve to forward guidance shocks. As described in 2.2, we augmented the monetary authority reaction function with some news shocks, in sense of (42), which can be used to simulate forward guidance announcements. Our aim is describe how different monetary policy news can impact macroeconomic variables and term structure in an estimated model that enables time varying price of risk. Two types of policies are evaluated. The first is an announcement of decrease in future shortterm interest rates implemented when the economy does not suffer from zero lower bound (ZLB). That is an announced shock in isolation assessed through impulse response functions.

The second exercise is conduced in a framework where the economy is restricted to ZLB and the monetary authority announces that short-term interest rates will be close to ZLB during a certain period. Actually FED sets the short-term rate in 25 basis points during a certain amount of time. Our aim is to evaluate how real variables and term structure react to this policy, and compare the model's predictions to empirical findings presented in the literature. The model described in Section 2.2 was not built to operate 
in ZLB, hence in this scenario the implementations carries further difficulties beyond impulse response functions analyses. We must using anticipated shocks to condition the model's prediction on a given interest-rate path. The algorithm used is a slightly modification from (24), and its described bellow.

\subsection{1}

\section{Announced shock in isolation}

Monetary authority announces future expansionary shocks through innovations in reaction function that hits the economy some period ahead. This monetary innovation is a surprise only in the time it is announced. In each scenario only one of these shocks takes place, in other words, each announced monetary shock is done in isolation. Figure 2.8 contains the impulse response to an announced reduction of 100 basis points in the short-term interest rate for 1-quarter, 3-quarters, 5-quarters and 8-quarters ahead.

The effects on consumption depends on the date that the shock hits the economy. Announcements about future decreases in 1- and 3-quarters ahead raises consumption. Announcements about decreases that take place 5- and 8-quarters ahead have ambiguous effects: consumption initially falls but raises after some quarters. This peculiar behavior is explained by the zig-zag path of Fed funds rate. The movements in the short-term rate combines two distinct effects. The first is the exogenous shock in the short rate, which causes a downward effect on long rates, therefore, consumption raises. The second is an endogenous effect via feedback of Taylor rule; the short-term rate raises to control inflation and, as a consequence, consumption falls. This also causes an upward effect on long rates. If the central bank's reaction function is excessively inflation averse as long as the economy works with lower price stickiness, then the endogenous effect overwhelms the exogenous, resulting in a downward effect on consumption and upward in long rates. Both the term premium and consumption can increase or decrease following an announced monetary policy shock: a lower price stickiness, $\xi \rightarrow 0$, increases the endogenous channel. In brief, in a strong endogenous channel the short rates increase prior the expansion horizon.

As exposed by (58), the term structure changes depend on the parameters of the model, which in turn set the size of the exogenous and endogenous channels. The argument that forward guidance promotes lower nominal long rates must not be stated freely. It depends on the magnitudes of exogenous and endogenous effects and the nature of the policy as well.

Nominal short-rate follows an awkward zig-zag pattern because inflation and output increase before the monetary shock takes place and the magnitude 
Figure 2.8: Impulse-Responses to Monetary News Shocks
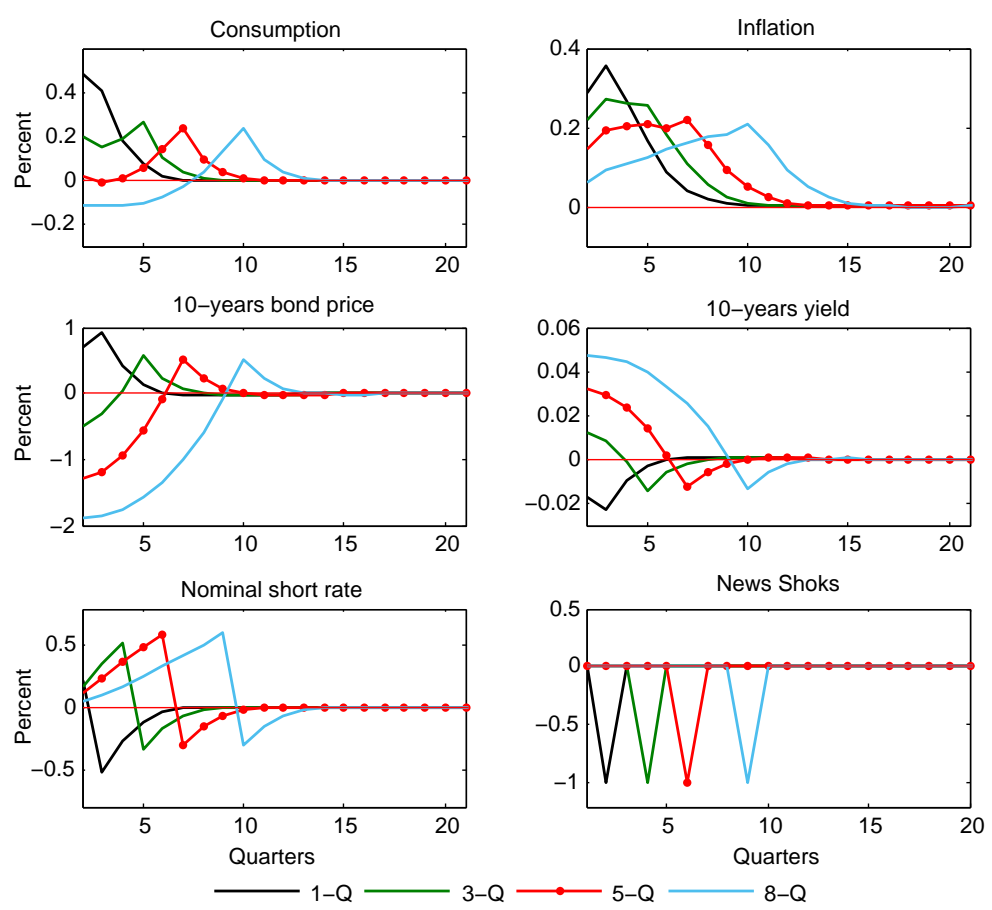

Note: Impulse responses to a negative one standard deviation shocks to monetary news shocks for different horizons. News shocks are considered in isolation.

depends on the price stickiness, $\xi$, and past inflation indexation, $\varpi$. As monetary authority must follow the Taylor rule, nominal short-rate follows a necessary path to suppress the growing inflation. A negative 8-quarters ahead monetary shock is recessive during the first seven quarters because short-term rate increases a lot before the expansionary monetary shock takes place. It should be noticed that is unlikely to see an eight periods ahead shock in isolation.

The parameters estimation performed here indicates a"peculiar scenario" in which consumption can decreases and long-term bond prices (yields) decrease (increase) as expansionary news shocks arise in longer horizons. That means the U.S. macroeconomic variables data suggests its economy works with a endogenous channel larger than the exogenous. In spite of the low Calvo's parameter, the FED's reaction functions is not aggressive in respect to deviations of inflation from its target. That is an evidence that forward guidance not necessarily promotes lower nominal long rates, despite the small effects showed in Figure 2.8. A 1-quarter ahead monetary news shock innovation of 100 basis points implies changes around 0.02 percent in the 10-years yields.

To clarify the endogenous channel, we analyze how the macroeconomic variables respond to monetary news shocks when $\xi$ varies. Figure 2.9 shows the responses to an announcement of 100 basis points reduction on short- 
Figure 2.9: Impulse-Responses to Monetary News Shocks
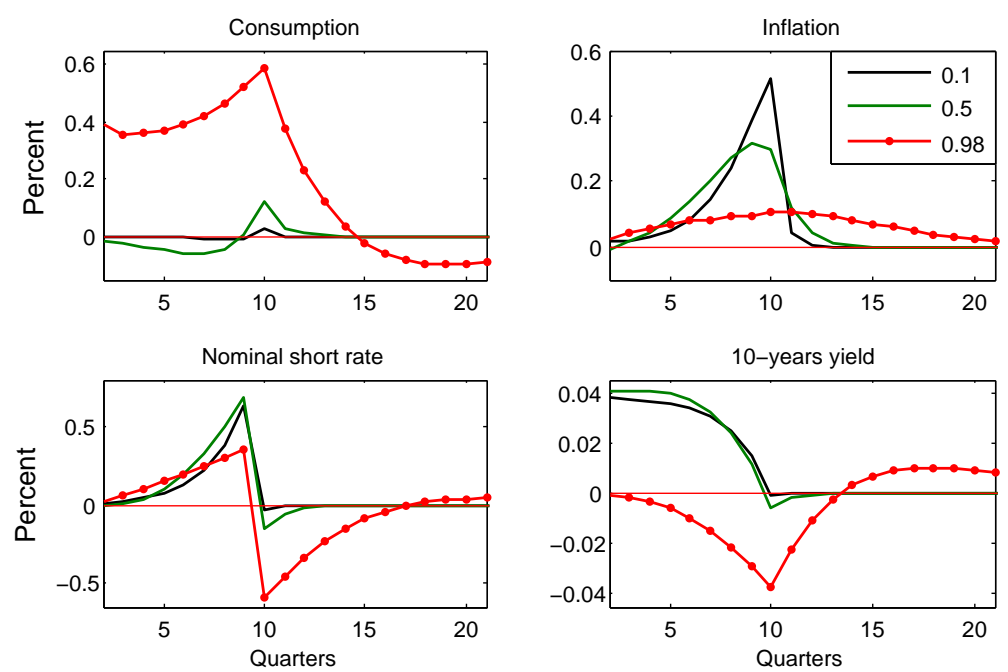

Note: Impulse responses to a 100 basis points decrease in 8-quarters monetary news shocks. Lines represent different values for $\xi$. The black line corresponds to $\xi=0.1$; Green line corresponds to $\xi=0.5$; and, red-pointed line corresponds to $\xi=0.98$.

term rate 8-quarter ahead. As we can see, in so far as $\xi \rightarrow 1$ (prices become stickier), the monetary news shock becomes less inflationary decreasing the endogenous channel in nominal short rate, which, in turns, induces higher consumption. Therefore, a expansionary monetary news shock can be recessive in the firs quarters of the announcement depending on how flexible the prices are. The expansionary monetary news shock induces higher output growth as prices become stickier. Furthermore, long-term yields decrease as endogenous channel becomes weaker. That relation is straightforward: bond prices are negatively correlated with inflation, as prices become stickier, inflation becomes less responsive to monetary shocks and, therefore, puts low pressure on bond prices. At same time, consumption is positively correlated with bond prices, and as consumption increases, yields decrease.

In all simulations the shorter yields are more responsive than longer yields. That is a natural behavior since short-term rate must return to steady state long before the maturity. As exposed by (24), the monetary economics literature has generally agreed with the evidence that longer-term bonds are more sensitive to forward guidance shocks than monetary surprises, however that is only true in the ZLB context. When nominal short rate is pegged to a low level, than announcements about longer horizons of the peg regime should impact longer rates more than shorter ones because shorter rates are bonded to level peg. In a less restricted scenario where short rate obeys the Taylor rule, we have rates of longer maturities less responsive than shorter maturities. As isolated shocks, forward guidance announcements have much higher impact in 
shorter maturities yields than longer maturities, and this same pattern can be seen in $(25)$.

The responses of 5- and 10-year yields reach their lowest point at the time the shock takes place and then decreases monotonically with the anticipation horizon, exactly as documented by (24). The impact on in inflation also increases monotonically with the horizon of announcement, but the strongest effect is on persistence, differently from what is reported by (24).

(35) using an event-study methodology find that 100 basis points innovation to the one period ahead forward guidance causing responses of 41 and 28 basis points in one- and ten- years Treasury yields. (25) make use of asset prices regressions to estimate asset prices responses to forward guidance shocks. They find that an increase of 100 basis points to the one period ahead forward guidance (the monetary policy is announced in $t$ and to occur in the next quarter) is associated with raises of 200 basis points in 2- and 5-year Treasury yields and the 10-year Treasury yield by about 150 basis points. Their estimated effects of forward guidance are much larger than the corresponding effects identified by (35). We performed the same exercise and measure the effects of forward guidance in the yield curve. Our model results indicate very small yields responses, even smaller than those of (35) findings. The model says that a 100 basis points increase to the one period ahead forward guidance is associated with 8.6, 3.6 and 0.32 basis points in 2-, 5- and 10-years bond yields.

Two points must be taken into account when comparing our estimates with those papers cited above. First, empirical studies should be interpreted with a bit of caution for some reasons. First, it is very difficult to obtain a pure measure of forward guidance shock because these announcements are often combined with other policy actions which may have independent effects on long-term interest rates, such as LSAPs. In our model we ensure we have a pure forward guidance shock. Therefore the event studies might be overestimating the true effect of these shocks. Furthermore, forward guidance may change the agent's beliefs about the economic fundamentals, the already mentioned Delphic statement. In our model there is no room for Delphic forward guidance, then the estimated responses presented in Figure 2.8 raise only as agents react to future changes in nominal short rates.

Second, the event-studies and reduced-form estimates may be evaluated during ZLB, which may produce different responses. The results in Figure 2.8 are estimated in a scenario in which the monetary authority follows a Taylor rule and agents price bonds forecasting the short-term interest rate responses to news shocks announcements. Then, one must be careful comparing the model's 
results with event-studies estimation. Nevertheless, our results indicate that the yield curve responses to news shocks are smaller than those presented in event-studies and reduced-form estimation literature. One possible explanation is that the event-studies overestimate the true effect due to other policy actions acting along forward guidance statements.

The estimated model says that announcements to longer horizons shocks imply a longer lasting increase in long-term yields. Those yields become lower than they steady-states values just before the shocks take place. The model does not report evidence in accordance with the FED's communication argument that forward guidance supports the economy through lowering the long term interest rate and the term premium. Our findings are in accordance with (58), that is, yield curve movements depends on parameter estimates: the argument that forward guidance promotes lower nominal long rates must not be stated freely.

Our results do not go against (35) main finding, that is: a policy factor, not associated with the current federal funds rate decision, accounts for more than three-fourths of the explainable variation in the movements of five- and ten-year Treasury yields around FOMC meetings. Our model can replicate this finding if we have an monetary authority that executes monetary policy mainly by news shocks. Our discordance with (35) is about the magnitude of news shocks effects over yield curves, not about their importance to yield curves movements.

\subsection{2}

\section{Anticipated shocks to condition interest rate path}

Thus far we have considered only isolated announcements. However it is interesting to investigate unconventional monetary policy implementations of interest rate peg near ZLB. We proceed with the policy experiment in which the monetary authority sets the short-term nominal rate to 25 basis points for five quarters. First we summarize the procedure used to condition the model's prediction. The algorithm follows (24) with a slight adjustment due to the definition of vectors used in model's solution.

The monetary authority announces to follow a given nominal short-rate path. ${ }^{8}$ The economy is initially in steady state in time $T$. Then, in $T+1$ the monetary authority commits itself to set a path, $\left\{\bar{i}_{T+1}, \ldots, \bar{i}_{T+S}\right\}$, surprising the agents in the time the policy is announced. To successfully employ this nominal short-rate the central bank must set the monetary shock in a way that makes

${ }^{8}$ The authority is fully committed in the path announced so that deviations are not possible nor even taken in account by agents. 
the path announced feasible. This means that there is a certain realization of the unanticipated monetary shock and the news shocks that implement the announced path $\left\{\bar{i}_{T+1}, \ldots, \bar{i}_{T+S}\right\}$. Define the realization that implements the path as $\left\{\bar{\varepsilon}_{T+1}^{*}, \bar{\varepsilon}_{1, T+1}^{\text {news } *}, \bar{\varepsilon}_{2, T+2}^{\text {news } *}, \bar{\varepsilon}_{3, T+3}^{\text {news* }}, \bar{\varepsilon}_{4, T+4}^{\text {news } *}\right\}$. All monetary policy shocks are used to implement the nominal short rate, so that we have five policy shocks to implement a path that lasts five periods, $S=5$. Therefore, we can identify the five policy shocks realizations because there are five periods in the announced path. The choice of five quarters of ZLB was not arbitrary. We chose this to make the solution easier insofar as we have four anticipated and one unanticipated policy shocks. Its possible to determine the time $T+1$ monetary policy shocks as a function of the announced short-rate path and generate conditional predictions of the state variables.

The model's solution takes the form described by Equations (2-40)(2-41). With mode of posterior distribution in hands, we can evaluate the parameter matrices. Then we follow the steps described bellow.

Step one: The Kalman filter is used to compute the mean $s_{T \mid T}$.

Step two: Follows from the model's solution, the system of matrices

$$
\begin{aligned}
\bar{i}_{T+1}= & \Gamma_{i} H_{s} s_{T}+\Gamma_{i} H_{\varepsilon}\left[\bar{\varepsilon}_{T+1}^{*}, 0, \ldots, 0, \bar{\varepsilon}_{1, T+1}^{\text {news } *}, \bar{\varepsilon}_{2, T+2}^{\text {news } *}, \bar{\varepsilon}_{3, T+3}^{\text {news } *}, \bar{\varepsilon}_{4, T+4}^{\text {news } *}\right]^{\prime} \\
\bar{i}_{T+2}= & \Gamma_{i}\left(H_{s}\right)^{2} s_{T}+ \\
& \Gamma_{i} H_{s} H_{\varepsilon}\left[\bar{\varepsilon}_{T+1}^{*}, 0, \ldots, 0, \bar{\varepsilon}_{1, T+1}^{\text {news } *}, \bar{\varepsilon}_{2, T+2}^{\text {news } *}, \bar{\varepsilon}_{3, T+3}^{\text {news } *}, \bar{\varepsilon}_{4, T+4}^{\text {new } *}\right]^{\prime} \\
\vdots & \\
\bar{i}_{T+5}= & \Gamma_{i}\left(H_{s}\right)^{5} s_{T}+ \\
& \Gamma_{i}\left(H_{s}\right)^{4} H_{\varepsilon}\left[\bar{\varepsilon}_{T+1}^{*}, 0, \ldots, 0, \bar{\varepsilon}_{1, T+1}^{\text {news } *}, \bar{\varepsilon}_{2, T+2}^{\text {news } *}, \bar{\varepsilon}_{3, T+3}^{\text {news* }}, \bar{\varepsilon}_{4, T+4}^{\text {news } *}\right]^{\prime}
\end{aligned}
$$

where $\Gamma_{i}$ is a vector that selects the variable $i_{t}$ in $H_{s}$ and $H_{\varepsilon}$. The sequence of zeros in the innovations vector are the realizations of the other shocks. They have no role here because we assume no other shocks hits the economy. This linear system has 5 equations and 5 unknowns and can be solved for the vector $\bar{\varepsilon}^{*}=\left[\bar{\varepsilon}_{T+1}^{*}, \bar{\varepsilon}_{1, T+1}^{\text {news }}, \bar{\varepsilon}_{2, T+2}^{\text {news } *}, \bar{\varepsilon}_{3, T+3}^{\text {news }}, \bar{\varepsilon}_{4, T+4}^{\text {news } *}\right]^{\prime}$. The solution can be expressed by

$$
\begin{aligned}
\bar{\varepsilon}^{*}= & \left(\left[\Gamma_{i}, \Gamma_{i} H_{s}, \ldots, \Gamma_{i}\left(H_{s}\right)^{4}\right] H_{\varepsilon}\right)^{-1} \times \\
& \left(\left[\bar{i}_{T+1}, \bar{i}_{T+2}, \ldots, \bar{i}_{T+5}\right]-\left[\Gamma_{i} H_{s} s_{T}, \Gamma_{i}\left(H_{s}\right)^{2} s_{T}, \ldots, \Gamma_{i}\left(H_{s}\right)^{5} s_{T}\right]^{\prime}\right)
\end{aligned}
$$

Step three: Input $s_{T \mid T}$ in Equation (2-40) and iterate forward to obtain the sequence $s_{T+1: T+5 \mid T}$ : 


$$
s_{t \mid T}=H_{s} s_{t-1 \mid T}+H_{\varepsilon}\left[\varepsilon_{t}^{i}, 0, \ldots, 0, \varepsilon_{1, t+1}^{\text {news }}, \varepsilon_{2, t+2}^{\text {news }}, \varepsilon_{3, t+3}^{\text {news }}, \varepsilon_{4, t+4}^{\text {news }}\right] \quad t=T+1, \ldots, T+S .
$$

where $\bar{\varepsilon}^{*}=\left[\varepsilon_{t}^{i}, \varepsilon_{1, t+1}^{\text {news }}, \varepsilon_{2, t+2}^{\text {news }}, \varepsilon_{3, t+3}^{\text {news }}, \varepsilon_{4, t+4}^{\text {news }}\right]$, hence we use the solved value, $\bar{\varepsilon}^{*}$ in period $T+1$ and zeros thereafter.

Step four: The measurement equation 2-41 is used to compute $y_{T+1: T+H}$ based on $s_{T+1: T+H \mid T}$.

The results are presented in Figure 2.10. The output increases monotonically with the policy peg horizon. The solid line indicates a policy in which the monetary authority sets the short-term nominal rate to 25 basis points for two quarters. Dotted line represents the five quarters peg. There are no explosions in the growth of the macroeconomic variables. Output and inflation responses are persistent, but not explosive, even with five quarters of the nominal shortterm rate kept on 25 basis points. The magnitude of effects are much bigger than those exposed in Figure 2.8. The output increases 6.35 percent (above its steady-state value) in the first quarter after the implementation of the longer fixed nominal rate path, while inflation increases 2.45 percent.

Despite the high responses of economic activity to a fixed interest rate of five periods, they are smaller than those reported by (59). DSGE models appear to deliver unreasonably large responses of key macroeconomic variables to forward guidance announcements. As documented by (24), the Euler equation states that contemporaneous consumption is directly negatively related to the long-term interest rates. Announcements about last-longing fixed interest rate affect the long-term bond yields, which in turn affect the economic activity. The author suggests conditioning the model to generate plausible changes in long-term rates, which in turn should force the model to generate reasonable macroeconomic effects. As our model delivers smaller responses of the longterm bond yield to monetary policy announcements - compared with those reported by (59) - then it predicts lower responses of key macroeconomic variables to central bank announcements.

Nevertheless the responses reported in Figure 2.10 still remain larger than what we would consider to be a reasonable response. Of course, a reasonable level of economic growth response is far from being a consensus, however the historical data following November 2008 suggest that the responses of output and inflation are much lower than those reported in Figure 2.10. To clarify the large responses generated by the model we present the effects of fixed interest rate path as a forecast.

Figure 2.11 shows how the shorter and longer ZLB path should impact the output growth, inflation and nominal short rate. The thicker solid black 
Figure 2.10: Impulse Response Functions to Monetary News Shocks at ZLB.
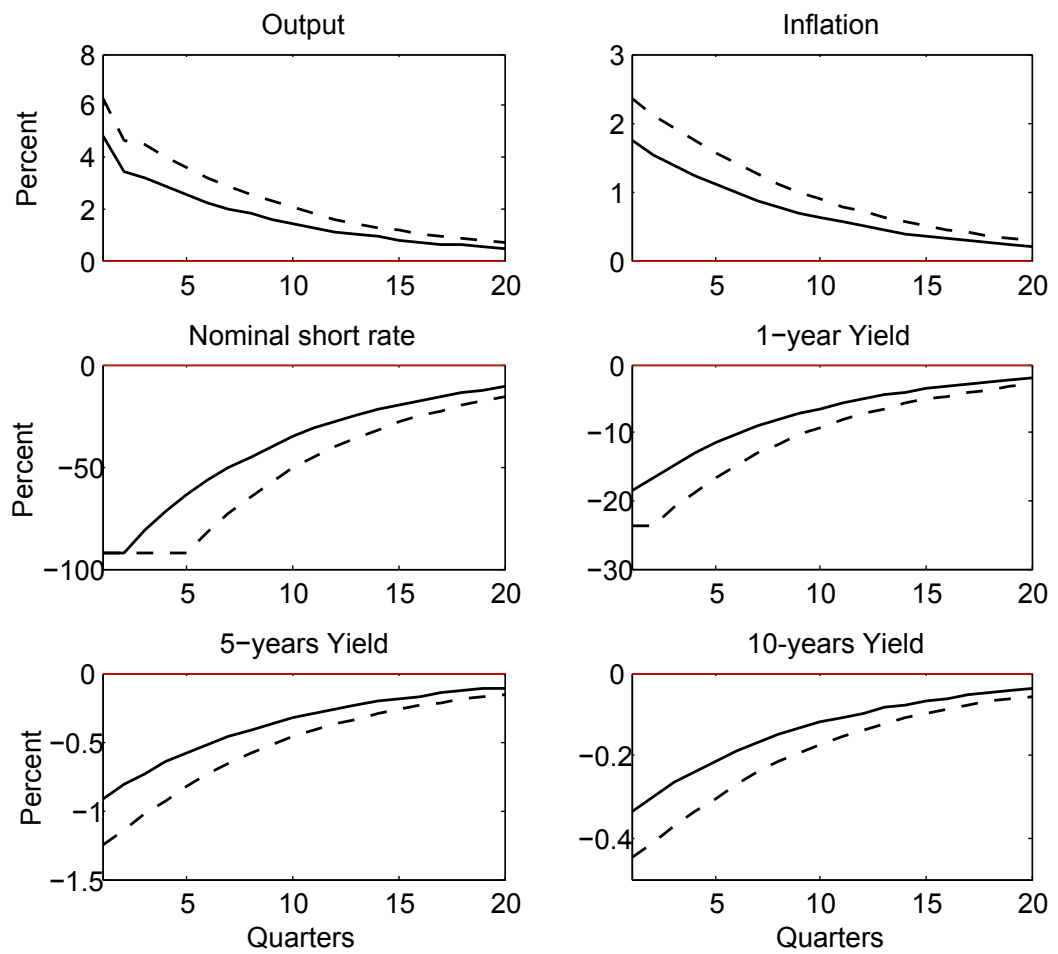

Note: Solid line represents ZLB during two periods. To implement this path the 1-quarter ahead news shocks was used. Dotted line is the ZLB during five periods, in which the unanticipated monetary shock and the 1-,2-,3- and 4-quarters ahead news shocks were used to implement this path. All effects are in percentage deviations from steady-state.

line is the historical data until last quarter of 2009. The solid black line shows the model's prediction in a scenario which the FED maintains the fed rate at 25 basis points during six months. The dotted black line is the model's prediction to five quarters fed rate peg. All results are in annualized percentages, apart from output deviation from steady state. Remarkably, GDP growth is 23 percent in annualized terms in the longer period of fixed interest rate. This huge boost of economic activity is generated by a positive deviation of 6.35 from the steady state. Inflation raises 2.45 percent leading the annual rate from 3.38 to 4.15 percent.

These results show that a promise by the central bank to peg interest rates below the natural rate of interest for two and a half years generates a grossly overestimated dynamics for output. Interest rate peg implies a tremendous output response due to the overreaction of the short- -term rates. 1- and 2-years yields fall by 23 and 9 percent, or 137 and 60 basis points respectively. However, analyzing the yield historical data, the most striking change in yields happened in March 18, 2009 with QE1 announcement. On that date, the 1- and 2-years yields fell 18 and 27 basis points, that is much 
Figure 2.11: Macroeconomic Consequences of Forward Guidance
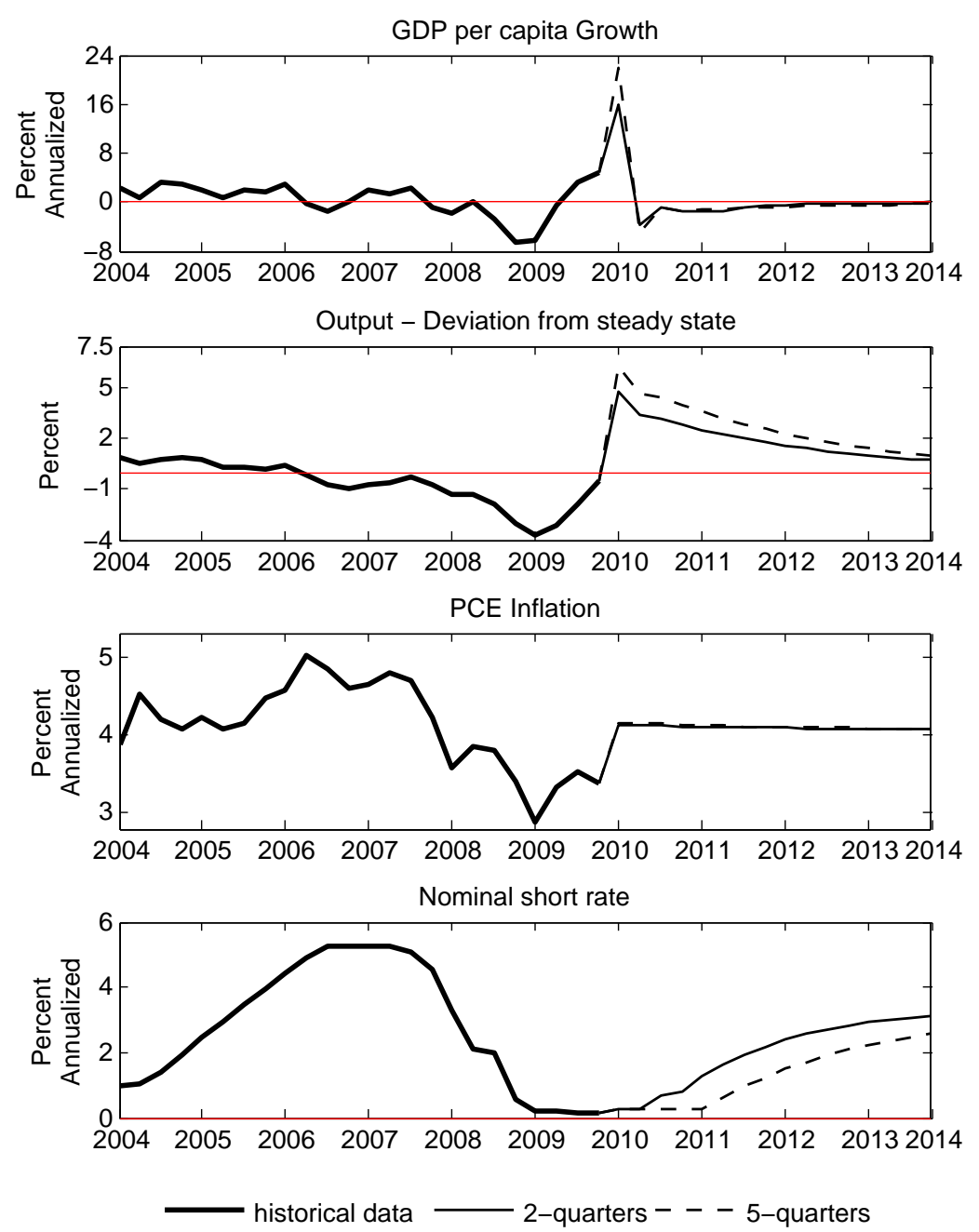

lower than those predicted by the model. At same time, the model predicts much lower changes to longer maturities; 5- and 10-year yields fall by 1.26 and 0.3 percent, or 9 and 3 basis points. Checking historical yield data, one can see that 8- and 10-years yields fell 46 and 53 basis points, higher values than those predicted by the model. For example, after January 2012 FOMC meeting, in which the the FED announced an extension of the first liftoff date, the 5- and 10-years yields fell 8 and 7 basis points. (59) simulations find that the SmeetWouters model should generates a drop of 50 basis points in 10-year yield to a fixed peg of 5 quarters. That indicates our model's prediction about long-term responses are rather plausible. The effects on level and slope of the yield curves are also overrated because the responses on the short maturities domain the changes in level and slope. Figure 2.12 brings the level and slope factor under the announcement of the two peg regimes. A more detailed discussion about the underlying mechanisms through which the forward guidance operates is made in Appendix.

The model says that forward guidance should have more impact in 
Figure 2.12: Forward Guidance and Yield Curve
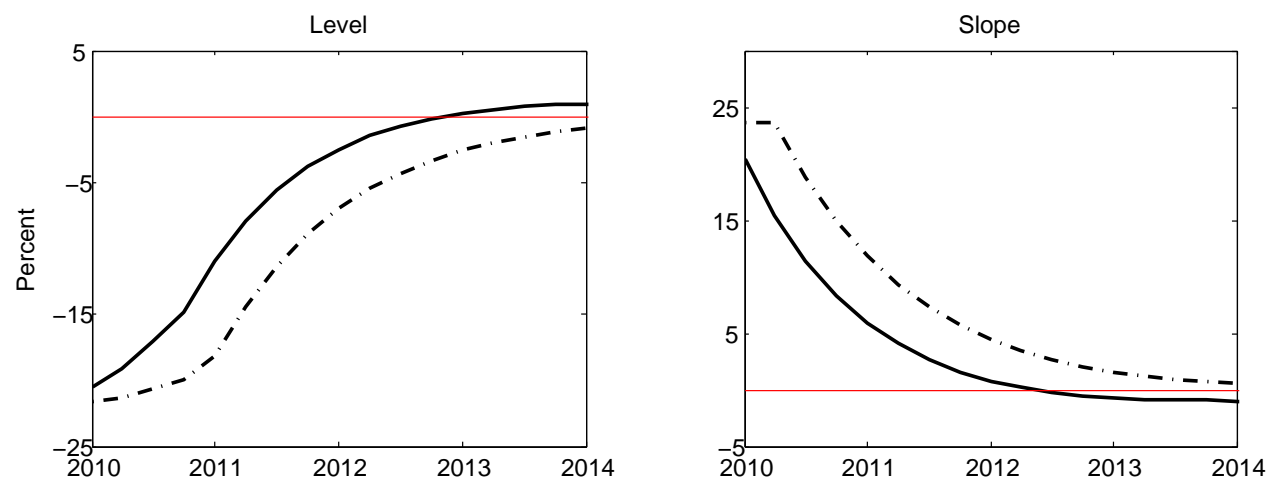

yields of shorter maturities, what makes sense since it is hard to believe that announcements about the path of nominal short rate, for the next two years, should have large impacts on the 8- and 10-years bonds. Moreover, our model does not suffer from the drawback pointed by (24), which is to overestimate the long-term yields responses. Therefore, what make the model's prediction grossly overestimate the impact of forward guidance on the macroeconomic variables is the overestimated impact on the shorter maturities. The responses of the shorter yield maturities are greatly overrated and this causes a large effect on current consumption, and, in a lower degree, on inflation.

Furthermore, the high degree of persistence in the Taylor rule - the mode of posterior of $\rho_{i}$ is 0.9 - avoid the fast return of the interest rates to its steadystate value after the fixed interest rate policy has expired. This implies a further stimulus on macroeconomic activity. As discussed by (24), an experiment in which the model is conditioned to replicate a small change in long-term bonds, should restrict the nominal short interest-rate path in a way that reduces the stimulus to macroeconomic variables. However, our model is able to replicate the small responses of the long-term bonds but not able to generate reasonable responses of the macroeconomic variables. The problem resides on the nominal interest-rate path; as the interest rate rule is highly persistent, the policy conduced after the commitment to peg the short rate - the policy rule followed after the rate's liftoff date - becomes excessively expansionary. The high degree of interest rate persistence produces an enlargement of the forward guidance effects.

To illustrate that, we calibrate the interest rate rule to be less persistent, we set $\rho_{i}=0.65$, and replicate the exercise of an announcement of five consecutive periods of fed funds pegged to 25 basis points. The result can be seen in Figure 2.13. The blue line is the model's responses with $\rho_{i}=0.65$. The nominal short rate clearly converges faster to its steady-state value after the peg regime has expired and, therefore the expansionary monetary effect 
Figure 2.13: Macroeconomic Consequences of Forward Guidance in a Calibrated Liftoff.
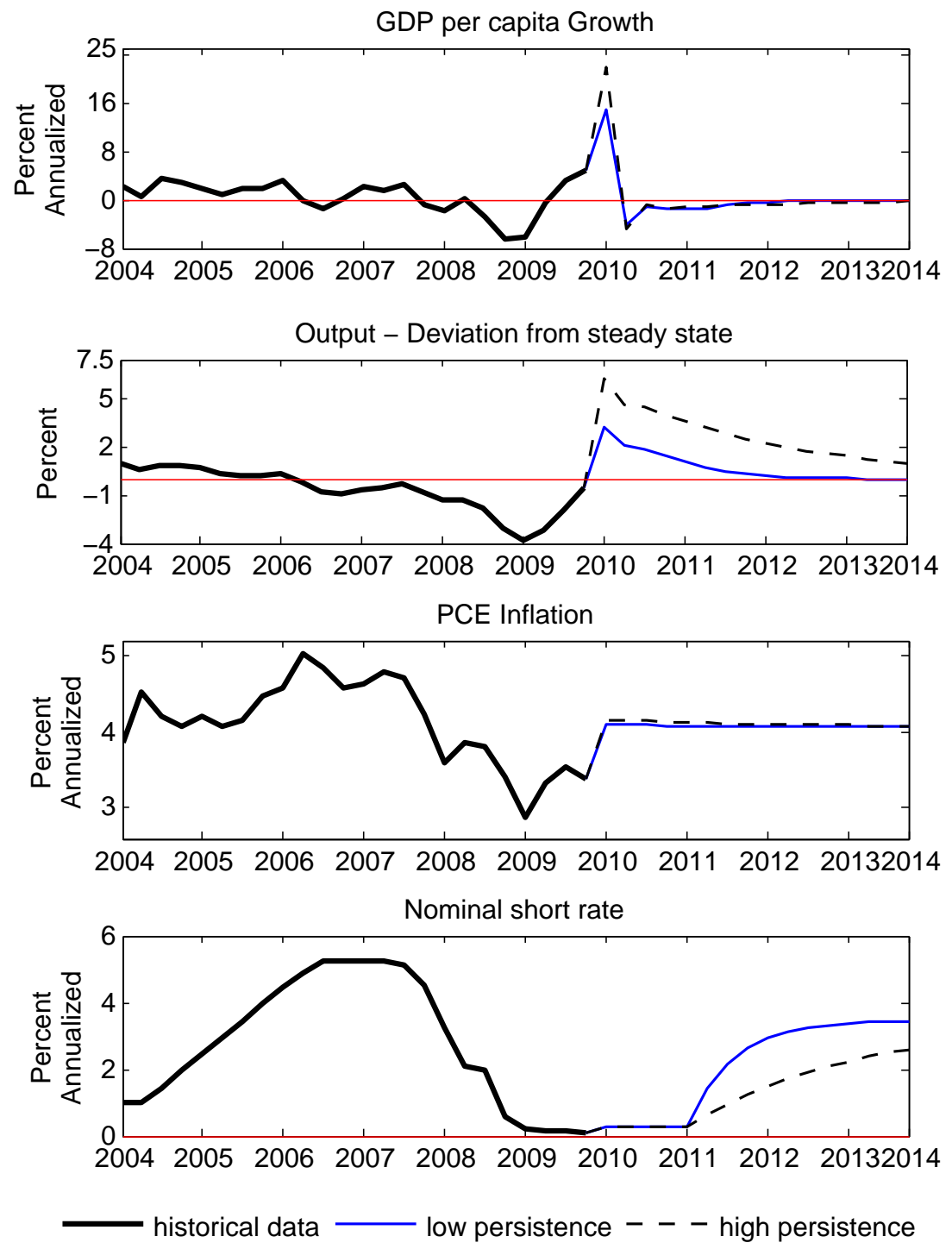

on the economic activity is shrunken. The output raises to 3.24 percent above the steady state against a raise of 6.35 percent in the case of a more persistent policy rule. Inflation increases only 1 percent under lower policy rule persistence. The Figure 2.13 highlights the importance of the way the policy is conduced after the fixed interest rate regime has expired.

These observations give rise to some questions about the forward guidance experiments conduced through DSGE models. First, the entire yield curve responses are important to make the model generates plausible macroeconomic effects under forward guidance statements. The expected future rates, through Euler equation, amplify the impacts of forward guidance on those models. Therefore, to properly evaluate forward guidance, in the light of DSGE models, it is important to obtain a good fit of the entire yield curve.

Second, the experiment of fixing the the nominal short rate for a certain 
time depends crucially on the way policy is conducted after the pegging regime has expired. If one assumes the policy will be conducted according to Taylor rule, then the degree of persistence of interest rates will determinate the speed of liftoff. Further economic stimulus are generated under a highly persistent interest rate that avoids the fast return to the steady state. It raises discussion if the monetary rule must be necessarily the same as before the ZLB with regard to its persistence.

Further, properly comparing the model's predictions with the historical yield data after 2009 is not a simple task insofar as FOMC's forward guidance statements overlapped each other. Some of them were more related to Delphic than Odyssean statements, and these unconventional policies were backed by different rules; calendar-based or threshold-based forward guidance - peg regime periods conditioned to an unemployment rate threshold. Thus, properly evaluating the model's predictions to the historical yield data can not be done without simplified assumptions about the average yield curve. However, the overall pattern suggests a shrinkage of all yields after a peg regime implementation. Alternatively, a more complicated model - a model able to draw different beliefs for different agents in the model - in accordance with a more realistic counterfactual experiment - allowing more finely-grained differentiation among the types of forward guidance - must be employed to correctly assess the model's prediction based on yield data.

Our model's predictions show evidences that forward guidance statements have a limited capacity to influence long-term yields, no matter the kind of unanticipated monetary policy implementation. A state of affairs in which the monetary authority announces a monetary news shock of 100 basis points in isolation can imply a fall at most of 2 basis points in the 10-years yield. The exact long-rate response depends on the length of the horizon before the shock takes place, but anyway those responses are closer. Our findings evidence what was suggested by (57), that forward guidance is more effective at moving short-term than long-term Treasury yields. Also, these effects are not very persistent.

Finally, the sensitivity of bond yields to macroeconomic variables appears to vary both over time and over forecast horizons. Since different sample data might generate different responses to structural shocks, to better conduct fixed fed funds rates experiments, the model estimation should take into account data on the ZLB period. A state in which the nominal short rate stays near to zero for a long time could be interpreted as a different structural regime; structural parameters should be free to change, as well as fundamental relations as the neutral interest rate. 


\section{6}

\section{Conclusion}

This paper builds a DSGE model with risk aversion, which enables a varying term premium in the structure of interest rates. The solution method employed enables standard Bayesian estimation of structural parameters yielding a better estimation of yield curve along with macroeconomic variables. This estimated model is capable of matching several features of the term structure of interest rates without losing its good fit of macroeconomic variables. With this framework in hand, we analyze the responses of the yield curve and macroeconomic variables to monetary policy news shocks. This laboratory economy is used to perform different types of forward guidance policies and evaluate their effects. By construction, the forward guidance shocks do not suffer from poor identification and can be studied in isolation.

First, we find that forward guidance shocks make bond yields fall lower than the effects identified on event-studies and reduced-form regression estimations. Our estimates say that an increase of 100 basis points to one period ahead forward guidance associated with 8.6, 3.6 and 1.4 basis points in 1-, 2- and 10-years bond yields. We do not find evidence that forward guidance shocks affect rates for a much longer time than do conventional monetary policy surprises, as stated by some works (see (60)). Our policy experiment based on announced shocks in isolation indicates that unanticipated and anticipated shocks have similar effects on bonds for shorter horizons.

We draw attention to the fact that forward guidance policies, performed through isolated anticipated shocks, do not necessarily promotes lower longterm yields. Our model, evaluated at the mode of posterior, generates higher long-term yields for announcement of longer horizons. This result goes towards (58) findings, making use of a calibrated small-scale DSGE model. Here we demonstrate that the higher yields may arise on an estimated medium-scale DSGE model.

We also document some issues when dealing with fixed interest rate path implementation. To generate plausible macroeconomic responses to forward guidance shocks, a DSGE model needs to exhibit a very good fit of the entire yield curve - all maturities are important -, otherwise, unrealistic macroeconomic effects emerge from Euler equation relations. Our model can generate plausible long-term yields movements, but generates high, and scarcely credible, large output responses to interest-rate pegs at ZLB. The model delivers lower responses than those reported by standard medium-scale DSGE models, however, forward guidance puzzle still remains. The macroeconomic responses to interest-rate peg are deeply connected with the entire term structure move- 
ments, and also the monetary rule followed after the liftoff. Also, fixed interest rate path simulation must be conducted with caution, the change in the stance of monetary path could be connected with structural changes, therefore the model estimates should consider data on both regimes. 


\section{A structural model to back out the forward guidance shocks}

\section{1 \\ Introduction}

In recent years, many central banks have made use of forward guidance statements to influence expectations and avoid economic slump. To evaluate the effect of this unconventional monetary policy on the economy it is necessary to measure the anticipated monetary shocks. Unfortunately, because of their nature, these shocks can not be observed, so they must be estimated. The literature has proposed several approaches to quantify the disturbances that provoke economic fluctuations. In DSGE models, anticipated shocks can be modeled through fundamentals as multi-period anticipation, then a straight approach has been to employ likelihood-based methods to identify and recover the fundamental shocks. This approach has been successfully in the assessment of news shocks in total factor productivity, government spending, preferences, among other shocks (see (61)). The key contribution of this paper is to analyze the performance of the DSGE models in estimating anticipated monetary policy shocks. Contrary to what is argued for technology news, we find that the standard New Keynesian models are not able to properly recover the news on monetary policy rules.

The standard methodology for estimating economic shocks relies on structural vector autoregression (SVAR). However, the presence of anticipated shocks with multi-period anticipation introduces multiple latent state variables. Those additional states imply the non-invertibility problem, as stated by (63). Non-invertibility arises when the current and past values of the observables variables fail to perfectly reveal the state variables of the model; VAR methodology may not identify the underling structural innovations. Therefore, the estimation of anticipated shocks has been centered around rational expectations general equilibrium models. Nevertheless, the macro-econometric literature has focused on the estimation of the anticipated shocks for total factor productivity (see (64), (65), and (61)). The monetary news shocks has been analyzed, mostly, through (34) methodology, which uses high-frequency data on asset prices to measure unanticipated changes in yields associated with 
FOMC statements.

DSGE models has become one of the cornerstones of modern macroeconomics. They are widely used among academics and central banks. Further, because of its structure, DSGEs can produce unobservables, and explain them in terms of the shocks that hit the economy. So they are a natural candidate to study news shocks. If that framework is appropriate to deal with unconventional monetary policy then we should be able to recover the anticipated monetary shocks. We develop and estimate a medium-size DSGE model that captures key features of the US economy for the recent period. The parameters estimation employed follows a Bayesian and classical likelihood-based method. The Kalman smooth filter, and a squared error minimization algorithm are used to compute the structural shocks. With the anticipated shocks in hands, we can map out the estimated anticipated shocks with observable data across the time. This allow us to assess the impact of these shocks and checking its correspondence with identifiable events of important FOMC statements during the recent economic crisis.

The novel element in our model formulation is the use of a macrofinancial DSGE model that fits the yield data very well. The identification of anticipated shocks is theoretically possible because the forward guidance statements influence asset prices, so the yield movements carry information about those statements. As the model can depicts a good fit of the observed yield curve, forward-looking agents, reacting to news about future changes in FFR, allow econometric identification. The agents will, in general, react differently to news and unanticipated fundamentals, as well as to news with different anticipation horizon. This enable the identification.

Another important aspect of our work is that the forward guidance language on FOMC meeting dates are easily identifiable. After the financial crises of 2008, the FOMC has used forward guidance explicitly through formal committee statements. There is some agreement in the literature about the compilation of relevant statements and the language that one can judges most pertinent to forward guidance. Those FOMC meeting dates provide a clear way to evaluate the estimated news shocks on monetary policy rule. The papers that evaluate anticipated total factor productivity shocks (TFP), employing DSGE models and likelihood methods, in generally, find a relevant role for those shocks in explaining aggregate fluctuations. However, there is some uncertainty over the TFP shocks. Different econometric methods can generate different estimated series. Also, it is not clear when and how news about future changes in TFP become public to economic agents. This makes it difficult to assess the anticipated TFP shocks estimation. It is one of the reasons why 
the literature has focused on the importance of these shocks in explaining the forecast error variance of consumption, output, and hours worked. Therefore the recent unconventional monetary policy undertaken by the Fed, through official statements, provides us a chance to evaluate the ability of the DSGE models in recover the anticipated monetary shocks. We can compare the sign and magnitude of the estimated shocks with the forward guidance dates.

Our model has some features that allow us to adequately estimate forward guidance shocks. First, the time-varying price of risk enables the model to match the slope of the term structure of interest rates and allows for deviations from expectation hypothesis. Forward guidance announcements affect asset prices so that yield data can provide useful information about FOMC announcements enabling anticipated shocks estimation. The model encompasses a term structure of interest rate block based in "essentially affine approximations" which allows time-varying term premium as shown in (29).

Second, the model considers occasionally binding constraints in the monetary policy rule. Binding constraints grants the model's solution in accordance with ZLB constraint on federal funds rate (FFR). Taking into account the ZLB forces private decisions to depend on the expected duration of ZLB, which is essential to describe expectations under the recent period. We adopt the occasionally binding (Occbin) approach developed by (66), and use a slight modification of the algorithm proposed by (67) that, given the state variables past realizations, gives the structural shocks estimate consistent with the non-linear solution. We are interested in evaluating whether a standard DSGE New Keynesian model can back out the news in monetary policy rule.

Our key findings can be summarized as follows. The model can recover, on average, the first forward guidance statements between 2008 and 2009. But it is not able to identify precisely the forward guidance of official FOMC statements over the entire subsample, from 2008 to 2016. There are two main points related to the model's flaw. First, the model presents difficulties to reproduce heterogeneous yield movements among different maturities. The yield curve movements after 2011 are not homogeneous among the maturities for the ZLB period. This imposes a challenge in terms of matching yield data after 2011 . Second, the limited model's ability to generate large risk premiums after the economic recovery seen in 2011 makes identification difficult. We show evidence that the standard New Keynesian models are not able to properly recover the news shocks on monetary policy rules.

Our paper is settled at the intersection of two complementaries branches of macro literature. A wide branch has focused on quantifying the contribution of news shocks to aggregate fluctuations. Much of the effort has been spent 
on news about future technology, government spending and taxation (see (64), (68) and (61)). The evidence points at news shocks as an important source of aggregate fluctuations. (54) focus on monetary news shocks arguing that the conventional estimates about monetary policy shocks confound the unanticipated and anticipated effects on output. They show that a surprise shock is smaller and more short-lived than the response usually obtained in the literature. At same time, anticipated monetary policy shocks have a large, delayed, and persistent effect. They present evidences that news shocks play a larger role in influencing the business cycle. The paper is also related to (62), who recover the fundamental shocks, from an estimate a DSGE model, to interpret the US recession of 2001.

Another large part of literature, as (69), and (24) has stressed the transmission channel whereby forward guidance (theoretically defined as news shocks) operates in general equilibrium models. They differ in quantifying the effectiveness of this policy, but both advocate the success of forward guidance as a monetary policy tool. (70) examines statement data to measure the impact that FOMC communications have had on private expectations. They use (34) methodology with high-frequency data on prices of FFR, and future contracts, to measure unanticipated yields changes on corporate bonds associated with FOMC statements. The estimated effects of FOMC forward guidance on asset prices and private forecasts suggest that the FOMC has had some success in communicating its future intentions to the public.

In Spite of articles briefly described above, not many studies have attempted to estimate forward guidance shocks in the light of a DSGE model. This paper has a methodological and empirical importance: If that framework is appropriate to study this unconventional monetary policy, then we should be able to recover anticipated monetary shocks. Also, isolating and measuring these shocks is crucial to evaluate this kind of tool, because it allows us to interpret recent macroeconomic variables path.

\section{2}

\section{A new keynesian model}

The model has generalized recursive preferences with consumption habit formation, nominal rigidities and time-varying risk aversion. We follow (38) and (39) to model the generalized recursive preferences. This is required to allow the elasticity of intertemporal substitution to be unrelated to risk aversion. This feature allows a better fit of the size of term premium in the data. Nominal rigidities are included to match the inflation and nominal interest behavior. lastly, time-varying risk aversion helps the essentially affine solution method to 
generate an approximation with higher accuracy than first-order perturbation (between second- and third-order perturbation).

The model follows a New Keynesian structure attached by a term structure of interest rates block. The structure is rather standard in New Keynesian models literature, so we describe the model briefly.

The household sector is composed by a unit continuum of representative households, living forever in discrete time. The household solves

$$
\begin{array}{ll}
\max _{\left\{c_{t}, a_{t+1}\right\}} & V_{t}=U\left(c_{t}, \bar{c}_{t-1}, l_{t}\right)-\beta E_{t}\left(-V_{t+1}^{1-\alpha_{t}}\right)^{\frac{1}{1-\alpha_{t}}} \\
\text { s.t. } & a_{t+1}=\exp \left(i_{t}\right) a_{t}+w_{t} l_{t}+d_{t}-P_{t} c_{t} .
\end{array}
$$

In each period the household receives the utility flow

$$
\begin{aligned}
U\left(c_{t}, \bar{c}_{t-1}, l_{t}\right) & =\frac{c_{t}^{\delta(1-\gamma)} \bar{c}_{t-1}^{(1-\delta)(1-\gamma)}}{1-\gamma}+\chi_{0} \frac{\left(1-l_{t}\right)^{1-\chi}}{1-\chi}, \\
\alpha_{t} & =\left(1-\rho_{\alpha}\right) \bar{\alpha}+\rho_{\alpha} \alpha_{t-1}+\varepsilon_{t}^{\alpha}
\end{aligned}
$$

where $c_{t}$ and $l_{t}$ denote household consumption and labor in period $t . w_{t}$ and $d_{t}$ denote the nominal wage and exogenous transfer to the household. $a_{t}$ is the beginning-of-period nominal assets. $\alpha_{t}$ is the coefficient of relative risk aversion, which is allowed to evolve over time following an $\mathrm{AR}(1)$ process. Risk aversion shocks may have small effects on $c_{t}$ and $l_{t}$, however, its volatility will be priced as a risk which will be taken into account generating precautionary saving effects. The utility function has a multiplicative habit formation term to ensure that changes in risk aversion are exclusive due to $\varepsilon_{t}^{\alpha}$.

Competitive final firms repackage intermediate goods $Y_{t}(f)$ to produce a final good $Y_{t}=\left(\int_{0}^{1} y_{t}(f)^{1 / \lambda} d f\right)^{\lambda}$. Profit maximization yields the demand schedule $y_{t}(f)=\left(\frac{p_{t}(f)}{P_{t}}\right)^{\frac{\lambda}{1-\lambda}} Y_{t}$ for each intermediate variety. A continuum of infinitely-lived monopolistically intermediate firms, indexed by $f \in[0,1]$, hire labor, as it's only input resource, from households in a competitive market following identical Cobb-Douglas production functions. Those firms set prices according to (41) price contracts, which expire with probability $1-\zeta$ each period, $\zeta \in[0,1)$. Each time a Calvo contract expires, the firm sets a new contract price $p_{t}^{*}(f)$ freely, which then remains in effect for the life of the contract, with indexation to the past and steady-state inflation rate. In each period $\tau \geq t$ that the contract remains in force, the firm must supply whatever output is demanded at the contract price $p_{t}^{*}(f) \exp (\tau-t) \pi_{t}^{\varpi} \bar{\pi}^{1-\varpi}$, hiring labor $l_{\tau}(f)$ from households at the market wage $w_{\tau}$. The intermediate firms selected solve: 


$$
\begin{array}{ll}
\max _{\left\{p_{t}^{*}\right\}} & E_{t} \sum_{j=0}^{\infty} \zeta^{j} S_{t, t+j}\left[p_{t+j}(f)-w_{t+j} l_{t+j}(f)\right] \\
\text { s.t. } & y_{t+j}=\left(\frac{p_{t+j}(f)}{P_{t+j}}\right)^{\frac{\lambda}{1-\lambda}} Y_{t+j} \\
& p_{t+j}(f)=p_{t}^{*} \prod_{l=1}^{j}\left(\pi_{t+l-1}\right)^{\varpi}(\bar{\pi})^{1-\varpi},
\end{array}
$$

where $S_{t, t+j}=\prod_{i=1}^{j} S_{t, t+i}=S_{t, t+1} \times S_{t+1, t+2} \times \ldots \times S_{t+j-1, t+j}$ denotes shareholders' stochastic discount factor from period $t+j$ back to $t$, and $y_{t+j}(f)$ and $l_{t+j}(f)$ denote the firm's output and labor output in period $t+j$, respectively, conditional on the price $p_{t}^{*}(f)$ still being in effect. The problem (3-4) shows that each intermediate firm faces a demand curve with negative slope with elasticity $\epsilon=\lambda / 1-\lambda$.

There is a monetary authority that sets the one-period nominal interest rate $i_{t}$ according to a Taylor policy rule

$$
i_{t}=i_{t-1}^{\rho_{i}}\left[i_{s s}\left(\frac{\pi_{t}}{\pi_{t}^{*}}\right)^{\phi_{\pi}}\left(\frac{y_{t}}{\bar{y}_{t}}\right)^{\phi_{y}}\right]^{1-\rho_{i}} \exp \left(\varepsilon_{t}^{i}\right) \underbrace{\exp \left(\varepsilon_{1, t-1}^{\text {news }}+\varepsilon_{3, t-3}^{\text {news }}+\varepsilon_{5, t-5}^{\text {news }}+\varepsilon_{8, t-8}^{\text {news }}\right)}_{\text {forward guidance shocks }},
$$

where $\pi_{t}=\log \left(P_{t} / P_{t-1}\right)$ denotes the inflation rate, $y_{t}=\log \left(Y_{t}\right)$, and

$$
\bar{y}_{t}=\rho_{\bar{y}} \bar{y}_{t-1}+\left(1-\rho_{\bar{y}}\right) y_{t},
$$

denotes a trailing moving average of log output, and $\phi_{\pi}, \phi_{y} \in \Re$, and $\rho_{\bar{y}} \in[0,1)$ are parameters. The monetary authority pursuits an inflation rate as close inflation target as possible. The inflation target evolves over time following an $\mathrm{AR}(1)$ process

$$
\pi_{t}^{*}=\left(1-\rho_{\pi^{*}}\right) \bar{\pi}+\rho_{\pi^{*}} \pi_{t-1}^{*}+\varepsilon_{t}^{\pi^{*}}+\sigma_{a, \pi} \varepsilon_{t}^{a} .
$$

The forward-guidance shocks are designed following (42). They are i.i.d news shocks with zero mean. In this setting, $\varepsilon_{k, t-k}^{\text {news }}$ is a shock that is known to private agents at time $t-k$, but affects the policy equation rule $k$ periods later. We chose arbitrarily news in $t-1, t-3, t-5, t-8$, which means that monetary authority can reveal monetary shocks one, three, five and/or eight quarters ahead. This specification enables the monetary authority to set forward guidance polices up to 2 years ahead. For the nominal bonds we have

$$
p_{t}^{\$(n)}=E_{t} S_{t, t+1} \frac{p_{t+1}^{\$(n-1)}}{\pi_{t+1}},
$$

where $p_{t}^{\$(n)}$ is the nominal bond price. As in (?), bond prices evolves as

$$
p_{t}^{\$(n)}=A_{n}+B_{n} X_{t} .
$$


The bond pricing and yield equations are recursively defined as

$$
\text { yield }_{t}^{\$(n)}=-\log p_{t}^{\$(n)}=-\frac{A_{n}}{n}-\frac{B_{n}}{n} X_{t} .
$$

They are appended to the macroeconomic model described above and solved numerically along with the remaining macroeconomic variables. The term structure block is necessary to binding the model to the yield data. The essentially affine method allows term premium varying in time so that the yield curve is not necessarily flat.

\subsection{1}

\section{Essentially affine approach}

This paper uses the essentially affine approximation method laid out by (44). The essentially affine method delivers an approximation to the equilibrium dynamics of the model that is linear in the state variables but still allows time-varying risk aversion to affect the behavior of the endogenous variables. $^{1}$

The system equations can be divided into two types: those that do not involve taking expectations over the SDF, $D$, and those that do, $F$. In summary, the approximations to the equilibrium conditions are

$$
\begin{aligned}
0 & =D\left(s_{t-1}, s_{t}, s_{t+1}, \varepsilon_{t+1}\right) \\
1 & =E_{t}\left[M\left(s_{t}, s_{t+1}, \varepsilon_{t+1}\right) F\left(s_{t-1}, s_{t}, s_{t+1}, \varepsilon_{t+1}\right)\right],
\end{aligned}
$$

where $D$ and $F$ are vector-valued functions and $M$ is the (scalar-valued) stochastic discount factor.

For the equations that do not involve the SDF, we use standard perturbation methods and take a log-linear approximation. The second set of equations involves expectations. We take approximations to $M$ and $F$ separately.

$$
\begin{aligned}
0 & =D_{0}+D_{x} s_{t}+D_{s^{\prime}} s_{t+1}+D_{\varepsilon} \epsilon_{t+1} \\
m_{t+1} & =\exp \left(m_{0}+m_{s} s_{t}+m_{s^{\prime}} s_{t+1}+m_{\varepsilon} \varepsilon_{t+1}\right) \\
f_{t+1} & =\exp \left(f_{0}+f_{s} s_{t}+f_{s^{\prime}} s_{t+1}+f_{\varepsilon} \varepsilon_{t+1}\right) \\
0 & =\log E_{t} \exp \left(m_{t+1}+f_{t+1}\right) .
\end{aligned}
$$

Both real variables and bond prices are linear functions of the underlying state variables contained in the vector $s_{t}$, so we can write the model in statespace form. The guess the solution: $s_{t+1}=H_{s} s_{t}+H_{\varepsilon} \varepsilon_{t+1}$. The system (3-13)-

${ }^{1}(44)$ shows that Euler equation errors in simulated models are competitive with thirdorder perturbations. 
(3-16) can be written as

$$
\begin{aligned}
0= & D_{s} s_{t}+D_{s^{\prime}}\left(H_{s} s_{t}+H_{\varepsilon} \varepsilon_{t+1}\right)+D_{\varepsilon} \varepsilon_{t+1} \\
0= & \left(m_{s}+f_{s}\right) s_{t}+\left(m_{s^{\prime}}+f s^{\prime}\right) s_{t+1}+ \\
& \frac{1}{2}\left(m_{\varepsilon}+f_{\varepsilon}+\left(m_{s^{\prime}}+f s^{\prime}\right) H_{\varepsilon}\right) \Sigma\left(m_{\varepsilon}+f_{\varepsilon}+\left(m_{s^{\prime}}+f s^{\prime}\right) H_{\varepsilon}\right)^{\prime},
\end{aligned}
$$

where Equation (3-18) uses the log-normal property. To find the unknown matrices $H_{x}, H_{\varepsilon}$ we can solve the model iteratively where the initial guesses, $H_{x, 0}$ and $H_{\varepsilon, 0}$, are exactly the transition matrices obtained by log-linear approximation of system (3-11)-(3-12). ${ }^{2}$

\subsection{2}

\section{Occasionally binding constraints}

We use a nonlinear solution method to find the equilibrium under ZLB after 2007:Q4. The method was proposed by (66), and termed occasionally binding constraints (Occbin). Basically, the economy has two regimes. We define regime 1 (unconstrained) an environment where monetary policy rule is free to change, and regime 2 (constrained) when a lower bound constraints the monetary policy rule. We linearize the model under each regime around the non-stochastic steady state. The solution algorithm requires two conditions: (i) the existence of a rational expectation solution as described in (71) holds at the unconstrained regime; (ii) If shocks move the model away from unconstrained regime to constrained one, the model will return to the unconstrained regime in finite time under the assumption that agents expected that no future shocks will occur.

The linearized equilibrium equations of the model under the unconstrained regime can be written as

$$
A E_{t} X_{t+1}+B X_{t}+C X_{t-1}+E \varepsilon_{t}=0
$$

where $A, B, C, E$ are matrices $n x n$ of structural parameters and $n$ is the number of state variables. When the constraint binds, the analogous system of necessary conditions for an equilibrium under the constrained regime, can be written as

$$
A^{*} E_{t} X_{t+1}+B^{*} X_{t}+C^{*} X_{t-1}+D^{*}+E^{*} \varepsilon_{t}=0 .
$$

Under the constrained regime there is a column vector denoted by $D^{*}$ which arises from the fact that monetary policy rule is constrained by a constant to avoid interest rate becoming negative. When ZLB is not binding,

${ }^{2}$ Using (45) method. 
we use the standard linear solution methods to describe the decision rule for the model as

$$
X_{t}=P X_{t-1}+Q \varepsilon_{t}
$$

When ZLB is binding, we follow a guess-and-verify approach in which we guess the duration of ZLB period and compute paths for state variables to verify the current guess of regimes. We iterate this approach until the guess is verified for all periods.

The solution for this model can be cast as

$$
\begin{aligned}
& X_{t}=P_{t} X_{t-1}+R_{t}+Q_{1} \varepsilon_{t} \quad \text { for } \quad t=1 \\
& X_{t}=P_{t} X_{t-1}+R_{t} \quad \forall \quad t \in\{2, \infty\} .
\end{aligned}
$$

As we can see from Eq.(3-22)-(3-23), the solution does not need to be linear. Matrices $P_{t}, Q_{t}, R_{t}$ are time varying and they are functions of $X_{t-1}$ and $\varepsilon_{t}$. In other words, the model solution can be described by a policy function of the form:

$$
X_{t}=P\left(X_{t-1}, \varepsilon_{t}\right) X_{t-1}+D\left(X_{t-1}, \varepsilon_{t}\right)+Q\left(X_{t-1}, \varepsilon_{t}\right) \varepsilon_{t} .
$$

The matrices of reduced-form coefficients $P, D, Q$ are state-dependent: they are functions of the past state variables and of the current innovations. However, $X_{t}$ is still linear in $\varepsilon_{t}{ }^{3}$

The Kalman filter is not able to retrieve the estimates of the innovations $\varepsilon_{t}$ because the reduced-form coefficients in Eq.(3-24) endogenously depend on $\varepsilon_{t}$. Instead, we use and algorithm based on (67) that, given the set of observable variables and the state $X_{t-1}$, finds values of $\varepsilon_{t}$ that are consistent with Eq.(3$24)$ and minimizes the sum of squared error prediction of the model.

\section{3}

\section{What Yield Data Tells Us About Financial Crisis}

The movements in yield data reflect expectations on the future paths of macroeconomic variables and the term premium, and therefore the FOMC's announcements influence changes in yields. Thus, a way of measuring forward guidance statements is to look at yield data movements because they carry information about those statements in form of expectations and term premium. Periods in which the nominal interest rate is not constrained to ZLB, yield movements capture both unanticipated monetary shocks and anticipated when they come to knowledge of private agents, so they are "surprises"-,

\footnotetext{
${ }^{3}$ The solution algorithm is fully described in (66).
} 
therefore it is difficult to sort out surprises and news. However, when ZLB is binding, movements in yield data reflect news in FOMC's announcements even though the actual nominal interest rates presents no changes. Our model uses the movements in yield data after 2007 to measure monetary news shocks.

It is important to note that some movements in yield data reflect the FOMC's announcements of large-scale asset purchase (LSAPs). The literature presents evidences that LSAP policies can alter long-term interest rates, as exposed in (36) and (37). These studies suggests that one feature of LSAPs resembles forward guidance policy. The model we built does not have a financial intermediate sector and the LSAPs have no room here. For this reason, the model is unable to recover "pure" forward guidance shocks, in the sense that policy action is reflected solely in the statement's relevant language. Also those movements could indicate Delphic forward guidance, but the estimated anticipated shocks are announcements about the future path of short-term nominal interest rates. For that reason we interpret them only as Odyssean forward guidance.

Figure 3.1 shows the observed yields during the ZLB. Each shaded area corresponds to a decrease, in average, of the yields to all maturities. In 2008:Q4 we had three FOMC statements related to forward guidance that made yields of all maturities fall:

October 29,2008 $\Longrightarrow$ Federal funds target rate $($ FFTR $)=1 \% \Longrightarrow$ "...downside risks to growth remain."

November 25, $2008 \Longrightarrow$ FFTR $=0-0.25 \% \Longrightarrow$ "...purchases (of $\$ 100$ billion of Government-Sponsored Enterprise (GSE) and $\$ 500$ billion of Mortgage-Backed Security (MBSs)) are expected to take place over several quarters."

December 16, $2008 \Longrightarrow$ FFTR $=0-0.25 \% \Longrightarrow$ "... the Committee anticipates that weak economic conditions are likely to warrant exceptionally low levels of the federal funds rate for some time."

In 2009:Q1 we had two FOMC statements:

January 28,2009 $\Longrightarrow$ FFTR $=0-0.25 \% \Longrightarrow$ "... The Committee continues to anticipate that economic conditions are likely to warrant exceptionally low levels of the federal funds rate for some time." 
Figure 3.1: Observed Yields

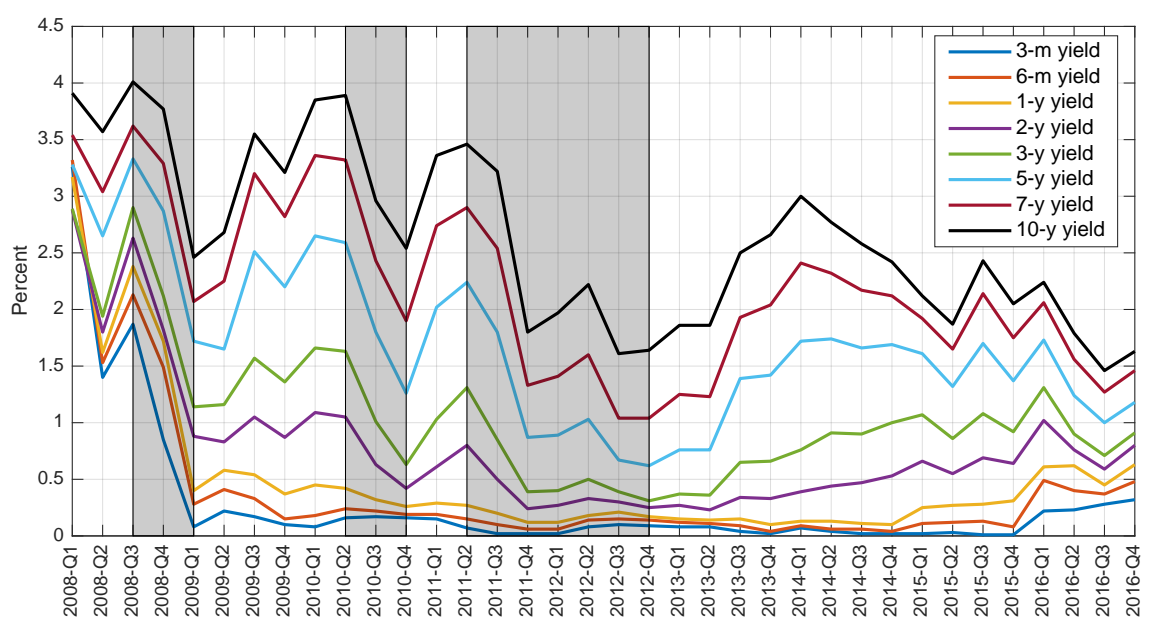

March 18,2009 $\Longrightarrow$ FFTR $=0-0.25 \% \Longrightarrow$ "... economic conditions are likely to warrant exceptionally low levels for an extended period. QE1 announcement."

Those quarters are associated with a sharp fall in market expectations of future rates as well as loose monetary policy through undoubtedly forward guidance statements. The next shaded area corresponds to 2010:Q3 when we had two FOMC statements related to forward guidance:

August 10,2010 $\Longrightarrow$ FFTR $=0-0.25 \% \Longrightarrow$ "... the Committee will keep constant the Federal Reserve's holdings of securities at their current level by reinvesting principal payments from agency debt and agency (MBSs) in longer-term Treasury securities."

September $21,2010 \Longrightarrow$ FFTR $=0-0.25 \% \Longrightarrow$ Same as previus, plus "In addition, the Committee intend to purchase a further $\$ 600$ billion of longer-term Treasury securities by the end of the second quarter of 2011."

Finally, the last shaded area is during 2011:Q3-2012:Q3. In this period we had three relevant FOMC statements:

August $9,2011 \Longrightarrow$ FFTR $=0-0.25 \% \Longrightarrow$ "Economic conditions (...) are likely to warrant exceptionally low levels of the federal funds rate at least through mid-2013."

January 25,2012 $\Longrightarrow$ FFTR $=0-0.25 \% \Longrightarrow$ "Economic conditions (...) are likely to warrant exceptionally low levels of the federal funds rate at 
least through late 2014."

September 13,2012 $\Longrightarrow$ FFTR $=0-0.25 \% \quad \Longrightarrow \quad$ "Exceptionally low levels of the federal funds rate are likely to be warrant at least through mid-2015."

Figure 3.1, along with historic interpretation of FOMC statements, demonstrate the yields capacity to carry information about forward guidance shocks. All shaded area are associated with fall in almost all yield maturities although the effective FFR has been unchanged. Our model explores recent yield movements to recover monetary news shocks. That is the reason to append a term structure of interest rates in the model. The need of an essentially affine solution, as exposed by (44), is to ensure that the model can endogenously generate term premium to estimating news shocks adequately. ${ }^{4}$

\section{4}

\section{Smoothed Shocks Prior 2008 Financial Crisis}

We use a Bayesian estimation procedure and the Metropolis-Hasting algorithm with 250,000 draws. Initially we present the estimated structural shocks prior 2008 to clarify how the model interprets business cycle fluctuations under the entire sample. The estimates are restricted to the 1985:Q1-2007:Q2 period, and we relate them to movements in output and inflation, to verify which shocks are responsible for the greatest macroeconomic variations. ${ }^{5}$ The model estimated has no monetary news shocks because we believe news were not an important driver of macroeconomic variables before 2008. It is not to deny the presence of relevant information in FOMC statements during this earlier period, but only to assign a small importance to these shocks between 1985:Q1-2007:Q2. For this reason, the monetary news shocks are not included in the estimation. Analyzing the smoothed shocks for the period prior the 2008 financial crises works as a robustness test. Finally, we back out the shocks at the mode of the posterior distribution of the structural parameters. If the model can recover the shocks properly, we should see the estimates of structural shocks match some stylized facts and literature evidence about this period.

Figure 3.2 plots the deviations of the fitted yields from their actual values and are reported in annualized basis points. As measurement errors are attached to yield equations, those filtered errors captures movements that

${ }^{4}$ Large yield decrease after 2013 may correspond in part to threshold-based instead of calendar-based forward guidance.

${ }^{5}$ We thrown away the three first years of the sample because they are used to initialize the Kalman filter, so the smoothed series are very noisy. 
Figure 3.2: Bond Yield Errors
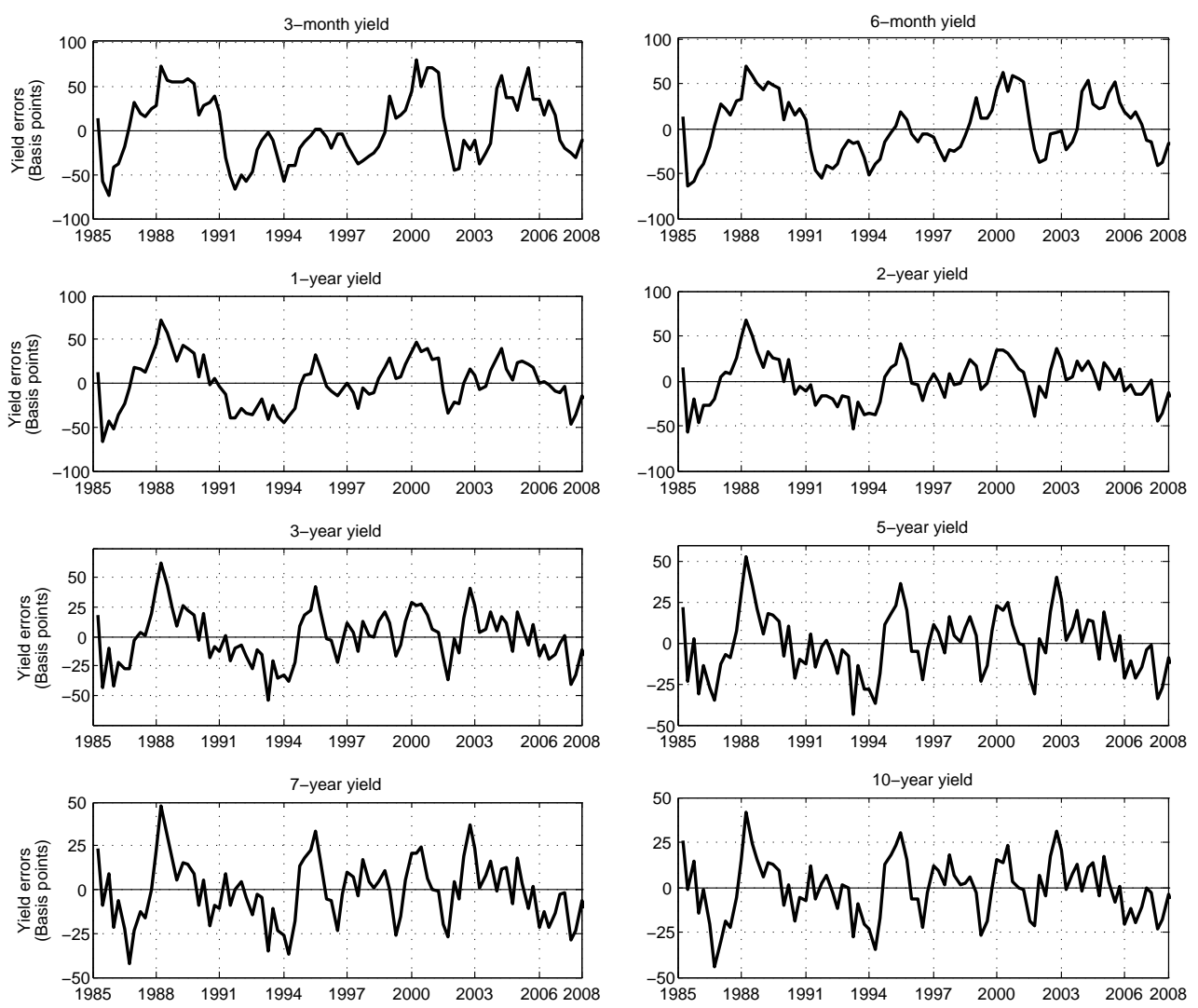

Note: Measurement errors in annual basis points. Errors are obtained from the Kalmanfiltered estimates at the posterior mode.

can not be explained by the model. The estimated standard deviations of the errors are 37, 32, 28, 25, 22, 19, 17 and 16 basis points (in annual terms) for the 3-month, 6-month, 1-year, 2-year, 3-year, 5-year, 7-year and 10-year yield respectively. The yield errors are all centered around zero, meaning that the model can capture the shape of the term structure on average.

Figure 3.3 shows the correlation of the productivity shocks with the growth in output (the correlation is 0.36 ). The model interprets the changes in output during recessions as product of negative technology shocks, both 199091 and 2001 recessions (first and second hatched areas). At the same time, negative technology shocks do not necessarily imply recessions. Between 19941998 some negative shocks occurred and output did not fall. Other structural shocks may have contribute to boost output growth during this period. As the model does not account for government spending, we are not allowed to distinguish between supply and demand shocks. (62) estimate productivity and demand shocks for the period 1989-2003 using a DSGE model. They conclude that demand shocks (government spending) were large negative in 1991 and 2002-2003 while productivity shocks were close to zero. However, under those short periods of time, our model attributes large and negative productivity 
Figure 3.3: The correlation of Output Growth with Productivity

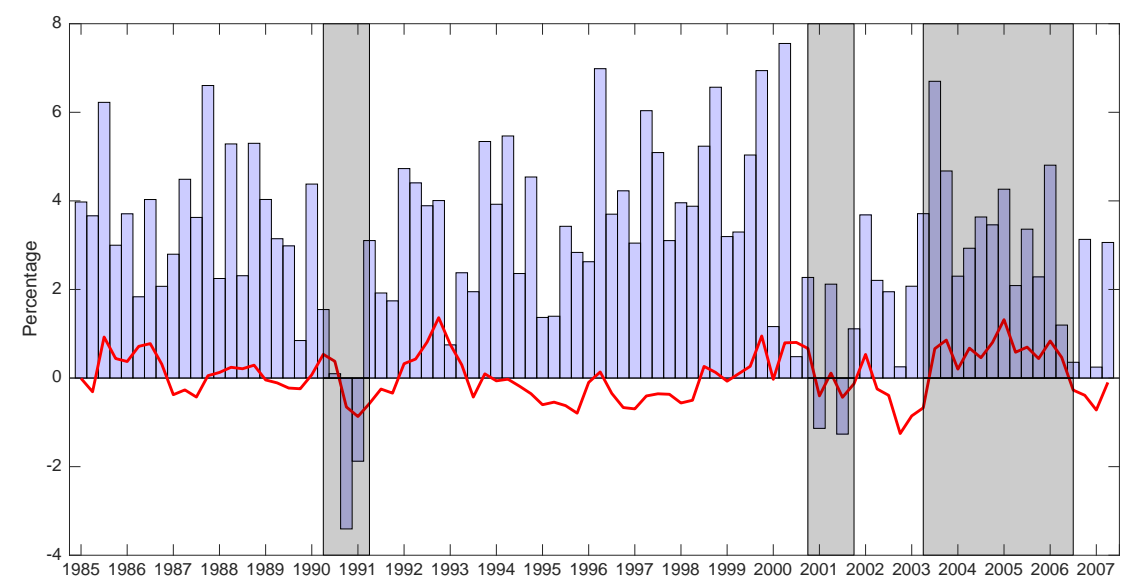

Note: Solid red line gives the productivity shocks estimation (\% deviation). Blue bars correspond to GDP change (seasonally adjusted annual rates quarter-over-quarter) from U.S. Bureau of Economic Analysis.

shocks. What may be occurring is that our model estimates government and productivity shock together, it attributes to productivity shocks the demand shocks that are not specified in the model equations. That feature does not disturb our analysis since we are interested in monetary shocks. Distinguish between supply and demand shocks is not pertinent to us, therefore it is not a trouble if the shock estimates are consistent with data.

The third hatched area corresponds to 2003-2007 period for which the model attaches highly persistent positive technology shocks. This finding is consistent with Bureau of Labor Statistics data that show that measured labor productivity grew at strong pace during the 2001-07 period (the growth rates of labor productivity had 2.7-percent in average annual growth). Since our model has no investment/capital, productivity reflects labor productivity and not total factor productivity, therefore these findings are consistent with U.S. labor productivity during that period.

Figure 3.4 compares the nominal FFR and the monetary policy shock for the same period (the correlation is 0.54 ). The monetary policy shocks are small in magnitude, and the model generates monetary policy shocks that are consistent with historic events: the negative monetary policy shocks at beginning of 1990; and 2001-2003 as well. Those two last longer loosening of policy occurred during recessions and the monetary surprise shocks capture those movements.

The model captures monetary shocks and productivity shocks over 19582007 period. Despite its strength, the model is unable to distinguish between supply and demand shocks as well as consumption and investment demand. The lack of capital in the model avoids consumption/investment movements 
Figure 3.4: The Correlation of th Federal Funds Rate with Monetary Policy Shock

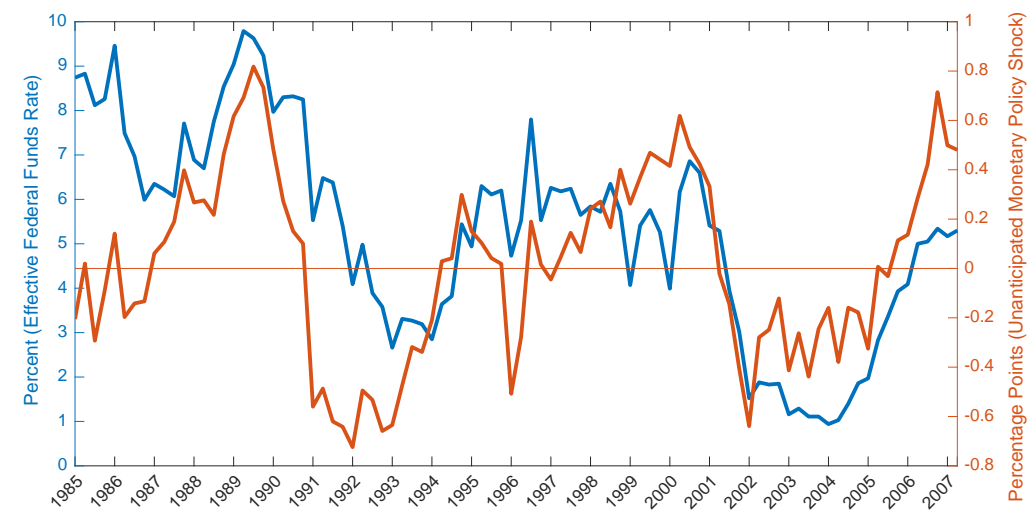

Note: Solid blue line gives the effective federal funds rate. Orange line gives the unanticipated monetary policy shock estimation. The horizontal line indicates zero in secondary y-axis. (\% deviation).

under business cycle, which translates into the inability to describe total factor productivity. Instead, our productivity estimate only reflects labor productivity.

\section{5}

\section{Smoothed Shocks During 2008 Financial Crisis}

The set of observable variables is crucial to recover the structural shocks because their movements over the business cycle, conditional to model specification, determine the sign and magnitude of the shocks estimate. The specific problem associated with monetary news shocks under the ZLB is that the interest rates has almost no changes. The effective FFR has varied from $0.6 \%$ to $0.36 \%$ in annual percent between $2009-16$. If we consider this period of time as characterized by a constant nominal interest rate, then we lose one source of variation in data and, as a result, the effective FFR must be excluded from observable data and no shocks attributed to Taylor rule equation can be recovered. This becomes a problem to us due to model specification: monetary news shocks enter only in the Taylor rule equation. To overcome this issue we recover the news shocks under two different approaches. Firstly we recover the unanticipated and anticipated monetary shocks from a model unconstrained to ZLB. The second approach is associated with a constant nominal interest rate with a slightly modification - using (66) solution algorithm. 
Figure 3.5: Bond Yield Errors
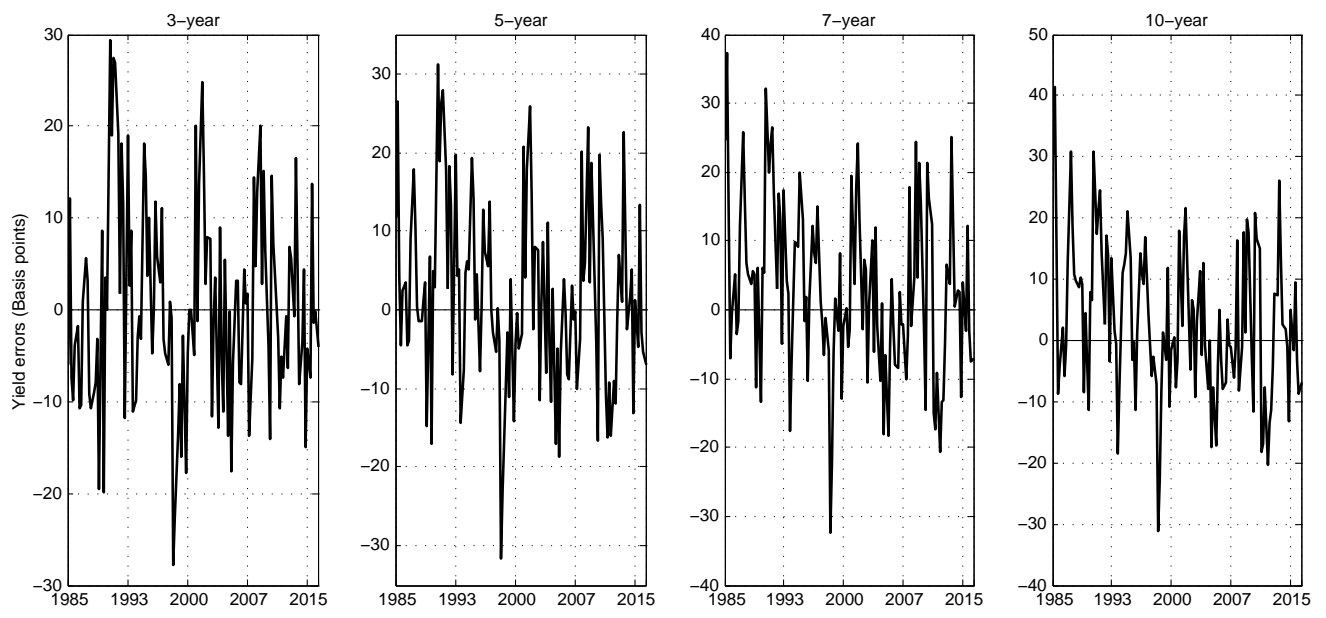

Note: Measurement errors in annual basis points. Errors are obtained from the Kalmanfiltered estimates at the posterior mode.

\subsection{1}

\section{Smoothed Shocks from Unconstrained Model}

We use the deviations of effective federal funds rate from its trend HP-filter is used to generate the trend - as an observable variable. With this measure we capture deviations from steady states values. Under this formulation the ZLB is not incorporated to the model, so it is possible to have a large negative short-term rate deviation of its steady state value resulting in a negative nominal interest rate; the shadow short rate is set via a Taylor rule and can goes negative. We compute the estimated structural shocks at the mode of the parameter estimates.

Figure 3.5 plots the deviations of the fitted yields from their actual values in annualized basis points. Measurement errors are attached to last four yield equations (3-year, 5-year, 7-year and 10-year). We do not add measurement errors to shorter bond yields because with additional news shocks we have eight structural shocks and twelve observed variables, then we must include only four measurement errors to sidestep the stochastic singularity. The yield errors are all centered around zero and are relatively small.

We are interested in evaluating two auxiliary variables: the sum of anticipated monetary shocks that hit economy to each period, $a_{t}^{\text {news }}=\varepsilon_{1, t-1}^{\text {news }}+$ $\varepsilon_{3, t-3}^{\text {news }}+\varepsilon_{5, t-5}^{\text {news }}+\varepsilon_{8, t-8}^{\text {news }}$, which we will label "actual monetary news" henceforth; and the sum of all anticipated shocks generated in each period to be realized in the future, $b_{t}=\sum_{k=1}^{K} \varepsilon_{k, t+k}, \quad k=\{1,3,5,8\}$, which we will label "bin of announced shocks" henceforth. The first auxiliary variable is useful to facilitate the interpretation of the contribution of estimated anticipated shocks to shortterm rate movements; $\left\{a_{t}\right\}_{t=8}^{T}$ collects all anticipated shocks that affect the 
Figure 3.6: Output Growth and Actual Monetary News

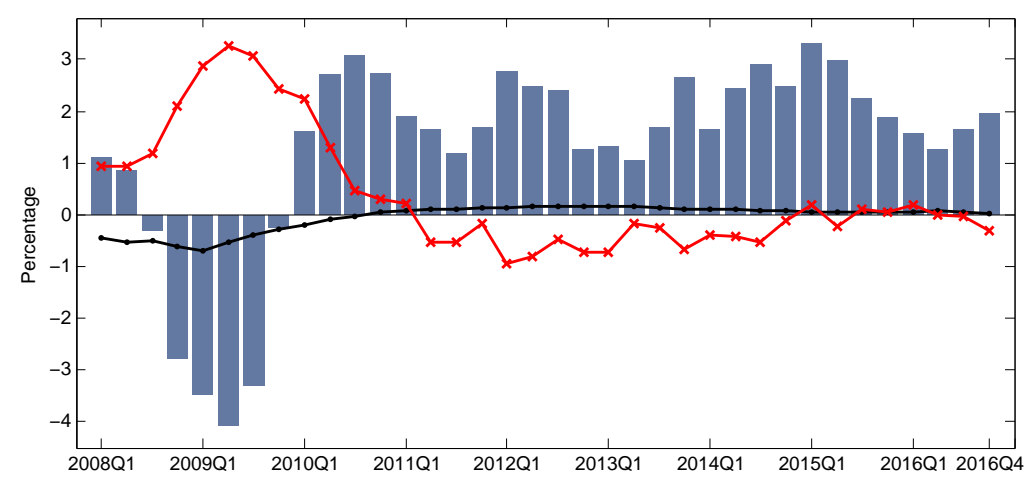

Note: Solid red line gives the actual monetary news shocks estimation. Blue bars correspond to GDP change (seasonally adjusted annual rates quarter-over-quarter) from U.S. Bureau of Economic Analysis. Solid black line gives the short term interest rate deviations from its steady-state values.

monetary policy rule in each period but were announced early. The latter auxiliary variable, $\left\{b_{t}\right\}_{t=8}^{T}$, is the measure of forward guidance, it tell us what are the monetary authority's announcements in $t$ that will affect the the economy in period $t+1, t+3, t+5$, and $t+8$.

Figure 3.6 displays the actual monetary news along with GDP growth and short term interest rate deviations from its steady-state values. The actual monetary news is negatively correlated with GDP growth, the coefficient is 0.26. The sum of anticipated shocks that take place in each period works as contractionary monetary policy during recession quarters. But the deviations of the interest rate from its steady-state value are expansionary during the same period. That means the monetary surprise is quite negative and the actual monetary news offset the large negative monetary surprise shock. The actual monetary news works to compensate a magnified estimated unanticipated monetary shock. In fact the correlation between the unanticipated monetary shock and the actual monetary news is -0.52 . The interest rate movements are positively correlated with GDP growth, as expected, then we have two shocks with different effects: the actual monetary news is contractionary; but the monetary surprise is expansionary. The net effect is expansionary, for that reason we see interest rate that displays small declines during recessions and small increases during economic booms (positively related with output). Also, the correlation between the estimated actual monetary news and technological shock is -0.71 .

If smoothed actual news shocks are negative related to realized shortterm rate, then these smoothed shocks work easing short-term rate responses. The last term of the equation bellow, $a_{t}^{\text {news }}$, offset part of the rest of the terms from right side. 
Figure 3.7: Output Growth and Bin of Announced Shocks

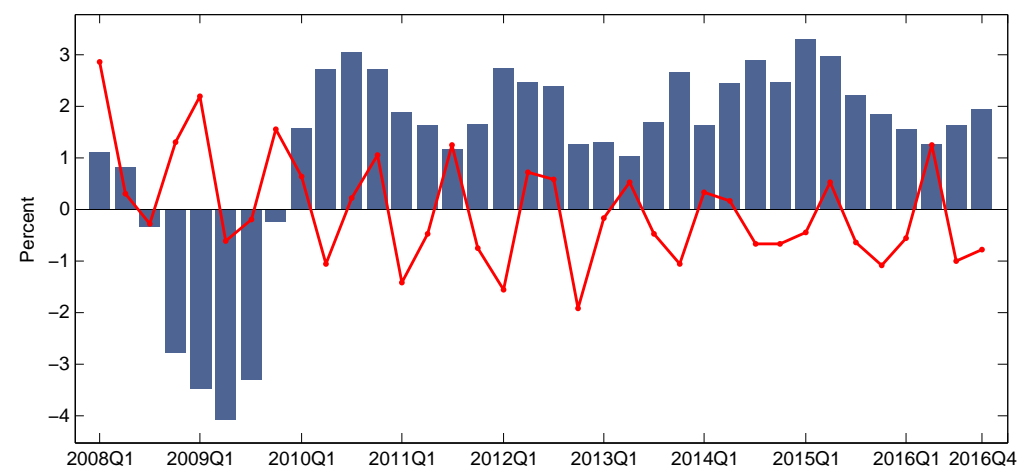

Note: Solid red line gives the actual monetary news shocks estimation. Blue bars correspond to GDP change (seasonally adjusted annual rates quarter-over-quarter) from U.S. Bureau of Economic Analysis.

$$
i_{t}=f\left(\pi_{t}, y_{t}, i_{t-1}\right)+\varepsilon_{t}^{i}+a_{t}^{\text {news }} .
$$

Figure 3.7 displays the the bin of announced shocks along with GDP growth. The correlation between the bin of announced shocks and GDP growth is -0.31 . That means the monetary authority, in generally, announces in period $t$ contractionary shocks to take place in periods $t+1, t+3, t+5$ and $t+8$. $^{6}$ This result is contrary to expected. As described in Section 3.3, bond yields fell heavily in 2009, 2010 and 2012, after FOMC communications about future path of FFR. So, we would expect expansionary news shocks hitting the economy in these periods.

All the estimated news shocks are positively correlated with the forward guidance dates, which corroborates that the estimated shocks are contractionary, when they should be expansionary. The correlations varies from 0.04 up to 0.38 , as we can see in Table 3.1 .

It is clear that smoothed shocks from unconstrained model can not back out the monetary news shocks properly. Between 2008Q1-2010Q2 the output is below its steady-state value and part of this decrease is due to negative technological shocks. At same time, the FFR is below its steady-state value, which should assist output recovery. What makes the fall in output so large are the news shocks announced and realized during this period. The model forces the news shocks to be responsible for drops in output. In 2009Q1 the bin of announced shocks is positive as do all news shocks. Those innovations will hit the economy only in 1-,3-,5-, and 8- quarters ahead, but output falls

${ }^{6} \mathrm{It}$ is important to bear in mind that the bin of announced shocks is the sum of those future innovations, then it is possible to have future expansionary shocks at $t+1$ and $t+3$ and contractionary ones at $t+5$ and $t+8$. 
Table 3.1: Correlation Among News Shocks and FG Dates

\begin{tabular}{lccccc}
\hline & \multicolumn{4}{c}{ Estimated News Shocks } & \\
\cline { 2 - 5 } & 1-q ahead & 3-q ahead & $5-q$ ahead & 8-q ahead & FG dates \\
\cline { 2 - 5 } 1-q ahead & 1 & 0.5592 & 0.3679 & 0.3876 & 0.3861 \\
3-q ahead & 1 & 0.2712 & 0.7455 & 0.2468 \\
5-q ahead & & & 1 & 0.1855 & 0.2220 \\
8-q ahead & & & 1 & 0.0474 \\
FG dates & & & & 1 \\
\hline
\end{tabular}

at the date of these shocks are known by the agents, thanks to Euler equation: people know that interest rate will rise in future, as current consumption is negatively correlated to long term interest rate, it follows that an increase in the future real interest rate decrease consumption today. The model uses anticipated monetary shocks to induce current changes in output, not reflecting FOMC statements about future monetary policy. The fall in output is left to be explained by productivity shocks and monetary news shocks (through expectation mechanism).

Despite the good fit of yield structure, the unconstrained model can not recover forward guidance shocks as the literature conceptualizes this policy.

\subsection{2}

\section{News Shocks from Occbin Solution}

In this section we consider the model built on previous sections with occasionally binding constraints - the solution method was described in Section 3.2.2 -, therefore, the ZLB is incorporated into the model. (66) algorithm allows for a stable path under ZLB solution by imposing a restriction on the sequences of ZLB expected durations. The yield curve is determined mainly by the current and future path of FFR. As the FFR can not goes negative, we would expect the falls in yield curve to be a consequence of the monetary news shocks in that the short rate has an active lower bound. This mechanism will work every time the agents predict that FFR will reach its lower bound. Incorporating occasionally binding constraints is an attempt to force the model to back out monetary news shocks.

We restrict the news shocks to be positively correlated. The main reason to that is to bring the the model closer to reality: FOMC announcements usually indicate an expansionary path to FFR, and there are no reasons to think that future shocks are independent to each other. The news about the future must be positively correlated. The structure of correlation among the 
news shocks are defined as follows:

$$
\begin{array}{ll}
\varepsilon_{k, t-k}^{\text {news }}=\tau^{k} \varepsilon_{k-2, t-k-2}^{\text {news }}+v_{k} & \text { if } \quad k=\{1,3\} \\
\varepsilon_{k, t-k}^{\text {news }}=\tau^{k} \varepsilon_{k-3, t-k-3}^{\text {news }}+v_{k} & \text { if } \quad k=\{5\} \\
\varepsilon_{k, t-k}^{\text {news }}=v_{k} & \text { if } \quad k=\{8\},
\end{array}
$$

where $v_{k}$ is i.i.d $N\left(0, \sigma_{k}^{\text {news }}\right)$. We use the correlations displayed on Table 3.1 to calibrate $\tau=0.56$. The equations (3-26)-(3-28) follow an autoregressive structure allowing positive correlation among the news shocks that emerge from the same FOMC statement. Also, we impose a positive correlation between the monetary policy surprise, $\varepsilon_{t}^{i}$, and the news shock, $\varepsilon_{1, t-1}^{n e w s}$. The intuition behind this constraint is that the FOMC generally announces forward actions in accordance with monetary surprises. We arbitrarily impose a coefficient correlation of 0.7 .

The model parameters are set following the estimation for the prior 2008 financial crisis period, as describe in Section 3.4. Therefore, the post-2008 sample period is used only to estimate the fundamental shocks. According to this specification, we are imposing no structural changes over the parameters as the economy goes to ZLB period. The parameter estimation during ZLB period was not undertaken due to excessive computational burden. However, the occasionally binding constraints change the magnitudes of the transmission mechanisms from the shocks to the state variables when the ZLB is binding. The occasionally binding constraints implications over the yield curve is described in Appendix A.

Generally these structural shocks can be estimated using a Kalman smoother or through any smoothing algorithm. However the ZLB imposes a binding constraint into FFR which produces nonlinearities on monetary policy rule. The estimation procedure is done through an algorithm that minimizes the sum of squared error prediction of the model. The algorithm finds shocks values that are consistent with the occasionally binding constraints. This method is described in Appendix A.

Figures (3.8)-(3.9) plot the deviations of the smoothed observable variables from their actual values. Figure (3.8) shows GDP growth, inflation, FFR and hours worked. The correlations between observed and smoothed variables are high - varying from 0.7 up to 0.99 - , except for the FFR. The smoothed FFR falls long before its observed counterpart. That discrepancy occurs due to estimation method. As the output falls abruptly, around 2008, the model optimal response is to set the FFR lower than zero. However, the occasionally binding constraints avoid that the interest rate goes to negative, and, instead, 
Figure 3.8: The Correlation of the Observable with Smoothed Variables
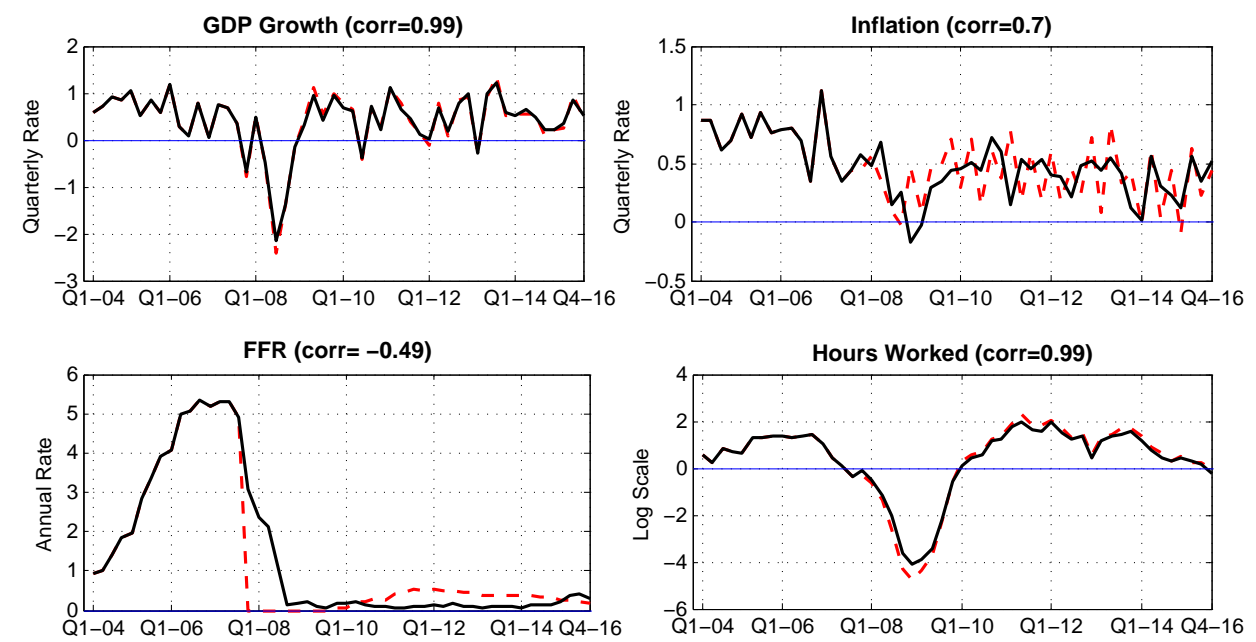

Note: The solid black line represents the observable variables. The red dotted line represents the smoothed series. Smoothed are generated from the constrained model.

sets FFR equal to zero. The direct way to make smoothed yield curves match the observable yields, is set FFR equal to zero. The observed yields exhibit a big fall soon after 2007, as the FFR is the main driver of the yields movements, a trade-off occurs: to generate a big drop in yield curve as a whole, the model jumps the economy to ZLB. If the model were absent to the fit yield curve, the minimization would result in a smoothed FFR very close to the actual observed. However, without forcing the model to fit the yield curve, we would lose information about FOMC's statement. As a result, the smoothed yield curve matches the actual observed very well - both by the path and volatility. The correlations between smoothed and observed variables range from 0.82 to 0.99 .

Figure 3.10 displays the actual monetary news, $a_{t}^{\text {news }}$, along with GDP growth. The actual monetary news is positively correlated with GDP growth, the correlation coefficient is 0.45 . $a_{t}^{\text {news }}$ works as an expansionary monetary policy during recession quarters, as we would expect. ${ }^{7}$ From 2008 to 2011, we have identified three periods of explicit expansionary FOMC's forward guidance statements. Therefore, the auxiliary variable, $a_{t}^{\text {news }}$, behaves expansionary, as expected, until 2011. After 2011, it becomes positive, which indicates future increases in the FFR. In fact, after 2012, we did not identify any significant FOMC's statement related to forward guidance, neither the yield curve showed large falls - see Figure 3.1. Therefore, there is no reason to expect recover any negative anticipated shocks for the last half of the sample. In short, the estimated actual monetary news is in agreement with the FG literature;

${ }^{7}$ It is the opposite behavior found in the unconstrained model. 
Figure 3.9: The Correlation of the Observable with Smoothed Yields
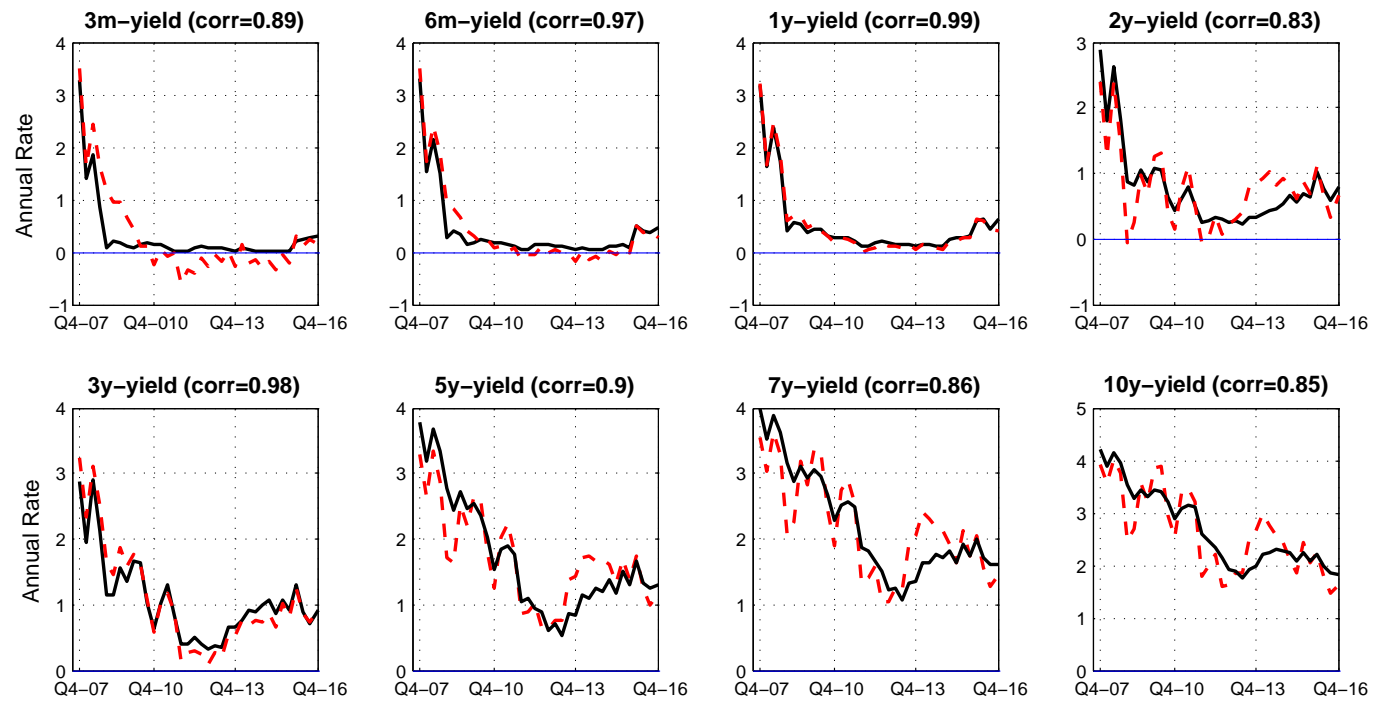

Note: The solid black line represents the observable yields. The red dotted line represents the smoothed yields. Smoothed are generated from the constrained model.

the shocks are expansionary between 2008-Q1 up to 2012-Q1.

Figure 3.11 displays the bin of announced shocks along with GDP growth. The correlation between the bin of announced shocks and GDP growth is 0.74 . That means the monetary authority, in generally, announces in period $t$ expansionary shocks to take place in periods $t+1, t+3, t+5$ and $t+8$, when the output growth is negative. The two large negative bins are in 2009-Q1 and 2009-Q3, however the most significant drops in the yield curve occur between 2008Q3-2009Q1, and 2010Q2-2010Q4. Nevertheless, the explicit FOMC's forward guidance statements - defined by a compilation of relevant statements and the language in each that the literature judges most pertinent to forward guidance -, do not represent precisely the periods with the large negative smoothed forward guidance shocks. Therefore, the model enables us to recover large negative forward guidance shocks for the period of expressive falls in yields, however, it is not able to identify precisely the forward guidance dates.

To clarify this point, Figure 3.12 plots each individual monetary news shock announced; they are the components of the bin of monetary shocks, in other words, $\hat{\varepsilon}_{1, t+1}, \hat{\varepsilon}_{3, t+3}, \hat{\varepsilon}_{5, t+5}$, and $\hat{\varepsilon}_{8, t+8}$. The shaded areas report the quarters associated with a sharp fall in market expectations of future rates as well as loose monetary policy through explicit, clear, undoubtedly forward guidance statements.

The first shaded area is in 2008-Q3 to 2009-Q1. On that date we had three FOMC statements related to forward guidance: October 29, 2008; 
Figure 3.10: Output Growth and Actual Monetary News - Constrained Model

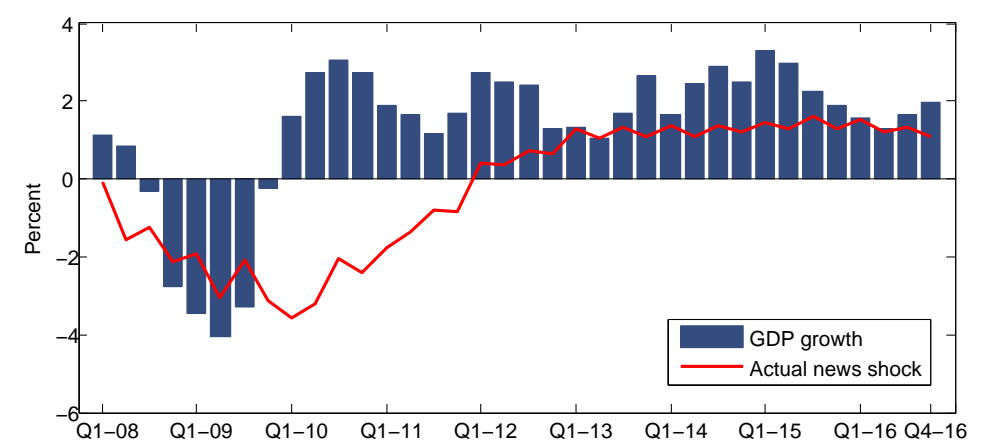

Note: Blue bars correspond to GDP change (seasonally adjusted annual rates quarter-overquarter) from U.S. Bureau of Economic Analysis.

November, 25, 2008; and, December, 16, 2008. In those FOMC releases, the board explicitly demonstrates worrying about future economic performance. In the first quarter of 2009 there were two FOMC statements related to forward guidance; January, 28, and March, 18, respectively. Further, the March meeting came with the QE 1 announcement, which were the most responsible factor for the sharp decline in the yield curve. At the end of 2008, the FFR target were $0-0.25 \%$. Then we would expect very large negative smoothed news shocks. In fact, in those quarters the 1-, 3-, and 5-quarter smoothed news shocks are negative. The model estimates a bin of announced shocks of $-4.32 \%$ for 2009 Q1 (the sum of the news shocks), that is, the FOMC statements correspond, quantitatively, to a decrease of more than 430 basis point in the FFR in the next two years. That is the "size" of forward guidance that the model delivers. However, the 8-quarter news shock is positive in that date. The sum of all news shocks is very negative, but not all news shocks are expansionary.

The second shaded area is in 2010-Q2 to 2010-Q4. On that date we had two FOMC statements related to forward guidance: August, 10; and, September, 21. In fact, the sum of smoothed news shocks is negative. The model attributes a decrease of approximately 200 basis points in the FFR for the next two years. However, the 1-, and 5-quarters smoothed news shocks get less negative during those quarters. Also, the 3-quarter smoothed news shock is positive around 25 basis points. Although the sum of the smoothed news is negative, we would expect a downward path for these shocks.

Finally, the third shaded area is in 2011-Q2 to 2012-Q4. On that date we had three FOMC statements related to forward guidance: August, 9, 2011; January 25,2012; and, September 13,2012. ${ }^{8}$ However, the sum of news shocks is positive on average; around 70 basis points. The two first quarters of this subsample have a negative bin of the shocks, -30 , and -10 basis points

${ }^{8}$ With explicit forward guidance language. 
Figure 3.11: Output Growth and Bin of Announced Shocks - Constrained Model

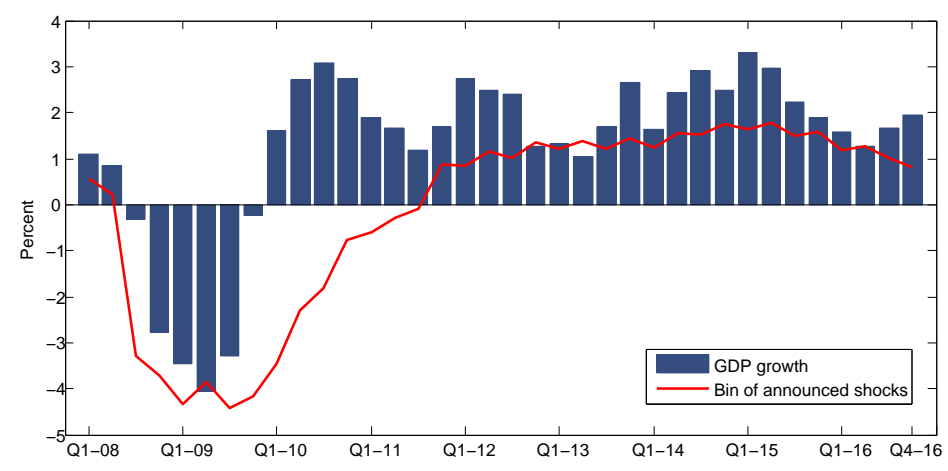

Note: Blue bars correspond to GDP change (seasonally adjusted annual rates quarter-overquarter) from U.S. Bureau of Economic Analysis.

respectively. Nevertheless, the remaining quarters have positive bin of shocks. Also, almost all news shocks have an increasing trend during the third shaded area, contrary to what we would expect.

The estimates presented show that the model can recover, on average, the forward guidance statements of the two first shaded areas. But it is not able to identify precisely the forward guidance of official FOMC statements over the entire subsample. There are two main points related to its model's flaw: the yield curve behavior after 2012; and, the model's ability to generate risk premium.

The yield curve behavior after 2012: Not all shaded areas are equal in Figure 3.1. A brief look at the yields movements shows that the yields with longer maturities begin to increase soon after the last half of the 2012. This rise lasts until mid-2014. To match the yield movements, the model attributes positive shocks to the FFR through anticipated monetary shocks. We can see that in Figure 3.8. The estimated FFR increases long before the observed variable. As the monetary shocks are the main driver to the yield curve, the model forces the monetary news shocks to become positive some quarters before the rise of the observed yield curve. The bin of news shocks, $b_{t}^{\text {news }}$, becomes positive in the mid-2011 to generate an increase on longer maturities. For that reason, the actual monetary news, $a_{t}^{\text {news }}$, turns out to be positive only in the second quarter of 2012, because the future contractionary shocks only hit the economy some quarters after they have been publicized. Therefore, the model shows a dependency on monetary shocks to generate yield curve movements. The forward guidance statements related to second and third shaded areas, presented in Figure 3.1, and Figure 3.8, are not identified by the estimated news shocks because those news are used to fit the yields with longer maturities. This leads us to the second point highlighted in the previous 
Figure 3.12: Decomposition of Bin of Announced Shocks - Constrained Model

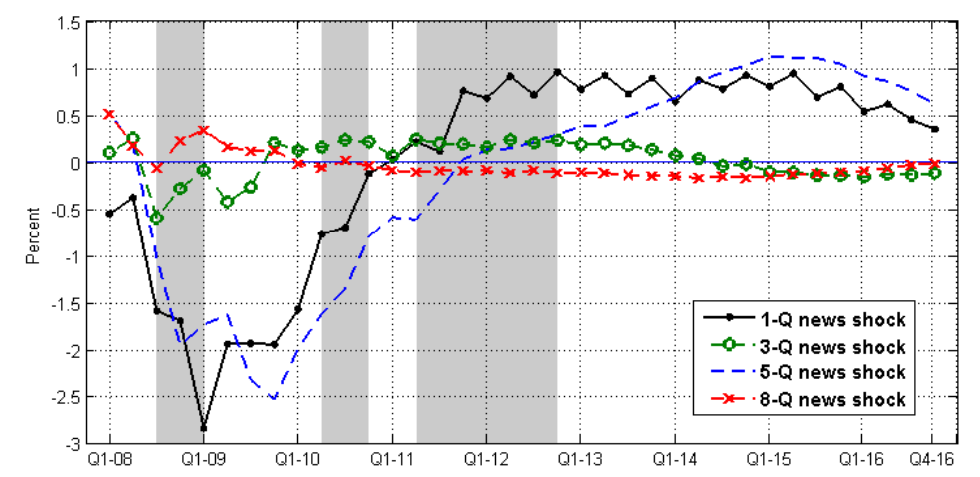

Note: Individual estimation of the news shocks. The sum of the shocks correspond to auxiliary variable "bin of announced shocks". The shaded areas are defined in Section 3.3; they correspond to FOMC statements related to forward guidance.

paragraph.

Model ability to generate risk premium: Much of the increase in the long term of the yield curve is probably due to risk premium associated with that period. One source of term premium variation is a risk aversion shock. The model's responses to an increase in risk aversion are: a fall in output; an increase in the yield curve; and, an increase in term premium. So, what could help the model to fit the yield curve, mainly after 2011, is a risk aversion shock. A high risk aversion could rise long term yields, through term premium, without a need of contractionary news shocks. Figure 3.13 displays the estimated risk aversion shock, and the technological shock. The risk aversion is high over the output downturn period, but it falls abruptly soon after the economic recovery. Between 2010 and 2014, the risk aversion shock is negative, what implies lower yields, and term premium. Therefore, the model attributes positive news shocks, during forward guidance dates, to increase the longer-maturity yields.

When forward guidance is associated with a fall in the yields of all maturities, the model is able to recover news shocks properly. However, when ZLB avoid shorter yields movements, the model is not able to recover the monetary news. It is linked to the model's limited capacity to generate variation over the yields of longer maturities. The model constrained to ZLB attributes future rises on longer yields to contractionary monetary news shocks. They are announced today, but hit the economy in the future.

Other potential issues: There are a few more considerations that must be taken in account to evaluate the monetary news shocks estimation. First, even with a essentially affine approximation, both the constrained, and unconstrained model, have limited capacity to generate large term premiums. Also, the volatility of term premium is influenced by some parameters as the Calvo 
Figure 3.13: Risk Aversion and Technological Shocks - Constrained Model

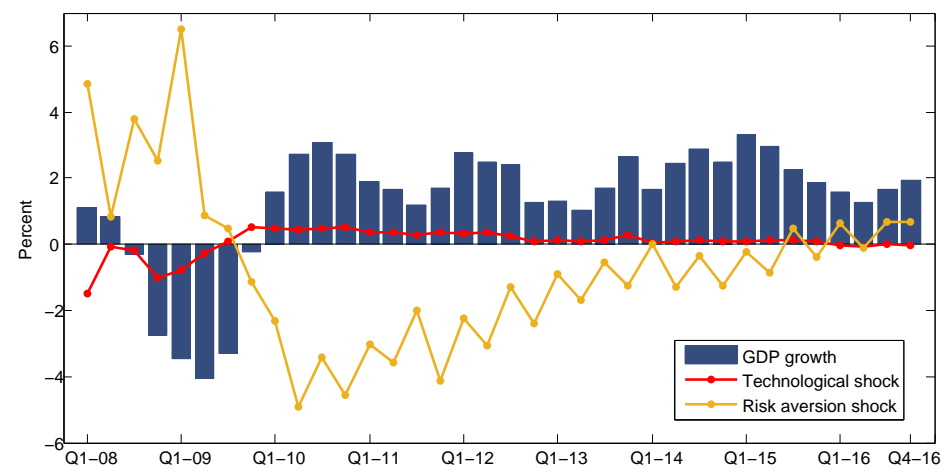

Note: Blue bars correspond to GDP change (seasonally adjusted annual rates quarter-overquarter) from U.S. Bureau of Economic Analysis.

probability - which determines the frequency of firms re-optimization -, and the inflation target persistence - which determines the sensibility of monetary authority to inflation deviations from its target. More flexible prices enable larger decline in term premium. A more persistent inflation target generates large term premium variations, as well as a lower Calvo parameter. So, depending on the parameters estimation, the limited capacity in generating large term premium can be overstated.

Second, the absence of a financial market coerces the model to explain output deviations through a combination of technological, monetary surprises and news. As we see in the case of the unconstrained model, part of the economic downturn is explained by a contractionary news shock. A DSGE model with financial frictions can, possibly, enhance the results by explain the economic performance with a large number of fundamental shocks.

Third, the yield data used in this paper has quarterly frequency. However, the daily changes in yields, or even intra-day data, can be more effective in capturing the term structure responses to FOMC meetings. This is the approach followed by the empirical literature, as (70), and (34). We may have been throwing valuable information away when aggregating daily data in quarterly frequency.

It is noteworthy that the DSGE model built here does not distinguish between Delphic and Odyssean forward guidance. When implementing anticipated shocks as described in Section 3.2, we only can recover one anticipated shock for each period, which means that we are not able to say whether it is from a Delphic or an Odyssean statement. ${ }^{9}$ There is no distinction between

${ }^{9}$ The term "forward guidance" has a broader meaning. One must distinguish between Odyssean forward guidance, which publicly commits the FOMC to a future action, and Delphic forward guidance, which merely forecasts macroeconomic performance and likely monetary policy actions - which is based on the policymaker's potentially superior information 
central bank and private forecasts inside the model. So the estimated anticipated shocks are announcements about the future path of FFR. For that reason we interpret them only as Odyssean forward guidance. Furthermore, the model is absent of time inconsistency between discretion and desire to commit to a policy path. The model assumes that policymakers are fully committed to the pre-announced policy path and that the public believes policymakers will follow through with their stated intentions. Here there is no option to deviate from the announced path likewise any New Keynesian DSGE model. All of those features reveal potential limitations to the model's ability to deal with forward guidance statements as news shocks in monetary policy rule.

\section{6}

\section{Conclusion}

In this paper we argue that the standard New Keynesian models are not able to properly recover the forward guidance shocks. We focus on a standard case in which the monetary news shocks are added to DSGE model through moving average shocks, as proposed by (63). We work with the unconstrained, and the ZLB constrained framework, covering a widely accepted analytical macroeconomic structure. Our identification strategy is to use yield curve movements to extract information, contained in FOMC statements, about the the likely future course of monetary policy. This identification approach relies on the fact that forward-looking agents react to news shocks before they materialize. The unconstrained model is not capable of backing out the information about the future path of interest rate. The constrained model can back out the news only partially. Both are not able to recover the news shocks adequately.

Some works have highlighted the importance of news shocks in explaining the economic fluctuations. Also many papers have used New Keynesian DSGE models to evaluate role of news in macroeconomic performance (see (64), (65), and (61)). The recent unconventional monetary policy undertaken by the Fed, through official statements, provides us a chance to evaluate the ability of the DSGE models in recovering the anticipated monetary policy shocks. Here we compare the sign and magnitude of the estimated shocks with the forward guidance dates. Our results show that standard DSGE models are not able to back out forward guidance shocks: The estimated shocks, from unconstrained model, are not in accordance with the forward guidance dates; The model

about future macroeconomic fundamentals and its own policy goals. A Delphic statement theoretically reduces private uncertainty and improves macroeconomic outcomes. Delphic and Odyssean language can influence the yields. 
constrained to ZLB can recover the news in monetary policy only for the early FG dates.

The failure to recover the forward guidance shocks is probably linked to the absence of a richer mechanism in describe the term structure of interest rates. Although the model presents a satisfactory fit of the yield curve, it has difficulties in dealing with heterogeneous movements among different yield maturities. Even with a essentially affine approximation, it is extremely hard to perfectly match the yield data during the ZLB. The model forces the shocks attached to the monetary policy rule to account for most variation in the yield curve. Also, financial frictions can probably enhance the results by adding a new source of economic fluctuation. This could help the model to explain the economic downturn observed in 2008-2009. Further, this addition could be useful as the news shocks estimation is not independent of which shocks are driving economic fluctuations.

We focus on the limitation of standard models to identify the expansionary news shocks in the US monetary policy rule after 2008. Albeit we augmented the New Keynesian model with a term structure of the interest rates, time-varying term premium, ZLB constraints, and correlation among news shocks, the findings are insufficiently robust to offer a satisfactory estimation of the recent course of forward guidance shocks through ZLB period. 


\section{Bibliography}

[1] TAYLOR, J. B.. Discretion versus policy rules in practice. In: CARNEGIE-ROCHESTER CONFERENCE SERIES ON PUBLIC POLICY, volumen 39, p. 195-214. Elsevier, 1993.

[2] TAYLOR, J. B.. A historical analysis of monetary policy rules. In: MONETARY POLICY RULES, p. 319-348. University of Chicago Press, 1999.

[3] RUDEBUSCH, G. D.. Monetary policy inertia: Fact or fiction? International Journal of Central Banking, 2(4):85-135, 2006.

[4] SIMS, E.. Identification and estimation of interest rate rules in new keynesian models, 2008.

[5] SIMS, E. R.. Taylor rules and technology shocks. Economics Letters, 116(1):92-95, 2012.

[6] CLARIDA, R.; GALI, J. ; GERTLER, M.. Monetary policy rules and macroeconomic stability: Evidence and some theory.: Evidence and some theory. Quaterly journal of economics, 115(1):147, 2000.

[7] MEHRA, Y. P.; MINTON, B. D.. A taylor rule and the greenspan era. Economic Quarterly, 93(3):229-251, 2007.

[8] CLARIDA, R.; GALI, J. ; GERTLER, M.. Monetary policy rules and macroeconomic stability: Evidence and some theory.: Evidence and some theory. Quaterly journal of economics, 115(1):147, 2000.

[9] COIBION, O.; GORODNICHENKO, Y.. Why are target interest rate changes so persistent? American Economic Journal. Macroeconomics, 4(4):126, 2012.

[10] JUDD, J. P.; RUDEBUSCH, G. D.. Taylor's rule and the fed: 19701997. Economic Review-Federal Reserve Bank of San Francisco, 1(3):3-16, 1998.

[11] ORPHANIDES, A.. Monetary policy rules, macroeconomic stability, and inflation: A view from the trenches. Journal of Money, Credit and Banking, p. 151-175, 2004. 
[12] COCHRANE, J. H.. Determinacy and identification with taylor rules. Journal of Political Economy, 119(3):565-615, 2011.

[13] DE VRIES, C.; LI, W.. Estimating monetary policy rules with serially correlated monetary policy shocks. Unpublished manuscript, 2013.

[14] GALI, J.. Monetary Policy, Inflation, and the Business Cycle: An Introduction to the New Keynesian Framework. Princeton University Press, 2008.

[15] STOCK, J. H.; WRIGHT, J. H. ; YOGO, M.. A survey of weak instruments and weak identification in generalized method of moments. Journal of Business \& Economic Statistics, 2012.

[16] STOCK, J. H.; YOGO, M.. Testing for weak instruments in linear iv regression. Identification and inference for econometric models: Essays in honor of Thomas Rothenberg, 2005.

[17] MAVROEIDIS, S.. Identification issues in forward-looking models estimated by gmm, with an application to the phillips curve. Journal of Money, Credit and Banking, p. 421-448, 2005.

[18] KLEIBERGEN, F.; MAVROEIDIS, S.. Weak instrument robust tests in gmm and the new keynesian phillips curve. Journal of Business \& Economic Statistics, 27(3):293-311, 2009.

[19] SMETS, F.; WOUTERS, R.. Shocks and frictions in us business cycles: A bayesian dsge approach. The American Economic Review, p. 586-606, 2007.

[20] CHRISTIANO, L. J.; EICHENBAUM, M. ; EVANS, C. L.. Nominal rigidities and the dynamic effects of a shock to monetary policy. Journal of political Economy, 113(1):1-45, 2005.

[21] HANSEN, L. P.; HEATON, J. ; YARON, A.. Finite-sample properties of some alternative gmm estimators. Journal of Business \& Economic Statistics, 14(3):262-280, 1996.

[22] ISKREV, N.. Local identification in dsge models. Journal of Monetary Economics, 57(2):189-202, 2010.

[23] RATTO, M.; ROEGER, W. ; IN'T VELD, J.. Quest iii: An estimated open-economy dsge model of the euro area with fiscal and monetary policy. economic Modelling, 26(1):222-233, 2009. 
[24] GIANNONI, M.; PATTERSON, C.; DEL NEGRO, M. ; OTHERS. The forward guidance puzzle. In: 2016 MEETING PAPERS, número 143. Society for Economic Dynamics, 2016.

[25] CAMPBELL, J. R.; EVANS, C. L.; FISHER, J. D. ; JUSTINIANO, A.. Macroeconomic effects of federal reserve forward guidance. Brookings Papers on Economic Activity, 2012(1):1-80, 2012.

[26] DUFFIE, D.; KAN, R.. A yield-factor model of interest rates. Mathematical finance, 6(4):379-406, 1996.

[27] DAI, Q.; SINGLETON, K. J.. Specification analysis of affine term structure models. The Journal of Finance, 55(5):1943-1978, 2000.

[28] SWANSON, E. T.. A macroeconomic model of equities and real, nominal, and defaultable debt. 2015 Meeting Papers, Society for Economic Dynamics, 273, 2015.

[29] DEW-BECKER, I.. Bond pricing with a time-varying price of risk in an estimated medium-scale bayesian dsge model. Journal of Money, Credit and Banking, 46(5):837-888, 2014.

[30] WOODFORD, M.. Methods of policy accommodation at the interest-rate lower bound. In: THE CHANGING POLICY LANDSCAPE: 2012 JACKSON HOLE SYMPOSIUM. Federal Reserve Bank of Kansas City, 2012.

[31] SWANSON, E. T.; WILLIAMS, J. C.. Measuring the effect of the zero lower bound on medium-and longer-term interest rates. The American Economic Review, 104(10):3154-3185, 2014.

[32] SWANSON, E.. A macroeconomic mmodel of equities and real, nominal, and defaultable bonds. Technical report, Technical report, University of California, Irvine, 2015.

[33] PLOSSER, C. I.; OTHERS. Forward guidance. In: REMARKS AT STANFORD INSTITUTE FOR ECONOMIC POLICY RESEARCHS (SIEPR) ASSOCIATES MEETING, 2013.

[34] GÜRKAYNAK, R. S.; SACK, B. ; SWANSON, E.. The sensitivity of longterm interest rates to economic news: Evidence and implications for macroeconomic models. American economic review, p. 425-436, 2005. 
[35] GÜRKAYNAK, R. S.; SACK, B. ; SWANSONC, E. T.. Do actions speak louder than words? the response of asset prices to monetary policy actions and statements. International Journal of Central Banking, 2005.

[36] GAGNON, J.; RASKIN, M.; REMACHE, J. ; SACK, B. P.. Large-scale asset purchases by the federal reserve: did they work? FRB of New York Staff Report, (441), 2010.

[37] KRISHNAMURTHY, A.; VISSING-JORGENSEN, A.. The effects of quantitative easing on interest rates: Channels and implications for policy. Brookings Papers on Economic Activity: Fall 2011, p. 215, 2012.

[38] EPSTEIN, L. G.; ZIN, S. E.. Substitution, risk aversion, and the temporal behavior of consumption and asset returns: A theoretical framework. Econometrica, 57(4):937-969, 1989.

[39] SWANSON, E. T.; OTHERS. Risk aversion, risk premia, and the labor margin with generalized recursive preferences. Federal Reserve Bank of San Francisco Working Paper, 17, 2013.

[40] WOODFORD, M.. Interest rate and prices. Princeton University Press Princeton, NJ, and Oxford, 2003.

[41] CALVO, G. A.. Staggered prices in a utility-maximizing framework. Journal of monetary Economics, 12(3):383-398, 1983.

[42] LASÉEN, S.; SVENSSON, L. E.. Anticipated alternative policy-rate paths in policy simulations. Riksbank Research Paper Series, (79), 2011.

[43] HAMILTON, J. D.; WU, J. C.. Identification and estimation of gaussian affine term structure models. Journal of Econometrics, 168(2):315-331, 2012.

[44] DEW-BECKER, I.. A model of time-varying risk premia with habits and production. Unpublished manuscript, 2012.

[45] SIMS, C. A.. Solving linear rational expectations models. Computational economics, 20(1):1-20, 2002.

[46] BILS, M.; KLENOW, P. J.. Some evidence on the importance of sticky prices. Journal of political economy, 112(5):947-985, 2004. 
[47] CAMPBELL, J. Y.; COCHRANE, J. H.. Explaining the poor performance of consumption-based asset pricing models. The Journal of Finance, 55(6):2863-2878, 2000.

[48] COCHRANE, J. H.; OTHERS. Financial markets and the real economy. Foundations and Trends $₫$ in Finance, 1(1):1-101, 2005.

[49] RUDEBUSCH, G. D.; SACK, B. P. ; SWANSON, E. T.. Macroeconomic implications of changes in the term premium. FEDERAL RESERVE BANK OF ST. LOUIS REVIEW, 89(4):241-69, 2007.

[50] RUDEBUSCH, G. D.; SWANSON, E. T.. The bond premium in a dsge model with long-run real and nominal. American Economic Journal: Macroeconomics, 4(1):105-143, 2012.

[51] PIAZZESI, M.. Bond yields and the federal reserve. Journal of Political Economy, 113(2):311-344, 2005.

[52] BEKAERT, G.; CHO, S. ; MORENO, A.. New keynesian macroeconomics and the term structure. Journal of Money, Credit and Banking, 42(1):33-62, 2010.

[53] KURMANN, A.; OTROK, C.. News shocks and the slope of the term structure of interest rates. The American Economic Review, 103(6):2612-2632, 2013.

[54] MILANI, F.; TREADWELL, J.. The effects of monetary policy "news" and "surprises". Journal of Money, Credit and Banking, 44(8):1667-1692, 2012.

[55] CARLSTROM, C. T.; FUERST, T. S. ; PAUSTIAN, M.. Inflation and output in new keynesian models with a transient interest rate peg. Journal of Monetary Economics, 76:230-243, 2015.

[56] MCKAY, A.; NAKAMURA, E. ; STEINSSON, J.. The power of forward guidance revisited. The American Economic Review, 106(10):3133-3158, 2016.

[57] SWANSON, E. T.. Measuring the effects of federal reserve forward guidance and asset purchases on financial markets. Technical report, National Bureau of Economic Research, 2017.

[58] DE GRAEVE, F.; ILBAS, P. ; WOUTERS, R.. Forward guidance and long term interest rates: inspecting the mechanism. Sveriges Riksbank Stockholm, 2014. 
[59] CARLSTROM, C. T.; FUERST, T. S. ; PAUSTIAN, M.. How inflationary is an extended period of low interest rates? FRB of Cleveland Working Paper, 1202, 2012.

[60] SMITH, A. L.; BECKER, T.. Has forward guidance been effective? Economic Review-Federal Reserve Bank of Kansas City, p. 57, 2015.

[61] SCHMITT-GROHÉ, S.; URIBE, M.. What's news in business cycles. Econometrica, 80(6):2733-2764, 2012.

[62] BAUER, A.; HALTOM, N. ; RUBIO-RAMIREZ, J. F.. Smoothing the shocks of a dynamic stochastic general equilibrium model. Economic Review-Federal Reserve Bank of Atlanta, 90(2):35, 2005.

[63] LEEPER, E. M.; WALKER, T. B. ; YANG, S.-C. S.. Fiscal foresight: analytics and econometrics. Technical report, National Bureau of Economic Research, 2008.

[64] BEAUDRY, P.; PORTIER, F.. Stock prices, news, and economic fluctuations. The American economic review, 96(4):1293-1307, 2006.

[65] FUJIWARA, I.; HIROSE, Y. ; SHINTANI, M.. Can news be a major source of aggregate fluctuations? a bayesian dsge approach. Journal of Money, Credit and Banking, 43(1):1-29, 2011.

[66] GUERRIERI, L.; IACOVIELLO, M.. Occbin: A toolkit for solving dynamic models with occasionally binding constraints easily. Journal of Monetary Economics, 70:22-38, 2015.

[67] GUERRIERI, L.; IACOVIELLO, M.. Collateral constraints and macroeconomic asymmetries. International Finance Discussion Papers 1082, Board of Governors of the Federal Reserve System (U.S.).

[68] BEAUDRY, P.; LUCKE, B.. Letting different views about business cycles compete. NBER Macroeconomics Annual, 24(1):413-456, 2010.

[69] GAVIN, W. T.; KEEN, B. D.; RICHTER, A. W. ; THROCKMORTON, N. A.. The limitations of forward guidance. FRB of St. Louis Working Paper No, 2013.

[70] EVANS, JEFFREY R CAMPBELL, A. J. J. F.; OTHERS. Macroeconomic effects of federal reserve forward guidance. Brookings Papers on Economic Activity: Spring 2012, p. 1, 2012. 
[71] BLANCHARD, O. J.; KAHN, C. M.. The solution of linear difference models under rational expectations. Econometrica: Journal of the Econometric Society, p. 1305-1311, 1980.

[78] CHRISTIANO, L. J.; EICHENBAUM, M. ; EVANS, C. L.. Monetary policy shocks: What have we learned and to what end? Handbook of macroeconomics, 1:65-148, 1999. 


\section{A \\ Chapter 1 - Asymptotic Bias - 3-equation New Keynesian Model}

\section{A.1}

Solving by undetermined coefficients

$$
\begin{aligned}
\tilde{y}_{t} & =\Omega\left[\sigma E_{t}\left(\tilde{y}_{t+1}\right)+\left(1-\beta \phi_{\pi}\right) E_{t}\left(\pi_{t+1}\right)+\left(\hat{r}_{t}^{n}-v_{t}\right)\right] \\
\pi_{t} & =\Omega\left[\sigma \kappa E_{t}\left(\tilde{y}_{t+1}\right)+\left(\kappa+\beta\left(\sigma+\phi_{y}\right)\right) E_{t}\left(\pi_{t+1}\right)+\kappa\left(\hat{r}_{t}^{n}-v_{t}\right)\right]
\end{aligned}
$$

$$
\begin{aligned}
v_{t} & =\rho_{v} v_{t-1}+\varepsilon_{t}^{v} \\
a_{t} & =\rho_{a} a_{t-1}+\varepsilon_{t}^{a} \\
\hat{r}_{t}^{n} & =r_{t}^{n}-\rho=-\sigma \psi_{y a}^{n}\left(1-\rho_{a}\right) a_{t} \\
E_{t}\left(\hat{r}_{t+1}^{n}\right) & =\rho_{a} \hat{r}_{t}^{n} \\
E_{t}\left(v_{t+1}\right) & =\rho_{v} v_{t}
\end{aligned}
$$

Guess:

$$
\begin{aligned}
& \tilde{y}_{t}=\psi_{y v} v_{t}+\psi_{y a} \hat{r}_{t}^{n} \\
& \pi_{t}=\psi_{\pi v} v_{t}+\psi_{\pi a} \hat{r}_{t}^{n}
\end{aligned}
$$

Replacing the first guess in the first equation and rearranging:

$$
\left.\begin{array}{rl}
\tilde{y}_{t} & =\Omega\left[\sigma E_{t}\left(\psi_{y v} v_{t+1}+\psi_{y a} \hat{r}_{t+1}^{n}\right)+\left(1-\beta \phi_{\pi}\right) E_{t}\left(\psi_{\pi v} v_{t+1}+\psi_{\pi a} \hat{r}_{t+1}^{n}\right)+\left(\hat{r}_{t}^{n}-v_{t}\right)\right] \\
& =\Omega\left\{\sigma\left[\psi_{y v} E_{t}\left(v_{t+1}\right)+\psi_{y a} E_{t}\left(\hat{r}_{t+1}^{n}\right)\right]+\left(1-\beta \phi_{\pi}\right)\left[\psi_{\pi v} E_{t}\left(v_{t+1}\right)+\psi_{\pi a} E_{t}\left(\hat{r}_{t+1}^{n}\right)\right]+\left(\hat{r}_{t}^{n}-v_{t}\right)\right\} \\
& =\Omega\left\{\sigma\left[\psi_{y v}\left(\rho_{v} v_{t}\right)+\psi_{y a}\left(\rho_{a} \hat{r}_{t}^{n}\right)\right]+\left(1-\beta \phi_{\pi}\right)\left[\psi_{\pi v}\left(\rho_{v} v_{t}\right)+\psi_{\pi a}\left(\rho_{a} \hat{r}_{t}^{n}\right)\right]+\left(\hat{r}_{t}^{n}-v_{t}\right)\right\} \\
& =\Omega\left\{\sigma\left[\psi_{y v} \rho_{v} v_{t}+\psi_{y a} \rho_{a} \hat{r}_{t}^{n}\right]+\left(1-\beta \phi_{\pi}\right)\left[\psi_{\pi v} \rho_{v} v_{t}+\psi_{\pi a} \rho_{a} \hat{r}_{t}^{n}\right]+\left(\hat{r}_{t}^{n}-v_{t}\right)\right\} \\
& =\Omega\left\{\sigma\left[\left(\psi_{y a} \rho_{a}\right) \hat{r}_{t}^{n}\right]+\Omega \sigma \psi_{y v} \rho_{v} v_{t}+\left(1-\beta \phi_{\pi}\right) \psi_{\pi a} \rho_{a} \hat{r}_{t}^{n}+\hat{r}_{t}^{n}+\left(1-\beta \phi_{\pi}\right)\left[\psi_{\pi v} \rho_{v} v_{t}\right]-v_{t}\right\} \\
& =\Omega\left[\begin{array}{c}
\sigma \psi_{y a} \rho_{a} \\
+\left(1-\beta \phi_{\pi}\right) \psi_{\pi a} \rho_{a} \\
+1
\end{array}\right] \hat{r}_{t}^{n}+\Omega\left[\begin{array}{c}
\Omega \sigma \psi_{y v} \rho_{v} \\
+\left(1-\beta \phi_{\pi}\right) \psi_{\pi v} \rho_{v} \\
-1
\end{array}\right] v_{t}
\end{array}\right]
$$




$$
\left.\begin{array}{rl}
\pi_{t}= & \Omega\left[\sigma \kappa E_{t}\left(\psi_{y v} v_{t+1}+\psi_{y a} \hat{r}_{t+1}^{n}\right)+\left(\kappa+\beta\left(\sigma+\phi_{y}\right)\right) E_{t}\left(\psi_{\pi v} v_{t+1}+\psi_{\pi a} \hat{r}_{t+1}^{n}\right)+\kappa\left(\hat{r}_{t}^{n}-v_{t}\right)\right] \\
= & \Omega\left\{\sigma \kappa\left[\psi_{y v} E_{t}\left(v_{t+1}\right)+\psi_{y a} E_{t}\left(\hat{r}_{t+1}^{n}\right)\right]+\left(\kappa+\beta\left(\sigma+\phi_{y}\right)\right)\left[\psi_{\pi v} E_{t}\left(v_{t+1}\right)+\psi_{\pi a} E_{t}\left(\hat{r}_{t+1}^{n}\right)\right]\right\} \\
& +\Omega\left\{\kappa\left(\hat{r}_{t}^{n}-v_{t}\right)\right\} \\
= & \Omega\left\{\sigma \kappa\left[\psi_{y v} \rho_{v} v_{t}+\psi_{y a} \rho_{a} \hat{r}_{t}^{n}\right]+\left(\kappa+\beta\left(\sigma+\phi_{y}\right)\right)\left[\psi_{\pi v} \rho_{v} v_{t}+\psi_{\pi a} \rho_{a} \hat{r}_{t}^{n}\right]+\kappa\left(\hat{r}_{t}^{n}-v_{t}\right)\right\} \\
= & \Omega\left[\begin{array}{c}
\sigma \kappa \psi_{y a} \rho_{a} \\
+\left[\kappa+\beta\left(\sigma+\phi_{y}\right)\right] \psi_{\pi a} \rho_{a} \\
+\kappa
\end{array}\right] \hat{r}_{t}^{n}+\Omega\left[\begin{array}{c}
\sigma \kappa \\
+\left[\kappa+\beta\left(\sigma+\phi_{y}\right)\right] \psi_{\pi v} \rho_{v} \\
-\kappa
\end{array}\right] v_{t}
\end{array}\right]
$$

Now for the coefficient matching:

$$
\begin{aligned}
& \psi_{y a}=\Omega\left[\begin{array}{c}
\sigma \psi_{y a} \rho_{a} \\
+\left(1-\beta \phi_{\pi}\right) \psi_{\pi a} \rho_{a} \\
+1
\end{array}\right] \\
& \psi_{y v}=\Omega\left[\begin{array}{c}
\sigma \psi_{y v} \rho_{v} \\
+\left(1-\beta \phi_{\pi}\right) \psi_{\pi v} \rho_{v} \\
-1
\end{array}\right] \\
& \psi_{\pi a}=\Omega\left[\begin{array}{c}
\sigma \kappa \psi_{y a} \rho_{a} \\
+\left[\kappa+\beta\left(\sigma+\phi_{y}\right)\right] \psi_{\pi a} \rho_{a} \\
+\kappa \\
\sigma \kappa \psi_{y v} \rho_{v}
\end{array}\right] \\
& \psi_{\pi v}=\Omega\left[\begin{array}{c}
+\left[\kappa+\beta\left(\sigma+\phi_{y}\right)\right] \psi_{\pi v} \rho_{v} \\
-\kappa
\end{array}\right]
\end{aligned}
$$

If the interest rate policy does not respond to $\tilde{y}, \phi_{y}=0$ and we have two systems of two equations and a new definition for $\Omega$ :

$$
\begin{aligned}
\Omega & =\frac{1}{\sigma+\phi_{y}+\kappa \phi_{\pi}} \rightarrow \frac{1}{\sigma+\kappa \phi_{\pi}} \\
\psi_{y a} & =\Omega\left[\sigma \psi_{y a} \rho_{a}+\left(1-\beta \phi_{\pi}\right) \psi_{\pi a} \rho_{a}+1\right] \\
\psi_{\pi a} & =\Omega\left[\sigma \kappa \psi_{y a} \rho_{a}+[\kappa+\beta \sigma] \psi_{\pi a} \rho_{a}+\kappa\right] \\
\psi_{y v} & =\Omega\left[\sigma \psi_{y v} \rho_{v}+\left(1-\beta \phi_{\pi}\right) \psi_{\pi v} \rho_{v}-1\right] \\
\psi_{\pi v} & =\Omega\left[\sigma \kappa \psi_{y v} \rho_{v}+[\kappa+\beta \sigma] \psi_{\pi v} \rho_{v}-\kappa\right]
\end{aligned}
$$




\section{A.1.0.1}

Testing solutions for the technology shock:

$$
\begin{gathered}
\psi_{y a}=\Omega\left[\sigma \psi_{y a} \rho_{a}+\left(1-\beta \phi_{\pi}\right) \psi_{\pi a} \rho_{a}+1\right] \\
\psi_{\pi a}=\Omega\left[\sigma \kappa \psi_{y a} \rho_{a}+[\kappa+\beta \sigma] \psi_{\pi a} \rho_{a}+\kappa\right] \\
\Omega=\frac{1}{\sigma+\kappa \phi_{\pi}}
\end{gathered}
$$

From the book:

$$
\begin{aligned}
\psi_{y a} & =\frac{\left(1-\beta \rho_{a}\right)}{\left(1-\beta \rho_{a}\right)\left[\sigma\left(1-\rho_{a}\right)\right]+\kappa\left(\phi_{\pi}-\rho_{a}\right)} \\
\psi_{\pi a} & =\frac{\kappa}{\left(1-\beta \rho_{a}\right)\left[\sigma\left(1-\rho_{a}\right)\right]+\kappa\left(\phi_{\pi}-\rho_{a}\right)}
\end{aligned}
$$

Guess that:

$$
\psi_{y a}=\frac{\left(1-\beta \rho_{a}\right)}{\kappa} \psi_{\pi a}
$$

Departing from:

$$
\psi_{\pi a}=\Omega\left[\sigma \kappa \frac{\left(1-\beta \rho_{a}\right)}{\kappa} \psi_{\pi a} \rho_{a}+[\kappa+\beta \sigma] \psi_{\pi a} \rho_{a}+\kappa\right]
$$

$$
\begin{aligned}
\left\{1-\Omega \sigma\left(1-\beta \rho_{a}\right) \rho_{a}-\Omega(\kappa+\beta \sigma) \rho_{a}\right\} \psi_{\pi a} & =\Omega \kappa \\
\left\{1-\Omega \sigma \rho_{a}+\Omega \sigma \beta \rho_{a}^{2}-\Omega \rho_{a} \kappa-\Omega \rho_{a} \beta \sigma\right\} \psi_{\pi a} & =\Omega \kappa
\end{aligned}
$$

$$
\begin{aligned}
\left\{1-\frac{1}{\sigma+\kappa \phi_{\pi}} \sigma \rho_{a}+\frac{1}{\sigma+\kappa \phi_{\pi}} \sigma \beta \rho_{a}^{2}-\frac{1}{\sigma+\kappa \phi_{\pi}} \kappa \rho_{a}-\frac{1}{\sigma+\kappa \phi_{\pi}} \sigma \rho_{a} \beta\right\} \psi_{\pi a}=\frac{1}{\sigma+\kappa \phi_{\pi}} \kappa \\
\left\{\sigma+\kappa \phi_{\pi}-\sigma \rho_{a}+\sigma \beta \rho_{a}^{2}-\kappa \rho_{a}-\sigma \rho_{a} \beta\right\} \psi_{\pi a}=\kappa \\
\left\{+\kappa \phi_{\pi}-\kappa \rho_{a}+\sigma-\sigma \rho_{a}+\sigma \beta \rho_{a}^{2}-\sigma \rho_{a} \beta\right\} \psi_{\pi a}=\kappa \\
\left\{\kappa\left(\phi_{\pi}-\rho_{a}\right)+\sigma-\sigma \rho_{a}+\sigma \beta \rho_{a}^{2}-\sigma \rho_{a} \beta\right\} \psi_{\pi a}=\kappa \\
\left\{\kappa\left(\phi_{\pi}-\rho_{a}\right)+\sigma\left(1-\rho_{a}\right)+\sigma \beta\left(\rho_{a}^{2}-\rho_{a}\right)\right\} \psi_{\pi a}=\kappa \\
\left\{\kappa\left(\phi_{\pi}-\rho_{a}\right)+\sigma\left(1-\rho_{a}\right)-\sigma \beta \rho_{a}\left(1-\rho_{a}\right)\right\} \psi_{\pi a}=\kappa \\
\left\{\kappa\left(\phi_{\pi}-\rho_{a}\right)+\left(1-\beta \rho_{a}\right) \sigma\left(1-\rho_{a}\right)\right\} \psi_{\pi a}=\kappa
\end{aligned}
$$

$$
\psi_{\pi a}=\frac{\kappa}{\left(1-\beta \rho_{a}\right)\left[\sigma\left(1-\rho_{a}\right)\right]+\kappa\left(\phi_{\pi}-\rho_{a}\right)}
$$




\section{Appendix A. Chapter 1 - Asymptotic Bias - 3-equation New Keynesian Modal0}

Now departing from:

$$
\begin{aligned}
& \psi_{y a}=\Omega\left[\sigma \psi_{y a} \rho_{a}+\left(1-\beta \phi_{\pi}\right) \psi_{\pi a} \rho_{a}+1\right] \\
& \psi_{y a}=\Omega\left[\sigma \psi_{y a} \rho_{a}+\left(1-\beta \phi_{\pi}\right) \frac{\kappa}{\left(1-\beta \rho_{a}\right) \sigma\left(1-\rho_{a}\right)+\kappa\left(\phi_{\pi}-\rho_{a}\right)} \rho_{a}+1\right] \\
& \psi_{y a}=\frac{1}{\sigma+\kappa \phi_{\pi}}\left[\sigma \psi_{y a} \rho_{a}+\left(1-\beta \phi_{\pi}\right) \frac{\kappa}{\left(1-\beta \rho_{a}\right) \sigma\left(1-\rho_{a}\right)+\kappa\left(\phi_{\pi}-\rho_{a}\right)} \rho_{a}+1\right] \\
& \psi_{y a}=\frac{\sigma \rho_{a}}{\sigma+\kappa \phi_{\pi}} \psi_{y a}+\frac{1}{\sigma+\kappa \phi_{\pi}}\left(1-\beta \phi_{\pi}\right) \frac{\kappa}{\left(1-\beta \rho_{a}\right) \sigma\left(1-\rho_{a}\right)+\kappa\left(\phi_{\pi}-\rho_{a}\right)} \rho_{a} \\
& +\frac{1}{\sigma+\kappa \phi_{\pi}} \\
& \left(1-\frac{\sigma \rho_{a}}{\sigma+\kappa \phi_{\pi}}\right) \psi_{y a}=\frac{1}{\sigma+\kappa \phi_{\pi}}\left(1-\beta \phi_{\pi}\right) \frac{\kappa}{\left(1-\beta \rho_{a}\right) \sigma\left(1-\rho_{a}\right)+\kappa\left(\phi_{\pi}-\rho_{a}\right)} \rho_{a}+ \\
& \frac{1}{\sigma+\kappa \phi_{\pi}} \\
& \left(\sigma+\kappa \phi_{\pi}-\sigma \rho_{a}\right) \psi_{y a}=\left(1-\beta \phi_{\pi}\right) \frac{\kappa}{\left(1-\beta \rho_{a}\right) \sigma\left(1-\rho_{a}\right)+\kappa\left(\phi_{\pi}-\rho_{a}\right)} \rho_{a}+1 \\
& \left(\sigma\left(1-\rho_{a}\right)+\kappa \phi_{\pi}\right) \psi_{y a}=\frac{\left(1-\beta \phi_{\pi}\right) \kappa \rho_{a}+\left[\kappa \phi_{\pi}-\kappa \rho_{a}+\sigma-\sigma \rho_{a}+\sigma \beta \rho_{a}^{2}-\sigma \rho_{a} \beta\right]}{\left(1-\beta \rho_{a}\right) \sigma\left(1-\rho_{a}\right)+\kappa\left(\phi_{\pi}-\rho_{a}\right)} \\
& \left(\sigma\left(1-\rho_{a}\right)+\kappa \phi_{\pi}\right) \psi_{y a}=\frac{\kappa \rho_{a}-\beta \phi_{\pi} \kappa \rho_{a}+\kappa \phi_{\pi}-\kappa \rho_{a}+\sigma-\sigma \rho_{a}+\sigma \beta \rho_{a}^{2}-\sigma \rho_{a} \beta}{\left(1-\beta \rho_{a}\right) \sigma\left(1-\rho_{a}\right)+\kappa\left(\phi_{\pi}-\rho_{a}\right)} \\
& \left(\sigma\left(1-\rho_{a}\right)+\kappa \phi_{\pi}\right) \psi_{y a}=\frac{-\beta \phi_{\pi} \kappa \rho_{a}+\kappa \phi_{\pi}+\sigma-\sigma \rho_{a}+\sigma \beta \rho_{a}^{2}-\sigma \rho_{a} \beta}{\left(1-\beta \rho_{a}\right) \sigma\left(1-\rho_{a}\right)+\kappa\left(\phi_{\pi}-\rho_{a}\right)} \\
& \left(\sigma\left(1-\rho_{a}\right)+\kappa \phi_{\pi}\right) \psi_{y a}=\frac{\sigma\left(1-\rho_{a}\right)+\kappa \phi_{\pi}-\beta \rho_{a} \phi_{\pi} \kappa-\beta \rho_{a} \sigma\left(1-\rho_{a}\right)}{\left(1-\beta \rho_{a}\right) \sigma\left(1-\rho_{a}\right)+\kappa\left(\phi_{\pi}-\rho_{a}\right)} \\
& \left(\sigma\left(1-\rho_{a}\right)+\kappa \phi_{\pi}\right) \psi_{y a}=\frac{\left[\sigma\left(1-\rho_{a}\right)+\kappa \phi_{\pi}\right]-\beta \rho_{a}\left[\kappa \phi_{\pi}+\sigma\left(1-\rho_{a}\right)\right]}{\left(1-\beta \rho_{a}\right) \sigma\left(1-\rho_{a}\right)+\kappa\left(\phi_{\pi}-\rho_{a}\right)} \\
& \left(\sigma\left(1-\rho_{a}\right)+\kappa \phi_{\pi}\right) \psi_{y a}=\frac{\left[\sigma\left(1-\rho_{a}\right)+\kappa \phi_{\pi}\right]\left(1-\beta \rho_{a}\right)}{\left(1-\beta \rho_{a}\right) \sigma\left(1-\rho_{a}\right)+\kappa\left(\phi_{\pi}-\rho_{a}\right)} \\
& \psi_{y a}=\frac{\left(1-\beta \rho_{a}\right)}{\left(1-\beta \rho_{a}\right)\left[\sigma\left(1-\rho_{a}\right)\right]+\kappa\left(\phi_{\pi}-\rho_{a}\right)}
\end{aligned}
$$

And the solutions are:

$$
\begin{aligned}
\psi_{\pi a} & =\frac{\kappa}{\left(1-\beta \rho_{a}\right)\left[\sigma\left(1-\rho_{a}\right)\right]+\kappa\left(\phi_{\pi}-\rho_{a}\right)} \\
\psi_{y a} & =\frac{\left(1-\beta \rho_{a}\right)}{\left(1-\beta \rho_{a}\right)\left[\sigma\left(1-\rho_{a}\right)\right]+\kappa\left(\phi_{\pi}-\rho_{a}\right)}
\end{aligned}
$$

It's easy to verify that:

$$
\psi_{y a}=\frac{\left(1-\beta \rho_{a}\right)}{\kappa} \psi_{\pi a}
$$




\section{A.1.0.2}

Testing solution for the monetary shock:

$$
\begin{aligned}
& \psi_{y v}=\Omega\left[\sigma \psi_{y v} \rho_{v}+\left(1-\beta \phi_{\pi}\right) \psi_{\pi v} \rho_{v}-1\right] \\
& \psi_{\pi v}=\Omega\left[\sigma \kappa \psi_{y v} \rho_{v}+[\kappa+\beta \sigma] \psi_{\pi v} \rho_{v}-\kappa\right]
\end{aligned}
$$

Guess that $\psi_{y v}=\frac{\left(1-\beta \rho_{v}\right)}{\kappa} \psi_{\pi v}$, and replace at the second equation:

$$
\begin{aligned}
\psi_{\pi v} & =\Omega\left[\sigma \kappa\left(\frac{\left(1-\beta \rho_{v}\right)}{\kappa} \psi_{\pi v}\right) \rho_{v}+[\kappa+\beta \sigma] \psi_{\pi v} \rho_{v}-\kappa\right] \\
\psi_{\pi v} & =\Omega\left[\sigma\left(\left(1-\beta \rho_{v}\right) \psi_{\pi v}\right) \rho_{v}+[\kappa+\beta \sigma] \psi_{\pi v} \rho_{v}-\kappa\right] \\
\psi_{\pi v} & =\Omega \sigma\left(1-\beta \rho_{v}\right) \psi_{\pi v} \rho_{v}+\Omega[\kappa+\beta \sigma] \psi_{\pi v} \rho_{v}-\kappa \Omega
\end{aligned}
$$

$$
\begin{aligned}
\left\{1-\Omega \sigma\left(1-\beta \rho_{v}\right) \rho_{v}-\Omega(\kappa+\beta \sigma) \rho_{v}\right\} \psi_{\pi v} & =-\kappa \Omega \\
\left\{1-\frac{1}{\sigma+\kappa \phi_{\pi}} \sigma\left(1-\beta \rho_{v}\right) \rho_{v}-\frac{1}{\sigma+\kappa \phi_{\pi}}(\kappa+\beta \sigma) \rho_{v}\right\} \psi_{\pi v} & =-\frac{1}{\sigma+\kappa \phi_{\pi}} \kappa \\
\left\{\sigma+\kappa \phi_{\pi}-\sigma\left(1-\beta \rho_{v}\right) \rho_{v}-(\kappa+\beta \sigma) \rho_{v}\right\} \psi_{\pi v} & =-\kappa \\
\left\{\sigma-\sigma \rho_{v}+\beta \sigma \rho_{v}^{2}-\beta \sigma \rho_{v}+\kappa \phi_{\pi}-\kappa \rho_{v}\right\} \psi_{\pi v} & =-\kappa \\
\left\{\sigma\left(1-\rho_{v}\right)-\beta \sigma \rho_{v}\left(1-\rho_{v}\right)+\kappa\left(\phi_{\pi}-\rho_{v}\right)\right\} \psi_{\pi v} & =-\kappa \\
\left\{\left(1-\beta \sigma \rho_{v}\right) \sigma\left(1-\rho_{v}\right)+\kappa\left(\phi_{\pi}-\rho_{v}\right)\right\} \psi_{\pi v} & =-\kappa \\
\psi_{\pi v}=\frac{-\kappa}{\left(1-\beta \sigma \rho_{v}\right) \sigma\left(1-\rho_{v}\right)+\kappa\left(\phi_{\pi}-\rho_{v}\right)} &
\end{aligned}
$$

And since the two systems above are symmetric, the solution implies:

$$
\begin{aligned}
& \psi_{\pi v}=\frac{-\kappa}{\left(1-\beta \sigma \rho_{v}\right) \sigma\left(1-\rho_{v}\right)+\kappa\left(\phi_{\pi}-\rho_{v}\right)} \\
& \psi_{y v}=\frac{-\left(1-\beta \rho_{v}\right)}{\left(1-\beta \sigma \rho_{v}\right) \sigma\left(1-\rho_{v}\right)+\kappa\left(\phi_{\pi}-\rho_{v}\right)}
\end{aligned}
$$

\section{A.1.1}

With monetary shocks only:

$$
\begin{gathered}
i_{t}=\rho+\phi_{\pi} \pi_{t}+v_{t} \\
\pi_{t}=-\kappa \Lambda_{v} v_{t}
\end{gathered}
$$


Appendix A. Chapter 1 - Asymptotic Bias - 3-equation New Keynesian Modd/2

$$
i_{t}=\rho+\phi_{\pi}\left(-\kappa \Lambda_{v} v_{t}\right)+v_{t}
$$

$$
\begin{aligned}
\operatorname{plim} \hat{\phi}_{\pi}^{O L S} & =\frac{\operatorname{cov}(i, \pi)}{\operatorname{var}(\pi)} \\
& =\frac{\operatorname{cov}\left(\rho+\phi_{\pi}\left(-\kappa \Lambda_{v} v_{t}\right)+v_{t},-\kappa \Lambda_{v} v_{t}\right)}{\operatorname{var}\left(-\kappa \Lambda_{v} v_{t}\right)} \\
& =\frac{\operatorname{cov}\left(-\phi_{\pi} \kappa \Lambda_{v} v_{t},-\kappa \Lambda_{v} v_{t}\right)+\operatorname{cov}\left(v_{t},-\kappa \Lambda_{v} v_{t}\right)}{\operatorname{var}\left(-\kappa \Lambda_{v} v_{t}\right)} \\
& =\frac{\phi_{\pi}\left(\kappa \Lambda_{v}\right)^{2} \operatorname{var}\left(v_{t}\right)-\kappa \Lambda_{v} \operatorname{var}\left(v_{t}\right)}{\left(\kappa \Lambda_{v}\right)^{2} \operatorname{var}\left(v_{t}\right)} \\
& =\phi_{\pi}-\frac{1}{\kappa \Lambda_{v}}
\end{aligned}
$$

where:

$$
\begin{aligned}
\Lambda_{v} & =\frac{1}{\left(1-\beta \rho_{v}\right) \sigma\left(1-\rho_{v}\right)+\kappa\left(\phi_{\pi}-\rho_{v}\right)} \\
\kappa & =\lambda\left(\sigma+\frac{\varphi+\alpha}{1-\alpha}\right)
\end{aligned}
$$

If $\rho_{v}=0$,

$$
\begin{aligned}
\Lambda_{v} & =\frac{1}{\sigma+\kappa \phi_{\pi}} \\
\kappa & =\lambda\left(\sigma+\frac{\varphi+\alpha}{1-\alpha}\right)
\end{aligned}
$$

A.1.1.1

Solving:

$$
\begin{aligned}
{\left[\left(1-\beta \rho_{v}\right) \psi_{\pi v}-\kappa \psi_{y v}\right] v_{t} } & =-\left[\left(1-\beta \rho_{a}\right) \psi_{\pi a}-\kappa \psi_{y a}\right] a_{t} \\
{\left[\psi_{y v}\left(1+\rho_{v}+\frac{\phi_{y}}{\sigma}\right)+\frac{1+\left(\phi_{\pi}-\rho_{v}\right) \psi_{\pi v}}{\sigma}\right] v_{t}=} & -\left[\psi_{y a}\left(1+\rho_{a}+\frac{\phi_{y}}{\sigma}\right)\right] \\
& -\left[\frac{\sigma \psi_{y a}^{n}\left(1-\rho_{a}\right)+\left(\phi_{\pi}-\rho_{a}\right) \psi_{\pi a}}{\sigma}\right] a_{t}
\end{aligned}
$$




$$
\begin{aligned}
{\left[\left(1-\beta \rho_{v}\right) \psi_{\pi v}-\kappa \psi_{y v}\right] } & =\left[\psi_{y v}\left(1+\rho_{v}+\frac{\phi_{y}}{\sigma}\right)+\frac{1+\left(\phi_{\pi}-\rho_{v}\right) \psi_{\pi v}}{\sigma}\right] \\
\left(1-\beta \rho_{v}-\frac{\left(\phi_{\pi}-\rho_{v}\right)}{\sigma}\right) \psi_{\pi v} & =\psi_{y v}\left(1+\rho_{v}+\frac{\phi_{y}}{\sigma}+\kappa\right)+\frac{1}{\sigma} \\
\frac{\left(1-\beta \rho_{v}-\frac{\left(\phi_{\pi}-\rho_{v}\right)}{\sigma}\right)}{\left(1+\rho_{v}+\frac{\phi_{y}}{\sigma}+\kappa\right)} \psi_{\pi v} & =\psi_{y v}+\frac{1}{\sigma\left(1+\rho_{v}+\frac{\phi_{y}}{\sigma}+\kappa\right)} \\
{\left[\left(1-\beta \rho_{a}\right) \psi_{\pi a}-\kappa \psi_{y a}\right] } & =\left[\psi_{y a}\left(1+\rho_{a}+\frac{\phi_{y}}{\sigma}\right)+\frac{\sigma \psi_{y a}^{n}\left(1-\rho_{a}\right)+\left(\phi_{\pi}-\rho_{a}\right) \psi_{\pi a}}{\sigma}\right] \\
\left(1-\beta \rho_{a}-\frac{\left(\phi_{\pi}-\rho_{a}\right)}{\sigma}\right) \psi_{\pi a} & =\left(1+\rho_{a}+\frac{\phi_{y}}{\sigma}+\kappa\right) \psi_{y a}+\frac{\sigma \psi_{y a}^{n}\left(1-\rho_{a}\right)}{\sigma} \\
\frac{\left(1-\beta \rho_{a}-\frac{\left(\phi_{\pi}-\rho_{a}\right)}{\sigma}\right)}{\left(1+\rho_{a}+\frac{\phi_{y}}{\sigma}+\kappa\right)} \psi_{\pi a} & =\psi_{y a}+\frac{\sigma \psi_{y a}^{n}\left(1-\rho_{a}\right)}{\sigma} \\
\left(1+\rho_{a}+\frac{\phi_{y}}{\sigma}+\kappa\right) &
\end{aligned}
$$

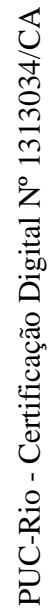

$$
\begin{aligned}
& \psi_{\pi v}=A_{v} \psi_{y v}, \quad A_{v}=\frac{\kappa}{1-\beta \rho_{v}} \\
& \psi_{\pi a}=A_{a} \psi_{y a}, \quad A_{a}=\frac{\kappa}{1-\beta \rho_{a}}
\end{aligned}
$$$$
\left[\frac{\left(1-\beta \rho_{a}-\frac{\left(\phi_{\pi}-\rho_{a}\right)}{\sigma}\right)}{\left(1+\rho_{a}+\frac{\phi_{y}}{\sigma}+\kappa\right)} A_{a}-1\right] \psi_{y a}=\frac{\frac{\sigma \psi_{y a}^{n}\left(1-\rho_{a}\right)}{\sigma}}{\left(1+\rho_{a}+\frac{\phi_{y}}{\sigma}+\kappa\right)}
$$$$
\left[\frac{\left(1-\beta \rho_{v}-\frac{\left(\phi_{\pi}-\rho_{v}\right)}{\sigma}\right)}{\left(1+\rho_{v}+\frac{\phi_{y}}{\sigma}+\kappa\right)} A_{v}-1\right] \psi_{y v}=\frac{1}{\sigma\left(1+\rho_{v}+\frac{\phi_{y}}{\sigma}+\kappa\right)}
$$

$$
\begin{aligned}
& {\left[\frac{\left(1-\beta \rho_{a}-\frac{\left(\phi_{\pi}-\rho_{a}\right)}{\sigma}\right)}{\left(1+\rho_{a}+\frac{\phi_{y}}{\sigma}+\kappa\right)} A_{a}-1\right] \psi_{y a} }=\frac{\frac{\sigma \psi_{y a}^{n}\left(1-\rho_{a}\right)}{\sigma}}{\left(1+\rho_{a}+\frac{\phi_{y}}{\sigma}+\kappa\right)} \\
& \psi_{y a}=\frac{\frac{\sigma \psi_{y a}^{n}\left(1-\rho_{a}\right)}{\sigma}}{\left[\frac{\left(1+\rho_{a}+\frac{\phi_{y}}{\sigma}+\kappa\right)}{\sigma}\right.} \\
& {\left[\frac{\left(1-\beta \rho_{a}-\frac{\left(\phi_{\pi}-\rho_{a}\right)}{\sigma}\right)}{\left(1+\rho_{a}+\frac{\phi_{y}}{\sigma}+\kappa\right)} \frac{\kappa}{1-\beta \rho_{a}}-1\right] }
\end{aligned}
$$




$$
\begin{aligned}
\psi_{y a} & =\frac{\frac{\frac{\sigma \psi_{y a}^{n}\left(1-\rho_{a}\right)}{\sigma}}{\left(1+\rho_{a}+\frac{\phi_{y}}{\sigma}+\kappa\right)}}{\left[\frac{\left(1-\beta \rho_{a}-\frac{\left(\phi_{\pi}-\rho_{a}\right)}{\sigma}\right)}{\left(1+\rho_{a}+\frac{\phi_{y}}{\sigma}+\kappa\right)} \frac{\kappa}{1-\beta \rho_{a}}-1\right]}=\frac{\frac{\frac{\sigma \psi_{y a}^{n}\left(1-\rho_{a}\right)}{\sigma}}{\left(1+\rho_{a}+\frac{\phi_{y}}{\sigma}+\kappa\right)}}{\left[\frac{\kappa\left(1-\beta \rho_{a}-\frac{\left(\phi_{\pi}-\rho_{a}\right)}{\sigma}\right)-\left(1+\rho_{a}+\frac{\phi_{y}}{\sigma}+\kappa\right)\left(1-\beta \rho_{a}\right)}{\left(1+\rho_{a}+\frac{\phi_{y}}{\sigma}+\kappa\right)\left(1-\beta \rho_{a}\right)}\right]} \\
& =\frac{\left(1-\beta \rho_{a}\right) \frac{\sigma \psi_{y a}^{n}\left(1-\rho_{a}\right)}{\sigma}}{\left[\kappa\left(1-\beta \rho_{a}-\frac{\left(\phi_{\pi}-\rho_{a}\right)}{\sigma}\right)-\left(1+\rho_{a}+\frac{\phi_{y}}{\sigma}+\kappa\right)\left(1-\beta \rho_{a}\right)\right]} \\
& =\frac{\sigma \psi_{y a}^{n}\left(1-\rho_{a}\right)\left(1-\beta \rho_{a}\right)}{\left[\kappa\left(\sigma-\beta \sigma \rho_{a}-\left(\phi_{\pi}-\rho_{a}\right)\right)-\left(\sigma+\sigma \rho_{a}+\phi_{y}+\sigma \kappa\right)\left(1-\beta \rho_{a}\right)\right]} \\
& \frac{\sigma \psi_{y a}^{n}\left(1-\rho_{a}\right)\left(1-\beta \rho_{a}\right)}{\left[\kappa\left(\sigma-\beta \sigma \rho_{a}-\left(\phi_{\pi}-\rho_{a}\right)\right)-\left(\sigma+\sigma \rho_{a}+\phi_{y}+\sigma \kappa\right)\left(1-\beta \rho_{a}\right)\right]}
\end{aligned}
$$

Rewriting the denominator:

$$
\begin{aligned}
& {\left[\kappa\left(\sigma\left(1-\beta \rho_{a}\right)-\left(\phi_{\pi}-\rho_{a}\right)\right)-\left(\sigma\left(1+\rho_{a}\right)+\phi_{y}+\sigma \kappa\right)\left(1-\beta \rho_{a}\right)\right] } \\
= & \left(1-\beta \rho_{a}\right)\left[-\left(\sigma\left(1+\rho_{a}\right)+\phi_{y}+\sigma \kappa\right)+\kappa \sigma\right]-\kappa\left(\phi_{\pi}-\rho_{a}\right) \\
= & \left(1-\beta \rho_{a}\right)\left[-\sigma\left(1+\rho_{a}\right)-\phi_{y}-\sigma \kappa+\kappa \sigma\right]-\kappa\left(\phi_{\pi}-\rho_{a}\right) \\
= & \left(1-\beta \rho_{a}\right)\left[-\sigma\left(1+\rho_{a}\right)-\phi_{y}\right]-\kappa\left(\phi_{\pi}-\rho_{a}\right)
\end{aligned}
$$

And this implies:

$$
\psi_{y a}=\frac{-\sigma \psi_{y a}^{n}\left(1-\rho_{a}\right)\left(1-\beta \rho_{a}\right)}{\left(1-\beta \rho_{a}\right)\left[\sigma\left(1+\rho_{a}\right)+\phi_{y}\right]+\kappa\left(\phi_{\pi}-\rho_{a}\right)}
$$

\section{A.1.2}

With only productivity shocks:

$$
\begin{aligned}
a_{t} & =\rho_{a} a_{t-1}+\varepsilon_{t}^{a} \\
\pi_{t} & =-\sigma \psi_{y a}^{n}\left(1-\rho_{a}\right) \kappa \Lambda_{a} a_{t}
\end{aligned}
$$




$$
\begin{aligned}
\operatorname{plim} \hat{\phi}_{\pi}^{O L S} & =\frac{\operatorname{cov}(i, \pi)}{\operatorname{var}(\pi)} \\
& =\frac{\operatorname{cov}\left(\rho+\phi_{\pi}\left(-\sigma \psi_{y a}^{n}\left(1-\rho_{a}\right) \kappa \Lambda_{a} a_{t}\right),-\sigma \psi_{y a}^{n}\left(1-\rho_{a}\right) \kappa \Lambda_{a} a_{t}\right)}{\operatorname{var}\left(-\sigma \psi_{y a}^{n}\left(1-\rho_{a}\right) \kappa \Lambda_{a} a_{t}\right)} \\
& =\frac{\operatorname{cov}\left(\phi_{\pi}\left(-\sigma \psi_{y a}^{n}\left(1-\rho_{a}\right) \kappa \Lambda_{a} a_{t}\right),-\sigma \psi_{y a}^{n}\left(1-\rho_{a}\right) \kappa \Lambda_{a} a_{t}\right)}{\operatorname{var}\left(-\sigma \psi_{y a}^{n}\left(1-\rho_{a}\right) \kappa \Lambda_{a} a_{t}\right)} \\
& =\phi_{\pi} \frac{\operatorname{var}\left(-\sigma \psi_{y a}^{n}\left(1-\rho_{a}\right) \kappa \Lambda_{a} a_{t}\right)}{\operatorname{var}\left(-\sigma \psi_{y a}^{n}\left(1-\rho_{a}\right) \kappa \Lambda_{a} a_{t}\right)}=\phi_{\pi}
\end{aligned}
$$

\section{A.1.3}

\section{With both shocks - variance decomposition:}

$$
\begin{gathered}
i_{t}=\rho+\phi_{\pi} \pi_{t}+v_{t} \\
\pi_{t}=-\kappa \Lambda_{v} v_{t}-\sigma \psi_{y a}^{n}\left(1-\rho_{a}\right) \kappa \Lambda_{a} a_{t}
\end{gathered}
$$

$$
\begin{aligned}
\operatorname{plim} \hat{\phi}_{\pi}^{O L S}= & \frac{\operatorname{cov}(i, \pi)}{\operatorname{var}(\pi)} \\
= & \frac{\operatorname{cov}\left(\rho+\phi_{\pi}\left(-\kappa \Lambda_{v} v_{t}-\sigma \psi_{y a}^{n}\left(1-\rho_{a}\right) \kappa \Lambda_{a} a_{t}\right)+v_{t},-\kappa \Lambda_{v} v_{t}-\sigma \psi_{y a}^{n}\left(1-\rho_{a}\right) \kappa \Lambda_{a} a_{t}\right)}{\operatorname{var}\left(-\kappa \Lambda_{v} v_{t}-\sigma \psi_{y a}^{n}\left(1-\rho_{a}\right) \kappa \Lambda_{a} a_{t}\right)} \\
= & \frac{\operatorname{cov}\left(\phi_{\pi}\left(-\kappa \Lambda_{v} v_{t}-\sigma \psi_{y a}^{n}\left(1-\rho_{a}\right) \kappa \Lambda_{a} a_{t}\right),-\kappa \Lambda_{v} v_{t}-\sigma \psi_{y a}^{n}\left(1-\rho_{a}\right) \kappa \Lambda_{a} a_{t}\right)}{\operatorname{cov}\left(v_{t},-\kappa \Lambda_{v} v_{t}-\sigma \psi_{y a}^{n}\left(1-\rho_{a}\right) \kappa \Lambda_{a} a_{t}\right)} \\
= & \frac{\phi_{\pi} \operatorname{var}\left(-\kappa \Lambda_{v} v_{t}-\sigma \psi_{y a}^{n}\left(1-\rho_{a}\right) \kappa \Lambda_{a} a_{t}\right)}{\operatorname{var}\left(-\kappa \Lambda_{v} v_{t}-\sigma \psi_{y a}^{n}\left(1-\sigma \psi_{y a}^{n}\left(1-\rho_{a}\right) \kappa \Lambda_{a} a_{t}\right)-\kappa \Lambda_{v} \operatorname{var}\left(v_{t}\right)\right.} \\
= & \phi_{\pi}-\frac{\left.\kappa \Lambda_{v}\right)}{\operatorname{var}\left(-\kappa \Lambda_{v} v_{t}-\sigma \psi_{y a}^{n}\left(1-\rho_{a}\right) \kappa \Lambda_{a} a_{t}\right)} \\
= & \phi_{\pi}-\frac{1}{\kappa \Lambda_{v}} \frac{\left(\kappa \Lambda_{v}\right)^{2} \operatorname{var}\left(v_{t}\right)}{\left(\kappa \Lambda_{v}\right)^{2} \operatorname{var}\left(v_{t}\right)+\left(\sigma \psi_{y a}^{n}\left(1-\rho_{a}\right) \kappa \Lambda_{a}\right)^{2} \operatorname{var}\left(a_{t}\right)} \\
= & \phi_{\pi}-\frac{1}{\kappa \Lambda_{v}} \lambda_{v}, \quad
\end{aligned}
$$

where $\lambda_{v} \equiv \frac{\left(\kappa \Lambda_{v}\right)^{2} \operatorname{var}\left(v_{t}\right)}{\left(\kappa \Lambda_{v}\right)^{2} \operatorname{var}\left(v_{t}\right)+\left(\sigma \psi_{y a}^{n}\left(1-\rho_{a}\right) \kappa \Lambda_{a}\right)^{2} \operatorname{var}\left(a_{t}\right)}$ is the fraction of the variance of $\pi_{t}$ that is accounted for by monetary policy shocks. 


\section{B \\ Chapter 2 - The Model}

\section{B.1}

\section{Solving the model}

We follow (50) to define the utility kernel $U$ :

$$
U\left(c_{t}, l_{t}\right)=\frac{c_{t}^{\delta(1-\gamma)} c_{t-1}^{(1-\delta)(1-\gamma)}}{1-\gamma}+\chi_{0} \frac{\left(1-l_{t}\right)^{1-\chi}}{1-\chi} .
$$

where $\left.U_{1, t}^{\prime}=\delta c_{t}^{\delta(1-\gamma)-1} c_{t-1}^{(} 1-\delta\right)(1-\gamma), U_{11, t}^{\prime \prime}=\delta^{2}(1-\gamma) c_{t}^{\delta(1-\gamma)-2}$, $U_{2, t}^{\prime}=-\chi_{0}\left(1-l_{t}\right)^{-\chi}$, and $U_{22, t}^{\prime \prime}=-\chi_{0} \chi\left(1-l_{t}\right)^{-\chi-1}$. Therefore we have the following elasticity of intertemporal substitution (EIS) and Frisch elasticity $(\mathrm{FE})$

$$
\begin{gathered}
E I S=\frac{d \ln \left(\frac{U_{1, t+1}^{\prime}}{U_{1, t}^{\prime}}\right)}{d \ln \left(\frac{c_{t+1}}{c_{t}}\right)}=\frac{1}{1-\delta(1-\gamma)} \\
F E=\frac{U_{1, t}^{\prime}}{l_{s s}\left(U_{22, s s}^{\prime \prime}-\frac{U_{12, s s}^{\prime \prime}}{U_{11, s s}^{\prime \prime}}\right)}=\frac{1-l_{s} s}{l_{s s} \chi} .
\end{gathered}
$$

\section{B.1.1}

\section{Household}

There is an unit continuum of representative households, living forever in discrete time. The household solves the problem

$$
\begin{array}{ll}
\max _{\left\{c_{t}, a_{t+1}\right\}} & V_{t}=U\left(c_{t}, \bar{c}_{t-1}, l_{t},\right)-\beta E_{t}\left(-V_{t+1}^{1-\alpha_{t}}\right)^{\frac{1}{1-\alpha_{t}}} \\
\text { s.t. } & q_{t} a_{t+1}=a_{t}+w_{t} l_{t}+d_{t}-P_{t} c_{t}
\end{array}
$$

where $\alpha_{t}=\left(1-\rho_{\alpha}\right) \bar{\alpha}+\rho_{\alpha} \alpha_{t-1}+\varepsilon_{t}^{\alpha}$. The Lagrangean can be state as

$$
\begin{aligned}
L \equiv & V_{0}-\sum_{t=0}^{\infty} \psi_{t}\left[V_{t}-U\left(c_{t}, \bar{c}_{t-1}, l_{t},\right)-\beta\left(E_{t}\left(V_{t+1}^{1-\alpha_{t}}\right)^{\frac{1}{1-\alpha_{t}}}\right)\right] \\
& -\sum_{t=0}^{\infty} \lambda_{t}\left[-q_{t} a_{t+1}+a_{t}+w_{t} l_{t}+d_{t}-P_{t} c_{t}\right]
\end{aligned}
$$


The household's first-order conditions (FOC's) are:

$$
\begin{aligned}
c_{t}: & \psi_{t} U_{1, t}-\lambda_{t} P_{t}=0 \\
l_{t}: & \psi_{t} U_{2, t}+\lambda_{t} w_{t}=0 \\
a_{t+1}: & -\lambda_{t} q_{t}+\lambda_{t+1}=0 \\
V_{t}: & -\psi_{t}+\beta \psi_{t-1} E_{t-1}\left[\left(-V_{t}\right)^{1-\alpha_{t-1}}\right]^{\frac{\alpha_{t-1}}{1-\alpha_{t-1}}}\left(-V_{t}\right)^{-\alpha_{t-1}}=0
\end{aligned}
$$

where $U_{1, t}$ represents the derivative with relation to $c_{t}$, and $U_{2, t}$ the derivative with relation to $l_{t}$. From the FOC's we have

$$
\begin{gathered}
\frac{\psi_{t}}{\psi_{t-1}}=\beta E_{t-1}\left[\left(-V_{t}\right)^{1-\alpha_{t-1}}\right]^{\frac{\alpha_{t-1}}{1-\alpha_{t-1}}}\left(-V_{t}\right)^{-\alpha_{t-1}} \\
U_{1, t}^{\prime}=\frac{i_{t}}{\pi_{t}} E_{t}\left[U_{1, t+1} \frac{\psi_{t+1}}{\psi_{t}}\right] \\
\frac{U_{2, t}}{U_{1, t}}=-\frac{w_{t}}{P_{t}}
\end{gathered}
$$

Inserting Eq.(B-5) in Eq.(B-6) we obtain the household Euler equation:

$$
1=E_{t}\left[\beta \frac{U_{1, t+1}}{U_{1, t}} E_{t}\left[\left(-V_{t+1}\right)^{1-\alpha_{t}}\right]^{\frac{\alpha_{t}}{1-\alpha_{t}}}\left(-V_{t+1}\right)^{-\alpha_{t}} \frac{i_{t}}{\pi_{t+1}}\right]
$$

\section{B.1.1.1}

\section{The Stochastic Discount Factor}

Here is useful derivate the stochastic discount factor (SDF), which is a key driver to pricing bonds among different maturities. The SDF is the marginal substitution rate of consumption between two periods:

$$
\begin{aligned}
S D F_{t, t+1} & =\frac{\partial V_{t} / \partial c_{t+1}}{\partial V_{t} / \partial c_{t}} \\
S D F_{t, t+1} & =\beta E_{t}\left[\frac{U_{1, t+1}}{U_{1, t}^{\prime}} E_{t}\left[\left(-V_{t+1}\right)^{1-\alpha_{t}}\right]^{\frac{\alpha_{t}}{1-\alpha_{t}}}\left(-V_{t+1}\right)^{-\alpha_{t}}\right]
\end{aligned}
$$

Insofar as $V_{t+1}$ can not be observable, Eq.(B-9) must be rewritten in therms of the return of wealth. We express the SDF in terms of an asset which pays units of consumption (return on wealth). Consider an asset which pays $U_{t} U_{1, t}^{-1}$ as its dividend in each period. Define $J_{t}=V_{t} U_{1, t}$ the cum-dividend asset's price. To verify that $V_{t} U_{1, t}$ is the $J_{t}$ cum-dividend price, we should find 
the value functions when inserting $V_{t} U_{1, t}$ in Euler Equation of $J_{t}$. Follows that

$$
\begin{aligned}
J_{t} & =\frac{U_{t}}{U_{1, t}}+E_{t}\left[S D F_{t, t+1} J_{t+1}\right] \\
\frac{V_{t}}{U_{1, t}} & =\frac{U_{t}}{U_{1, t}}+E_{t}\left[S D F_{t, t+1} \frac{V_{t+1}}{U_{1, t+1}}\right] \\
V_{t} & =U_{t}+\beta E_{t}\left[\frac{U_{1, t+1}}{U_{1, t}} \frac{\left(-V_{t+1}\right)^{-\alpha_{t}}}{\left(E_{t}\left(-V_{t+1}^{1-\alpha_{t}}\right)\right)^{\frac{-\alpha_{t}}{1-\alpha_{t}}}} \frac{\left(-V_{t+1}\right)(-1)}{U_{1, t+1}}\right] \\
V_{t} & =U_{t}-\beta E_{t}\left[\left(-V_{t+1}\right)^{1-\alpha_{t}}\right]\left[E_{t}\left(-V_{t+1}\right)^{1-\alpha_{t}}\right]^{\frac{\alpha_{t}}{1-\alpha_{t}}} \\
V_{t} & =U_{t}-\beta\left[E_{t}\left(-V_{t}+1\right)^{1-\alpha_{t}}\right]^{\frac{1}{1-\alpha_{t}}}
\end{aligned}
$$

Notice that we can rewrite the Euler Equation of $J_{t}$ in terms of its return:

$$
\begin{aligned}
J_{t} & =\frac{U_{t}}{U_{1, t}} E_{t}\left[S_{t, t+1} J_{t+1}\right] \\
1 & =E_{t}\left[S_{t, t+1} \frac{J_{t+1}}{J_{t}-U_{t} U_{1, t}^{-1}}\right] \\
R_{j, t+1} & =\frac{J_{t+1}}{J_{t}-U_{t} U_{1, t}^{-1}}
\end{aligned}
$$

Rewriting the SDF as a function of $R_{j, t+1}$ :

$$
\begin{aligned}
R_{j, t+1} & =\frac{V_{t+1} U_{1, t+1}^{-1}}{V_{t} U_{1, t}^{-1}-U_{t} U_{1, t}^{-1}} \\
& =\frac{V_{t+1} U_{1, t+1}^{-1}}{U_{1, t}^{-1}\left[V_{t}-U_{t}\right]} \\
& =\frac{V_{t+1} U_{1, t+1}^{-1}}{U_{1, t}^{-1}\left[-\beta\left(E_{t}\left(-V_{t+1}\right)^{1-\alpha_{t}}\right)^{\frac{1}{1-\alpha_{t}}}\right]} \\
& =\frac{U_{1, t}}{U_{1, t+1} \beta\left(E_{t}\left(-V_{t+1}\right)^{1-\alpha_{t}}\right)^{\frac{1}{1-\alpha_{t}}}} \\
\beta R_{j, t+1} \frac{U_{1, t+1}}{U_{1, t}} & =\frac{-V_{t+1}}{\left(E_{t}\left(-V_{t+1}\right)^{1-\alpha_{t}}\right)^{\frac{1}{1-\alpha_{t}}}} \\
{\left[\beta R_{j, t+1} \frac{U_{1, t+1}}{U_{1, t}}\right]^{-\alpha_{t}} } & =E_{t}\left(-V_{t+1}^{1-\alpha_{t}}\right)^{\frac{\alpha_{t}}{1-\alpha_{t}}}\left(-V_{t+1}\right)^{-\alpha_{t}}
\end{aligned}
$$

Inserting Eq.(B-11) in Eq.(B-9) we obtain the SDF as a function of the return of wealth, $R_{j, t+1}$ :

$$
S_{t, t+1}=\beta^{1-\alpha_{t}}\left(\frac{U_{1, t+1}}{U_{1, t}}\right)^{1-\alpha_{t}}\left(R_{j, t+1}\right)^{-\alpha_{t}}
$$


Therefore we can input Eq.(B-12) in Eq.(B-8) and rewrite the Euler Equation of consumption as follows:

$$
\begin{gathered}
1=E_{t}[\underbrace{\left.\beta \frac{U_{1, t+1}}{U_{1, t}} E_{t}\left[\left(-V_{t+1}\right)^{1-\alpha_{t}}\right]^{\frac{\alpha_{t}}{1-\alpha_{t}}}\left(-V_{t+1}\right)^{-\alpha_{t}} \frac{i_{t}}{\pi_{t+1}}\right]}_{S_{t, t+1}} \\
1=E_{t}\left[\beta^{1-\alpha_{t}}\left(\frac{U_{1, t+1}}{U_{1, t}}\right)^{1-\alpha_{t}}\left(R_{j, t+1}\right)^{-\alpha_{t}} \frac{i_{t}}{\pi_{t+1}}\right]
\end{gathered}
$$

The household problem give us the following equilibrium conditions described by Eq.(B-14), Eq.(B-10), also

$$
\begin{gathered}
1=E_{t} \beta^{1-\alpha_{t}}\left(\frac{U_{1, t+1}}{U_{1, t}}\right)^{1-\alpha_{t}}\left(R_{j, t+1}\right)^{1-\alpha_{t}} \\
U_{t}=\frac{c_{t}^{\delta(1-\gamma)} \bar{c}_{t-1}^{(1-\delta)(1-\gamma)}}{1-\gamma}+\chi_{0} A_{t}^{1-\gamma} \frac{\left(1-l_{t}\right)^{1-\chi}}{1-\chi} \\
U_{1, t}=\delta c_{t}^{\delta(1-\gamma)-1} \bar{c}_{t-1}^{(1-\delta)(1-\gamma)} \\
\frac{w_{t}}{P_{t}}=\chi_{0} A_{t}\left(1-l_{t}\right)^{-\chi} U_{1, t}^{-1}
\end{gathered}
$$

where Eq.(B-15) represents the return of the wealth measured in consumption units, Eq.(B-16) the Utility function (which must be in the equilibrium system because Eq.(B-10)), Eq.(B-17) the marginal utility of consumption (must be in the equilibrium system because Eq.(B-10)), Eq.(B-18) the real wage respectively.

\section{B.1.2 \\ Firms}

Each firm produces following:

$$
y_{f, t}=A_{t} l_{f, t}^{\theta}
$$

The productivity evolves as

$$
\log A_{t}=\rho_{a} \log A_{t-1}+\varepsilon_{t}^{A}
$$

A final good producer, working in a competitive market, uses $y_{f, t}$ as input and follows:

$$
Y_{t}=\left(\int_{0}^{1} y_{f, t}^{\frac{1}{\lambda}} d f\right)^{\lambda}
$$

The final producer takes $p_{f, t}$, the price of the inputs, and $P_{t}$, its final price, as given to maximize the profit: 


$$
\begin{array}{ll}
\max _{\left\{y_{f, t}\right\}} & P_{t} Y_{t}-\int_{0}^{1} p_{f, t} y_{f, t} \quad d f \\
\text { s.t. } & Y_{t}=\left(\int_{0}^{1} y_{f, t}^{\frac{1}{\lambda}} \quad d f\right)^{\lambda}
\end{array}
$$

FOC:

$$
y_{f, t}: \quad P_{t}\left(\int_{0}^{1} y_{f, t}^{\frac{1}{\lambda}} \quad d f\right)^{\lambda-1} y_{f, t}^{\frac{1-\lambda}{\lambda}}-p_{f, t}=0
$$

Then we have

$$
y_{f, t}=\left(\frac{p_{f, t}}{P_{t}}\right)^{\frac{\lambda}{1-\lambda}} Y_{t}
$$

which is the final producer's demand curve. Furthermore, the zero profit condition implies that

$$
\begin{aligned}
P_{t} Y_{t} & =\int_{0}^{1} y_{f, t} p_{f, t} d f \\
P_{t} Y_{t} & =\int_{0}^{1}\left(\left(\frac{p_{f, t}}{P_{t}}\right)^{\frac{\lambda}{1-\lambda}} Y_{t}\right) p_{f, t} d f \\
P_{t}^{\frac{1}{1-\lambda}} & =\int_{0}^{1} p_{f, t}^{\frac{1}{1-\lambda}} d f \\
P_{t} & =\left(\int_{0}^{1} p_{f, t}^{\frac{1}{1-\lambda}} d f\right)^{1-\lambda}
\end{aligned}
$$

Eq.(B-25) is the aggregate index of prices. Insofar as some intermediary firms can not optimize every period of time, only a fraction $1-\zeta$ of the firms is allowed to reoptimize, the rest of them indexes a composition of past inflation and steady-state inflation. The aggregate index can be written by:

$$
\begin{aligned}
P_{t} & =\left[(1-\xi)\left(p_{t}^{*}\right)^{\frac{1}{1-\lambda}}+\xi\left(P_{t-1}\left(\pi_{t-1}\right)^{\varpi}(\bar{\pi})^{1-\varpi}\right)^{\frac{1}{1-\lambda}}\right]^{1-\lambda} \\
1 & =(1-\xi)\left(\frac{p_{t}^{*}}{P_{t}}\right)^{\frac{1}{1-\lambda}}+\xi\left(\pi_{t}^{-1}\left(\pi_{t-1}\right)^{\varpi}(\bar{\pi})^{1-\varpi}\right)^{\frac{1}{1-\lambda}}
\end{aligned}
$$

where $p_{t}^{*}$ is the price that maximizes the value of shareholders of the intermediate firm's cash flows over the lifetime of the Calvo contract. In other words, the intermediate firm solves

$$
\begin{array}{ll}
\max _{\left\{p_{t}^{*}\right\}} & E_{t} \sum_{j=0}^{\infty} \zeta^{j} S_{t, t+j} \frac{P_{t}}{P_{t+j}}\left[p_{f, t+j}-\mu_{t+j} P_{t+j}\right] y_{f, t+j} \\
\text { s.t. } & y_{f, t+j}=\left(\frac{p_{f, t+j}}{P_{t+j}}\right)^{\frac{\lambda}{1-\lambda}} Y_{t+j} \\
& p_{f, t+j}=p_{t}^{*} \prod_{l=1}^{j}\left(\pi_{t+l-1}\right)^{\varpi}(\bar{\pi})^{1-\varpi},
\end{array}
$$

where $S_{t, t+j}$ is the real SDF and $\mu_{t+j}$ is the real marginal cost. The 
objective function can be rewritten as:

$$
\begin{aligned}
f(.)= & E_{t} \sum_{j=0}^{\infty} \zeta^{j} S_{t, t+j} \frac{P_{t}}{P_{t+j}}\left[p_{t}^{*} \prod_{l=1}^{j}\left(\pi_{t+l-1}\right)^{\varpi}(\bar{\pi})^{1-\varpi}-\mu_{t+j} P_{t+j}\right]\left(\frac{p_{f, t+j}}{P_{t+j}}\right)^{\frac{\lambda}{1-\lambda}} Y_{t+j} \\
= & E_{t} \sum_{j=0}^{\infty} \zeta^{j} S_{t, t+j} \frac{P_{t}}{P_{t+j}}\left[p_{t}^{*} \prod_{l=1}^{j}\left(\pi_{t+l-1}\right)^{\varpi}(\bar{\pi})^{1-\varpi}-\mu_{t+j} P_{t+j}\right] \times \\
& \left(\frac{p_{t}^{*} \prod_{l=1}^{j}\left(\pi_{t+l-1}\right)^{\varpi}(\bar{\pi})^{1-\varpi}}{P_{t+j}}\right)^{\frac{\lambda}{1-\lambda}} Y_{t+j} \\
= & E_{t} \sum_{j=0}^{\infty} \zeta^{j} S_{t, t+j} \frac{P_{t}}{P_{t+j}}\left[p_{t}^{*} \prod_{l=1}^{j}\left(\pi_{t+l-1}\right)^{\varpi}(\bar{\pi})^{1-\varpi}-\mu_{t+j} P_{t+j}\right] \times \\
\frac{\left(p_{t}^{*}\right)^{\frac{\lambda}{1-\lambda}}\left(\prod_{l=1}^{j}\left(\pi_{t+l-1}\right)^{\varpi}(\bar{\pi})^{1-\varpi}\right)^{\frac{\lambda}{1-\lambda}} Y_{t+j}}{\left(P_{t+j}\right)^{\frac{\lambda}{1-\lambda}}} & E_{t} \sum_{j=0}^{\infty} \zeta^{j} S_{t, t+j} \frac{P_{t}}{P_{t+j}}\left[\left(p_{t}^{*}\right)^{\frac{1}{1-\lambda}}\left(\prod_{l=1}^{j}\left(\pi_{t+l-1}\right)^{\varpi}(\bar{\pi})^{1-\varpi}\right)^{\frac{1}{1-\lambda}}\left(P_{t+j}\right)^{\frac{\lambda}{\lambda-1}}\right] Y_{t+j}- \\
& E_{t} \sum_{j=0}^{\infty} \zeta^{j} S_{t, t+j} \frac{P_{t}}{P_{t+j}}\left[\mu_{t+j} \frac{\left(p_{t}^{*}\right)^{\frac{\lambda}{1-\lambda}}\left(\prod_{l=1}^{j}\left(\pi_{t+l-1}\right)^{\varpi}(\bar{\pi})^{1-\varpi}\right)^{\frac{\lambda}{1-\lambda}}}{\left(P_{t+j}\right)^{\frac{2-1}{1-\lambda}}}\right] Y_{t+j}(\mathrm{~B}-28)
\end{aligned}
$$

The FOC for Eq.(B-28) is:

$$
\begin{gathered}
p_{t}^{*}: \quad E_{t} \sum_{j=0}^{\infty} \zeta^{j} S_{t, t+j} \frac{P_{t}}{P_{t+j}}\left[\frac{\left(p_{t}^{*} \frac{\lambda}{1-\lambda}\right.}{(1-\lambda)}\left(\prod_{l=1}^{j}\left(\pi_{t+l-1}\right)^{\varpi}(\bar{\pi})^{1-\varpi}\right)^{\frac{1}{1-\lambda}}\left(P_{t+j}\right)^{\frac{\lambda}{\lambda-1}}\right] Y_{t+j}= \\
E_{t} \sum_{j=0}^{\infty} \zeta^{j} S_{t, t+j} \frac{P_{t}}{P_{t+j}}\left[\lambda \frac{\mu_{t+j}}{(1-\lambda)} \frac{\left(p_{t}^{*}\right)^{\frac{2 \lambda-1}{1-\lambda}}\left(\prod_{l=1}^{j}\left(\pi_{t+l-1}\right)^{\varpi}(\bar{\pi})^{1-\varpi}\right)^{\frac{\lambda}{1-\lambda}}}{\left(P_{t+j}\right)^{\frac{2 \lambda-1}{1-\lambda}}}\right] Y_{t+j}
\end{gathered}
$$

Note that $p_{t}^{*}$ may leave the sum, and $\frac{P_{t}}{P_{t-1}}=\pi_{t}$ :

$$
\begin{aligned}
& \frac{p_{t}^{*}}{P_{t}} E_{t} \sum_{j=0}^{\infty} \zeta^{j} S_{t, t+j}\left[\left(\prod_{l=1}^{j}\left(\pi_{t+l-1}\right)^{\varpi}(\bar{\pi})^{1-\varpi}\right)^{\frac{1}{1-\lambda}}\left(\frac{P_{t+j}}{P_{t}}\right)^{\frac{1}{\lambda-1}}\right] Y_{t+j}= \\
& \quad \lambda E_{t} \sum_{j=0}^{\infty} \zeta^{j} S_{t, t+j} \frac{P_{t}}{P_{t+j}}\left[\mu_{t+j}\left(\prod_{l=1}^{j}\left(\pi_{t+l-1}\right)^{\varpi}(\bar{\pi})^{1-\varpi}\right)^{\frac{\lambda}{1-\lambda}}\left(\frac{P_{t+j}}{P_{t}}\right)^{\frac{\lambda}{\lambda-1}}\right] Y_{t+j}
\end{aligned}
$$


Rewritten equation above in terms of inflation:

$$
\begin{aligned}
& \frac{p_{t}^{*}}{P_{t}} E_{t} \sum_{j=0}^{\infty} \zeta^{j} S_{t, t+j}\left[\left(\prod_{l=1}^{j}\left(\pi_{t+l-1}\right)^{\varpi}(\bar{\pi})^{1-\varpi}\right)^{\frac{1}{1-\lambda}}\left(\prod_{m=1}^{j} \pi_{t+m}\right)^{\frac{1}{\lambda-1}}\right] Y_{t+j}= \\
& \lambda E_{t} \sum_{j=0}^{\infty} \zeta^{j} S_{t, t+j}\left[\mu_{t+j}\left(\prod_{l=1}^{j}\left(\pi_{t+l-1}\right)^{\varpi}(\bar{\pi})^{1-\varpi}\right)^{\frac{\lambda}{1-\lambda}}\left(\prod_{m=1}^{j} \pi_{t+m}\right)^{\frac{\lambda}{\lambda-1}}\right] Y_{t+j} .
\end{aligned}
$$

Isolating $\frac{p_{t}^{*}}{P_{t}}$, we have:

$$
\frac{p_{t}^{*}}{P_{t}}=\lambda \frac{E_{t} \sum_{j=0}^{\infty} \zeta^{j} S_{t, t+j} \mu_{t+j} Y_{t+j}\left(\prod_{l=1}^{j}\left(\pi_{t+l-1}\right)^{\varpi}(\bar{\pi})^{1-\varpi}\right)^{\frac{\lambda}{1-\lambda}}\left(\prod_{m=1}^{j} \pi_{t+m}\right)^{\frac{\lambda}{\lambda-1}}}{E_{t} \sum_{j=0}^{\infty} \zeta^{j} S_{t, t+j} Y_{t+j}\left(\prod_{l=1}^{j}\left(\pi_{t+l-1}\right)^{\varpi}(\bar{\pi})^{1-\varpi}\right)^{\frac{1}{1-\lambda}}\left(\prod_{m=1}^{j} \pi_{t+m}\right)^{\frac{1}{\lambda-1}}} .
$$

Denote

$$
z_{t}^{n}=E_{t} \sum_{j=0}^{\infty} \zeta^{j} S_{t, t+j} \mu_{t+j} Y_{t+j}\left(\prod_{l=1}^{j}\left(\pi_{t+l-1}\right)^{\varpi}(\bar{\pi})^{1-\varpi}\right)^{\frac{\lambda}{1-\lambda}}\left(\prod_{m=1}^{j} \pi_{t+m}\right)^{\frac{\lambda}{\lambda-1}}
$$

$$
z_{t}^{d}=E_{t} \sum_{j=0}^{\infty} \zeta^{j} S_{t, t+j} Y_{t+j}\left(\prod_{l=1}^{j}\left(\pi_{t+l-1}\right)^{\varpi}(\bar{\pi})^{1-\varpi}\right)^{\frac{1}{1-\lambda}}\left(\prod_{m=1}^{j} \pi_{t+m}\right)^{\frac{1}{\lambda-1}}
$$

then we can write:

$$
\frac{p_{t}^{*}}{P_{t}}=\lambda \frac{z_{t}^{n}}{z_{t}^{d}}
$$

Eq.(B-30) and Eq.(B-31) will be log-linearized, thus it is useful simplify those equations. Some tedious algebra manipulations can do that:

$$
\begin{aligned}
z_{t}^{d} & =E_{t} \sum_{j=0}^{\infty} \zeta^{j} S_{t, t+j} Y_{t+j}\left(\prod_{l=1}^{j}\left(\pi_{t+l-1}\right)^{\varpi}(\bar{\pi})^{1-\varpi}\right)^{\frac{1}{1-\lambda}}\left(\prod_{m=1}^{j} \pi_{t+m}\right)^{\frac{1}{\lambda-1}} \\
& =Y_{t}+\zeta E_{t} \sum_{j=1}^{\infty} \zeta^{j-1} S_{t, t+j} Y_{t+j}\left(\prod_{l=1}^{j}\left(\pi_{t+l-1}\right)^{\varpi}(\bar{\pi})^{1-\varpi}\right)^{\frac{1}{1-\lambda}}\left(\prod_{m=1}^{j} \pi_{t+m}\right)^{\frac{1}{\lambda-1}}
\end{aligned}
$$

Note that $S_{t, t+j}=S_{t, t} \times S_{t, t+1} \times S_{t, t+2} \times \ldots \times S_{t, t+j}, \quad j=\{0,1,2, \ldots\}$ 
and $S_{t, t}=1$. Then we can write $S_{t, t+j}=S_{t, t+1} \times S_{t+1, t+j}, \quad j=\{1,2,3, .$.$\} .$

$$
\begin{aligned}
z_{t}^{d}= & Y_{t}+\zeta E_{t} \sum_{j=1}^{\infty} \zeta^{j-1} S_{t, t+1} S_{t+1, t+j} Y_{t+j}\left(\prod_{l=1}^{j}\left(\pi_{t+l-1}\right)^{\varpi}(\bar{\pi})^{1-\varpi}\right)^{\frac{1}{1-\lambda}}\left(\prod_{m=1}^{j} \pi_{t+m}\right)^{\frac{1}{\lambda-1}} \\
= & Y_{t}+\zeta E_{t} \sum_{j=1}^{\infty} \zeta^{j-1} S_{t, t+1} S_{t+1, t+j} Y_{t+j}\left(\pi_{t+1}\right)^{\frac{1}{\lambda-1}}\left(\pi_{t}\right)^{\frac{\varpi}{1-\lambda}}(\bar{\pi})^{\frac{1-\varpi}{1-\lambda}} \times \\
& \left(\prod_{l=2}^{j}\left(\pi_{t+l-1}\right)^{\varpi}(\bar{\pi})^{1-\varpi}\right)^{\frac{1}{1-\lambda}}\left(\prod_{m=2}^{j} \pi_{t+m}\right)^{\frac{1}{\lambda-1}} \\
= & Y_{t}+\zeta E_{t} S_{t, t+1}\left(\pi_{t+1}\right)^{\frac{1}{\lambda-1}}\left(\pi_{t}\right)^{\frac{\varpi}{1-\lambda}}(\bar{\pi})^{\frac{1-\varpi}{1-\lambda}} \times \\
& \sum_{j=1}^{\infty} \zeta^{j-1} S_{t+1, t+j} Y_{t+j}\left(\prod_{l=2}^{j}\left(\pi_{t+l-1}\right)^{\varpi}(\bar{\pi})^{1-\varpi}\right)^{\frac{1}{1-\lambda}}\left(\prod_{m=2}^{j} \pi_{t+m}\right)^{\frac{1}{\lambda-1}}
\end{aligned}
$$

Replacing the index $j$ by $j=s+1$ :

$$
\begin{aligned}
z_{t}^{d}= & Y_{t}+\zeta E_{t} S_{t, t+1}\left(\pi_{t+1}\right)^{\frac{1}{\lambda-1}}\left(\pi_{t}\right)^{\frac{\varpi}{1-\lambda}}(\bar{\pi})^{\frac{1-\varpi}{1-\lambda}} \times \\
& \sum_{s=0}^{\infty} \zeta^{s} S_{t+1, t+s+1} Y_{t+s+1}\left(\prod_{l=2}^{s+1}\left(\pi_{t+l-1}\right)^{\varpi}(\bar{\pi})^{1-\varpi}\right)^{\frac{1}{1-\lambda}}\left(\prod_{m=2}^{s+1} \pi_{t+m}\right)^{\frac{1}{\lambda-1}} \\
= & Y_{t}+\zeta E_{t} S_{t, t+1}\left(\pi_{t+1}\right)^{\frac{1}{\lambda-1}}\left(\pi_{t}\right)^{\frac{\varpi}{1-\lambda}}(\bar{\pi})^{\frac{1-\varpi}{1-\lambda}} \times \\
& \sum_{s=0}^{\infty} \zeta^{s} S_{t+1, t+s+1} Y_{t+s+1}\left(\prod_{l=1}^{s}\left(\pi_{t+l-1}\right)^{\varpi}(\bar{\pi})^{1-\varpi}\right)^{\frac{1}{1-\lambda}}\left(\prod_{m=1}^{s} \pi_{t+m}\right)^{\frac{1}{\lambda-1}}(\mathrm{~B}-33)
\end{aligned}
$$

According to previous equation we must have

$$
z_{t+1}^{d}=E_{t+1} \sum_{j=0}^{\infty} \zeta^{j} S_{t+1, t+j+1} Y_{t+j+1}\left(\prod_{l=1}^{j}\left(\pi_{t+l-1}\right)^{\varpi}(\bar{\pi})^{1-\varpi}\right)^{\frac{1}{1-\lambda}}\left(\prod_{m=1}^{j} \pi_{t+m}\right)^{\frac{1}{\lambda-1}}
$$

and that is exactly the last term exposed in Eq.(B-33), then we can write:

$$
z_{t}^{d}=Y_{t}+\zeta E_{t} S_{t, t+1}\left(\pi_{t+1}\right)^{\frac{1}{\lambda-1}}\left(\pi_{t}\right)^{\frac{\varpi}{1-\lambda}}(\bar{\pi})^{\frac{1-\varpi}{1-\lambda}} z_{t+1}^{d}
$$

Analogously

$$
z_{t}^{n}=\mu_{t} Y_{t}+\zeta E_{t} S_{t, t+1}\left(\pi_{t+1}\right)^{\frac{\lambda}{\lambda-1}}\left(\pi_{t}\right)^{\frac{\lambda \varpi}{1-\lambda}}(\bar{\pi})^{\frac{\lambda(1-\varpi)}{1-\lambda}} z_{t+1}^{n}
$$

At this point it should be clear that marginal cost, $\mu_{t}$, is an endogenous variable and must be described by an equilibrium condition. The intermediary firms take the marginal cost in account when deciding its price (inflation will be high when firms are expect average markups below the desired steady state value). ${ }^{1}$ The intermediary firm minimizes total cost subject to production

${ }^{1}$ In the standard New Keynesian model, inflation results from the intermediary firms price decision. The firms adjust its price due to expected conditions about current and future marginal costs. There is no demand neither supply of money. Inflation arise from 
function:

$$
\begin{array}{ll}
\min _{\left\{l_{f, t}\right\}} & w_{t}^{N} L_{f, t} \\
\text { s.t. } & y_{f, t+j}=A_{t} l_{f, t}^{\theta}
\end{array}
$$

From minimization (B-37) we have

$$
T C_{f, t}^{N}=w_{t}^{N}\left(\frac{y_{f, t}}{A_{t}}\right)^{\frac{1}{\theta}}
$$

However the problem (B-37) is solved equally by all intermediary firms, therefore we can write

$$
T C_{t}^{N}=w_{t}^{N}\left(\frac{Y_{t}}{A_{t}}\right)^{\frac{1}{\theta}}
$$

Dividing both side by $P_{t}$ we obtain the real total cost, $T C_{t}$, as a function of the real wage, $w_{t}$. To reach the real marginal we derivate the total cost with relation to output, $\frac{\partial T C_{t}}{\partial Y_{t}}$ :

$$
\mu_{t}=\frac{w_{t}}{\theta}\left(\frac{Y_{t}}{A_{t}}\right)^{\frac{1-\theta}{\theta}}
$$

The final and intermediary firms problems give us equilibrium conditions described by Eq.(B-19), Eq.(B-20), Eq.(B-26), Eq.(B-32), Eq.(B-35), Eq.(B36), and Eq.(B-40).

\section{B.1.3}

\section{Market Clearing}

$$
\begin{gathered}
Y_{t}=C_{t} \\
l_{t}=\int_{0}^{1} l_{f, t} d f=\int_{0}^{1}\left(\frac{y_{f, t}}{A_{t}}\right)^{\frac{1}{\theta}} d f \\
=\frac{1}{A_{t}^{\frac{1}{\theta}}} \int_{0}^{1}\left(y_{f, t}\right)^{\frac{1}{\theta}} d f=\frac{1}{A_{t}^{\frac{1}{\theta}}} \int_{0}^{1}\left(\left(\frac{p_{f, t}}{P_{t}}\right)^{\frac{\lambda}{\lambda-1}} Y_{t}\right)^{\frac{1}{\theta}} d f \\
=\frac{1}{A_{t}^{\frac{1}{\theta}}} \int_{0}^{1}\left(\frac{p_{f, t}}{P_{t}}\right)^{\frac{\lambda}{\theta(\lambda-1)}} Y_{t}^{\frac{1}{\theta}} d f=\left(\frac{Y_{t}}{A_{t}}\right)^{\frac{1}{\theta}} \underbrace{\int_{0}^{1}\left(\frac{p_{f, t}}{P_{t}}\right)^{\frac{\lambda}{\theta(\lambda-1)}} Y_{t}^{\frac{1}{\theta}} d f}_{\text {price dispersion }}
\end{gathered}
$$

Price dispersion is approximately equal one in a first-order approximation. Therefore we have

$$
l_{t}=\left(\frac{Y_{t}}{A_{t}}\right)^{\frac{1}{\theta}}
$$

The market clearing conditions give us the equilibrium conditions described by Eq.(B-41), and Eq.(B-42).

markup oscillations from its steady state value. 


\section{B.1.4}

\section{Real and Nominal Default-Free Bonds}

Complete markets guarantee the existence and uniqueness of a pricing kernel such that

$$
p_{t}^{\$(n)}=E_{t} S_{t, t+1} p_{t+1}^{\$(n-1)}
$$

where $p_{t}^{\$(n)}$ is the price of a nominal bond with maturity $n$. In particular, $p_{t}^{\$(1)}=e^{-i_{t}}$. The real bond price can be stated as that

$$
p_{t}^{(n)}=E_{t} S_{t, t+1} p_{t+1}^{(n-1)}
$$

in particular, $p_{t}^{(1)}=e^{-i_{t}+\pi_{t}}$. Let $y_{t}^{\$(n)}$ denote the n-period continuouslycompounded yield to maturity on a nominal zero-coupon bond, an $y_{t}^{(n)}$ the corresponding yield on a n-period nominal bond. Then

$$
y_{t}^{\$(n)}=-\frac{1}{n} \log p_{t}^{\$(n)}
$$

and

$$
y_{t}^{(n)}=-\frac{1}{n} \log p_{t}^{(n)}
$$

The term premium (risk premium) is the difference between yield to maturity and and the hypothetical risk-neutral yield to maturity. According as the risk-neutral real price $\hat{p}_{t}^{(n)}$ of an n-period zero-coupon real bond is given by

$$
\hat{p}_{t}^{(n)}=e^{-i_{t}+\pi_{t}} E_{t} \hat{p}_{t+1}^{(n-1)}
$$

where $\hat{p}_{t}^{(0)} \equiv 1$. The real term-premium, $\psi_{t}^{(n)}$, is given by

$$
\psi_{t}^{(n)}=\frac{1}{n}\left(\log \hat{p}_{t}^{(n)}-\log p_{t}^{\$(n)}\right)
$$

As our model encompasses the term premium, then Eq.(B-43), Eq.(B45), Eq.(B-47), and Eq.(B-48) are part of the equilibrium conditions.

\section{B.1.5}

\section{Model Equations}

In summary, the equilibrium conditions are:

Euler Equation:

$$
1=E_{t} \beta^{1-\alpha_{t}}\left(\frac{U_{1, t+1}}{U_{1, t}}\right)^{1-\alpha_{t}} R_{j, t+1}^{-\alpha_{t}} \frac{i_{t}}{\pi_{t+1}}
$$

Return of wealth in consumption units:

$$
R_{j, t}=\frac{J_{t}}{J_{t-1}-U_{t-1} U_{1, t-1}^{-1}}
$$

Asset price (return of wealth): 


$$
1=E_{t} \beta^{1-\alpha_{t}}\left(\frac{U_{1, t+1}}{U_{1, t}}\right)^{1-\alpha_{t}} R_{j, t+1}^{1-\alpha_{t}}
$$

Utility function:

$$
U_{t}=\frac{c_{t}^{\delta(1-\gamma)} \bar{c}_{t-1}^{(1-\delta)(1-\gamma)}}{1-\gamma}+\chi_{0} A_{t}^{1-\gamma} \frac{\left(1-l_{t}\right)^{1-\chi}}{1-\chi}
$$

Marginal utility of consumption:

$$
U_{1, t}=\delta c_{t}^{\delta(1-\gamma)-1} \bar{c}_{t}^{(1-\delta)(1-\gamma)}
$$

Real wage and marginal cost:

$$
\begin{gathered}
w_{t}=\chi_{0} A_{t}^{1-\gamma}\left(1-l_{t}\right)^{-\chi} U_{1, t}^{-1} \\
\mu_{t}=\frac{w_{t}}{\theta}\left(\frac{Y_{t}}{A_{t}}\right)^{\frac{1-\theta}{\theta}}
\end{gathered}
$$

Optimal price setting by firms:

$$
\begin{gathered}
1=(1-\xi)\left(\frac{p_{t}^{*}}{P_{t}}\right)^{\frac{1}{1-\lambda}}+\xi\left(\pi_{t}^{-1}\left(\pi_{t-1}\right)^{\varpi}(\bar{\pi})^{1-\varpi}\right)^{\frac{1}{1-\lambda}} \\
\frac{p_{t}^{*}}{P_{t}}=\lambda \frac{z_{t}^{n}}{z_{t}^{d}} \\
z_{t}^{d}=Y_{t}+\zeta E_{t} \beta^{1-\alpha_{t}}\left(\frac{U_{1, t+1}}{U_{1, t}}\right)^{1-\alpha_{t}} R_{j, t+1}^{-\alpha_{t}}\left(\pi_{t+1}\right)^{\frac{1}{\lambda-1}}\left(\pi_{t}\right)^{\frac{\varpi}{1-\lambda}}(\bar{\pi})^{\frac{1-\varpi}{1-\lambda}} z_{t+1}^{d} \\
z_{t}^{n}=\mu_{t} Y_{t}+\zeta E_{t} \beta^{1-\alpha_{t}}\left(\frac{U_{1, t+1}}{U_{1, t}}\right)^{1-\alpha_{t}} R_{j, t+1}^{-\alpha_{t}}\left(\pi_{t+1}\right)^{\frac{\lambda}{\lambda-1}}\left(\pi_{t}\right)^{\frac{\lambda \varpi}{1-\lambda}}(\bar{\pi})^{\frac{\lambda(1-\varpi)}{1-\lambda}} z_{t+1}^{n}
\end{gathered}
$$

Production and resource constraints:

$$
\begin{gathered}
Y_{t}=A_{t} l_{t}^{\theta} \\
Y_{t}=C_{t}
\end{gathered}
$$

Monetary policy rule, potential output and inflation target:

$$
\begin{gathered}
i_{t}=i_{t-1}^{\rho_{i}}\left[i_{s s}\left(\frac{\pi_{t}}{\pi_{t}^{*}}\right)^{\phi_{\pi}}\left(\frac{y_{t}}{\bar{y}_{t}}\right)^{\phi_{y}}\right]^{1-\rho_{i}} \exp \left(\varepsilon_{t}^{i}\right) \exp \left(\varepsilon_{1, t-1}^{\text {news }}+\varepsilon_{3, t-3}^{\text {news }}+\varepsilon_{5, t-5}^{\text {news }}+\varepsilon_{8, t-8}^{\text {news }}\right) \\
\bar{y}_{t}=\rho_{\bar{y}} \bar{y}_{t-1}+\left(1-\rho_{\bar{y}}\right) y_{t} \\
\pi_{t}^{*}=\left(1-\rho_{\pi^{*}}\right) \bar{\pi}+\left(1-\rho_{\pi^{*}}\right) \pi_{t-1}^{*}+\varepsilon_{t}^{\pi^{*}} .
\end{gathered}
$$

Technology shock and risk aversion shock: 


$$
\begin{gathered}
\log A_{t}=\rho_{a} \log A_{t-1}+\varepsilon_{t}^{A} \\
\alpha_{t}=\left(1-\rho_{\alpha}\right) \bar{\alpha}+\rho_{\alpha} \alpha_{t-1}+\varepsilon_{t}^{\alpha}
\end{gathered}
$$

Nominal bonds and term premium:

$$
\begin{gathered}
p_{t}^{\$(n)}=E_{t} S_{t, t+1} p_{t+1}^{\$(n-1)} \\
y_{t}^{\$(n)}=-\frac{1}{n} \log p_{t}^{\$(n)} \\
\hat{p}_{t}^{(n)}=e^{-i_{t}+\pi_{t}} E_{t} \hat{p}_{t+1}^{(n-1)} \\
\psi_{t}^{(n)}=\frac{1}{n}\left(\log \hat{p}_{t}^{(n)}-\log p_{t}^{\$(n)}\right)
\end{gathered}
$$




\section{B.2}

\section{Appendix: Model Solution}

\section{B.2.1}

\section{Steady State}

The steady state relations follows:

$$
\begin{aligned}
\alpha_{s s} & =\bar{\alpha} \\
J_{s s} & =\frac{U_{s s} U_{1, s s}^{-1}}{1-\beta} \\
R_{j, s s} & =\frac{1}{\beta} \\
i_{s s}-\pi_{s s} & =\frac{1}{\beta} \\
\pi_{s s} & =\bar{\pi} \\
U_{s s} & =\frac{c_{s} s^{1-\gamma}}{1-\gamma}+\chi_{0} \frac{\left(1-l_{s s}\right)^{1-\chi}}{1-\chi} \\
A_{s s} & =1 \\
U_{1, s s} & =\delta c_{s s}^{-\delta} \\
p_{s s}^{*} & =1 \\
z_{s s}^{n} & =\frac{Y_{s s} \mu_{s s}}{(1-\beta \xi)} \\
z_{s s}^{d} & =\frac{Y_{s s}}{(1-\beta \xi)} \\
\mu_{s s} & =\frac{1}{\lambda} \\
w_{s s} & =\frac{\chi_{0}}{\delta}\left(1-l_{s} s\right)^{-\chi} Y_{s s}^{\gamma} \\
l_{s} s & =\frac{1}{3} \\
\pi_{s s}^{*} & =\bar{\pi} \\
Y_{s s} & =c_{s s}=l_{s s}^{\theta}
\end{aligned}
$$

\section{B.2.2}

\section{Essentially affine approximation}

This paper uses the essentially affine approximation method laid out by (44). This method delivers an approximation to the equilibrium dynamics of the model that is linear in the state variables but still allows time-varying risk aversion to affect the behavior of the endogenous variables.

The solution method can be stated as follows: we divide the system of equations into two types: those that do not involve taking expectations over the 
SDF, and those that do. For the equations that do not involve the SDF, we use standard perturbation methods and simply take a log-linear approximation. The second set of equations is dynamic and involves expectations. The key source of nonlinearity in the model is the time variation in risk aversion, which induces heteroskedasticity in the SDF and make use of the formula for expectation of a log-normally distributed variable. The essentially affine approximation uses the log-normality property:

$$
\begin{aligned}
\log \left(E_{t}\left[e^{h(x)}\right]\right) & =\log \left(e^{E_{t}[h(x)]+\frac{1}{2} \operatorname{var}_{t}[h(x)]}\right) \\
& =E_{t}[h(x)]+\frac{1}{2} \operatorname{var}_{t}[h(x)]
\end{aligned}
$$

where $H_{x}=E_{t}\left[S_{t, t+1} F\left(x_{t}, x_{t+1}\right)\right]$, as described in Eq.(3-12), and $h(x)=$ $s_{t, t+1}+f\left(x_{t}, x_{t+1}\right)$ is the log-linear approximation of $S_{t, t+1}$ and $F\left(x_{t}, x_{t+1}\right)$ took separately. See Eq.(3-14)-(3-15).

This solution method differs from perturbation because it corrects for the time-varying risk premium. (29) shows that this procedure can generate a large and volatile term premium. This is driven by the combination of two factors: A negative response of interest rates to positive technology shocks; and variation in risk aversion, which is modeled by a structural shock. In essence, risk aversion and technology shocks determine average asset returns, and they have only weak effects on real variables at business-cycle frequencies.

The system of equations described in B.1.5 can be divided into two types: the set of equations that involves expectations over the SDF, Eq.(B-8), Eq.(B-15), Eq.(B-35), Eq.(B-36), and Eq.(B-43); and the set that do not, the rest of equilibrium conditions.

From Eq.(B-15), we have:

$$
\begin{aligned}
1 & =E_{t} \beta^{1-\alpha_{t}}\left(\frac{U_{1, t+1}}{U_{1, t}}\right)^{1-\alpha_{t}}\left(R_{j, t+1}\right)^{1-\alpha_{t}} \\
& =E_{t} \exp \left[\log \left(\beta^{1-\alpha_{t}}\left(\frac{U_{1, t+1}}{U_{1, t}}\right)^{1-\alpha_{t}}\left(R_{j, t+1}\right)^{1-\alpha_{t}}\right)\right] \\
& =E_{t} \exp \left[\left(1-\alpha_{t}\right) \log \beta+\left(1-\alpha_{t}\right) \log U_{1, t+1}-\left(1-\alpha_{t}\right) \log U_{1, t}+\left(1-\alpha_{t}\right) \log R_{j, t+1}\right] \\
& =E_{t} \exp \left[\left(1-\alpha_{t}\right)\left(\tilde{U}_{1, t+1}-\tilde{U}_{1, t}\right)+\left(1-\alpha_{t}\right)\left(\log R_{j, t+1}-\log \beta^{-1}\right)\right] \\
& =E_{t} \exp \left[\left(1-\alpha_{t}\right)\left(\tilde{U}_{1, t+1}-\tilde{U}_{1, t}\right)+\left(1-\alpha_{t}\right) \tilde{R}_{j, t+1}\right]
\end{aligned}
$$

where $\tilde{x}_{t} \equiv \log x_{t}-\log x_{s s}$. Denotes $\left(1-\alpha_{t}\right)=\varphi_{t}$. Define $\Gamma_{x}$ as a matrix that select individual elements of $s_{t}$ such that $\tilde{x}_{t}=\Gamma_{x} \tilde{s}_{t}$, and rewrite Eq.(B-72) 
in matrix notation:

$$
1=E_{t} \exp \underbrace{\left[\varphi_{t}\left(\Gamma_{U c}-\Gamma_{R j}\right) \tilde{X}_{t+1}-\varphi_{t} \Gamma_{U c} \tilde{X}_{t}\right]}_{h\left(x_{t}, x_{t+1}\right)}
$$

where $X_{t}$ is the vector of endogenous variables. Applying log both sides and making use of the log-normal property, we have:

$$
\begin{aligned}
0 & =\log \left(E_{t}\left[e^{h\left(x_{t}, x_{t+1}\right)}\right]\right) \\
0 & =E_{t}\left[h\left(x_{t}, x_{t+1}\right)\right]+\frac{1}{2} \operatorname{var}_{t}\left[h\left(x_{t}, x_{t+1}\right)\right] \\
0 & =\varphi_{t}\left(\Gamma_{U c}+\Gamma_{R j}\right) E_{t}\left[\tilde{X}_{t+1}\right]-\varphi_{t} \Gamma_{U c} \tilde{X}_{t}+\frac{1}{2} \operatorname{var}_{t}\left[\varphi_{t}\left(\Gamma_{U c}+\Gamma_{R j}\right) \tilde{X}_{t+1}-\varphi_{t} \Gamma_{U c} \tilde{X}_{t}\right] \\
0 & =\varphi_{t}\left(\Gamma_{U c}+\Gamma_{R j}\right) E_{t}\left[\tilde{X}_{t+1}\right]-\varphi_{t} \Gamma_{U c} \tilde{X}_{t}+\frac{1}{2} \operatorname{var}_{t}\left[\varphi_{t}\left(\Gamma_{U c}+\Gamma_{R j}\right) \tilde{X}_{t+1}\right]
\end{aligned}
$$

At this point we must to know who is the term $\tilde{X}_{t+1}$ to properly describes its variance in Eq.(B-73). (44) proposes the use of initial guess, which is the standard solution to the first-order model approximation. Guess the solution takes the form

$$
\tilde{X}_{t+1}=H_{0}+H_{x} \tilde{X}_{t}+H_{\varepsilon} \varepsilon_{t+1} .
$$

That is the exactly the solution given by Gensys. Defines $\Sigma_{\varepsilon}$ as the covariance matrix of the structural shocks. Using this first guess, we have:

$$
\begin{aligned}
0= & \varphi_{t}\left(\Gamma_{U c}+\Gamma_{R j}\right) E_{t}\left[\tilde{X}_{t+1}\right]-\varphi_{t} \Gamma_{U c} \tilde{X}_{t}+\frac{1}{2} \operatorname{var}_{t}\left[\varphi_{t}\left(\Gamma_{U c}+\Gamma_{R j}\right)\left(H_{0}+H_{x} \tilde{X}_{t}+H_{\varepsilon} \varepsilon_{t+1}\right)\right] \\
0= & \varphi_{t}\left(\Gamma_{U c}+\Gamma_{R j}\right) E_{t}\left[\tilde{X}_{t+1}\right]-\varphi_{t} \Gamma_{U c} \tilde{X}_{t}+\frac{1}{2} \operatorname{var}_{t}\left[\varphi_{t}\left(\Gamma_{U c}+\Gamma_{R j}\right) H_{\varepsilon} \varepsilon_{t+1}\right] \\
0= & \varphi_{t}\left(\Gamma_{U c}+\Gamma_{R j}\right) E_{t}\left[\tilde{X}_{t+1}\right]-\varphi_{t} \Gamma_{U c} \tilde{X}_{t}+ \\
& \frac{1}{2}\left[\left(\varphi_{t}\right)^{2}\left(\Gamma_{U c}+\Gamma_{R j}\right) H_{\varepsilon} \Sigma_{\varepsilon} H_{\varepsilon}\left(\Gamma_{U c}+\Gamma_{R j}\right)^{\prime}\right] \\
0= & \left(\Gamma_{U c}+\Gamma_{R j}\right) E_{t}\left[\tilde{X}_{t+1}\right]-\Gamma_{U c} \tilde{X}_{t}+\frac{\varphi_{t}}{2}\left(\Gamma_{U c}+\Gamma_{R j}\right) H_{\varepsilon} \Sigma_{\varepsilon} H_{\varepsilon}\left(\Gamma_{U c}+\Gamma_{R j}\right)^{\prime}
\end{aligned}
$$

Eq.(B-76) is linear in the state variables. But one last correction must be made, it is necessary express $\varphi_{t}$ as deviations from its steady-state value. 
We know that $\varphi_{t}=\varphi_{s s}+\varphi_{s s} \tilde{\varphi}_{t}$, therefore:

$$
\begin{aligned}
0= & \left(\Gamma_{U c}+\Gamma_{R j}\right) E_{t}\left[\tilde{X}_{t+1}\right]-\Gamma_{U c} \tilde{X}_{t}+\frac{\left(\varphi_{s s}+\varphi_{s s} \tilde{\varphi}_{t}\right)}{2}\left(\Gamma_{U c}+\Gamma_{R j}\right) H_{\varepsilon} \Sigma_{\varepsilon} H_{\varepsilon}\left(\Gamma_{U c}+\Gamma_{R j}\right)^{\prime} \\
0= & \left(\Gamma_{U c}+\Gamma_{R j}\right) E_{t}\left[\tilde{X}_{t+1}\right]-\Gamma_{U c} \tilde{X}_{t}+\frac{\varphi_{s s} \tilde{\varphi}_{t}}{2}\left(\Gamma_{U c}+\Gamma_{R j}\right) H_{\varepsilon} \Sigma_{\varepsilon} H_{\varepsilon}\left(\Gamma_{U c}+\Gamma_{R j}\right)^{\prime}+ \\
& \frac{\varphi_{s s}}{2}\left(\Gamma_{U c}+\Gamma_{R j}\right) H_{\varepsilon} \Sigma_{\varepsilon} H_{\varepsilon}\left(\Gamma_{U c}+\Gamma_{R j}\right)^{\prime} \\
0= & \left(\Gamma_{U c}+\Gamma_{R j}\right) E_{t}\left[\tilde{X}_{t+1}\right]-\Gamma_{U c} \tilde{X}_{t}+\frac{\varphi_{s s}}{2}\left(\Gamma_{U c}+\Gamma_{R j}\right) H_{\varepsilon} \Sigma_{\varepsilon} H_{\varepsilon}\left(\Gamma_{U c}+\Gamma_{R j}\right)^{\prime} \Gamma_{\varphi} \tilde{X}_{t}+ \\
& \frac{\varphi_{s s}}{2}\left(\Gamma_{U c}+\Gamma_{R j}\right) H_{\varepsilon} \Sigma_{\varepsilon} H_{\varepsilon}\left(\Gamma_{U c}+\Gamma_{R j}\right)^{\prime} \\
0 & \left(\Gamma_{U c}+\Gamma_{R j}\right) E_{t}\left[\tilde{X}_{t+1}\right]+\left[\frac{\varphi_{s s}}{2}\left(\Gamma_{U c}+\Gamma_{R j}\right) H_{\varepsilon} \Sigma_{\varepsilon} H_{\varepsilon}\left(\Gamma_{U c}+\Gamma_{R j}\right)^{\prime} \Gamma_{\varphi}-\Gamma_{U c}\right] \tilde{X}_{t}+ \\
& \frac{\varphi_{s s}}{2}\left(\Gamma_{U c}+\Gamma_{R j}\right) H_{\varepsilon} \Sigma_{\varepsilon} H_{\varepsilon}\left(\Gamma_{U c}+\Gamma_{R j}\right)^{\prime}
\end{aligned}
$$

After some algebra manipulation we obtain the equilibrium solution Eq.(B-77), which is linear in the state variables and is described as deviations from the steady state, so we have a simple linear system to solve. Eq.(B-77) differs from the standard first-order approximation because accounts to riskaversion, $\varphi_{t}$.

From Eq.(B-14), we have:

$$
\begin{aligned}
1 & =E_{t}\left[\beta^{1-\alpha_{t}}\left(\frac{U_{1, t+1}}{U_{1, t}}\right)^{\left(1-\alpha_{t}\right)}\left(R_{j, t+1}\right)^{\left(1-\alpha_{t}\right)} \frac{i_{t}}{\pi_{t+1}}\right] \\
1 & =E_{t}\left[\exp \left(\log \left(\beta \frac{U_{1, t+1}}{U_{1, t}} E_{t}\left[\left(-V_{t+1}\right)^{1-\alpha_{t}}\right]^{\frac{\alpha_{t}}{1-\alpha_{t}}}\left(-V_{t+1}\right)^{-\alpha_{t}} \frac{i_{t}}{\pi_{t+1}}\right)\right)\right] \\
1 & =E_{t}\left[\exp (\varphi_{t}\left(\tilde{U}_{1, t+1}-\tilde{U}_{1, t}\right)-\left(\varphi_{t}-1\right)\left(\tilde{R}_{j, t+1}\right)+\log i_{t}-\log \pi_{t+1}-\underbrace{\log \beta}_{i_{s s}-\bar{\pi}})\right] \\
1 & =E_{t}\left[\exp \left(\varphi_{t}\left(\tilde{U}_{1, t+1}-\tilde{U}_{1, t}\right)-\left(\varphi_{t}-1\right)\left(\tilde{R}_{j, t+1}\right)+\tilde{i}_{t}-\tilde{\pi}_{t+1}\right)\right]
\end{aligned}
$$

Applying log in both sides, rewriting in matrix notation and making use of the log-normal property:

$$
\begin{aligned}
0= & \log E_{t}\left[\exp \left(\varphi_{t}\left(\tilde{U}_{1, t+1}-\tilde{U}_{1, t}\right)-\left(\varphi_{t}-1\right)\left(\tilde{R}_{j, t+1}\right)+\tilde{i}_{t}-\bar{\pi}_{t+1}\right)\right] \\
0= & \log E_{t}\left[\exp \left(\left(\varphi_{t}\left(\Gamma_{U c}+\Gamma_{R j}\right)-\Gamma_{R j}-\Gamma_{\pi}\right) \tilde{X}_{t+1}+\left(\Gamma_{i}-\varphi_{t} \Gamma_{U c}\right) \tilde{X}_{t}\right)\right] \\
0= & \log E_{t} \exp \left(\left(\varphi_{t}\left(\Gamma_{U c}+\Gamma_{R j}\right)-\Gamma_{R j}-\Gamma_{\pi}\right) \tilde{X}_{t+1}\right) \times \\
& \exp \left(\left(\Gamma_{i}-\varphi_{t} \Gamma_{U c}\right) \tilde{X}_{t}\right)
\end{aligned}
$$


Applying the log-normal property to Eq.(B-78) we have:

$$
\begin{aligned}
0= & \left(\varphi_{t}\left(\Gamma_{U c}+\Gamma_{R j}\right)-\Gamma_{R j}-\Gamma_{\pi}\right) E_{t}\left[\tilde{X}_{t+1}\right]+\left(\Gamma_{i}-\varphi_{t} \Gamma_{U c}\right) \tilde{X}_{t}+ \\
& \frac{1}{2} \operatorname{var}_{t}\left[\left(\varphi_{t}\left(\Gamma_{U c}+\Gamma_{R j}\right)-\Gamma_{R j}-\Gamma_{\pi}\right) \tilde{X}_{t+1}\right]
\end{aligned}
$$

Guess the solution takes the form

$$
\tilde{X}_{t+1}=H_{0}+H_{x} \tilde{X}_{t}+H_{\varepsilon} \varepsilon_{t+1}
$$

$$
\begin{aligned}
0= & \left(\varphi_{t}\left(\Gamma_{U c}+\Gamma_{R j}\right)-\Gamma_{R j}-\Gamma_{\pi}\right) E_{t}\left[\tilde{X}_{t+1}\right]+\left(\Gamma_{i}-\varphi_{t} \Gamma_{U c}\right) \tilde{X}_{t}+ \\
& \frac{1}{2}\left[\left(\varphi_{t}\left(\Gamma_{U c}+\Gamma_{R j}\right)-\Gamma_{R j}-\Gamma_{\pi}\right) H_{\varepsilon} \Sigma_{\varepsilon} H_{\varepsilon}\left(\varphi_{t}\left(\Gamma_{U c}+\Gamma_{R j}\right)-\Gamma_{R j}-\Gamma_{\pi}\right)^{\prime}\right] \\
0= & \varphi_{t}\left(\Gamma_{U c}+\Gamma_{R j}\right) E_{t}\left[\tilde{X}_{t+1}\right]-\varphi_{t} \Gamma_{U c} \tilde{X}_{t}+\left(-\Gamma_{R j}-\Gamma_{\pi}\right) E_{t}\left[\tilde{X}_{t+1}\right]+\Gamma_{i} \tilde{X}_{t}+ \\
& \frac{1}{2}\left[\left(\varphi_{t}\left(\Gamma_{U c}+\Gamma_{R j}\right)-\Gamma_{R j}-\Gamma_{\pi}\right) H_{\varepsilon} \Sigma_{\varepsilon} H_{\varepsilon}\left(\varphi_{t}\left(\Gamma_{U c}+\Gamma_{R j}\right)-\Gamma_{R j}-\Gamma_{\pi}\right)^{\prime}\right] \\
0= & \varphi_{t}\left(\Gamma_{U c}+\Gamma_{R j}\right) E_{t}\left[\tilde{X}_{t+1}\right]-\varphi_{t} \Gamma_{U c} \tilde{X}_{t}+\left(-\Gamma_{R j}-\Gamma_{\pi}\right) E_{t}\left[\tilde{X}_{t+1}\right]+\Gamma_{i} \tilde{X}_{t}+ \\
& \frac{\left(\varphi_{t}\right)^{2}}{2}\left(\Gamma_{U c}+\Gamma_{R j}\right) H_{\varepsilon} \Sigma_{\varepsilon} H_{\varepsilon}\left(\Gamma_{U c}+\Gamma_{R j}\right)^{\prime}+\frac{1}{2}\left(-\Gamma_{R j}-\Gamma_{\pi}\right) H_{\varepsilon} \Sigma_{\varepsilon} H_{\varepsilon}\left(-\Gamma_{R j}-\Gamma_{\pi}\right)^{\prime} \\
& \varphi_{t}\left(\Gamma_{U c}+\Gamma_{R j}\right) H_{\varepsilon} \Sigma_{\varepsilon} H_{\varepsilon}\left(-\Gamma_{R j}-\Gamma_{\pi}\right)^{\prime}
\end{aligned}
$$

Using Eq.(B-75) we can make Eq.(B-80) linear with respect to state variables; the return of wealth measured by consumption units,B-15, works to simplify the equations involved with SDF, making them linear with respect to state variables:

$$
\frac{\left(\varphi_{t}\right)^{2}}{2}\left(\Gamma_{U c}+\Gamma_{R j}\right) H_{\varepsilon} \Sigma_{\varepsilon} H_{\varepsilon}\left(\Gamma_{U c}+\Gamma_{R j}\right)^{\prime}=-\varphi_{t}\left(\Gamma_{U c}+\Gamma_{R j}\right) E_{t}\left[\tilde{X}_{t+1}\right]+\varphi_{t} \Gamma_{U c} \tilde{X}_{t}
$$

Therefore we have

$$
\begin{aligned}
0= & \varphi_{t}\left(\Gamma_{U c}+\Gamma_{R j}\right) E_{t}\left[\tilde{X}_{t+1}\right]-\varphi_{t} \Gamma_{U c} \tilde{X}_{t}+\left(-\Gamma_{R j}-\Gamma_{\pi}\right) E_{t}\left[\tilde{X}_{t+1}\right]+\Gamma_{i} \tilde{X}_{t}+ \\
& \varphi_{t}\left(\Gamma_{U c}+\Gamma_{R j}\right) H_{\varepsilon} \Sigma_{\varepsilon} H_{\varepsilon}\left(-\Gamma_{R j}-\Gamma_{\pi}\right)^{\prime}+\frac{1}{2}\left(-\Gamma_{R j}-\Gamma_{\pi}\right) H_{\varepsilon} \Sigma_{\varepsilon} H_{\varepsilon}\left(-\Gamma_{R j}-\Gamma_{\pi}\right)^{\prime} \\
& \underbrace{\frac{\left(\varphi_{t}\right)^{2}}{2}\left(\Gamma_{U c}+\Gamma_{R j}\right) H_{\varepsilon} \Sigma_{\varepsilon} H_{\varepsilon}\left(\Gamma_{U c}+\Gamma_{R j}\right)^{\prime}} \\
0= & \left.\left(-\Gamma_{R j}+\Gamma_{R j}\right) E_{t}\left[\tilde{X}_{t+1}\right]+\Gamma_{t}\right) E_{t c}\left[\tilde{X}_{t+1}\right]+\Gamma_{i} \tilde{X}_{t}+\varphi_{t}\left(\Gamma_{U c}+\Gamma_{R j}\right) H_{\varepsilon} \Sigma_{\varepsilon} H_{\varepsilon}\left(-\Gamma_{R j}-\Gamma_{\pi}\right)^{\prime}+ \\
& \frac{1}{2}\left(-\Gamma_{R j}-\Gamma_{\pi}\right) H_{\varepsilon} \Sigma_{\varepsilon} H_{\varepsilon}\left(-\Gamma_{R j}-\Gamma_{\pi}\right)^{\prime}
\end{aligned}
$$

Now express $\varphi_{t}$ as deviations from its steady-state value using $\varphi_{t}=$ 
$\varphi_{s s}+\varphi_{s s} \tilde{\varphi}_{t}:$

$$
\begin{aligned}
0= & \left(-\Gamma_{R j}-\Gamma_{\pi}\right) E_{t}\left[\tilde{X}_{t+1}\right]+\Gamma_{i} \tilde{X}_{t}+(1-\bar{\alpha})\left(\Gamma_{U c}+\Gamma_{R j}\right) H_{\varepsilon} \Sigma_{\varepsilon} H_{\varepsilon}\left(-\Gamma_{R j}-\Gamma_{\pi}\right)^{\prime} \Gamma_{\varphi} \tilde{X}_{t}+ \\
& (1-\bar{\alpha})\left(\Gamma_{U c}+\Gamma_{R j}\right) H_{\varepsilon} \Sigma_{\varepsilon} H_{\varepsilon}\left(-\Gamma_{R j}-\Gamma_{\pi}\right)^{\prime}+ \\
& \frac{1}{2}\left(-\Gamma_{R j}-\Gamma_{\pi}\right) H_{\varepsilon} \Sigma_{\varepsilon} H_{\varepsilon}\left(-\Gamma_{R j}-\Gamma_{\pi}\right)^{\prime}
\end{aligned}
$$

Eq.(B-82) is the new equilibrium solution (it substitutes Eq.(B-14)) and differs from the standard first-order approximation because accounts to risk-aversion, $\varphi_{t}$.

From Eq.(B-35), we have:

$$
\begin{aligned}
z_{t}^{d}= & Y_{t}+\zeta E_{t} S_{t, t+1}\left(\pi_{t+1}\right)^{\frac{1}{\lambda-1}}\left(\pi_{t}\right)^{\frac{\varpi}{1-\lambda}}(\bar{\pi})^{\frac{1-\varpi}{1-\lambda}} z_{t+1}^{d} \\
z_{t}^{d}= & Y_{t}+\zeta E_{t} \beta^{1-\alpha_{t}}\left(\frac{U_{1, t+1}}{U_{1, t}}\right)^{1-\alpha_{t}}\left(R_{j, t+1}\right)^{-\alpha_{t}}\left(\pi_{t+1}\right)^{\frac{1}{\lambda-1}}\left(\pi_{t}\right)^{\frac{\varpi}{1-\lambda}}(\bar{\pi})^{\frac{1-\varpi}{1-\lambda}} z_{t+1}^{d} \\
1= & E_{t}\left[\beta^{1-\alpha_{t}}\left(\frac{U_{1, t+1}}{U_{1, t}}\right)^{1-\alpha_{t}}\left(R_{j, t+1}\right)^{-\alpha_{t}}\left(\pi_{t+1}\right)^{\frac{1}{\lambda-1}}\right] \times \\
& {\left[\left(\pi_{t}\right)^{\frac{\varpi}{1-\lambda}} z_{t+1}^{d} \frac{\zeta(\bar{\pi})^{\frac{1-\varpi}{1-\lambda}}}{z_{t}^{d}-Y_{t}}\right] }
\end{aligned}
$$

Thus Eq.(B-83) is written in the form Eq.(3-12) and we can proceed taking advantage of the log-normal property (as we just did before). First use $e^{\log (.)}$ inside expectation to log-linearize SDF separately from the rest of the 
equation:

$$
\begin{aligned}
1= & E_{t} \exp \left(\log \left(\beta^{1-\alpha_{t}}\left(\frac{U_{1, t+1}}{U_{1, t}}\right)^{1-\alpha_{t}}\left(R_{j, t+1}\right)^{-\alpha_{t}}\left(\pi_{t+1}\right)^{\frac{1}{\lambda-1}}\left(\pi_{t}\right)^{\frac{\varpi}{1-\lambda}} z_{t+1}^{d} \frac{\zeta(\bar{\pi})^{\frac{1-\varpi}{1-\lambda}}}{z_{t}^{d}-Y_{t}}\right)\right) \\
1= & E_{t} \exp \left(\varphi_{t} \log \beta+\varphi_{t}\left(\tilde{U}_{1, t+1}-\tilde{U}_{1, t}\right)+\left(\varphi_{t}-1\right) \log R_{j, t+1}+\frac{1}{\lambda-1} \log \pi_{t+1}\right) \times \\
& \exp \left(\frac{\varpi}{1-\lambda} \log \pi_{t}+\tilde{z}_{t+1}^{d}+\log \left(\frac{\zeta(\bar{\pi})^{\frac{1-\varpi}{1-\lambda}}}{z_{t}^{d}-Y_{t}}\right)\right) \\
1= & E_{t} \exp \left(\varphi_{t} \log \beta+\varphi_{t}\left(\tilde{U}_{1, t+1}-\tilde{U}_{1, t}\right)+\left(\varphi_{t}-1\right) \log R_{j, t+1}+\frac{1}{\lambda-1} \log \pi_{t+1}\right) \times \\
& \exp \left(\frac{\varpi}{1-\lambda} \log \pi_{t}+\tilde{z}_{t+1}^{d}+\log \zeta+\frac{1-\varpi}{1-\lambda} \log \bar{\pi}-\log \left(z_{t}-Y_{t}\right)\right) \\
1= & E_{t} \exp \left(\varphi_{t}\left(\tilde{U}_{1, t+1}-\tilde{U}_{1, t}\right)+\left(\varphi_{t}-1\right)\left(\log R_{j, t+1}-\log \frac{1}{\beta}\right)+\frac{1}{\lambda-1}\left(\log \pi_{t+1}-\log \bar{\pi}\right)\right) \times \\
& \exp \left(\frac{\varpi}{1-\lambda}\left(\log \pi_{t}-\log \bar{\pi}\right)+\tilde{z}_{t+1}^{d}+\log \beta+\log \zeta-\log \left(z_{t}-Y_{t}\right)\right) \\
1= & E_{t} \exp \left(\varphi_{t}\left(\tilde{U}_{1, t+1}-\tilde{U}_{1, t}\right)+\left(\varphi_{t}-1\right) \tilde{R}_{j, t+1}+\frac{1}{\lambda-1} \tilde{\pi}_{t+1}+\frac{\varpi}{1-\lambda} \tilde{\pi}_{t}+\tilde{z}_{t+1}^{d}\right) \times \\
& \exp \left(-\frac{\tilde{z}_{t}}{\beta \zeta}-\frac{(1-\beta \zeta)}{\beta \zeta} \tilde{Y}_{t}\right)
\end{aligned}
$$

Apply log both sides and rewrite in matrix format

$$
\begin{aligned}
0= & \log E_{t} \exp \left(\varphi_{t}\left(\Gamma_{U c}+\Gamma_{R j}\right) \tilde{X}_{t+1}-\varphi_{t} \Gamma_{U c} \tilde{X}_{t}+\left(\frac{1}{\lambda-1} \Gamma_{\pi}-\Gamma_{R, j}+\Gamma_{z d}\right) \tilde{X}_{t+1}\right) \times \\
& \exp \left(\left(\frac{(1-\beta \zeta)}{\beta \zeta} \Gamma_{y}-\frac{1}{\beta \zeta} \Gamma_{z d}\right) \tilde{X}_{t}\right)
\end{aligned}
$$

Now use the log-normal property described by Eq.(B-71) in Eq.(B-84):

$$
\begin{aligned}
0= & \varphi_{t}\left(\Gamma_{U c}+\Gamma_{R j}\right) E_{t}\left[\tilde{X}_{t+1}\right]-\varphi_{t} \Gamma_{U c} \tilde{X}_{t}+\left(\frac{1}{\lambda-1} \Gamma_{\pi}-\Gamma_{R, j}+\Gamma_{z d}\right) E_{t}\left[\tilde{X}_{t+1}\right]+ \\
& \left(\frac{(1-\beta \zeta)}{\beta \zeta} \Gamma_{y}-\frac{1}{\beta \zeta} \Gamma_{z d}\right) \tilde{X}_{t}+ \\
& \frac{1}{2} \operatorname{var}_{t}\left[\left(\varphi_{t}\left(\Gamma_{U c}+\Gamma_{R j}\right)+\left(\frac{1}{\lambda-1} \Gamma_{\pi}-\Gamma_{R, j}+\Gamma_{z d}\right)\right) \tilde{X}_{t+1}\right]
\end{aligned}
$$

Guess the solution takes the form

$$
\tilde{X}_{t+1}=H_{0}+H_{x} \tilde{X}_{t}+H_{\varepsilon} \varepsilon_{t+1}
$$


Then we have

$$
\begin{aligned}
& 0= \varphi_{t}\left(\Gamma_{U c}+\Gamma_{R j}\right) E_{t}\left[\tilde{X}_{t+1}\right]-\varphi_{t} \Gamma_{U c} \tilde{X}_{t}+\left(\frac{1}{\lambda-1} \Gamma_{\pi}-\Gamma_{R, j}+\Gamma_{z d}\right) E_{t}\left[\tilde{X}_{t+1}\right]+ \\
&\left(\frac{(1-\beta \zeta)}{\beta \zeta} \Gamma_{y}-\frac{1}{\beta \zeta} \Gamma_{z d}\right) \tilde{X}_{t}+ \\
& \frac{1}{2}\left(\varphi_{t}\left(\Gamma_{U c}+\Gamma_{R j}\right)+\left(\frac{1}{\lambda-1} \Gamma_{\pi}-\Gamma_{R, j}+\Gamma_{z d}\right)\right)\left(H_{\varepsilon} \Sigma_{\varepsilon} H_{\varepsilon}\right) \times \\
&\left(\varphi_{t}\left(\Gamma_{U c}+\Gamma_{R j}\right)+\left(\frac{1}{\lambda-1} \Gamma_{\pi}-\Gamma_{R, j}+\Gamma_{z d}\right)\right)^{\prime} \\
& 0 \varphi_{t}\left(\Gamma_{U c}+\Gamma_{R j}\right) E_{t}\left[\tilde{X}_{t+1}\right]-\varphi_{t} \Gamma_{U c} \tilde{X}_{t}+\left(\frac{1}{\lambda-1} \Gamma_{\pi}-\Gamma_{R, j}+\Gamma_{z d}\right) E_{t}\left[\tilde{X}_{t+1}\right]+ \\
&\left(\frac{(1-\beta \zeta)}{\beta \zeta} \Gamma_{y}-\frac{1}{\beta \zeta} \Gamma_{z d}\right) \tilde{X}_{t}+ \\
& \frac{1}{2}\left(\frac{1}{\lambda-1} \Gamma_{\pi}-\Gamma_{R, j}+\Gamma_{z d}\right)\left(H_{\varepsilon} \Sigma_{\varepsilon} H_{\varepsilon}\right)\left(\frac{1}{\lambda-1} \Gamma_{\pi}-\Gamma_{R, j}+\Gamma_{z d}\right)^{\prime}+ \\
& \varphi_{t}\left(\Gamma_{U c}+\Gamma_{R j}\right)\left(H_{\varepsilon} \Sigma_{\varepsilon} H_{\varepsilon}\right)\left(\frac{1}{\lambda-1} \Gamma_{\pi}-\Gamma_{R, j}+\Gamma_{z d}\right)^{\prime}+ \\
& \frac{\left(\varphi_{t}\right)^{2}\left(\Gamma_{U c}+\Gamma_{R j}\right)\left(H_{\varepsilon} \Sigma_{\varepsilon} H_{\varepsilon}\right)\left(\Gamma_{U c}+\Gamma_{R j}\right)^{\prime}}{2} \underbrace{}_{t\left(\Gamma_{U c}+\Gamma_{R j}\right) E_{t}\left[\tilde{X}_{t+1}\right]+\varphi_{t} \Gamma_{U c} \tilde{X}_{t} \quad(\mathrm{by} \text { Eq.(B-75)) }} \\
& 0=\left.\frac{1}{\lambda-1} \Gamma_{\pi}-\Gamma_{R, j}+\Gamma_{z d}\right) E_{t}\left[\tilde{X}_{t+1}\right]+\left(\frac{(1-\beta \zeta)}{\beta \zeta} \Gamma_{y}-\frac{1}{\beta \zeta} \Gamma_{z d}\right)^{\prime} \tilde{X}_{t}+ \\
& \frac{1}{2}\left(\frac{1}{\lambda-1} \Gamma_{\pi}-\Gamma_{R, j}+\Gamma_{z d}\right)\left(H_{\varepsilon} \Sigma_{\varepsilon} H_{\varepsilon}^{\prime}\right)\left(\frac{1}{\lambda-1} \Gamma_{\pi}-\Gamma_{R, j}+\Gamma_{z d}\right)^{\prime}+ \\
& \varphi_{t}\left(\Gamma_{U c}+\Gamma_{R j}\right)\left(H_{\varepsilon} \Sigma_{\varepsilon} H_{\varepsilon}^{\prime}\right)\left(\frac{1}{\lambda-1} \Gamma_{\pi}-\Gamma_{R, j}+\Gamma_{z d}\right)^{\prime} \\
& 0
\end{aligned}
$$

Now express $\varphi_{t}$ as deviations from its steady-state value using $\varphi_{t}=$ $\varphi_{s s}+\varphi_{s s} \tilde{\varphi}_{t}$ : Then we have

$$
\begin{aligned}
0= & \left(\frac{1}{\lambda-1} \Gamma_{\pi}-\Gamma_{R, j}+\Gamma_{z d}\right) E_{t}\left[\tilde{X}_{t+1}\right]+\left(\frac{(1-\beta \zeta)}{\beta \zeta} \Gamma_{y}-\frac{1}{\beta \zeta} \Gamma_{z d}\right) \tilde{X}_{t}+ \\
& \frac{1}{2}\left(\frac{1}{\lambda-1} \Gamma_{\pi}-\Gamma_{R, j}+\Gamma_{z d}\right)\left(H_{\varepsilon} \Sigma_{\varepsilon} H_{\varepsilon}\right)\left(\frac{1}{\lambda-1} \Gamma_{\pi}-\Gamma_{R, j}+\Gamma_{z d}\right)^{\prime}+ \\
& (1-\bar{\alpha})\left(\Gamma_{U c}+\Gamma_{R j}\right)\left(H_{\varepsilon} \Sigma_{\varepsilon} H_{\varepsilon}^{\prime}\right)\left(\frac{1}{\lambda-1} \Gamma_{\pi}-\Gamma_{R, j}+\Gamma_{z d}\right)^{\prime}+ \\
& (1-\bar{\alpha})\left(\Gamma_{U c}+\Gamma_{R j}\right)\left(H_{\varepsilon} \Sigma_{\varepsilon} H_{\varepsilon}^{\prime}\right)\left(\frac{1}{\lambda-1} \Gamma_{\pi}-\Gamma_{R, j}+\Gamma_{z d}\right)^{\prime} \Gamma_{\varphi} \tilde{X}_{t}
\end{aligned}
$$


Analogously, for Eq.(B-36), we have

$$
\begin{aligned}
0= & \left(\frac{\lambda}{\lambda-1} \Gamma_{\pi}-\Gamma_{R, j}+\Gamma_{z n}\right) E_{t}\left[\tilde{X}_{t+1}\right]+\left(\frac{(1-\beta \zeta)}{\beta \zeta}\left(\Gamma_{y}+\Gamma_{\mu}\right)-\frac{1}{\beta \zeta} \Gamma_{z n}\right) \tilde{X}_{t}+ \\
& \frac{1}{2}\left(\frac{\lambda}{\lambda-1} \Gamma_{\pi}-\Gamma_{R, j}+\Gamma_{z n}\right)\left(H_{\varepsilon} \Sigma_{\varepsilon} H_{\varepsilon}^{\prime}\right)\left(\frac{\lambda}{\lambda-1} \Gamma_{\pi}-\Gamma_{R, j}+\Gamma_{z n}\right)^{\prime}+ \\
& (1-\bar{\alpha})\left(\Gamma_{U c}+\Gamma_{R j}\right)\left(H_{\varepsilon} \Sigma_{\varepsilon} H_{\varepsilon}^{\prime}\right)\left(\frac{\lambda}{\lambda-1} \Gamma_{\pi}-\Gamma_{R, j}+\Gamma_{z n}\right)^{\prime}+ \\
& (1-\bar{\alpha})\left(\Gamma_{U c}+\Gamma_{R j}\right)+\left(H_{\varepsilon} \Sigma_{\varepsilon} H_{\varepsilon}^{\prime}\right)\left(\frac{\lambda}{\lambda-1} \Gamma_{\pi}-\Gamma_{R, j}+\Gamma_{z n}\right)^{\prime} \Gamma_{\varphi} \tilde{X}_{t}
\end{aligned}
$$

Eq.(B-86)-(B-87) are the new equilibrium equations (it substitutes Eq.(B-35)-(B-36)) and differ from the standard first-order approximations because both accounts to risk-aversion, $\varphi_{t}$. The goal of this method solution is to find matrices $H_{0}, H_{x}, H_{\varepsilon}$ that solve the standard log-linearized problem exposed by B.1.5. We use the Gensys algorithm to find $H_{0}^{(1)}, H_{x}^{(1)}, H_{\varepsilon}^{(1)}$. But the system of equation that take in account the price of risk (risk aversion) involves unknown matrices. We therefore solve the model iteratively. We Iterate until the matrices $H_{0}^{(j)}, H_{x}^{(j)}, H_{\varepsilon}^{(j)}$ converge.

\section{B.2.3}

\section{Yields under Essentially affine approximation}

Following Section B.1.4, we have

$$
p_{t}^{\$(n)}=E_{t} S_{t, t+1} \frac{p_{t+1}^{\$(n-1)}}{\pi_{t+1}}
$$

where $p_{t}^{\$(n)}$ is the nominal bond price. Then we can write above equation as

$$
\begin{aligned}
p_{t}^{\$(n)} & =E_{t} \exp \left[\log \left(S_{t, t+1} F\left(x_{t}, x_{t+1}\right)\right)\right] \\
\log p_{t}^{\$(n)} & =\log E_{t} \exp \left[s_{t, t+1}+f\left(x_{t}, x_{t+1}\right)\right] \\
\log p_{t}^{\$(n)} & =\log E_{t} \exp \left[s_{t, t+1}+\log \pi_{t+1}+\log p_{t+1}^{\$(n-1)}\right]
\end{aligned}
$$

To solve for bond prices we follow (?). Guess that bond prices evolves as

$$
p_{t}^{\$(n)}=A_{n}+B_{n} X_{t}
$$


Thus we have

$$
\begin{aligned}
\log p_{t}^{\$(n)} & =\log E_{t} \exp \left[s_{t, t+1}+\log \pi_{t+1}+A_{n-1}+B_{n-1} x_{t+1}\right] \\
& =\log E_{t} \exp \left[\varphi_{t}\left(\tilde{U}_{c, t+1}-\tilde{U}_{c, t}\right)-\varphi_{t} \tilde{R}_{j, t+1}-\tilde{R}_{j, t+1}-\tilde{\pi}_{t+1}+A_{n-1}+B_{n-1} X_{t+1}\right] \\
& =\log E_{t} \exp \left[\varphi_{t}\left(\Gamma_{U c}-\Gamma_{R j}\right) \tilde{X}_{t+1}+\left(-\Gamma_{R j}-\Gamma_{\pi}\right) \tilde{X}_{t+1}-\varphi_{t} \Gamma_{U c} \tilde{X}_{t}+A_{n-1}+B_{n-1} X_{t+1}\right] \\
& =\log E_{t} \exp \left[A_{n-1}+\varphi_{t}\left(\Gamma_{U c}-\Gamma_{R j}\right) \tilde{X}_{t+1}+\left(B_{n-1}-\Gamma_{R j}-\Gamma_{\pi}\right) \tilde{X}_{t+1}-\varphi_{t} \Gamma_{U c} \tilde{X}_{t}\right]
\end{aligned}
$$

applying log-normal property and using the equation of the return of wealth:

$$
\begin{aligned}
\log p_{t}^{\$(n)}= & \log E_{t} \exp \left[A_{n-1}+\left(\varphi_{t}\left(\Gamma_{U c}+\Gamma_{R j}\right)+\left(B_{n-1}-\Gamma_{R j}-\Gamma_{\pi}\right)\right) \tilde{X}_{t+1}-\varphi_{t} \Gamma_{U c} \tilde{X}_{t}\right] \\
= & A_{n-1}+\frac{1}{2}\left(B_{n-1}-\Gamma_{R j}-\Gamma_{\pi}\right)\left(H_{\varepsilon} \Sigma_{\varepsilon} H_{\varepsilon}^{\prime}\right)\left(B_{n-1}-\Gamma_{R j}-\Gamma_{\pi}\right)^{\prime}+ \\
& \left(B_{n-1}-\Gamma_{R j}-\Gamma_{\pi}\right) H_{0}+(1-\bar{\alpha})\left(B_{n-1}-\Gamma_{R j}-\Gamma_{\pi}\right)\left(H_{\varepsilon} \Sigma_{\varepsilon} H_{\varepsilon}^{\prime}\right)\left(\Gamma_{U c}+\Gamma_{R j}\right)^{\prime}+ \\
& \left(B_{n-1}-\Gamma_{R j}-\Gamma_{\pi}\right) H_{x} \tilde{X}_{t}+ \\
& (1-\bar{\alpha})\left(\Gamma_{U c}+\Gamma_{R j}\right)\left(H_{\varepsilon} \Sigma_{\varepsilon} H_{\varepsilon}^{\prime}\right)\left(B_{n-1}-\Gamma_{R j}-\Gamma_{\pi}\right)^{\prime} \Gamma_{\varphi} \tilde{X}_{t}
\end{aligned}
$$

Making use of Eq.(C-2), follows that

$$
\begin{aligned}
A_{n}= & A_{n-1}+\frac{1}{2}\left(B_{n-1}-\Gamma_{R j}-\Gamma_{\pi}\right)\left(H_{\varepsilon} \Sigma_{\varepsilon} H_{\varepsilon}^{\prime}\right)\left(B_{n-1}-\Gamma_{R j}-\Gamma_{\pi}\right)^{\prime}+ \\
& \left(B_{n-1}-\Gamma_{R j}-\Gamma_{\pi}\right) H_{0}+(1-\bar{\alpha})\left(B_{n-1}-\Gamma_{R j}-\Gamma_{\pi}\right)\left(H_{\varepsilon} \Sigma_{\varepsilon} H_{\varepsilon}^{\prime}\right)\left(\Gamma_{U c}+\Gamma_{R j}\right)^{\prime} \\
B_{n}= & \left(B_{n-1}-\Gamma_{R j}-\Gamma_{\pi}\right) H_{x}+(1-\bar{\alpha})\left(\Gamma_{U c}+\Gamma_{R j}\right)\left(H_{\varepsilon} \Sigma_{\varepsilon} H_{\varepsilon}^{\prime}\right)\left(B_{n-1}-\Gamma_{R j}-\Gamma_{\pi}\right)^{\prime} \Gamma_{\varphi}
\end{aligned}
$$

All $A_{n}$ and $B_{n}$ coefficients can be computed recursively and yields are given by

$$
\operatorname{yield}_{t}^{\$(n)}=-\log p_{t}^{\$(n)}=-\frac{A_{n}}{n}-\frac{B_{n}}{n} X_{t} .
$$




\section{B.3}

\section{Why is Forward Guidance So Powerful?}

Suppose a standard 3-equation New Keynesian model without habit persistence and no other shocks than monetary policy. In this framework, the Euler equation reduces to

$$
c_{t}=E_{t} c_{t+1}-\left(r_{t}-E_{t} \pi_{t+1}\right),
$$

where the variables denotes deviations from steady state. Iterating forward we obtain

$$
c_{t}=-\sum_{j=0}^{\infty} E_{t}\left[r_{t+j}-\pi_{t+j+1}\right],
$$

this means that current consumption is negatively correlated with longterm real interest rate. It follows that anticipated changes in the short-term real rate affect consumption both today and in the future. The success of forward guidance is related to reductions in long-term real interest rate.

As highlighted by (58), forward guidance affect long-term nominal interest rate through two channels. First, anticipated shocks work as exogenous shocks in the short-term rate implying a downward effect on long-term rates. That is the exogenous channel. But there exist a endogenous channel working through Taylor rule feedback. The decrease of nominal short-term rate stated to the future by forward guidance announcements increase output and inflation today. The higher inflation induces to a higher unanticipated monetary shock through Taylor rule. As a result, the endogenous channel creates the expectation of higher short-term rate, so that a positive effect in nominal long-term interest rates.

When the endogenous channel is closed, as done in section 5.2, then the effects of forward guidance are explained only by future movements of real interest rates. These effects can be large if households expect large deviations of sort-, large- rates or both. 


\section{B.4 \\ Data}

The sample is 1982:Q1 to 2007:Q4. The sample is cut off in 1983 due to the evidence for breaks in monetary policy at earlier dates and the lack of yield data earlier than 1982. All data are in quarterly frequency.

The observable variables are real GDP, wage, hours worked, inflation, and short-term interest rate. The set of observable variables is extended to yield data: yields on 3-month, 6-month, 1-, 2-, 3-, 4-, 5-, 10-year Treasury bonds. All yields are from (?) except for the 3-month and 6-month yield, which are from Federal Reserve Bank of St. Louis.

This model is built in stationary form and completely abstracts away from growth. This stationary model only describes the behavior of economy around the balanced growth path (BGP), while abstracting from the movement along the BGP itself. Hence the data must be made/transformed stationary before entering the model. All nonstationary data are transformed into stationary form using backward-looking one-sided HP-filter presented in (?). We chose this filter particularly because the model solution takes the form of a backward looking state-space system as presented in Equations(2-40)-(2-41) i.e. the solution today depends only on current and past states and shocks.

For the output we use real GDP measure from Bureau of Economic Analysis: Real GDP in Billions of Chained 2009 Dollars - Seasonally Adjusted Annual Rate (BEA:GDPC96). The log of this time series is divided by civilian labor force available in Federal Reserve Bank of St. Louis (FRED:CLF16OV) to get real GDP per capita. This new time series is detrended by one-sided HP-filter. The result is the deviate form trend of real output per capita.

The price index used is the quarterly Gross Domestic Product Implicit Price Deflator seasonally adjusted from Federal Reserve Bank of St. Louis (FRED:A191RI1Q225SBEA). I work with the net inflation rate as observable, $\pi_{t}=\log \left(P_{t} / P_{t-1}\right)$. This new time series is stationary. ${ }^{2}$

For the interest rates we use the effective Federal Funds rate from Federal Reserve Bank of St. Louis (FRED:FF). These data are quoted in annualized form. In contrast, the model is written in quarterly frequency. For this reason I made a transformation in data by dividing $R_{t}^{\text {data }}$ by four hundred. These data are nonstationary, then this time series is detrended by one-sided HP-filter.

We follow (19) to settle the hours worked in the model: hour $s_{t}=$ $\log ((P R S 85006023 / 100 * C E 160 V)) / N_{t}$. Where (PRS85006023) is the Nonfarm, business, all persons, average weekly hours duration, seasonally adjusted, from U.S. Department of Labor; and CE160V is the Civilian Employment:

${ }^{2} \mathrm{CPI}$ data generates similar results. 
Sixteen Years and Over, Thousand, Seasonally Adjusted, from Department of Labor (Bureau of Economic Analysis). The time series hour $s_{t}$ is detrended by one-sided filter, which one is denoted by hour $s_{t}^{d}$.

All yield data corresponds to a zero-coupon yield continuously compounded monthly average. These time series are detrended by one-sided HPfilter. $^{3}$

The model has eight fundamental shocks, but we have twelve observable variables. To avoid stochastic singularity we assume that some yields have independent measurement errors with identical standard deviations. This procedure adds four measurement errors. Altogether we have four fundamental shocks, four news shocks and four measurement errors for twelve observable variables. The observable equations are specified as below: ${ }^{4}$

$$
\begin{aligned}
\text { GDP }_{t}^{d} & =y_{t} \\
\text { hours }_{t}^{d} & =h_{t} \\
\text { Deflator } & =\pi_{t} \\
F F_{t}^{d} & =i_{t} \\
\text { yield }_{t}^{3-\text { Month,d }} & =\text { yield }_{t}^{(1)} \\
\text { yield }_{t}^{6-\text { Month,d }} & =\text { yield }_{t}^{(2)} \\
\text { yield }_{t}^{1-Y e a r, d} & =\text { yield }_{t}^{(4)}+v_{t}^{1} \\
\text { yield }_{t}^{2-Y e a r, d} & =\text { yield }_{t}^{(8)}+v_{t}^{2} \\
\text { yield }_{t}^{3-Y e a r, d} & =\text { yield }_{t}^{(12)} \\
\text { yield }_{t}^{5-\text { Year,d }} & =\text { yield }_{t}^{(20)}+v_{t}^{3} \\
\text { yield }_{t}^{7-Y e a r, d} & =\text { yield }_{t}^{(28)} \\
\text { yield }_{t}^{10-Y e a r, d} & =\text { yield }_{t}^{(40)}+v_{t}^{4}
\end{aligned}
$$

where $v_{t}^{j} j=\{1,2,3,4\}$ are the measurement errors. The choice of $n=1,2,4,8,12,20,28,40$ (in quarters), in observed yields, aims to incorporate fluctuations over the entire yield curve.

${ }^{3}$ All nonstationary variables were detrended by one-sided HP-filter

${ }^{4}$ The superscript $d$ means detrended by one-sided filter. 


\section{C \\ Chapter 3 - Constrained Model}

\section{C.1}

\section{Yield Curve Equation under ZLB}

For the yield equations we have

$$
p_{t}^{\$(n)}=E_{t} S_{t, t+1} \frac{p_{t+1}^{\$(n-1)}}{\pi_{t+1}}
$$

where $p_{t}^{\$(n)}$ is the nominal bond price. Then we can write above equation as

$$
\begin{aligned}
p_{t}^{\$(n)} & =E_{t} \exp \left[\log \left(S_{t, t+1} F\left(x_{t}, x_{t+1}\right)\right)\right] \\
\log p_{t}^{\$(n)} & =\log E_{t} \exp \left[s_{t, t+1}+f\left(x_{t}, x_{t+1}\right)\right] \\
\log p_{t}^{\$(n)} & =\log E_{t} \exp \left[s_{t, t+1}+\log \pi_{t+1}+\log p_{t+1}^{\$(n-1)}\right]
\end{aligned}
$$

To solve for bond prices we follow (?). Guess that bond prices evolves as

$$
p_{t}^{\$(n)}=A_{n}+B_{n} X_{t}
$$

The essentially affine approximation gives us

$$
\begin{aligned}
\operatorname{logp} p_{t}^{\$(n)} & =\log E_{t} \exp \left[s_{t, t+1}+\log \pi_{t+1}+A_{n-1}+B_{n-1} x_{t+1}\right] \\
& =\log E_{t} \exp \left[\varphi_{t}\left(\tilde{U}_{c, t+1}-\tilde{U}_{c, t}\right)-\varphi_{t} \tilde{R}_{j, t+1}-\tilde{R}_{j, t+1}-\tilde{\pi}_{t+1}+A_{n-1}+B_{n-1} X_{t+1}\right] \\
& =\log E_{t} \exp \left[\varphi_{t}\left(\Gamma_{U c}-\Gamma_{R j}\right) \tilde{X}_{t+1}+\left(-\Gamma_{R j}-\Gamma_{\pi}\right) \tilde{X}_{t+1}-\varphi_{t} \Gamma_{U c} \tilde{X}_{t}+A_{n-1}+B_{n-1} X_{t+1}\right] \\
& =\log E_{t} \exp \left[A_{n-1}+\varphi_{t}\left(\Gamma_{U c}-\Gamma_{R j}\right) \tilde{X}_{t+1}+\left(B_{n-1}-\Gamma_{R j}-\Gamma_{\pi}\right) \tilde{X}_{t+1}-\varphi_{t} \Gamma_{U c} \tilde{X}_{t}\right]
\end{aligned}
$$

applying log-normal property and using the equation of the return of wealth:

$$
\begin{aligned}
\operatorname{logp} p_{t}^{\$(n)}= & \log E_{t} \exp \left[A_{n-1}+\left(\varphi_{t}\left(\Gamma_{U c}+\Gamma_{R j}\right)+\left(B_{n-1}-\Gamma_{R j}-\Gamma_{\pi}\right)\right) \tilde{X}_{t+1}-\varphi_{t} \Gamma_{U c} \tilde{X}_{t}\right] \\
= & A_{n-1}+\frac{1}{2}\left(B_{n-1}-\Gamma_{R j}-\Gamma_{\pi}\right)\left(H_{\varepsilon} \Sigma_{\varepsilon} H_{\varepsilon}^{\prime}\right)\left(B_{n-1}-\Gamma_{R j}-\Gamma_{\pi}\right)^{\prime}+ \\
& \left(B_{n-1}-\Gamma_{R j}-\Gamma_{\pi}\right) H_{0}+(1-\bar{\alpha})\left(B_{n-1}-\Gamma_{R j}-\Gamma_{\pi}\right)\left(H_{\varepsilon} \Sigma_{\varepsilon} H_{\varepsilon}^{\prime}\right)\left(\Gamma_{U c}+\Gamma_{R j}\right)^{\prime}+ \\
& \left(B_{n-1}-\Gamma_{R j}-\Gamma_{\pi}\right) H_{x} \tilde{X}_{t}+ \\
& (1-\bar{\alpha})\left(\Gamma_{U c}+\Gamma_{R j}\right)\left(H_{\varepsilon} \Sigma_{\varepsilon} H_{\varepsilon}^{\prime}\right)\left(B_{n-1}-\Gamma_{R j}-\Gamma_{\pi}\right)^{\prime} \Gamma_{\varphi} \tilde{X}_{t}
\end{aligned}
$$


Making use of Eq.(C-2), follows that

$$
\begin{aligned}
A_{n}= & A_{n-1}+\frac{1}{2}\left(B_{n-1}-\Gamma_{R j}-\Gamma_{\pi}\right)\left(H_{\varepsilon} \Sigma_{\varepsilon} H_{\varepsilon}^{\prime}\right)\left(B_{n-1}-\Gamma_{R j}-\Gamma_{\pi}\right)^{\prime}+ \\
& \left(B_{n-1}-\Gamma_{R j}-\Gamma_{\pi}\right) H_{0}+(1-\bar{\alpha})\left(B_{n-1}-\Gamma_{R j}-\Gamma_{\pi}\right)\left(H_{\varepsilon} \Sigma_{\varepsilon} H_{\varepsilon}^{\prime}\right)\left(\Gamma_{U c}+\Gamma_{R j}\right)^{\prime} \\
B_{n}= & \left(B_{n-1}-\Gamma_{R j}-\Gamma_{\pi}\right) H_{x}+(1-\bar{\alpha})\left(\Gamma_{U c}+\Gamma_{R j}\right)\left(H_{\varepsilon} \Sigma_{\varepsilon} H_{\varepsilon}^{\prime}\right)\left(B_{n-1}-\Gamma_{R j}-\Gamma_{\pi}\right)^{\prime} \Gamma_{\varphi} .
\end{aligned}
$$

All $A_{n}$ and $B_{n}$ coefficients can be computed recursively and yields are given by

$$
\text { yield }_{t}^{\$(n)}=-\log p_{t}^{\$(n)}=-\frac{A_{n}}{n}-\frac{B_{n}}{n} X_{t} .
$$

The Equation (C-4) is used for the unconstrained model. Under ZLB constrain, the yields follow a slightly different law of motion. In that case, we assume the solution is

$$
\begin{aligned}
X_{t} & =P\left(X_{t-1}, \varepsilon_{t}\right) X_{t-1}+D\left(X_{t-1}, \varepsilon_{t}\right)+Q\left(X_{t-1}, \varepsilon_{t}\right) \varepsilon_{t} \\
B_{t} & =A_{n}+B_{n}^{*} X_{t}
\end{aligned}
$$

where $B_{n}^{*}$ differs from $B_{n}$ stated earlier by $P\left(X_{t-1}, \varepsilon_{t}\right)$. We have

$$
B_{n}^{*}=\left(B_{n-1}^{*}-\Gamma_{R j}-\Gamma_{\pi}\right) P_{t}+(1-\bar{\alpha})\left(\Gamma_{U c}+\Gamma_{R j}\right)\left(Q_{t} \Sigma_{\varepsilon} Q_{t}^{\prime}\right)\left(B_{n-1}^{*}-\Gamma_{R j}-\Gamma_{\pi}\right)^{\prime} \Gamma_{\varphi} .
$$

Therefore, the yields responses to state variables, and fundamental shocks, are conditional to the state of the economy.

\section{C.1.1}

\section{The Minimization Algorithm}

We make use of the method in Guerrieri and Iacoviello (2015) to deal with the ZLB. The method define two regimes: regime 1 when the ZLB is not binding; and, regime 2 when the ZLB is bind. The agents form expectations depending on which regime is working and how long the economy will stay in that regime. The solution must deal with expectations when transitioning from one regime to another. To do that, we employ a guess-and-verify approach. First, we guess the period in which each regime applies. After, we proceed and verify and update (when it is necessary) the initial guess. We iterate in this fashion until the initial condition is reached, applying regimes 1 or 2 according to the current guess of regimes. All transition matrices are stored and we can generate the IRFs for state variables and check if the current guess of regimes is correct. If it is not correct, we update the guess and repeat the process. 
Table C.1: Chapter 3 model estimation - Priors and Posterior Modes

\begin{tabular}{|c|c|c|c|c|c|c|c|c|}
\hline & \multirow[b]{2}{*}{ Description } & \multicolumn{3}{|c|}{ Priors } & \multicolumn{4}{|c|}{ Posterior } \\
\hline & & Distribution & Mean & Std. Dev. & Mode & Std. Dev. & $5 \%$ & $95 \%$ \\
\hline$\chi$ & Frisch Elasticity & Gamma & 3 & 1 & 3.27 & 0.145 & 3.02 & 3.471 \\
\hline$\gamma$ & IES & Gamma & 2 & 1 & 2.259 & 0.061 & 2.119 & 2.344 \\
\hline$\theta$ & Concavity of production & Normal & 0.6 & 0.5 & 0.692 & 0.043 & 0.629 & 0.767 \\
\hline$\lambda$ & Steady-state markup & Normal & 1.1 & 0.5 & 1.143 & 0.056 & 1.057 & 1.259 \\
\hline$\xi$ & Calvo parameter & Beta & 0.8 & 0.2 & 0.777 & 0.009 & 0.762 & 0.793 \\
\hline$\rho_{i}$ & Interest rate persistence & Beta & 0.8 & 0.1 & 0.852 & 0.043 & 0.777 & 0.915 \\
\hline$\phi_{\pi}$ & Taylor rule inflation & Normal & 7.5 & 2.5 & 7.736 & 0.062 & 7.628 & 7.832 \\
\hline$\phi_{y}$ & Taylor rule output & Normal & 1 & 0.5 & 0.168 & 0.097 & 0.038 & 0.366 \\
\hline$\rho_{\bar{y}}$ & Output gap persistence & Beta & 0.5 & 0.2 & 0.846 & 0.072 & 0.960 & 0.960 \\
\hline$\rho_{a}$ & Technology persistence & Beta & 0.5 & 0.2 & 0.995 & 0.002 & 0.991 & 0.998 \\
\hline$\rho_{\alpha}$ & risk aversion persistence & Beta & 0.5 & 0.2 & 0.721 & 0.051 & 0.61 & 0.783 \\
\hline $\bar{\alpha}$ & Steady-state risk aresion & Gamma & 10 & 4 & 12.061 & 0.094 & 11.931 & 12.222 \\
\hline$\rho_{\pi}$ & inflation target persistence & Beta & 0.98 & 0.05 & 0.949 & 0.016 & 0.92 & 0.972 \\
\hline$\sigma_{a}$ & Technology vol. & Inv Gamma & 0.1 & 2 & 0.331 & 0.013 & 0.309 & 0.354 \\
\hline$\sigma_{i}$ & Interest vol. & Inv Gamma & 0.1 & 2 & 0.105 & 0.01 & 0.09 & 0.123 \\
\hline$\sigma_{\alpha}$ & Risk aversion vol. & Inv Gamma & 0.1 & 2 & 0.514 & 0.041 & 0.452 & 0.583 \\
\hline$\sigma_{\pi}$ & Inflation vol. & Inv Gamma & 0.1 & 2 & 0.094 & 0.008 & 0.08 & 0.109 \\
\hline$\sigma_{1}^{\text {news }}$ & 1-quarter News vol. & Inv Gamma & 0.1 & 2 & 0.143 & 0.012 & 0.132 & 0.158 \\
\hline$\sigma_{3}^{\text {news }}$ & 3-quarter News vol. & Inv Gamma & 0.1 & 2 & 0.09 & 0.008 & 0.07 & 0.11 \\
\hline$\sigma_{5}^{\text {news }}$ & 5-quarter News vol. & Inv Gamma & 0.1 & 2 & 0.124 & 0.018 & 0.08 & 0.163 \\
\hline$\sigma_{8}^{\text {news }}$ & 8-quarter News vol. & Inv Gamma & 0.1 & 2 & 0.088 & 0.006 & 0.07 & 0.101 \\
\hline$\sigma_{3 y}$ & 1-year measurement error & Inv Gamma & 0.1 & 2 & 0.09 & 0.008 & 0.076 & 0.107 \\
\hline$\sigma_{5 y}$ & 2-year measurement error & Inv Gamma & 0.1 & 2 & 0.091 & 0.009 & 0.079 & 0.12 \\
\hline$\sigma_{7 y}$ & 5-year measurement error & Inv Gamma & 0.1 & 2 & 0.087 & 0.008 & 0.083 & 0.13 \\
\hline$\sigma_{10 y}$ & 10-year measurement error & Inv Gamma & 0.1 & 2 & 0.008 & 0.03 & 0.082 & 0.121 \\
\hline
\end{tabular}

To obtain the smoothed shocks, for each period after 2008, we predict the state variables using the stored transition matrices. A minimization routine is applied to minimize the sum of squared error of the prediction. Therefore, the estimated shocks are those who makes the one-step-ahead prediction closest to observable variables. 